\title{
Puget Sound Area Electric Reliability Plan Draft Environmental Impact Statement
}

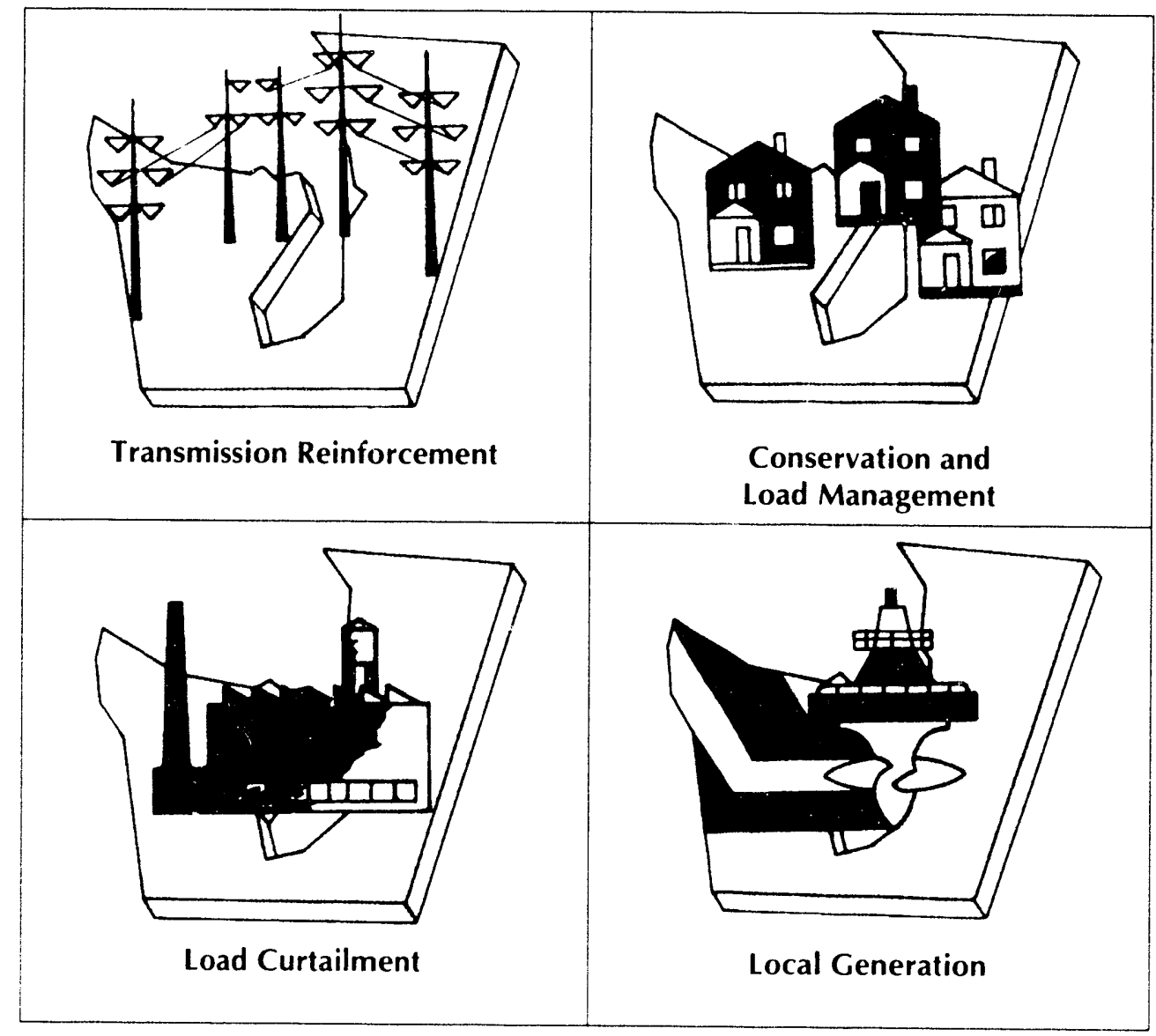


DOE/BP--1702

DE92 003500

DRAFT ENVIRONMENTAL IMPACT STATEMENT

PUGET SOUND AREA ELECTRIC RELIABILITY PLAN

DOE/EIS - 0160

Bonneville Power Administration

U. S. Department of Energy

September 1991
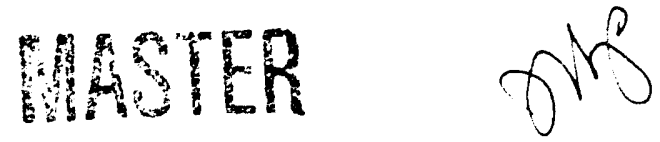

DASTRIBUTIR: 


\author{
Department of Energy \\ Borneville Power Administration \\ P.O. Box 3621 \\ Portland, Oregon 97208-3621
}

September 3, 1991

in eapiveter to $\quad$ EFBC

\title{
Dear Reviewer:
}

Here are some suggestions to help you review the draft environmental impact statement (DEIS) on the Puget Sound Area Electric Reliability Plan.

First, read through the DEIS, using these questions to guide you.

- Why is action being considered? Chapter 1 explains the need for action.

- What is proposed? Chapter 2 describes the alternatives for the Puget Sound Area Electric Reliability Plan.

- How would potential actions affect the environment? Chapter 3 describes generally the existing environment in the Puget Sound area and areas outside of Puget Sound that might be affected by the alternatives considered. Chapter 4 describes the impacts anticipated with any of the actions considered.

- Is the Preferred Alternative the best balance between environmental, economic, and technical objectives?

Second, consider these questions.

- Are there other ways to meet the need not considered in the DEIS? What are they?

- Can environmental impacts be reduced? If so, how?

Third, give BPA your comments. Where possible, please refer specific comments to the appropriate page number. You can call, write, or testify at one of the public meetings held to discuss this DEIS.

Please comment by the deadline listed on the cover sheet. Your comments will be evaluated, and all comment letters and BPA's response will! se published in the Final EIS. The decision on the proposed action will be made available in a Record of Decision.

If you need more information or would like any BPA publications mentioned in the DEIS, please call, toll free, from within Oregon (800) 452-8429; from other western states, (800) 547-6048; from elsewhere (not free) (503) 230-347£.

Thank you for your interest in this plan.

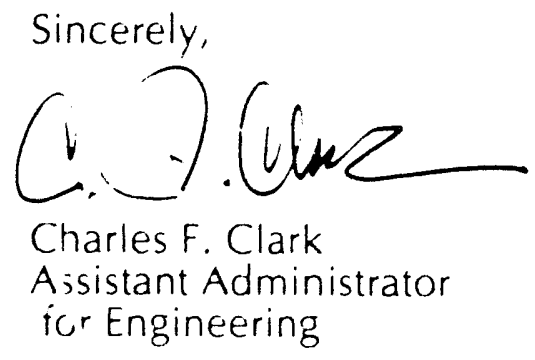




\section{Draft Environmental Impact Statement}

Responsible Agency: Department of Energy, Bonneville Power Administration (BPA)

Title of Proposed Action: Draft Environmental Impact Statement, Puget Sound Area Electric Reliability Plan, DOE/EIS - 0160

State and Counties Involved: Washington - Chelan, Clallam, Douglas, Grant, Grays Harbor, Island, Jefferson, King, Kitsap, Kittitas, Mason, Okanogan, Pierce, San Juan, Skagit, Snohomish, Thurston, Whatcom, Yakima

Abstract: BPA and Puget Sound Power \& Light, Seattle City Light, Snohomish County Public Utility District No. 1, and Tacoma City Light, are working on a coordinated plan to address a power system problem in the Puget Sound area of Washington State. A load forecast developed jointly by the utilities indicates an operating problem may develop on the power system if loads grow as expected. Independent action by utilities is not precluded by this coordination effort, however BP,A and these Puget Sound area utilities have developed certain solutions for this problem, and have selected a preferred alternative.

The preferred alternative (modified Alternative Strategy 2) would accelerate conservation programs in Puget Sound, add capacitors in BPA's Echo Lake Substation, establish a new $500-\mathrm{kV}$ substation near Ellensburg, Washington, and as a contingency against higher than expected demand begin environmental and permitting work on a new cross-Cascades transmission line. Other a. ernatives considered were Alternative Strategy 1 - Transmission line, Alternative Strategy 3 - Load Management and Fuel Switching, and Alternative Strategy 4 - Combustion Turbines. The preferred alternative would have lower environmental impacts than Alternative Strategies 1 \& 4, and slightly higher impacts than Alternative Strategy 3. Other alternatives, including other local generation measures, were evaluated arid found not feasible. Taking no action would put the area at risk for blackouts, and would violate regional utility criteria.

The DEIS is being rilailed to about 1000 agencies, groups, and individuals. There will be a 60 -day public review period. Commerits may be submitted in writing. Also, public meetings will be held at the following locations and times to receive comments:

November 6, Wednesday

7:00 - 10:00 P.M.

Mountaineers Club, Rhododendron Room

300 Third Ave. West

Seattle, Washington

November 7 , Thursday

7:00 - 10:00 P.M.

Mason County Public Utility District Office

Third and Cota Street

Shelton, Washington

November 12, Tuesday

7:00 - 10:00 P.M.

Red Lion Inn, Chelan/Wenatchee Room

1225 North Wenatchee Ave.

Wenatchee, Washington 
November 13, Wednesday

7:00 - 10:00 P.M.

Central Washington University, Samuelson Union Building Theater

Ellensburg, Washington

November 14, Thursday

7:00 - 10:00 P.M.

LaQuinta Inn, Olympia Echo Room

1425 East 27 th Street

Tacoma, Washington

November 18, Monday

7:00 - 10:00 P.M.

Bellevue Concourse, Eagle Room

505 106th Ave. NE

Bellevue, Washington

November 19, Tuesday

7:00 - 10:00 P.M.

West Coast Everett Pacific Hotel, Shaw/Loper Room

3105 Pine Street

Everett, Washington

Send comment letters, requests for copies of the Draft EIS, or requests for additional information on this project to the Public Involvement Manager, P.O. Box 12999, Portland, Oregon 97212.

FOR FURTHER INFORMATION CONTACT: Kenneth Barnhart, Environmental Team Leader, at 503-230-3667, or call the Public Involvement Office at 503-230-3478 in Portland; toll-free 800-452-8429 for Oregon outside Portland; 800-547-6048 for other Western States.

Information may also be obtained from:

Mr. Terence Esvelt, Puget Sound Area Manager, 201 Queen Anne Avenue, North, Suite 400, Seattle, Washington 98109-1030, 206-553-4130.

Mr. Wayne Lee, Upper Columbia Area Manager, Room 561, West 920 Riverside Avenue, Spokane, Washington 99201, 509-353-2518

Mr. Ron Rodewald, Wenatchee District Manager, 301 Yakima Street, Wenatchee, Washington 98807-0741, 509-662-4377 


\section{Table of Contents}

Table of Contents i-vii

\section{Summary}

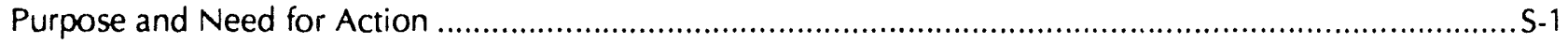

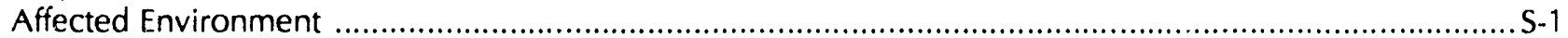

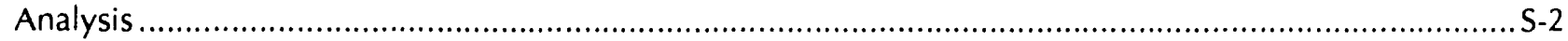

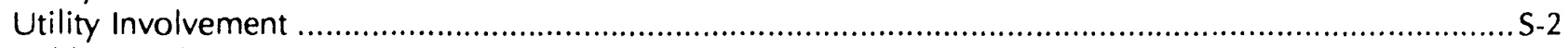

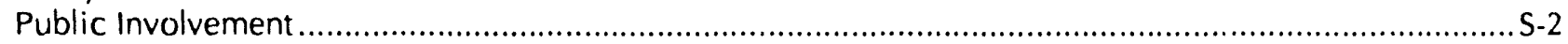

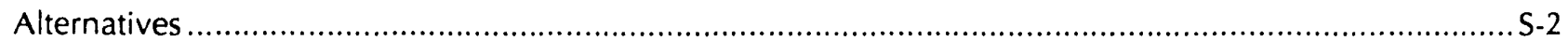

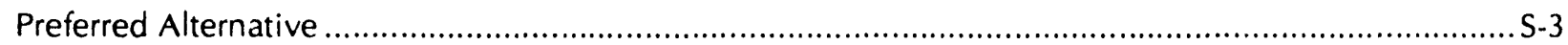

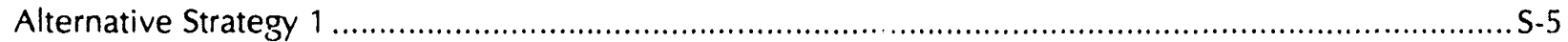

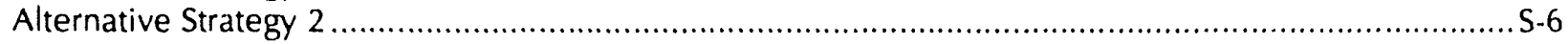

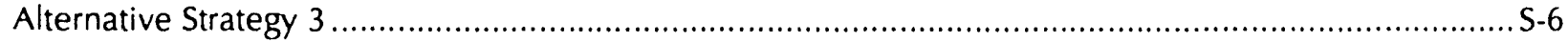

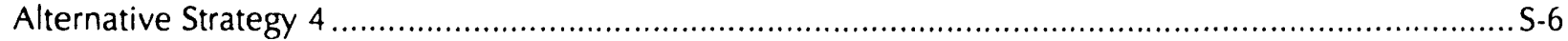

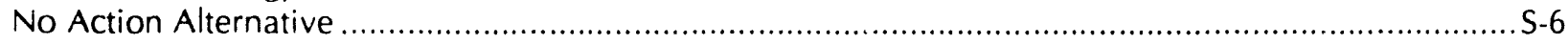

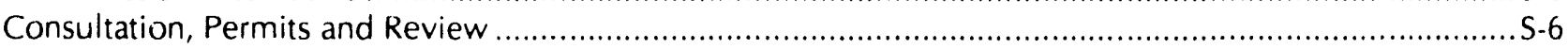

\section{Purpose and Need for Action}

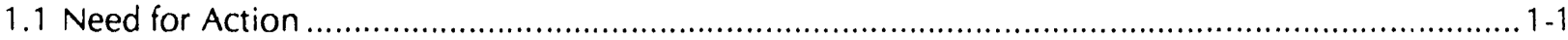

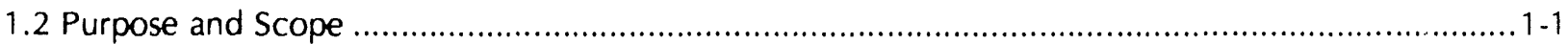

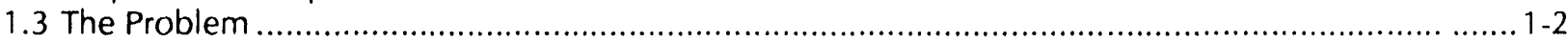

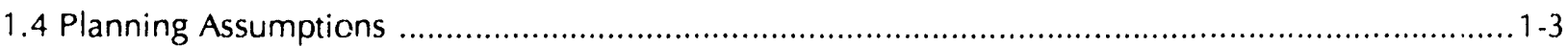

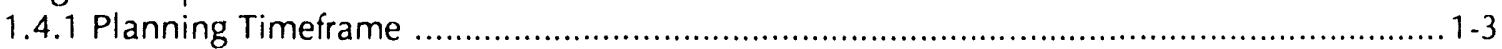

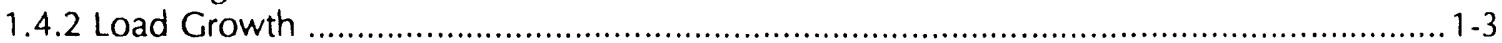

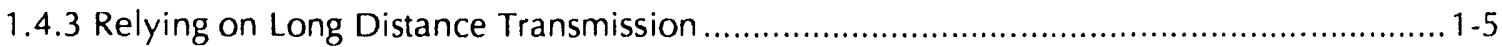

1.4.4 Local Generation and Conservation Resources ...................................................... 1-7

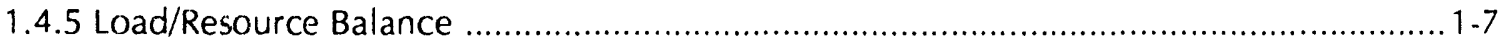

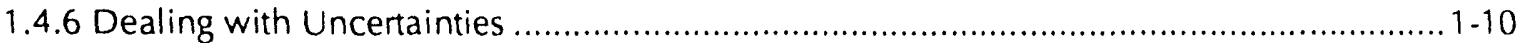

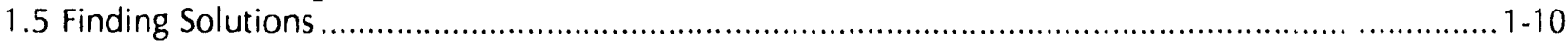

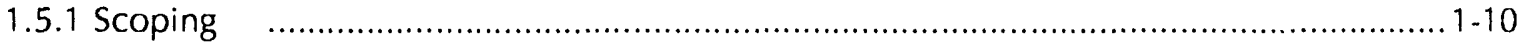

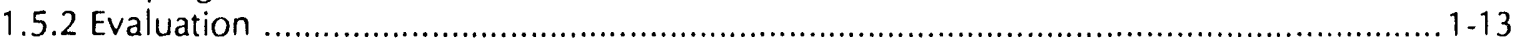

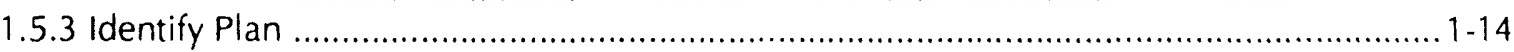

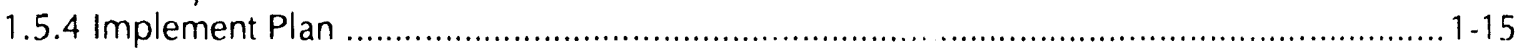

\section{Proposed Action and Alternatives}

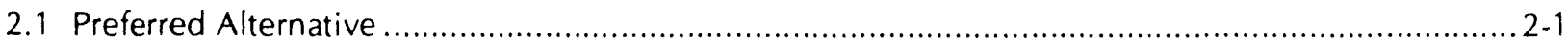

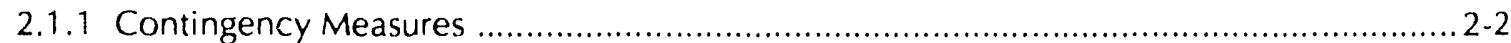

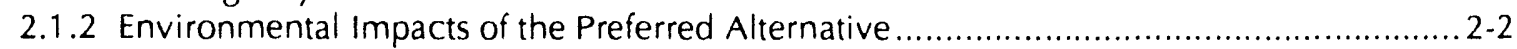

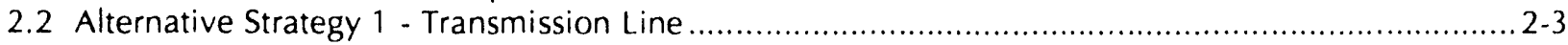

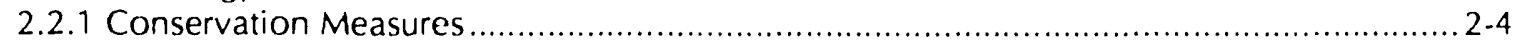

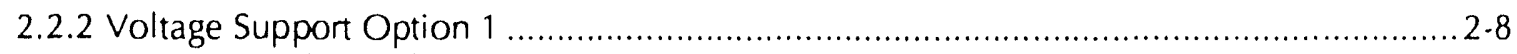

2.2.3 Cross-Cascade 500-kV AC Double Circuit Transmission Line ....................................... 2.9 
Puget Sound Area Electric Reliability Plan -. Draft Environmental Impact Stätement

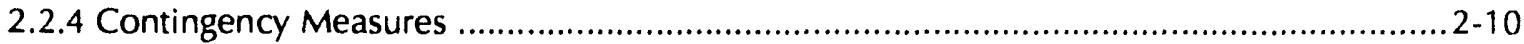

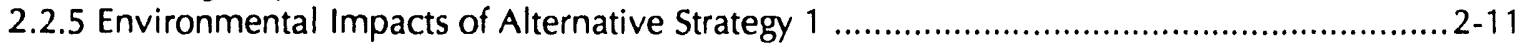

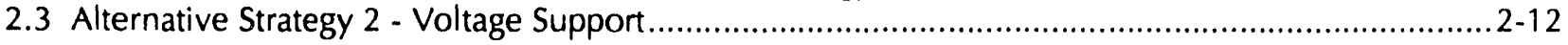

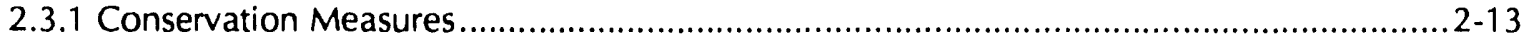

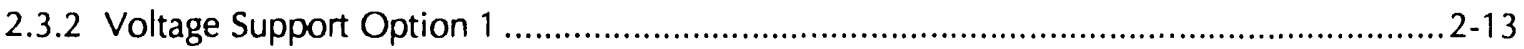

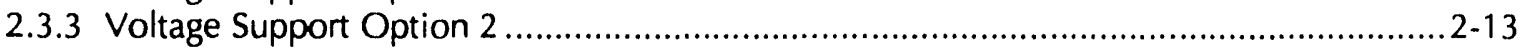

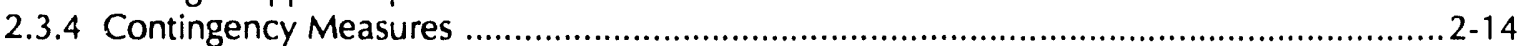

2.3.5 Environmental Impacts of Alternative Strategy 2 .................................................... $2-14$

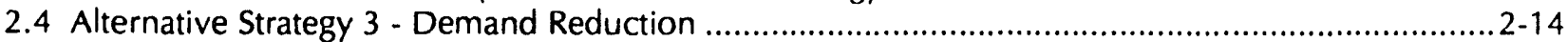

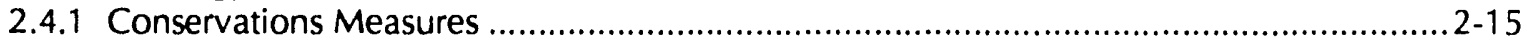

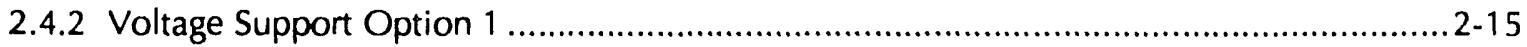

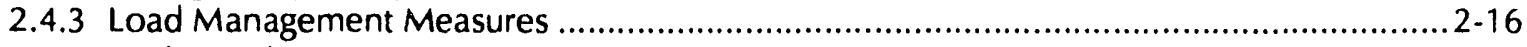

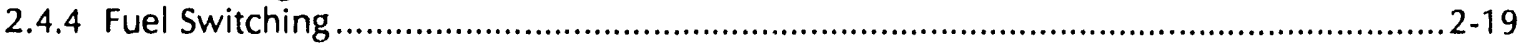

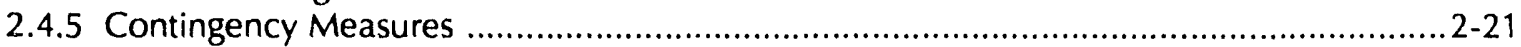

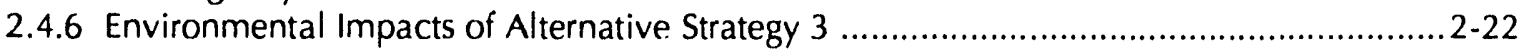

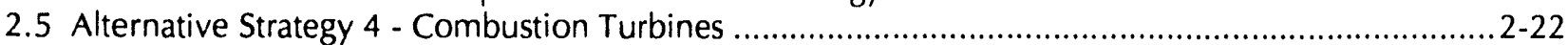

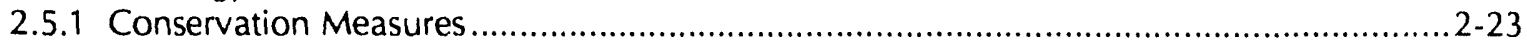

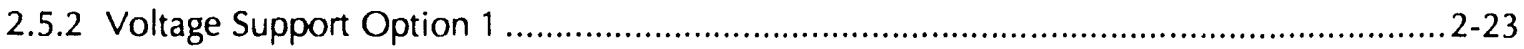

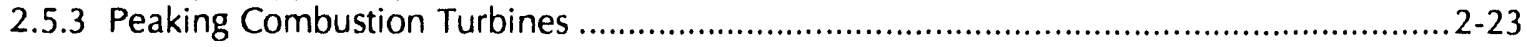

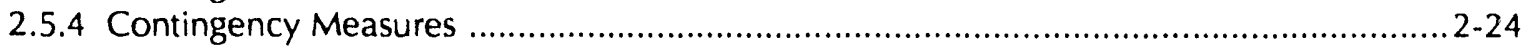

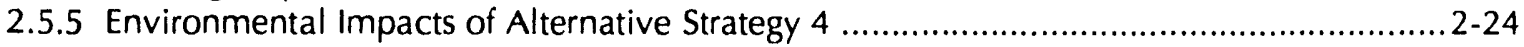

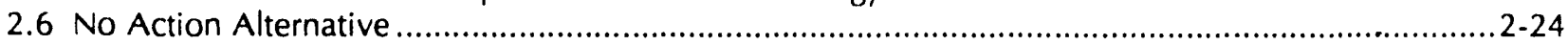

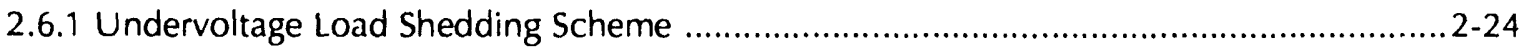

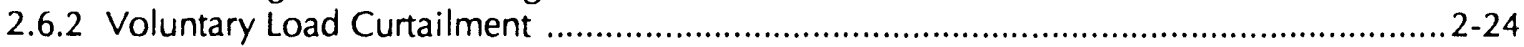

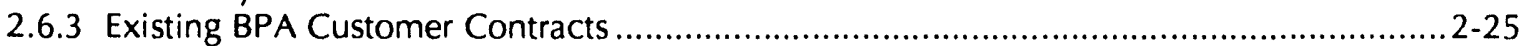

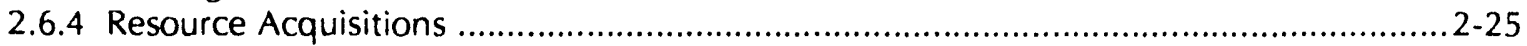

2.6.5 Increased Probability of Voltage Instability and Blackouts ........................................2.26

2.6.6 No Action Alternative Environmental Impacts ....................................................2.27

2.7 Measures Considered but not Included in the Alternative Strategies ..................................... 2-27

2.7.1 Conservation and Load Management Measures ........................................................2-27

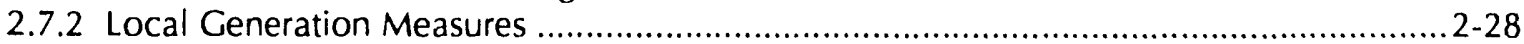

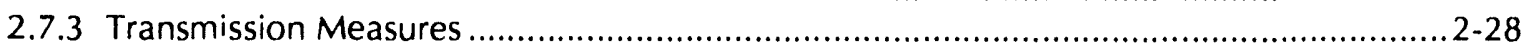

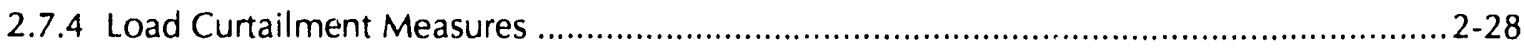

\section{Affected Environment}

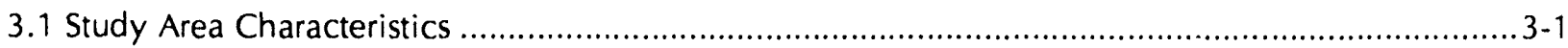

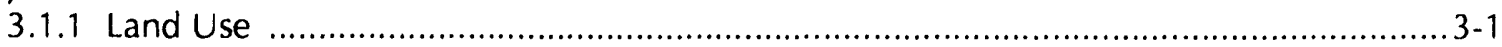

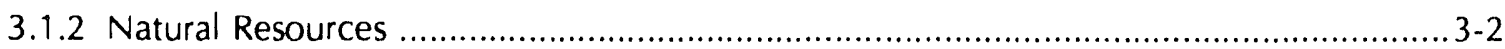

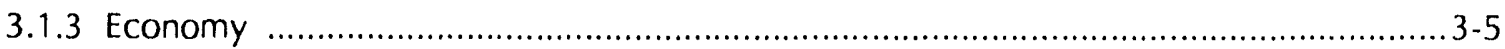

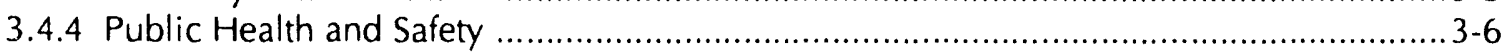

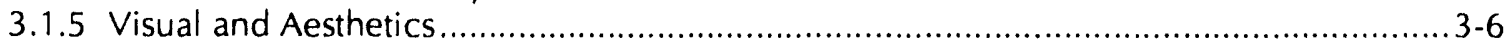

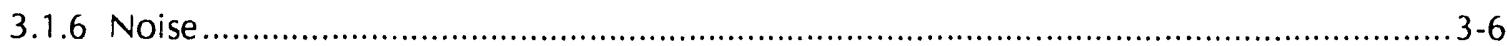

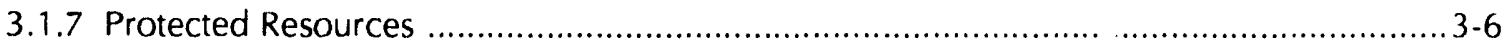

3.2 Areas Potentially Affected by Voltage Support Options or a Transmission Line .......................... 3-7

3.2.1 Alternative Transmission Line Corridor A ............................................................... 3-7

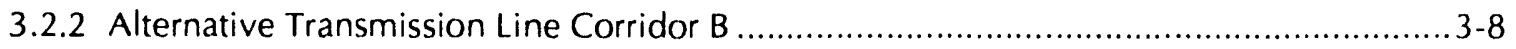

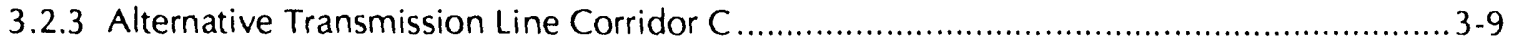

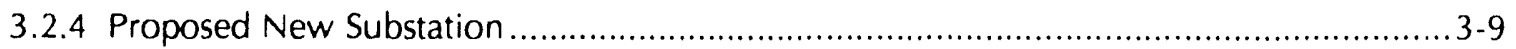




\section{Environmental Consequences}

4.1 Preferred Alternative $4-2$

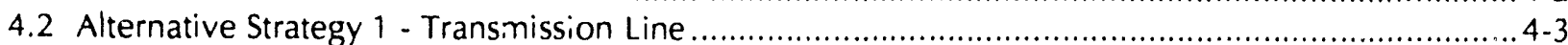

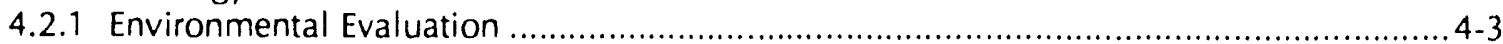

4.2.2 Mitigation Potential ................................................................................. 4-9

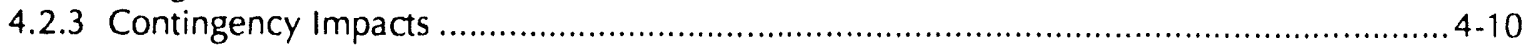

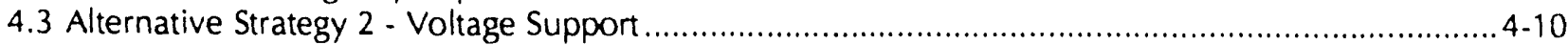

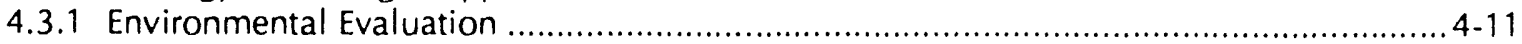

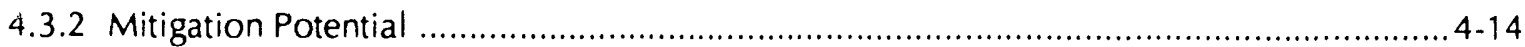

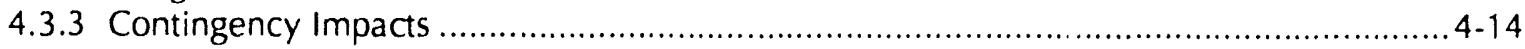

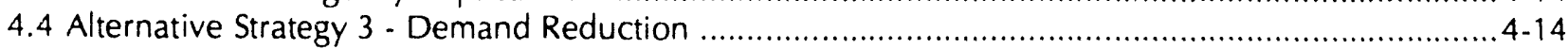

4.4.1 Environmental Evaluation ....................................................................... 45

4.4.2 Mitigation Potential ................................................................................ 45

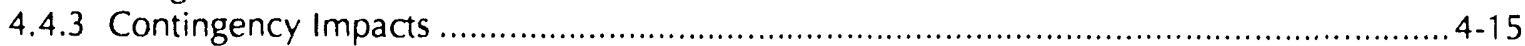

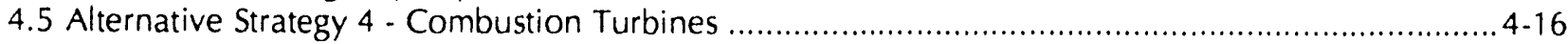

4.5.1 Environmental Evaluation ........................................................................... 46

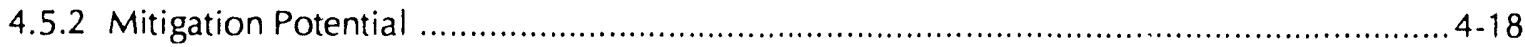

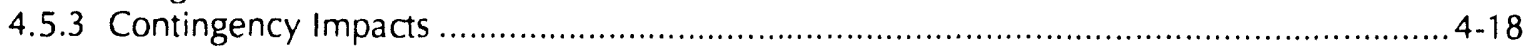

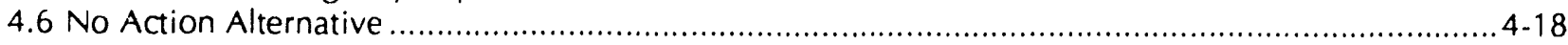

4.6.1 Environmental Evaluation ..................................................................... 4-19

4.6.2 Mitigation Potential .................................................................................. 4-20

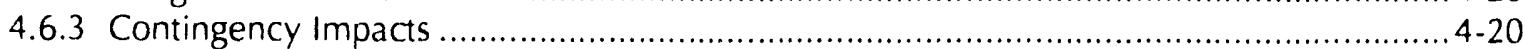

4.7 Environmental Comparison of Alternative Strategies and the No Action Alternative .......................4-20

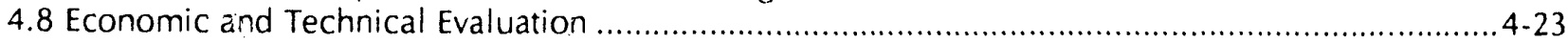

4.8.1 Description of Economic and Technical Study Framework ..................................4-23

4.8.2 Minimize Present Value of System Costs ...................................................... 4-23

4.8.3 Minimize Sensitivity to Load Growth ...............................................................24

4.8.4 Minimize Near-Term Revenue Requirements ............................................... 4-25

4.8.5 Minimize Long-Term Revenue Requirements .................................................4-26

4.8.6 Maximize Deliverability in View of Social and Political Factors ...............................4-26

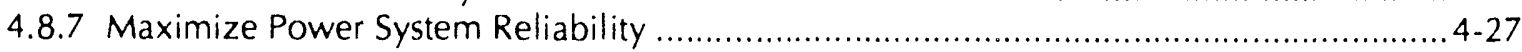

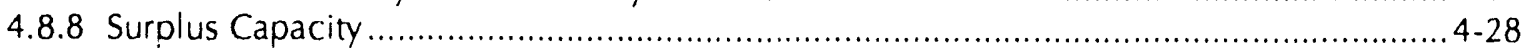

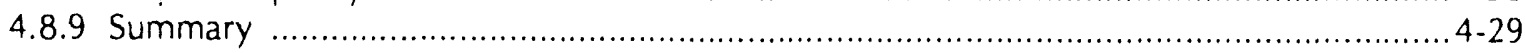

\section{Environmental Consultation, Review, and Permit Requirements}

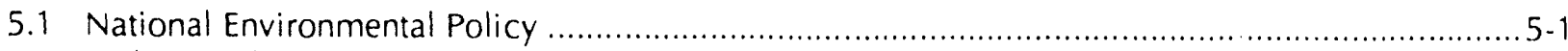

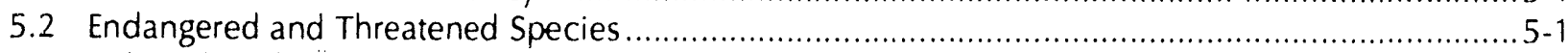

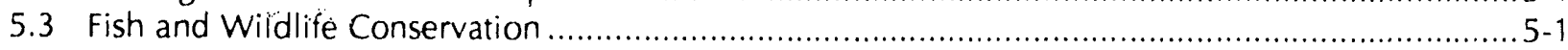

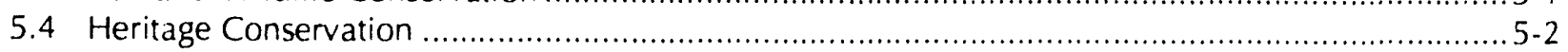

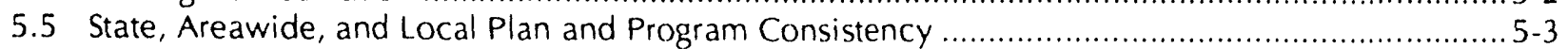

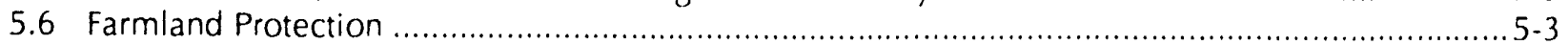

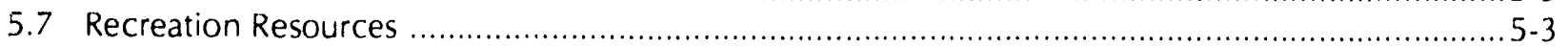

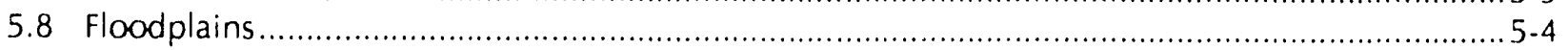

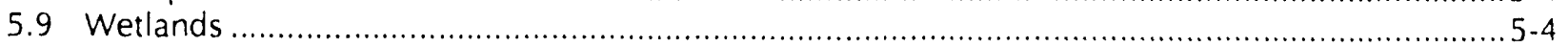

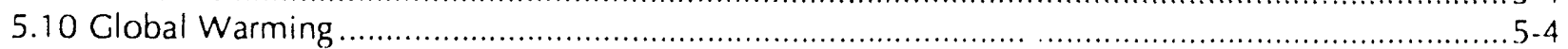

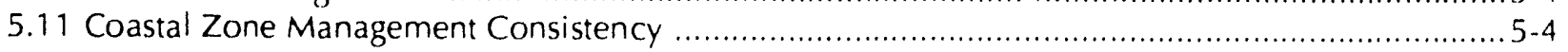

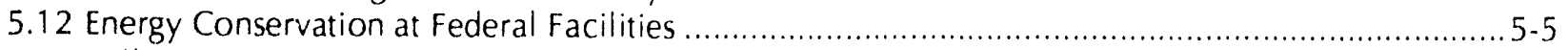

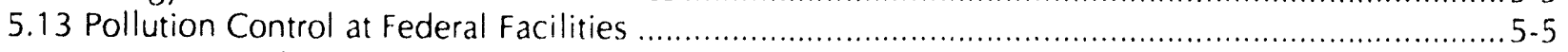

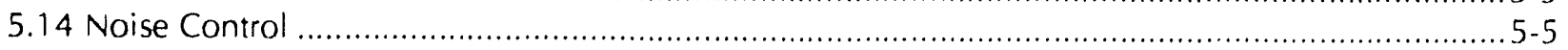

5.15 Federal Licensing and Permit Requirements for New Power Resources ...................................5-5 
5.15.1 Certification to DOE under the Powerplant and Industrial Fuel Use Act .....................5-5

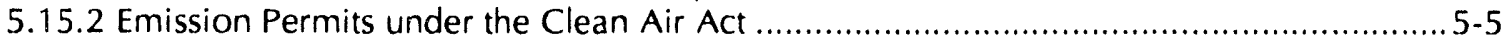

5.16 Discharge Permits under the Clean Water Act ................................................................... 5-6

5.17 Underground Injection Permits under the Safe Drinking Water Act ................................... 5-6

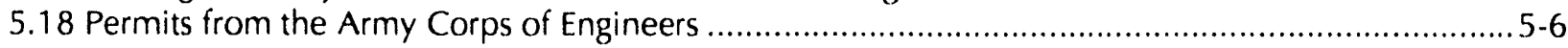

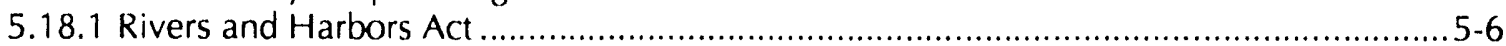

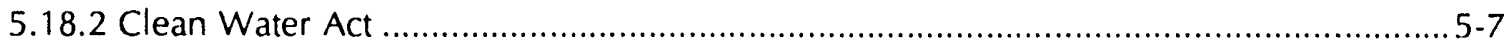

5.19 Geothermal Resource Development on Federal Lands........................................................ 5-7

5.20 Leases and Permits for using Federal Lands for a Power Plant ............................................... 5-7

5.21 Easement for Transmission Lines across Federal Lands ........................................................ 5-7

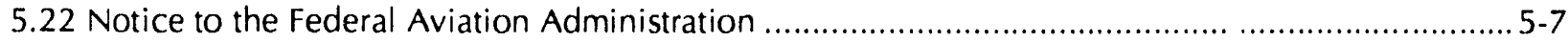

5.23 Permits under the Resource Conservation and Recovery Act ........................................ $5-8$

\section{List of Preparers}

7. List of Agencies, Organizations, and Persons to Whom Copies of the EIS are Sent

\section{References}

\section{Glossary/Acronyms}

10. Index

\section{Appendices}
A. Scoping Summary Report Part B: Preliminary Technical Analysis
B. Local Generation Evaluation
C. Economic and Technical Evaluation
D. Conservation, Load Management, and Fuel Switching Analysis
E. Transmission Reinforcement Analysis
F. Environmental Analysis
G. Supplemental Environmental Analysis - New Substation 


\section{LIST OF FIGURES}

Figure 1-1 Daily Peak Load and Temperature, February 1989 Cold Snap ....................................... 1-2

Figure 1-2 Puget Sound Area Peak Load Forecast ................................................................... 1-4

Figure 1-3 1990 Sources of Power for the Puget Sound Area ...................................................... 1-5

Figure 1-4 Puget Sound Area Peak Loads, Historical, Forecast and Transmission Capacity ................... 1-6

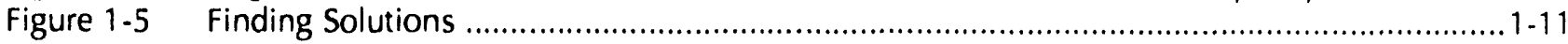

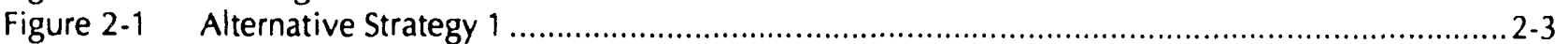

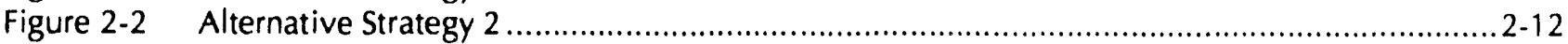

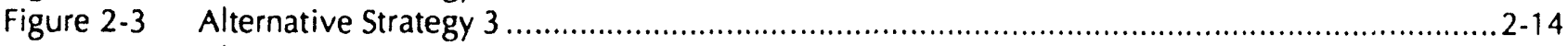

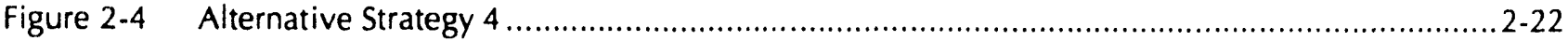

Figure 4-1 Environmental Impact Evaluation Matrix - Alternative Strategy 1 ....................................4-4

Figure 4-2 Environmental Impact Evaluation Matrix - Alternative Strategy $2 \ldots \ldots \ldots \ldots \ldots \ldots \ldots \ldots \ldots \ldots \ldots \ldots \ldots . . . .4-10$

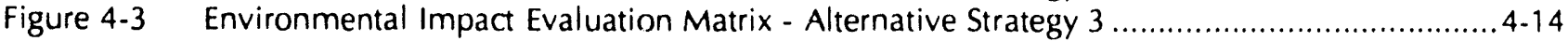

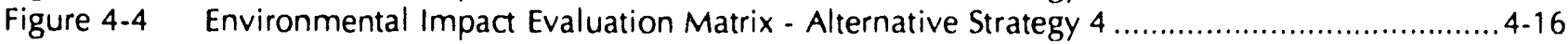

Figure 4-5 Environmental Impact Evaluation Matrix - No Action Strategy........................................4-19

Figure 4-6 Environmental Impact Comparison Matrix .............................................................. 4-21 
Puget Sound Area Elec tric Reliability Plan - Drait Enviroüméntal Impociat Statement

\section{LIST OF TABLES}

Table S-1 Preferred and Alternative Strategies Summary Table .............................................. S-3

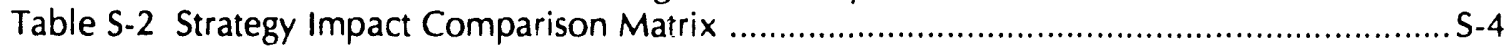

Table S-3 Economic and Technical Evaluation Summary Table .......................................... S-5

Table 1-1 Puget Sound Area Winter Peak Load Forecast (Year 1994 and 2003) ...................... 1-8

Table 1-2 Puget Sound Area Resources and Transmission System Capabilities

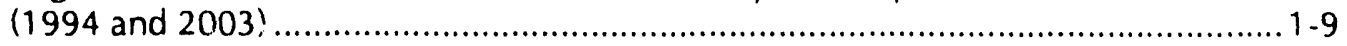

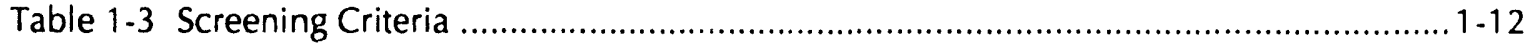

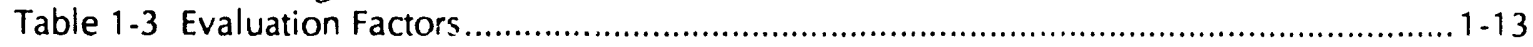

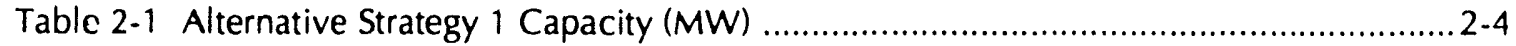

Table 2-2 Costs and Savings of Conservation Programs ...................................................... 2-5

Table 2-3 Transmission Measures Costs, Loss Savings, and Lead Time .................................. 2-8

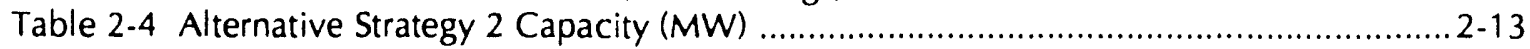

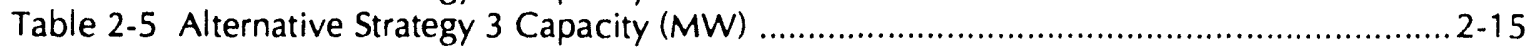

Table 2-6 Costs and Savings of Load Management Programs .............................................. 2-18

Table 2-7 Costs and Savings Potential of Fuel Switching .....................................................2-20

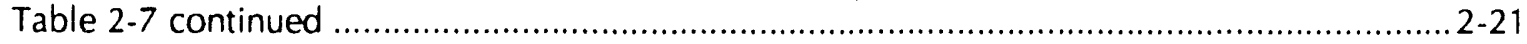

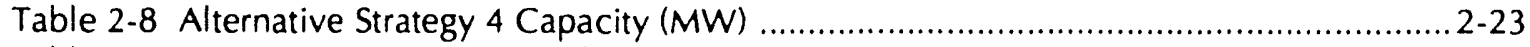

Table 4-1 Transmission Line Material Requirements ........................................................... 4-6

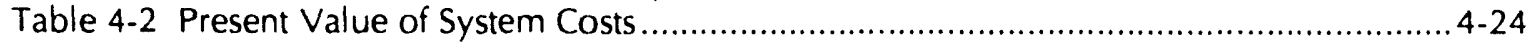

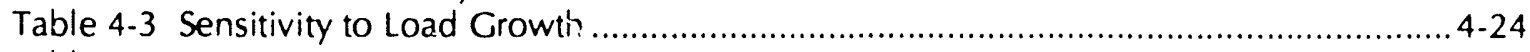

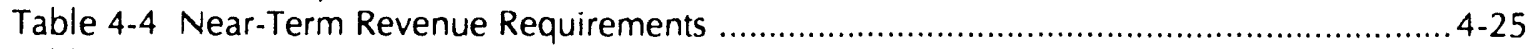

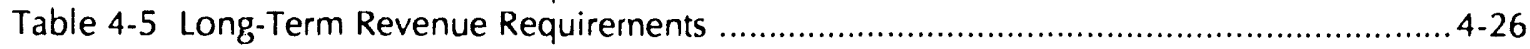

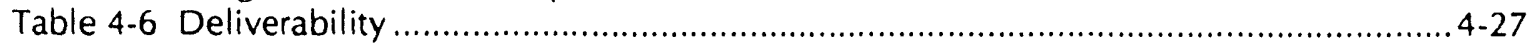

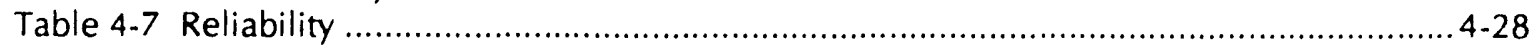

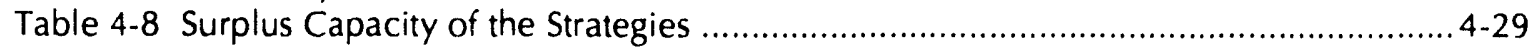

Table 4-9 Economic and Technical Evaluation Summary ................................................. 4-29

Table 5-1 Environmental Consultation, Review, and Permit Requirements Matrix .................. 5-2 


\section{LIST OF MAPS}

\begin{tabular}{|c|c|}
\hline Map 1 & $\begin{array}{l}\text { Follows Page } \\
2-10\end{array}$ \\
\hline Map 2 & Land Cover/Land Use \\
\hline Map 3 & Cultural Resources... \\
\hline Map 4 & Natural Vegetation Patterns . \\
\hline Map 5 & Wildlife Habitat Along Rivers. \\
\hline Map 6 & 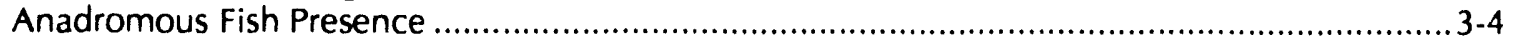 \\
\hline lap 7 & Resident Fish Habitat... \\
\hline lap 8 & Air Quality \\
\hline ap 9 & Puget Sound Area Environmental Hazards ..................... \\
\hline 10 & 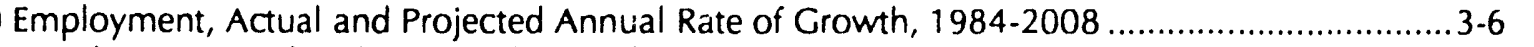 \\
\hline 1 & Population, Actual and Projected Annual Rate of Growth, 1984-2008 \\
\hline Map 12 & State Protected Areas.. \\
\hline 3 & Land Ownership.. \\
\hline 0 & New Substation Siting Area \\
\hline
\end{tabular}




\section{SUMMARY}

The Puget Sound Area Electric Reliability Plan Draft Environmental Impact Statement (DEIS) identifies the alternatives for solving a power system problem in the Puget Sound area. This Plan is undertaken by Bonneville Power Administration (BPA), Puget Sound Power \& Light, Seattle City Light, Snohomish Public Utility District No. 1 (PUD), and Tacoma Public Utilities. The Plan consists of potential actions in Puget Sound and other areas in the State of Washington.

\section{PURPOSE AND NEED FOR ACTION}

A specific need exists in the Puget Sound area for balance between east-west transmission capacity and the increasing demand to import power generated east of the Cascades. At certain times of the year, there is more demand for power than the electric system can supply in the Puget Sound area. This high demand, called peak demand, occurs during the winter months when unusually cold weather increases electricity use for heating. The existing power system can supply enough power if no emergencies coccur. However, during emergencies, the system will not operate properly. As demand grows, the system becomes more strained. To meet demand, the rate of growth of demand must be reduced or the ability to serve the demand inust be increased, or both.

The plan to balance Puget Sound's power demand and supply has these purposes:

- The plan should define a set of actions that would accommodate ten years of load grovith (1994-2003).

- Federal and State environmental quality requirements should be met.

- The plan should be consistent with the p'ans of the Northwest Power Planning Council.

- The plan should serve as a consensus guideline for coordinated utility action.

- The plan should be flexible to accommodate uncertainties and differing utility needs.

- The plan should balance environmental impacts and eronomic costs.

- The plan should provide electric system reliability consistent with customer expectations.

This plan is different from other ongoing regional planning processes that are related but address unique needs. The scope of this plan is to solve the peak load reliability problem whose root cause is that growth in demand has been highest in the Puget Sound area but most of the generation resources are east of the Cascades and existing transmission capacity limits how much power can be imported from the easi to Puget Sound.

The growing need for new energy resources in the Northwest is a distinctly different problem. Each utility has its own independent energy planning process under the cooidinating umbrella of the Northwest Power Planning Couricil's regional energy plan.

Transmission problems within the Puget Sound area also are not addressed by this plan. These problems, brought on by load growth, development of new generation, and inpacts of power exchange with Canada, are being aaciressed by the affected utilities under separate planning processes.

Actions planned to be completed now through late 1993, such as the Winter Operating Plan, are not part of this planning process. These actions will help prevent problems on the system during extreme weather conditions until late 1993.

\section{AFFECTED ENVIRONMENT}

This DEIS covers the Puget Sound area, and parts of the Columbia River Basin that might be affected. The land use, vegetation, topography, and natural and man-made features are varied. Land uses range from urban to forest and agricultural. Vegetaiion west of the Cascade Mountains reflects the wetter climate found there compared to the drier climate easi of the Cascades. The Puget Sound area includes Pacific coastline and the Cascade Mountains. East of the Cascades the forthills turn into agricultural and rangeland. Historic and cultural resources are found throughout the study area. 


\begin{abstract}
ANALYSIS
This DEIS describes the environmental analysis and an economic and technical analysis of alternatives. The environmental analysis covers effects to living and non-living resources. The analysis is generic in nature, except for the study area where a new substation, which is part of the Preferred Alternative, might be built. Each alternative is evaluated environmentally, economically and technically. The environmental analysis uses four environmental impact ratings: minimal, low, moderate, and high. The economic and technical evaluation covered the following factors: net present value of total system costs, sensitivity to load growth, revenue requirements (near-term and longterm), reliability, and deliverability.
\end{abstract}

\title{
UTILITY INVOLVEMENT
}

The planning which led to this Draft EIS was a cooperative effort between BPA and various Puget Sound area utilities, including Snohomish County PUD, Puget Sound Power \& Light, Seattle City Light and Tacoma City Light. A copy of the letter agreement establishing a management structure for this planning effort is enclosed in Appendix A.

\section{PUBLIC INVOLVEMENT}

Four public scoping meetings were held. Members of the general public, special interest groups, consultants and utility representatives attended. Comments from the scoping meetings and written comments are reflected in this DEIS.

A Technical Review Group (TRG) representing state and local government, business and industry, public interest groups, and the general public was formed to provide input and review results during this project.

In addition, to access the business community, labor, government agencies, key interest groups and others mostly outside the utility industry, a group called the Sounding Board was organized. This group provides opinions, suggestions and other feedback on elements of this Plan and represents a cross-section of community interests in the Puget Sound area.

\section{ALTERNATIVES}

The No Action Alternative and four Alternative Strategies were originally considered. The Alternative Strategies have common elements: accelerated conservation measures and Voltage Support Option 1, and, as a contingency, load curtailment measures. Elements of each strategy are shown in Table S-1. Unique elements of the each strategy are:

Alternative Strategy 1 - new cross-Cascade transmission line

Alternative Strategy 2 - new substation near Ellensburg, Washington

Alternative Strategy 3 - load management (water heater control, time-of-use rates) and fuel switching

Alternative Strategy 4 - combustion turbines in Puget Sound.

No Action Alternative - Uncoordinated planning

Because load growth and resource supply could vary substantially from that assumed in this analysis, each alternative strategy includes contingency measures that could be used to make each strategy flexible and able to respond to unexpected circumstances. 
Table S-1.

\section{Preferred and Alternative Strategies Summary Table}

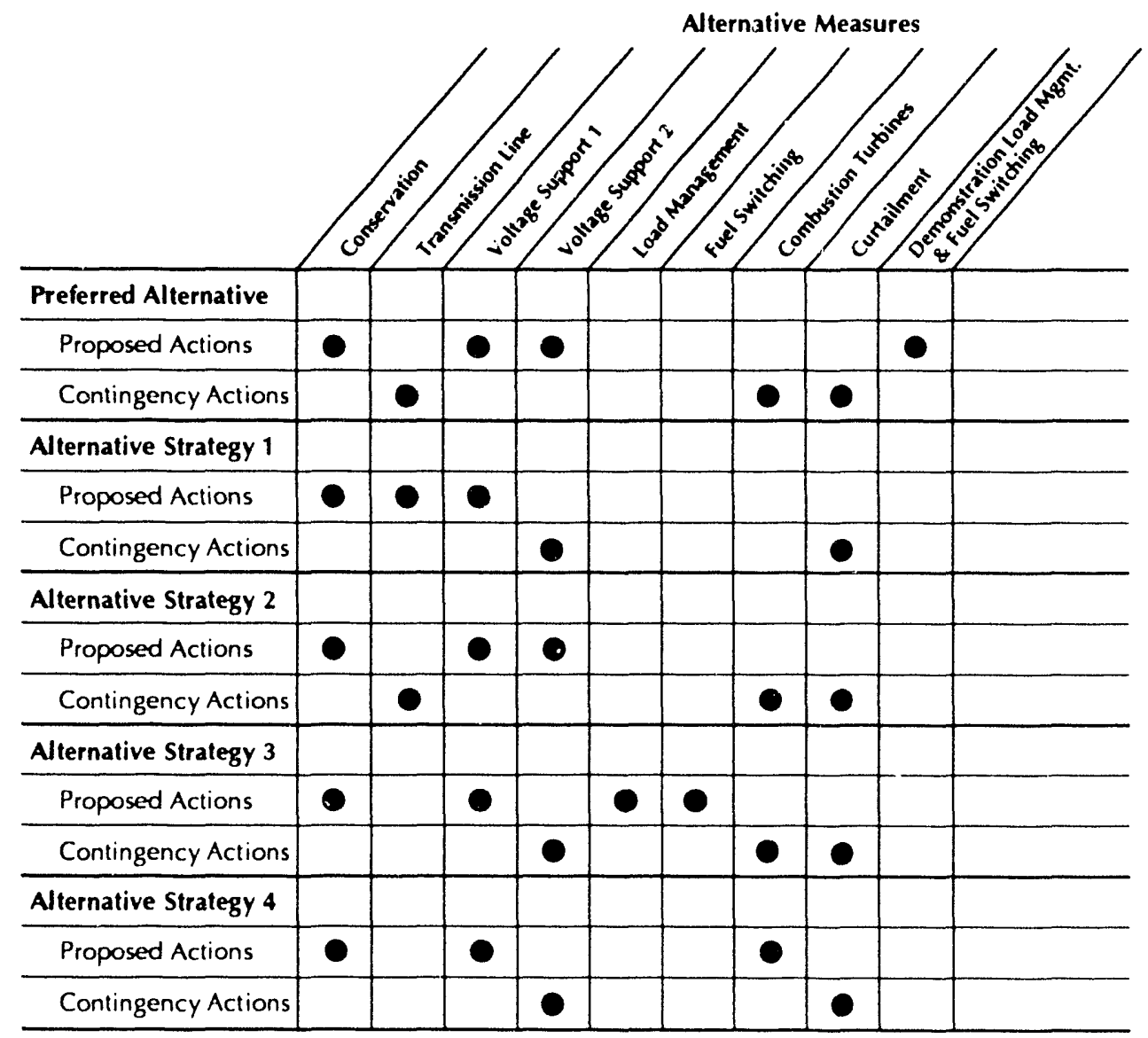

\section{Preferred Alternative}

After weighing the environmental, economic, and technical trade-offs and carefully considering recommendations of the Sounding Board, BPA and Puget Sound utilities decided Alternative Strategy 2 is preferred as the primary solution to the transmission reliability problem in the Puget Sound area. It ranks second to Alternative Strategy 3 in minimizing environmental impacts (see Table S-2), and ranks high in economic and technical evaluation factors (see Table S-3).

The Preferred Alternative, differs slightly from Alternative Strategy 2 in that it also recommends monitoring demonstration fuel switching and water heater load management prograrns underway within the region. These demonstration programs underway or anticipated will provide data on costs, benefits and deliverability. As the Puget Sound Area Electric Reliability Plan is periodically reviewed and updated, the potential of these measures would be evaluated.

Under this strategy, Puget Sound utilities will ramp up conservation programs in 1993 to achieve initial peak reductions by the winter of 1993-94. BPA will complete Voltage Support Option 1 by the fall of 1993, which would provide $600 \mathrm{MW}$ of additional transmission capacity. Another voltage support element, Voltage Support Option 2, would be implemented by the winter of 1994-1995. In Voltage Support Option 2, BPA would develop a new $500 \mathrm{kV}$ substation east of the Cascade Mountains (near Ellensburg, Washington.) This substation will provide 1000 $\mathrm{MW}$ of increased transmission capacity. 
Utilities and the Sounding Buard recognized the need for a plan to be broad and flexible to adapt to unanticipated future developments. There are three contingency actions for the Preferred Alternative. To provide the flexibility to respond to medium-high load growth, the preferred alternative includes preparing for a transmission line project to be available in 2000 if necessary. A 7-8 year lead time is assumed because a transmission line may be controversial. A decision will be necessary in 1996 to either complete or delay this project. The second contingency element of the Preferred Alternative is combustion turbines. One or more combustion turbines could be sited in the Puget Sound area to respond to a greater than expected peak load deficit. The third contingency is using load curtailment contracts.

Table S-2.

Strategy Impact Comparison Matrix

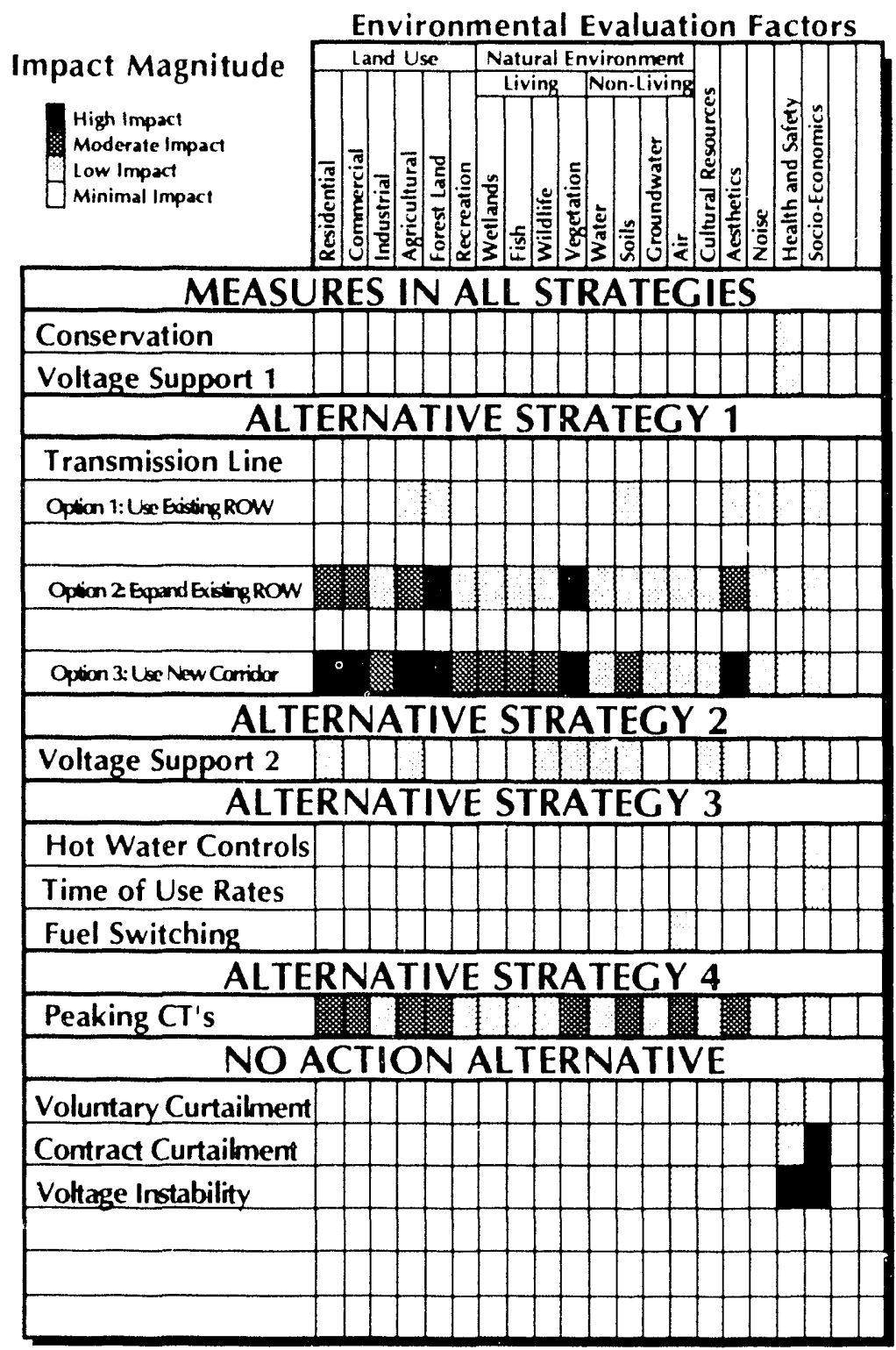


Environmentally, the Prtferred Alternative ranks a close second to Alternative Strategy 3. Conservation programs have low health and safety impacts. Voltage Support Option, 1 has minimal impacts because additions are in existing substation yards. The impacts of Voltage Support Option 2 are minimal or low and result from establishing a new substation. Demonstration load management and fuel switching pilot programs will have minimal impacts. Curtailment contracts would have low to moderate socio-economic impacts. The environmental impacts of the contingency transmission line and/or combustion turbines are described under Alternative Strategies 1 and 4 .

This alternative ranks highest in several economic and technical evaluation factors (see Table S-3).

Table S-3.

Economic and Technical Evaluation Summary Table

\begin{tabular}{|c|c|c|c|c|}
\hline \multirow[b]{2}{*}{ EVALUATION FACTORS } & \multicolumn{4}{|c|}{ ALTERNATIVE STRATEGIES } \\
\hline & Strategy 1 & Strategy $2^{*}$ & Strategy 3 & Strategy 4 \\
\hline Net Present Value & $\$ 67,000,000$ & $\$ 105,000,000$ & $-\$ 128,000,000$ & $\$ 39,000,000$ \\
\hline Sensitivity to Load Growth & $\$ 196,000,000$ & $\$ 126,000,000$ & $\$ 84,000,000$ & $\$ 102,000,000$ \\
\hline Near Term Revenue Requirements & $\$ 50,000,000$ & $\$ 25,000,000$ & $\$ 50,000,000$ & $\$ 20,000,000$ \\
\hline Long Termi Revenue Requirements & $\$ 75,000,000$ & $\$ 40,000,000$ & $\$ 110,000,000$ & $\$ 105,000,000$ \\
\hline Deliverability (1=Hi, 4=Low) & 1.6 & 1.5 & 2.0 & 1.7 \\
\hline Reliability $\quad(1=\mathrm{Hi}, 4=\mathrm{Low})$ & 2.0 & 2.0 & 2.0 & 2.0 \\
\hline
\end{tabular}

\section{Alternative Strategy 1}

This strategy includes a new cross-Cascades transmission line. The line, together with accelerated conservation prograrns and Voltage Support 1, provides a surplus capacity of 1600 megawatts in the year 2003. Given this large surplus contingency measures for Strategy 1 (load curtailment contracts and Voltage Support 2) would not be used for increased demand. They would be needed if completion of the transmission line is delayed. If the deficit is less than expected, completion of the transmission line would be delayed.

Conservation programs have low health and safety impacts. Voltage Support Option 1 has minimal impacts because the equipment will be installed in an existing substation. Transmission line impacts vary from low to high depending on the kind of corridor used (existing, exparided, or new).

If contingency measures are needed, Voltage Support 2, which involves a new substation near Ellensburg, Washington, will have minimal or low impacts. Curtailment contracts would have low to moderate socio-economic impacts.

This strategy ranks second in net present value, near and long term revenue requirements, and deliverability. The plan is least sensitive to load growth. The plan is judged reliable. 


\section{Alternative Strategy 2}

With the exception of demonstration load management and fuel switching projects, Alternative Strategy 2 is identical to the Preferred Alternative. For a description of the strategy refer to the Preferred Alternative discussion.

\section{Alternative Strategy 3}

This strategy adds load management programs (water heater control and time-of-use rates) and fuel switching (from electricity to natural gas). Contingency measures include load curtailment and adding Voltage Support Option 2 if the deficit increases, or delaying measures if the deficit decreases.

Load management creates low socio-economic impacts, and fuel switching creates low air quality impacts. This strategy has the fewest environmental impacts.

Alternative Strategy 3 is rariked best of al! strategies for the sensitivity to load growth evaluation factor. Economically, Strategy 3 is the least desirable plan. It has a negative net present value, and ranks highest in near and long term revenue requirements. The measures used in Strategy 3 were felt less deliverable than those used in other strategies.

\section{Alternative Strategy 4}

This strategy adds peaking combustion turbines used only during peak load periods. Combustion turbines require a site of about four acres. Contingency measures include additional combustion turbines, load curtailment contracts and Voltage Support Option 2 if the deficit increases, or delaying the combustion turbines if the deficit decreases.

Combustion turbines have low to moderate land use and natural environment impacts depending on the site selected. Air quality impacts are moderate. This strategy has the lowest short-term revenue requirements. Contingency measure impacts were described under the other strategies.

From an economic and technical standpoint Alternative Strategy 4 is tied for first with Strategy 2 for near term revenue requirements. Strategy 4 ranks third in net present value, long term revenue requirements, and deliverability. This strategy is second in sensitivity to load growth.

\section{No Action Alternative}

This alternative assumes utilities will take some actions to meet their individual needs. However, these actions may not be coordinated. This alternative is more likely to cause decreasing reliability as loads grow. By 2003 , normal winter peak load will stress the power system and minor disturbances could cause instability and blackout in the Puget Sound area.

This alternative could have high health and safety and socio-economic impacts, and moderate air quality impacts. It would avoid impacts of new facilities and it could result in increased utility emphasis on conservation and other demand-side programs.

The no action alternative was not evaluated from an economic and technical standpoint. It however would not yield reliable service and the costs of a blackout although difficult to determine precisely are expected to exceed the costs of the alternative strategies.

\section{CONSULTATION, PERMITS AND REVIEW}

The requirements for consultation, permits or review for different types of resource acquisitions are listed, and all alternatives were assumed to meet these requirements during the analysis. Consultation for siting a substation east of the Cascade Mountains as part of the Preferred Alternative has begun. 


\subsection{PURPOSE AND NEED FOR ACTION}

The Puget Sound area reaches from the Pacific Ocean to the Cascade Mountains and from just south of Centralia, Washington to the Canadian border. This chapter explains a problem that exists on the bulk power transmission system serving the Puget Sound area. The electric power system includes power plants that generate electricity, conservation that saves energy, and the transmission system that delivers power from resources to customers. This chapter also describes how Bonneville Power Administration (BPA), Puget Sound Power and Light, Seattle City Light, Snohomish County PUD, and Tacoma Public Utilities, developed and evaluated potential solutions to this problem.

\subsection{NEED FOR ACTION}

A specific need exists in the Puget Sound area for a balance between east-west transmission capacity and the increasing demand to import power generated east of the Cascades. At certain times of the year, and during certain conditions, there is more demand for power in the Puget Sound area than the transmission system and existing generation can reliably supply. This high demand, called peak demand, occurs during the winter months when cold weather boosts electricity use for heating. The existing power system can provide enough power now if no emergencies occur. However, during emergencies, the system will not operate properly. As demand grows, the system becomes more strained. To meet demand, the rate of growth of demand must be reduced or the ability to serve the demand must be increased, or both.

\subsection{PURPOSE AND SCOPE}

BPA and Puget Sound area utilities are developing a plan to solve the power system problem. Any plan that balances power demand and the ability to serve that demand, is expected to also accomplish the following purposes:

- The plan should define a set of actions that would accommodate 10 years of load growth (1994 - 2003).

- Federal and State environmental quality requirements should be met.

- The plan should be consistent with the plans of the Northwest Power Planning Council.

- The plan should serve as a consensus guideline for coordinated utility action.

- The plan should be flexible to accommodate both uncertainties and differing utility needs.

- The plan should balance environmental impacts and economic costs.

- The plan should provide electric system reliability consistent with customer expectations.

This plan is different from other ongoing regional planning processes that are related but address unique needs. The scope of this plan is to solve the peak load reliability problem whose root cause is that growth in demand has been highest in the Puget Sound area but most of the generation resources are east of the Cascades and existing transmission capacity limits how much power can be imported from the east to Puget Sound.

The growing need for new energy resources in the Northwest is a distinctly different problem. Each utility has its own independent energy planning process under the coordinating umbrella of the Northwest Power Planning Council's regional energy plan.

Transmission related problems within the Puget Sound area are not addressed by this plan. These problems, brought on by load growth, development of new generation, and inipacts of power exchange with Canada, are being addressed by the affected utilities under separate plans. These plans do not conflict with the alternative strategies. 
Puget Sound Area Electric Reliability Plan - Draft Environmental Impact Statement

Actions planned to be completed niow through 1993 such as the Winter Operating Plan, are not part of this planning process. These actions will help prevent problems on the system during extreme weather conditions until 1993.

\subsection{THE PROBLEM}

The power system in the Pacific Northwest can transmit the energy to supply the needs in the Puget Sound area under normal conditions. However, the Puget Sound area power system no longer meets BPA published criteria for reliable service during emergencies under periods of peak demand. During winter months, cold weather boosts electricity use for heating. Under peak load conditions, the electric power system is stressed. The system could not meet consumers' demands if a certain transmission line or generators in the Puget Sound area fail during cold weather peak load conditions. Under these conditions, the Puget Sound area could have a brownout or blackout.

How was this discovered? Planning studies done before the winter of 1988-1989 uncovered the possibility of a future problem. When the Puget Sound area had extreme cold temperatures in February of 1989, the highest electricity use ever was recorded and the system was severely stressed. In December 1090, the area again had extreme cold temperat!ies and record-breaking electricity use. This peak load, defined or live greatest electrical demand over a fifteen minute period, strained the transmission system delivering power to the Puget Sound area and confirmed that peak loads had grown faster than expected. Figure 1-1 shows how the cold affected electricity demand. The colder it was, the higher the demand for electricity.

Figure 1-1.

\section{Daily Peak Load and Temperature February 1989 Cold Snap}

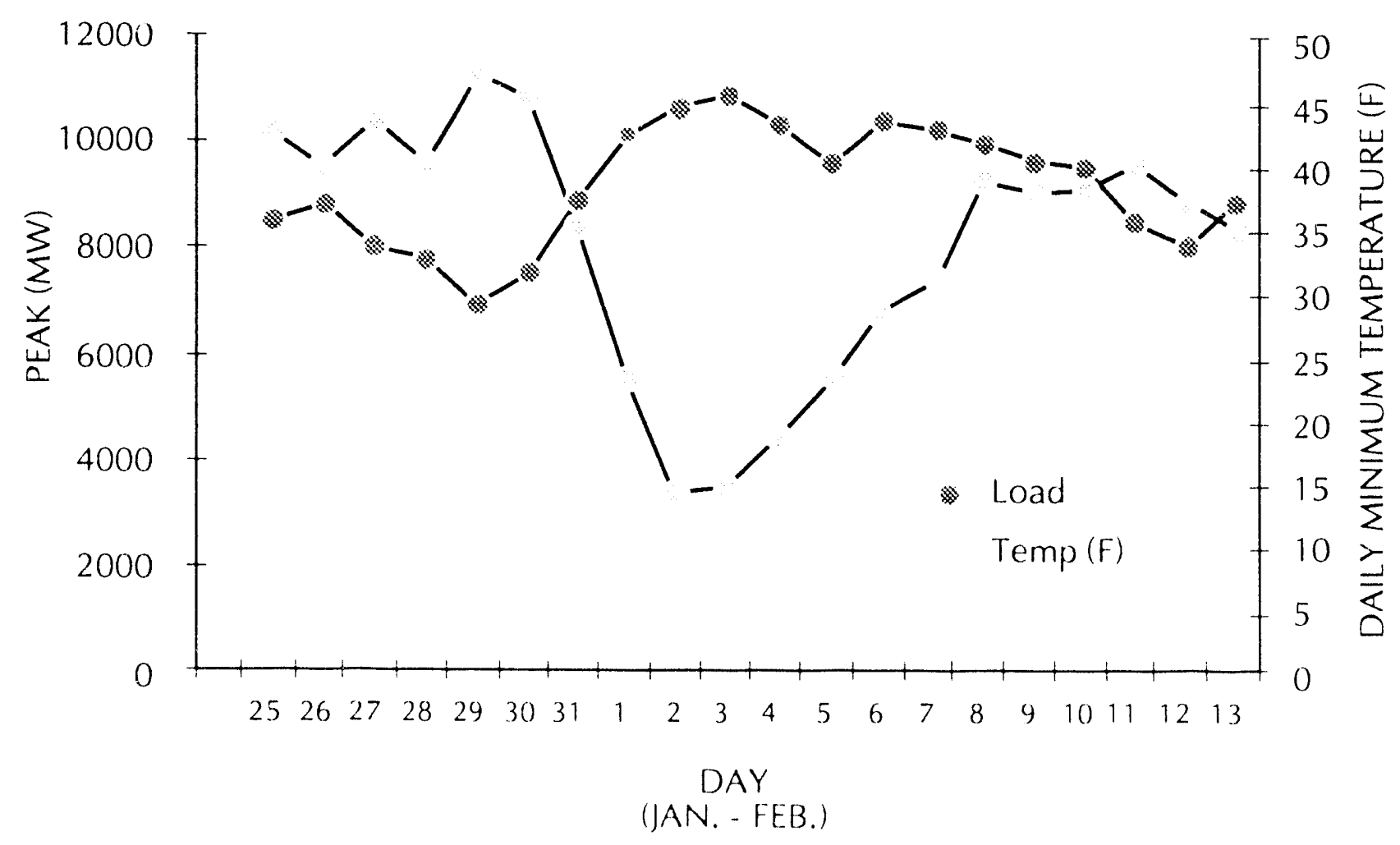


Although the transmission system and local generation sources supplied enough power to the Puget Sound area, if any emergency had occurred such as a transmission line going down, the system may have been unable to meet the power demand. If this happens, voltage on transmission lines can drop below acceptable levels causing a brownout. In extreme cases, automatic devices protect the system by disconnecting lines, which further lowers voltages and causes consumers to be disconnected. This is voltage collapse. If not stopped, it could spread throughout the Puget Sound area, to Portland, Oregon and Vancouver, British Columbia. As electricity use grows, the transmission system is strained more, and the likelihood of a blackout increases.

What might cause this? Three elements contribute to the problem: rapid load growth causing unprecedented peak demand; reliance on transmitting electricity over long distances from outside the area to serve the demand; and limited local generation. These elements combine to jeopardize the ieliability of the power system serving the Puget Sound area.

\subsection{PLANNING ASSUMPTIONS}

In a planning process, analysts make assumptions about the future based on past events and current trends. The objective of planning is to anticipate undesirable conditions in time to take actions to prevent them. Because no one can know the future, assumptions about future conditions are used. These assumptions are the "best guess" planners can make based on their past experience. Key assumptions used by planners for the Puget Sound Area Electric Reliability Plan (PSAERP) are described below. Other assumptions are provided in the Appendices.

\subsubsection{Planning Timeframe}

Utility planners focused detailed studies of the problem in the Puget Sound area on the ten year period from the winter of 1993-94 to the winter of 2002-03. Because the planning process takes several years, and any solutions require lead time to implement, the plan could not begin to take effect before the winter of 1993-94. Planned substation and generation additions already underway are expected to bring the system into balance by late 1993. The 2003 end date reflects the longest time planners believe technological changes, consumption patterns and environmental requirements can be predicted. To capture long-term impacts, the economic analysis was carried through 2010. However, the planning objective is to solve the problem during the ten-year period.

\subsubsection{Load Growth}

The Puget Sound area energy demand has been growing faster than that of any metropolitan area in the Northwest. From 1985 to 1989 annual energy consumption grew by about 3 percent per year. Peak demand grows as energy use increases. By the 1989 cold snap, loads had grown to 11,200 megawatts (MW) during the peak period. A megawatt is the amount needed to light 10,000 one hundred watt lightbulbs. On December 21, 1990, extremely cold weather caused even higher electricity use, with peak loads reaching 11,800 MW.

Will electrical use continue to grow? Predicting future load growth is difficult. Because there is uncertainty about the future, forecasters develop not just one load forecast, but five. These forecasts give decision makers a range of possibilities for planning actions by estimating load growth from low to high. Because many homes in the Puget Sound area use electricity for heat, loads in this area are highest during the winter, so forecasters look at normal and extreme weather conditions when predicting load growth. Figure 1-2 charts the peak load forecast under normal and extreme cold weather conditions, and shows the range of possible forecasts from low to high.

Norma! weather or a normal year is defined as the lowest daily average temperature which would have a fifty percent chance of being surpassed. That is, one would expect the actual temperature to be colder once every two years. Extreme weather or an extreme year is defined as the lowest daily average temperature that has a five percent chance of being surpassed; one would expect the actual temperature to be colder once every 20 years. 
Puget Sound Area Electric Reliability Plan - Draft Environmental Impact Statement

The chance or probability of actual growth being in the range between the medium high and the medium low forecasts is 50 percent. The probability that future loads will be between the high and the low forecasts is 90 percent. The middle or medium forecast is used for planning purposes, but decision makers consider how plans would be impacted by higher or lower load growth.

\section{Figure 1-2.}

\section{Puget Sound Area} Peak Load Forecast

\section{Normal \\ Cold Weather}

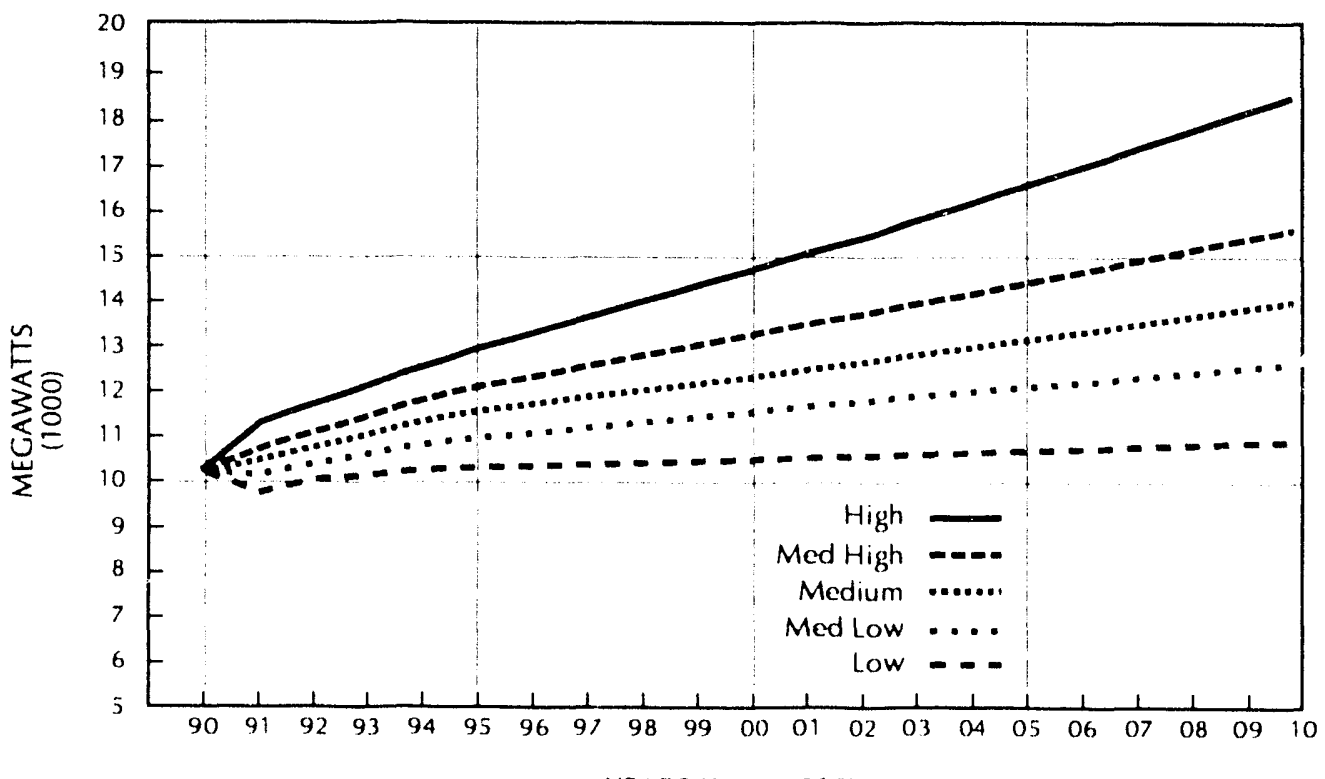

YEARS (1990-2010)

\section{Extreme \\ Cold Weather}

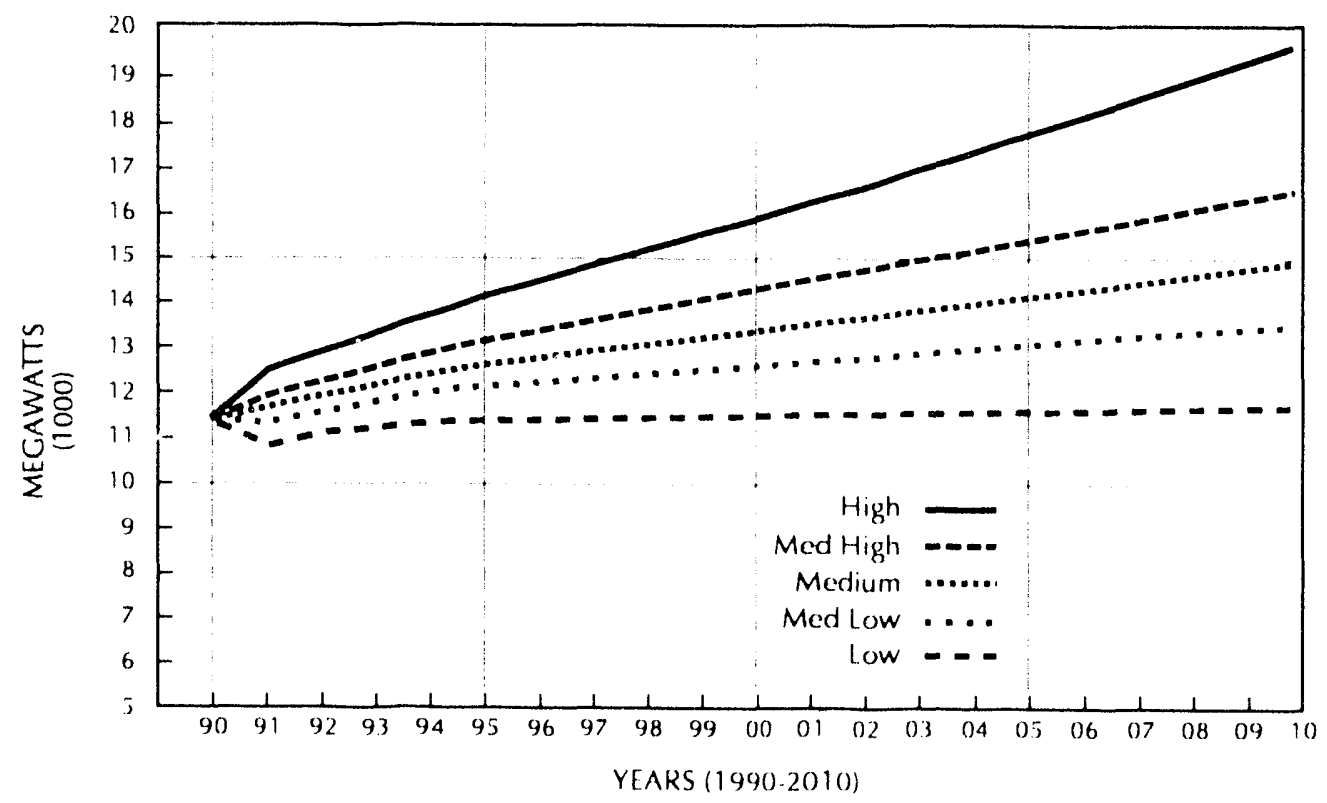

Assuming medium load growth, Figure 1-2 shows Puget Sound peak loads growing by 200-400 MW each year through 1995. Load growth slows after 1995 due to slower economic growth, increased energy efficiency and increased use of natural gas for space and water heating. 
Scoping Report Part B: Preliminary Technical Analyses (BPA, 1990), provides a detailed description of how load growth is forecast, and how system capacity is determined. This report is in Appendix $A$.

\subsubsection{Relying on Long Distance Transmission}

BPA owns and operates three-fourths of the transmission grid in the Pacific Northwest. BPA's high-voltage lines transmit power from Federal dams and other sources, including power generated by other utilities, to customers throughout the Pacific Northwest. Individual utilities in the Puget Sound area also own transmission facilities. When power needs in the Puget Sound area are the greatest, local electrical generating resources supply about 30 percent of the power. Hydro and thermal resources east of the Cascade Mountains supply about 70 percent via five 500 kilovolt $(\mathrm{kV})$ lines and seven lower voltage lines in three corridors. Figure 1-3, based on actual load data from the December 1990 cold spell, shows how the peak load was met by a combination of power generated locally and power transmitted from east of the Cascades and from Canada. Although total demand exceeded the reliable capacity of the transmission system by several hundred megawatts, the system survived because no major lines or generators went out of service. No major transmission additions have been made in the area since 197\%. The existing transmission system was designed assuming more local generation would be built in the Puget Sound area.

Figure 1-3.

1990 Sources of Power for the Puget Sound Area

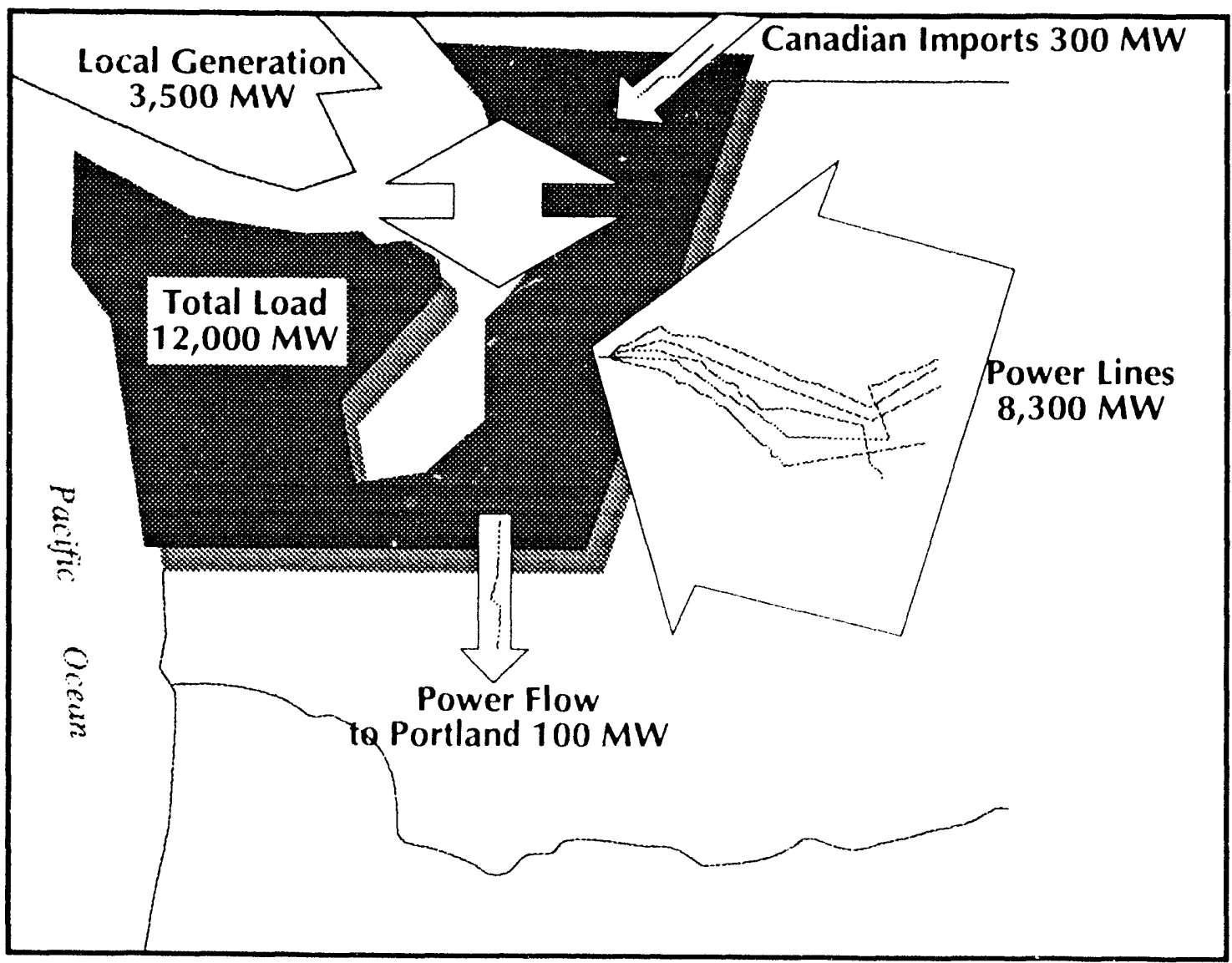


Reliability of the transmission network is critical to the reliability of Puget Sound's power supply. The effect of losing Cruss-Cascades transmission lines (outages) is shown in Figure 1.4. The horizontal lines are stepped and show system capacity for differeni outage conditions. The capacity increases between 1991 and 1993 reflect substation improvements and generation additions previously planned by utilities. The capacity increase resulting from energy resource additions after 1993 are shown as "Expected Resources" (Section 1.4.4). Normal and extreme peak forecasts are shown as dashed lines. With no emergencies on the transmission systern (no lines out of service), the transmission system will be unable to deliver power to meet an extreme peak demand by 2003. In most of the years shown, we run into difficulties during normal winter peaks with two transrilission lines out or with one line out during extreme winter peaks. If load growth exceeds the medium forecast, then these projected deficits will occur sooner and will grow much faster.

\section{Figure 1-4. \\ Puget Sound Area Peak Loads Historical, Forecast and System Capacity}

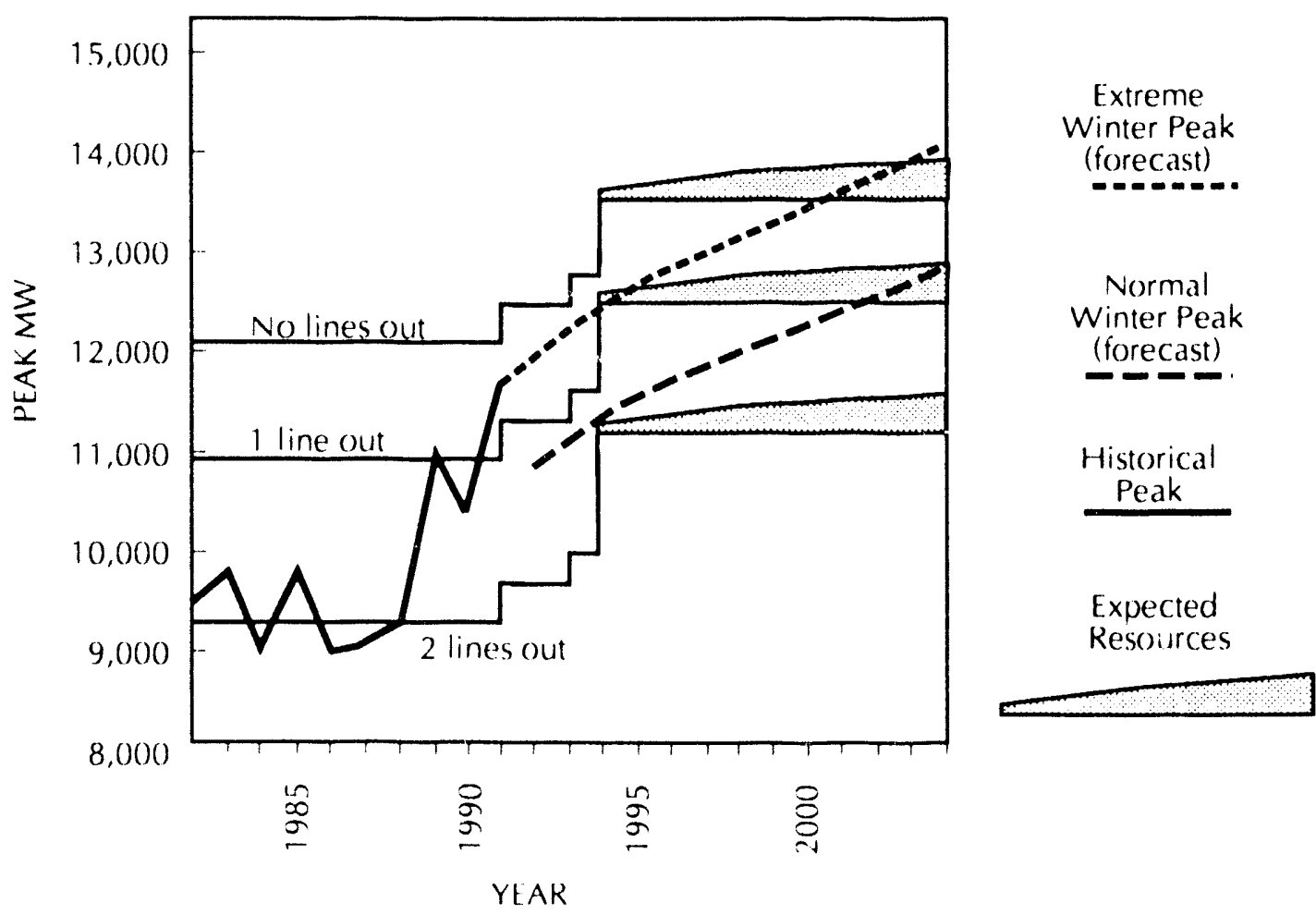

Reliability Criteria Assumptions - Utilities strive to provide reliable service at the best value for their customers. Cost-effectiveness is evaluated from the consumer's perspective. Reliability is a measure of the power system's ability to meet customer demands over a certain period. It is measured by how often power outages occur, how long they last, and how many customers are affected. A perfectly reliable system would always satisfy customer demand. Perfect reliability is not technically feasible and even if possible, would be extremely expensive for consumers.

Using rules based on experience, utilities design and operate transmissioni sy tems to meet high performance standards that come close $t 0$ this "perfect" system. These rules, called reliability criteria, set standards to ensure costeffective, reliable service. A reliable system should provide electrical service under normal and emergency condi- 
tions. A transmission line outage caused by wind, ice, lightning or other events; a power plant shutdown; or other major equipment failure are examples of system emergencies. Reliability criteria define acceptable service under these emergencies. BPA's Reliability Criteria, for example, require if one transmission line is out, the system should serve increased electricity use for heating during abnormal cold weather, maintain voltages, and not overload lines. If both a power plant and one transmission line are out, or two transmission lines are out, the system should serve electricity needs for normal (but not extreme) cold weather, maintain voltages, and not overload lines.

Each utility has its own reliability criteria unique to its system characteristics and customer needs. The BPA system is the backbone of the regional transmission grid, and its performance has widespread, regional impacts. For this reason, BPA's Reliability Criteria, which were updated in September 1989 after public review, set very high performance standards for the bulk power system. The utilities have agreed that BPA's criteria should be the standard for judging the adequacy of potential solutions to the cross-Cascade transmission capacity problem.

\subsubsection{Local Generation and Conservation Resources}

Energy resources, including conservation, provide the power utilities need to serve their customers' demands. Bonneville Dam on the Columbia River and the Centralia coal-fired generation station are examples of energy resources. Conservation programs are also resources because conserved energy is available to serve consumer demands. Of the 12,000 MW currently needed in the Puget Sound area during peak loads, local generation plants can now supply approximately $3,500 \mathrm{MW}$.

Analysts have conservatively estimated that 400 megawatts of new energy resources will be developed in the Puget Sound area by 2003 to meet the energy needs of utilities. This estimate is based on information from Puget Sound area utilities' energy planning processes. Plans for new resources are typically outlined in each utility's leastcost plan.

In the early stages of this planning process, adding more Puget Sound generation resources was considered a potential solution to meeting peak loads. After considering information gathered about these new resources, analysts concluded that although adding energy resources would help solve the peak load problem, peaking needs alone would not be enough to justify energy acquisitions. Generation plants that produce energy cost about 10 times more than comparable transmission additions, and many generation plants tend to operate on a relatively constant basis. For example, the Centralia coal plant operates about $85 \%$ of the hours in a year. If an extreme winter peak occurs, it occurs less than $5 \%$ of the year, and resources to meet peak would be needed during this time only. Analysts therefore removed most generating resources from the list of solutions for this problem. But they recognized that some of the resources utilities acquire to meet energy needs will be located in the Puget Sound area (Expected Resources). These resources will have a secondary benefit of reducing peak demand on the east-west transmission system. These resources are described in Appendix B.

\subsubsection{Load/Resource Balance}

Load growth, long-distance transmission, and local generation and conservation resources in the Puget Sound area must combine to provide a balance between power demand and power supply. This balance must be maintained to avoid potential regional blackouts and damage to the transmission system. Table 1-1 lists forecasted normal and extreme winter peak loads, by electricity use sector, for 1994 and 2003, the beginning and end of the planning period. It shows how much conservation and market-induced fuel switching has been included in the load forecast. Table 1-2 identifies generating resources and transmission system deliveries that supply power to the Puget Sound area under normal and extreme conditions. Combustion turbines are operated during extreme peaks, therefore their contribution during normal peak is zero. This table also shows the size of the deficit in 1994 and 2003. 
Table 1-1. Puget Sound Area Winter Peak Load Forecast (1994 and 2003)

\begin{tabular}{|c|c|c|c|c|}
\hline WINTER PEAK LOADS (MW) & $\begin{array}{c}1994 \\
\text { normal } \\
\text { peak }\end{array}$ & $\begin{array}{c}1994 \\
\text { extreme } \\
\text { peak }\end{array}$ & $\begin{array}{c}2003 \\
\text { normal } \\
\text { peak }\end{array}$ & $\begin{array}{c}2003 \\
\text { extreme } \\
\text { peak }\end{array}$ \\
\hline \multicolumn{5}{|l|}{ RESIDENTIAL LOADS } \\
\hline ELECTRIC SPACE HEATING & 3244 & 4306 & 3307 & 4408 \\
\hline ELECTRIC WATER HEATINNG & 1307 & 974 & 1339 & 991 \\
\hline OTHER & 1465 & 1403 & 1687 & 1608 \\
\hline \multicolumn{5}{|l|}{ COMMERCIAL / INSTITUTIONAL LOADS } \\
\hline $\begin{array}{l}\text { ELECTRIC SPACE HEATING, VENTILATION \& } \\
\text { AIR CONDITIONING (HVAC) }\end{array}$ & 1526 & 1859 & 2056 & 2479 \\
\hline ELECTRIC LIGHTING & 681 & 755 & 788 & 873 \\
\hline OTHER & 341 & 374 & 428 & 467 \\
\hline \multicolumn{5}{|l|}{ INDUSTRIAL LOADS } \\
\hline DIRECT SERVICE INDUSTRIES & 755 & 759 & 756 & 760 \\
\hline OTHER INDUSTRIAL & 1641 & 1616 & 1951 & 1912 \\
\hline MISCELLANEOUS & 440 & 454 & 488 & 502 \\
\hline WINTER PEAK LOAD TOTALS: & 11400 & 12500 & 12800 & 14000 \\
\hline \multicolumn{5}{|c|}{ LOAD REDUCTION AMOUNTS IN LOAD FORECAST } \\
\hline RESIDENTIAL CONSERVATION & 74 & 98 & 188 & 251 \\
\hline COMMERCIAL CONSERVATION & 28 & 32 & 90 & 102 \\
\hline INDUSTRIAL CONSERVATION & 15 & 16 & 69 & 70 \\
\hline MARKET INDUCED FUEL SWITCHING & 70 & 95 & 274 & 290 \\
\hline
\end{tabular}


Table 1-2. Puget Sound Area Resources and Transmission System Capabilities (1994 and 2003)

\begin{tabular}{|c|c|c|c|c|}
\hline ENERGY RESOURCES (MW) & $\begin{array}{c}1994 \\
\text { normal } \\
\text { peak }\end{array}$ & $\begin{array}{c}1994 \\
\text { extreme } \\
\text { peak }\end{array}$ & $\begin{array}{c}2003 \\
\text { normal } \\
\text { peak }\end{array}$ & $\begin{array}{c}2003 \\
\text { extreme } \\
\text { peak }\end{array}$ \\
\hline \multicolumn{5}{|l|}{ GENERATING RESOURCES (MW) } \\
\hline COMBUSTION TURBINES & 0 & 698 & 0 & 698 \\
\hline HYDROELECTRIC & 1419 & 1419 & 1419 & 1419 \\
\hline COAL & 1338 & 1338 & 1338 & 1338 \\
\hline OTHER & 43 & 45 & 43 & 45 \\
\hline EXPECTED RESOURCES & 60 & 60 & 400 & 400 \\
\hline TOTAL GENERATING RESOURCES & 2860 & 3560 & 3200 & 3900 \\
\hline \multicolumn{5}{|l|}{ TRANSMISSION SYSTEM DELIVERIES (MW) } \\
\hline CROSS-CASCADES TRANSMISSION LINES & $8100^{*}$ & $8700^{* *}$ & $8100^{*}$ & $8700^{* *}$ \\
\hline CANADIAN IMPORTS MINUS PORTLAND EXPORTS & 200 & 200 & 200 & 200 \\
\hline TOTAL TRANSMISSION SYSTEM CAPACITY & 8300 & 8900 & 8300 & 8900 \\
\hline TOTAL SYSTEM CAPACITY (MW) & 11160 & 12460 & 11500 & 12800 \\
\hline WINTER PEAK LOAD TOTALS (MW) & 11400 & 12500 & 12800 & 14000 \\
\hline DEFICIT (MW) & 240 & 40 & 1300 & 1200 \\
\hline \multicolumn{5}{|l|}{ * two transmission lines out of service } \\
\hline ut of service & & & & \\
\hline
\end{tabular}




\subsubsection{Dealing with Uncertainties}

The assumptions used in the analysis are based on the best information planners have available. Over a planning period of ten years, unexpected changes will occur. If the future turns out different than expected, the assumptions explained above and the predictions made about the future may be wrong. For example, these changes are possible:

- load growth may increase or decrease due to economic, energy price, or other forecast uncertainties

- benefits from Canadian dams on the Columbia river that were sold to the United States (called the Canadian Entitlement) will be returned to Canada when contracts expire beginning in 1998. Depending on the return arrangements agreed to, these deliveries could further stress the cross-Cascade transmission grid by up to $1000 \mathrm{MW}$.

- expected resources planned may be postponed or not built at all due to new environmental regulations

- new environmental requirements may cause some existing generation plants to shut down

- new technology may increase the efficiency of existing generation or new conservation measures

- research on electromagnetic field effects may hinder transmission line construction

- listing salmon as an endangered species may change river operations and limit power production

These uncertainties could affect the problem in the Puget Sound area, either increasing or decreasing the deficit shown in Table 1-2.

Keeping the potential for change in mind, planners continually track current conditions and change their assumptions if changes occur. For safety, they have identified contingency measures that could be done if, for example, load growth suddenly begins to follow the high load growth pattern and the demand for electricity increases sharply. Contingency measures are chosen for their ability to respond quickly to a significant change in circumstances. Chapter 2 identifies contingency measures for each alternative strategy and describes why they would be selected.

\section{$1.5 \quad$ FINDING SOLUTIONS}

The peak demand problem in the Puget Sound area is a complex one. When BPA and Puget Sound area utilities became aware of the risk of voltage instability and collapse, they began a process to define the problem and develop ways to solve it. They wanted the process to produce a plan to guide future actions by BPA and Puget Sound area utilities. This process, designed to include the public and meet all Federal and State environmental requirements, has many parts. Figure 1-5 identifies each part of the process. During this process, new information, suggestions, solutions, and ways to look at the problem surfaced. These new ideas and data continue to be incorporated into the analysis.

\subsubsection{Scoping}

A one-year scoping process was conducted beginning in October 1989. In January 1990, two public meetings were held in the Puget Sound area and two were held east of the Cascades in Wenatchee, Washington. Scoping had several objectives:

- confirming the voltage instability problem

- notifying the public of the problem and involving them in developing solutions

- identifying environmental issues to study and consider

- defining the nature and extent of the problem for analysis

- identifying measures that solve the problem

- performing preliminary feasibility studies on identified measures. 
A Technical Review Group (TRG) representing state and local government, business and industry, public interest groups, and the public was formed to help identify measures, critique study methods and assumptions, review screening criteria, and provide information on possible solutions. Membership in the TRG was open to anyone. Four TRG meetings were held during scoping.

Figure 1-5. Finding Solutions

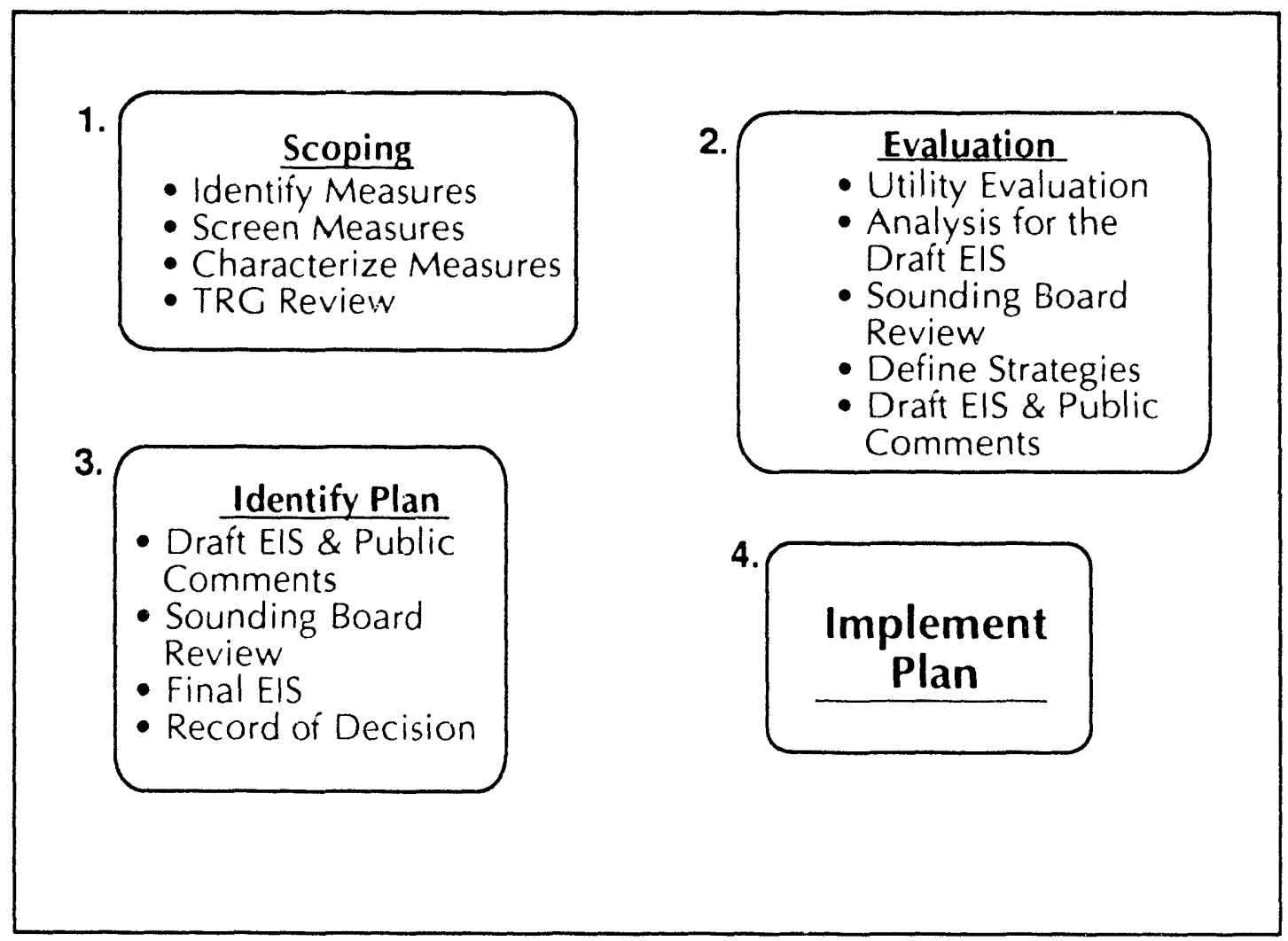

Identifying Measures - During scoping, a long list of measures that might solve the problem was identified biy members of the public, agencies, utilities, and other interested parties. Measures were divided into four categories:

- demand-side or reduce electric use: conservation, load management, and fuel switching

- local generation

- transmission

- load curtailment

Screening Measures - An evaluation team produced screening criteria to limit the "universe" of measures to the ones most feasible. The criteria developed include market factors, resource characteristics, and environmental concerns. Table 1-3 lists the screening criteria. 
Puget Sound Area Electric Reliability Plan - Draft Environimental Impact Statement

Utilities formed study teams representing the four categories and began screening the list of measures. Subcommittees used the criteria as rough guidelines, not absolutes. Applying the screening criteria shortened the list of measures.

\section{Table 1-3. Screening Criteria}

\section{Environmental Concerns}

Meets state and federal environmental quality laws and requirements (e.g., air quality standards, water quality standards, etc.)

Avoids protected sites and environmentally unique habitats (e.g., the Council's Protected Areas, wetlands, National parks, etc.)

\section{Resource Characteristics}

On-line date no later than 1999

Available during cold weather from November through March

Located within the Puget Sound area

Costs should be reasonable relative to the estimated cost of transmission (approximately $\$ 100$ per $\mathrm{kW}$ ), the estimated cost of a single cycle combustion turbine (approximately $\$ 650$ per $\mathrm{kW}$ ), and the regional energy cost-effectiveness limit of 50 mills per kWh.

\section{Market Factors}

Commercially Available Technology

Commercially Proven Technology/Confirmed Resource

Acceptable to the Market

Characterizing Measures - After the initial screening, team members began analyzing the measures that passed the first screen. For each measure, they gathered information about potential for generating or saving power, costs, and impacts to the environment. Measures are listed in Chapter 2 and described in the Appendices. 


\subsubsection{Evaluation}

Utility Evaluation - A methodology to evaluate and compare solutions was developed as described in Sections 4.7 and 4.8. Analysts use this methodology to study solutions, and consider new information about loads and resources as it becomes available. BPA and the Puget Sound area utilities constantly review and update their information on loads and resources, and revised numbers are incorporated into the analysis as needed. Still, predicting the future is uncertain, and although estimates reflect current conditions, they are only assumptions used as tools to find solutions.

This study has two relevant time periods. First, is the decision period, which extends from 1994-2003. It is during these ten years that utilities must take actions to meet peak loads. Second, is the evaluation period which continues beyond 2003 through 2010. This extended period is needed to capture adequately the costs and benefits of actions taken through 2003; some costs and benefits do not occur equally in all years.

Seven evaluation factors cover the range of concerns decision makers may consider. Table 1-4 lists the evaluation factors. Some factors, such as costs, can be quantified, while others such as envirormental impacts, can be compared qualitatively only. Since the evaluation factors represent different concerns and are measured differently, the evaluation methodology ranked solutions according to each factor individually rather than using a single score combining ranks from all factors. The methodology does not weigh the relative importance of each evaluation factor. If no solution ranks highest on all factors, trade-offs may be necessary to find the best one. The best solution will balance environmental, economic, and technical factors.

Table 1-4. Evaluation Factors

\begin{tabular}{|l|}
\hline Environmental \\
\hline Environmental Impacts \\
\hline Economic \\
\hline Present Value of Total Svstem Costs \\
\hline Sensitivity to Load Growth \\
\hline Near-Term Reveriue Requirements \\
\hline Long-Term Revenue Requirements \\
\hline Technical \\
\hline Reliability \\
\hline \begin{tabular}{l} 
Deliverability in View of Social and \\
\hline
\end{tabular} \\
\hline
\end{tabular}


Who will pay for implementing solutions is not addressed in this process. Any factors that evaluate costs treat the Puget Sound area as if it were served by a single utility.

Economic and technical assumptions used for the evaluation and results of sensitivity studies using different assumptions are in Appendix C.

Analysis for Draft EIS - Because of the nature of the peaking problem in Puget Sound and the characteristics of individual measures, it is unlikely one measure alone will provide a satisfactory solution. Identifying and evaluating individual measures and test cases was the focus of this analysis. The test cases are composed of measures from different measure categories. For example, a test case might include conservation and transmission system additions. The measures used are real solutions, but the test cases only represent possible combinations. Analyzing them provided a way for decision makers and the public to learn how the problem might be solved. To help predict environmental consequences and advise decision makers, an analysis of environmental impacts for each feasible measure was conducted. A technical analysis using the economic and technical evaluation factors was also completed for measures and test cases. The test cases presented in this analysis were used by utility teams to develop and test evaluation methodology for the Draft EIS. Appendix C describes test cases in greater detail.

Sounding Board Revitw - To involve the business community, labor, government agencies, key interest groups and others mostly outside the utility industry, a group called the Sounding Board was created. This group provided opinions and suggestions on elements of the Analysis for the Draft EIS, and the Draft EIS.

Define Strategies - Using the methodology developed and tested during the course of the Analysis for the Draft EIS, measures were put together into four bundles called alternative strategies. The alternative strategies discussed in the Draft EIS are considered realistic solutions to the Puget Sound's electric reliability problem. The Preferred Alternative was identified by the utility project Steering Committee using input from the Sounding Board.

Draft EIS and Public Comments - The objective of the EIS is to identify alternative strategies and a preferred alternative that solve the cross-Cascade transmission capacity problem in the 1994-2003 period, while satisfying the purposes and evaluation factors discussed in this chapter. It provides information on the alternative strategies to allow the public to identify their preference. All comments received will be recorded and responses included in the final EIS. Public response will be an important factor in decision making.

\subsubsection{Identify Plan}

Draft EIS and Public Comments - (see description above).

Sounding Board Review - (see description above).

Final EIS - After considering Sounding Bcard and public comments on the Draft EIS, and reevaluating plans, utility decision makers will decide on a plan. This plan, titled "The Puget Sound Area Electric Reliability Plan," may be adopted by BPA, Puget Sound Power and Light, Seattle City Light, Tacoma Public Utilities, and Snohomish County PUD. Puget Sound area utilities and BPA have been working together to achieve this goal. Sponsorship of parts of a final Plan is uncertain, and individual utilities must work within their own structures when making major decisions. The final Plan will include contingency measures to provide flexibility needed to manage uncertainty. Decision makers will consider all suggestions and these factors in the Final EIS. The chosen plan and responses to comments on the Draft EIS will be in the Final EIS. 
Record of Decision - The Record of Decision will report the decision about whether BPA adopts the Puget Sound Area Electric Reliability Plan. BPA decision making is subject to the procedural requirements of NEPA. Hence, BPA will prepare the Draft and Final EIS and the Record of Decision. The Record of Decision will state why BPA either endorses or does not endorse the Plan, and describe any actions that BPA is proposing. If future actions by the participating utilities require either Federal or state approvals, this EIS may be adopted by the involved federal or state agency, or supplemented.

\subsubsection{Implement Plan}

Following endorsement of the Plan, BPA and/or one or more of the Puget Sound utilities may sponsor individual actions to meet the Plan's objectives. Other utilities may take other actions consistent with ineir needs. Such decisions will be made in accordance with the utility's normal customs and practices. The PSAERP Environmental Impact Statement will, in part, satisfy Federal or State environmental requirements. Supplemental analyses may be required for proposals.

The utility team will periodically monitor power supply, resource development, and user demands during 1994-2003, to measure progress in accomplishing the Plan. Plan modifications may be required to respond to changing conditions. 


\subsection{PROPOSED ACTION AND ALTERNATIVES}

This chapter describes a preferred alternative and four alternative strategies that can solve the peak demand problem in the Puget Sound area. A No Action Alternative is also described.

Each strategy is composed of several measures. The Preferred Alternative is a combination of one alternative strategy, with additional measures from other strategies. To aid in understanding the strategies, three methods of describing each strategy are provided. A chart graphically shows the year in which measures are taken and the amount that each measure contributes to meeting peak power needs. Tables give a numerical summary of the strategies. Finally, each strategy is described in narrative. Supporting information is provided in the appendices.

The load forecast on which the plans are based takes into account planned conservation and market-driven fuel switching. All the strategies account for expected energy resource development within the region as described in Chapter 1. Two measures, accelerated energy conservation and Voltage Support Option 1, are included in all strategies.

While sharing these two measures, each strategy overall represents a different approach to meeting peak power needs. The objective of this chapter is to provide an understanding of the alternative strategies. Chapter 4 , Environmental Consequences, provides an evaluation of the strategies showing environmental differences. Economic and technical differences are also shown.

Finally, the success of the alternative strategies is highly dependent on the planning assumptions described in Chapter 1. If higher or lower than expected load growth occurs, the alternative strategies will be modified accordingly. Similarly, if energy resources now planned by Puget Sound utilities are not built, additional measures will be needed. Each strategy discussion ends with Contingency Actions that would be taken if the transmission capacity deficit is more than expected. The No Action Alternative is defined as an unplanned approach, thus no contingency measures are discussed for this alternative.

\subsection{PREFERRED ALTERNATIVE}

To hasten improved electric reliability, and focus public discussion on the potential solutions, a preferred alternative was identified by the five-utility Steering Committee with advice from the Sounding Board, a citizen review panel.

In chousing a preferred alternative plan, several qualities were looked for by the Steering Committee beyond the normal criteria such as environmental stability, cost, and technical performance. Adaptability in view of such uncertainties as higher than medium load growth, Canadian Entitlement return, local generation development or decommissioning, Endangered Species Act listings, and electromagnetic field health effects was one such desired quality. This flexibility was felt best achieved by identifying contingency measures to be taken if the capacity deficit grows faster than expected.

A second quality that the Steering Committee was sensitive to was the need to regularly review the electric reliability of Puget Sound and update the plan when changing conditions warrant it.

Finally, it was recognized that utilities are moving in new directions and that demand-reduction pilot projects in water heater load control and fuel switching will provide useful information on costs, benefits and the deliverability of these measures. Thus, the Puget Sound Area Electric Reliability Plan may be changed to take advantage of these and other technological developments as a part of the periodic review and updating process.

As a preface to the following discussion, it is important to remember that planned conservation and market- 
As a preface to the following discussion, it is important to remember that planned conservation and marketinduced conversions to natural gas are included in the load forecast. New energy resources expected to be developed in the Puget Sound area in response to utility energy needs are also included (see Section 1.4.4). In addition, two measures are common to all of the plans. These are:

- Accelerated Conservation Programs

- Voltage Support Option 1

To avoid repetition, measures common to all plans are discussed within Alternative Strategy 1 , and referred to in later discussions.

As stated above, the Preferred Alternative is a hybrid of one Alternative Strategy with additional elements of other strategies as contingency measures. The Preferred Alternative takes Alternative Strategy 2 and fleshes out details of where the substation involved may be sited, and suggests additional activities and planning for contingencies. The Preferred Alternative is described here briefly, with detailed information on individual strategy measures given under Alternative Strategies 1 - 4 .

The Preferred Alternative includes the common elements of all the strategies: accelerated conservation programs in the residential, commercial and industrial sectors, a high-efficiency shower head program, and Voltage Support Option 1. These elements are described in Sections 2.2.1 and 2.2.2 under Alternative Strategy 1. Puget Sound area utilities will ramp up conservation programs to achieve peak reductions by the winter of 1993-94. BPA will complete Voltage Support Option 1 by the fall of 1993, which will provide $600 \mathrm{MW}$ of additional transmission capacity for the winter of 1993-94. Another voltage support element, Voltage Support Option 2, would be implemerited. In Voltage Support Option 2, BPA would develop a 500-kV substation east of the Cascade Mountains that would provide 1000 MW of increased capacity by the winter of 1994-95. This substation would be located north of Ellensburg, Washington. (See Chapter 3 for possible sites).

These measures are all part of Alternative Strategy 2. The Preferred Alternative differs from Alternative Strategy 2, however, by recognizing pilot programs for investigating the costs, benefits and deliverability of fuel switching and water heater load control programs. These are demand-side programs discusseci in Sections 2.4.3 and 2.4.4 under Alternative Strategy 3.

\subsubsection{Contingency Measures}

Because load growth and resource supply could vary substantially from that assumed in this analysis, each alternative strategy includes contingency measures that could be used to make each strategy flexible and able to respond to unexpected circumstances. Two elements, a transmission line and combustion turbines are included in this alternative. A transmission line has typically required 5-6 years from the initial planning stage to completion. This alternative proposes beginning planning and design work on this transmission line early. The environmental process would start in late 1992 or early 1993 to assure availability by the year 2000 . As a contingency element, a lead time of $7-8$ years has been assumed. A decision to build would not be necessary until 1996, and if the line is unnecessary, it could be deferred at that time. If building a transmission line is controversial and unable to be built or built in time to supply the need for peaking powei, one or more combustion turbines could be built. Combustion turbines have a shorter lead time, and would only be used during peak loads.

\subsubsection{Environmental Impacts of the Preferred Alternative}

Information on the general environmental impacts of individual strategy measures is given under Alternative Strategies 1.4 in the following sections. For a more detailed discussion of impacts refer to Chapter 4. 


\subsection{ALTERNATIVE STRATEGY 1 - TRANSMISSION LINE}

This strategy varies from the other strategies because it calls for a new high-voltage transmission line to transmit power from generation resources east of the Cascades to the Puget Sound area. Figure 2-1 illustrates how measures are applied over time to meet the forecasted extreme winter peak load deficit for medium and medium-high loads. The strategy uses accelerated energy conservation measures and Voltage Support Option 1 in early years to meet forecasted peak loads. In 1998, a new line is added providing the large increase in capacity shown in the figure.

\section{Figure 2-1. Alternative Strategy 1}

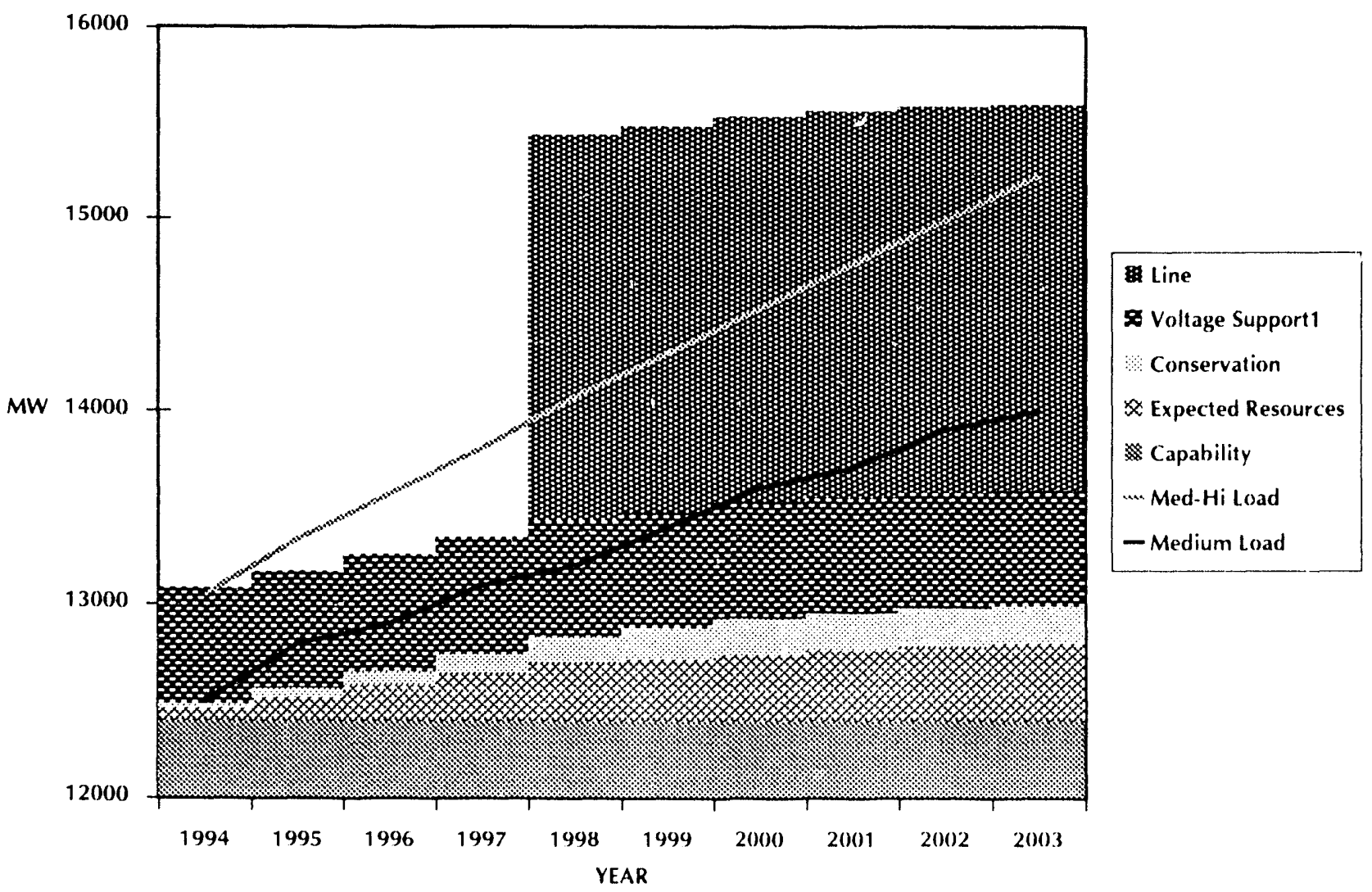

Table 2-1 provides numerical data on each of the measures included in the strategy. Data reflects megawatts available to meet extreme winter peak conditions. Load forecast data follows medium load growth for extreme winter peak. The table shows megawatts of surplus capacity for each year of the planning timeframe. Alternative Strategy 1 provides 1608 megawatts of surplus peaking capacity in Puget Sound in 2003. 
Table 2 -1. Alternative Strategy 1 Capacity (MW)

\begin{tabular}{|l|r|r|r|r|r|r|r|r|r|r|}
\hline \multicolumn{1}{|c|}{ ALTERNATIVE STRATEGY 1: TRANSMISSION LINE } \\
\hline YEAR & 1994 & 1995 & 1996 & 1997 & 1998 & 1999 & 2000 & 2001 & 2002 & 2003 \\
\hline CAPABILITY & 12400 & 12400 & 12400 & 12400 & 12400 & 12400 & 12400 & 12400 & 12400 & 12400 \\
\hline EXPECTED RESOURCES & 60 & 120 & 180 & 240 & 300 & 320 & 340 & 360 & 380 & 400 \\
\hline CONSERVATION & 21 & 48 & 82 & 116 & 148 & 180 & 211 & 214 & 218 & 208 \\
\hline VOLTAGE SUPPORT 1 & 600 & 600 & 600 & 600 & 600 & 600 & 600 & 600 & 600 & 600 \\
\hline NEW LINE & 0 & 0 & 0 & 0 & 2000 & 2000 & 2000 & 2000 & 2000 & 2000 \\
\hline $\begin{array}{l}\text { OOTAL PLAN } \\
\text { CAPACITY }\end{array}$ & 13081 & 13168 & 13262 & 13356 & 15448 & 15500 & 15551 & 15574 & 15598 & 15608 \\
\hline $\begin{array}{l}\text { LOAD FORECAST } \\
\text { (EXTREME PEAK) }\end{array}$ & 12500 & 12800 & 12900 & 13100 & 13200 & 13400 & 13600 & 13700 & 13900 & 14000 \\
\hline $\begin{array}{l}\text { SURPIUS CAPACITY } \\
\text { (PUGET SOUND) }\end{array}$ & 581 & 368 & 362 & 256 & 2248 & 2100 & 1951 & 1874 & 1698 & 1608 \\
\hline
\end{tabular}

\subsubsection{Conservation Measures}

Conservation means using electricity more efficiently. Conservation typically reduces electricity use at all hours and can reduce transmission requirements.

The conservation component of this and all strategies includes an accelerated weatherization program, an accelerated industrial conservation program, a high-efficiency shower head program, and an accelerated commercial retrofit program. All accelerated programs are those funded by BPA. Utilities may have other conservation programs that they implement on their own. These were not considered as part of the acceleration program. The accelerated programs provide savings starting in January 1994. A complete description of the conservation programs is given in Appendix D.

Conservation programs traditionally are programs used to reduce annual energy consumption rather than just energy use during peak hours. Except for the high-efficiency shower head program, the conservation measures are accelerated versions of the programs now being operated by BPA and Puget Sound area utilities. Besides providing peak load reductions, they also provide substantial energy benefits. These programs have not been redesigned to make them more effective in reducing peak loads. The analysis of these programs was done to determine if accelerating traditional programs would significantly reduce peak loads on very cold days.

Table 2-2 shows the costs and savings of the conservation programs. Program levels are levels above a baseline level of savings that includes all currently planned conservation included in the load forecast. Baseline levels are included in Table 2-2 in parentheses. Savings for some conservation programs seem small because the measure considered accelerates an exising program that is already being operated aggressively. Only modest acceleration is possible and the savings above the baseline level are limited. 
Table 2-2. Costs and Savings of Conservation Programs

\begin{tabular}{|c|c|c|c|c|c|c|c|c|c|c|}
\hline \multirow[b]{2}{*}{ Conservation } & \multicolumn{5}{|c|}{$\begin{array}{l}\text { PEAK COST (S/KW) } \\
\text { Norinal Winter Peak }\end{array}$} & \multicolumn{5}{|c|}{$\begin{array}{l}\text { ENERCY SAVINCS } \\
\text { (Average annual megawatts) }\end{array}$} \\
\hline & \multicolumn{3}{|c|}{ INITIAL COST } & \multicolumn{2}{|c|}{ ANNUAL COST } & 1994 & 1996 & 1998 & 2003 & 2010 \\
\hline $\begin{array}{l}\text { Residential } \\
\text { Weatherization }\end{array}$ & \multicolumn{3}{|c|}{$\mathbf{\$ 0}$} & \multicolumn{2}{|c|}{$\$ 62$} & $\begin{array}{l}2 \\
(17)\end{array}$ & $\begin{array}{l}7 \\
(26)\end{array}$ & $\begin{array}{l}12 \\
(32)\end{array}$ & $\begin{array}{l}11 \\
(43)\end{array}$ & $\begin{array}{l}0 \\
(54)\end{array}$ \\
\hline Commercial Retrofil & \multicolumn{3}{|c|}{$\$ 1420$} & \multicolumn{2}{|c|}{$\$ 0$} & $\begin{array}{l}2 \\
(18)\end{array}$ & $\begin{array}{l}12 \\
(28)\end{array}$ & $\begin{array}{l}25 \\
(37)\end{array}$ & $\begin{array}{l}52 \\
(58)\end{array}$ & $\begin{array}{l}87 \\
(81)\end{array}$ \\
\hline Industrial Retrofit & \multicolumn{3}{|c|}{ \$0 } & \multicolumn{2}{|c|}{$\$ 56$} & $\begin{array}{l}4 \\
(15)\end{array}$ & $\begin{array}{l}11 \\
(26)\end{array}$ & $\begin{array}{l}17 \\
(38)\end{array}$ & $\begin{array}{l}25 \\
(67)\end{array}$ & $\begin{array}{l}0 \\
(92)\end{array}$ \\
\hline $\begin{array}{l}\text { High-Efficiency } \\
\text { Shower Heads }\end{array}$ & \multicolumn{3}{|c|}{$\$ 335$} & \multicolumn{2}{|c|}{$\$ 0$} & 0 & 6 & 11 & 18 & 17 \\
\hline \multicolumn{6}{|l|}{ TOTALS* } & $\begin{array}{l}8 \\
(50)\end{array}$ & $\begin{array}{l}36 \\
(80)\end{array}$ & $\begin{array}{l}65 \\
(107)\end{array}$ & $\begin{array}{l}106 \\
(168)\end{array}$ & $\begin{array}{l}104 \\
(227)\end{array}$ \\
\hline & \multicolumn{5}{|c|}{$\begin{array}{r}\text { PEAK SAVINGS NORMAL YEAR } \\
\text { (Units are megawalts) }\end{array}$} & \multicolumn{5}{|c|}{$\begin{array}{l}\text { PEAK SAVINGS EXTREME YEAR } \\
\text { (Units are megawalls) }\end{array}$} \\
\hline Conservation & 1994 & 1996 & 1998 & 2003 & 2010 & 1994 & 1996 & 1998 & 2003 & 2010 \\
\hline $\begin{array}{l}\text { Residential } \\
\text { Weatherization }\end{array}$ & $\begin{array}{l}10 \\
(74)\end{array}$ & $\begin{array}{l}30 \\
(112)\end{array}$ & $\begin{array}{l}51 \\
(138)\end{array}$ & $\begin{array}{l}47 \\
(188)\end{array}$ & $\begin{array}{c}0 \\
(235)\end{array}$ & $\begin{array}{l}13 \\
(98)\end{array}$ & $\begin{array}{l}40 \\
(149)\end{array}$ & $\begin{array}{c}68 \\
(183)\end{array}$ & $\begin{array}{l}62 \\
(251)\end{array}$ & $\begin{array}{l}0 \\
(313)\end{array}$ \\
\hline Commercial Retrofit & $\begin{array}{c}4 \\
(28)\end{array}$ & $\begin{array}{l}18 \\
(44)\end{array}$ & $\begin{array}{l}39 \\
(58)\end{array}$ & $\begin{array}{l}81 \\
(90)\end{array}$ & $\begin{array}{l}138 \\
(126)\end{array}$ & $\begin{array}{c}4 \\
(32)\end{array}$ & $\begin{array}{l}21 \\
(50)\end{array}$ & $\begin{array}{l}44 \\
(65)\end{array}$ & $\begin{array}{c}91 \\
(102)\end{array}$ & $\begin{array}{l}157 \\
(143)\end{array}$ \\
\hline Industrial Retrofit & $\begin{array}{c}4 \\
(15)\end{array}$ & $\begin{array}{l}11 \\
(27)\end{array}$ & $\begin{array}{l}18 \\
(39)\end{array}$ & $\begin{array}{l}25 \\
(69)\end{array}$ & $\begin{array}{l}0 \\
(94)\end{array}$ & $\begin{array}{c}4 \\
(16)\end{array}$ & $\begin{array}{l}11 \\
(27)\end{array}$ & $\begin{array}{l}18 \\
(39)\end{array}$ & $\begin{array}{l}26 \\
(70)\end{array}$ & $\begin{array}{l}0 \\
(95)\end{array}$ \\
\hline $\begin{array}{l}\text { High-Efficiency } \\
\text { Shower Heads }\end{array}$ & 0 & 14 & 25 & 41 & 39 & $\mathbf{0}$ & 10 & 18 & 29 & 28 \\
\hline TOTALS* & $\begin{array}{l}18 \\
(117)\end{array}$ & $\begin{array}{l}73 \\
(183)\end{array}$ & $\begin{array}{r}133 \\
(235)\end{array}$ & $\begin{array}{l}194 \\
(347)\end{array}$ & $\begin{array}{l}177 \\
(455)\end{array}$ & $\begin{array}{l}21 \\
(146)\end{array}$ & $\begin{array}{l}82 \\
(226)\end{array}$ & $\begin{array}{l}148 \\
(287)\end{array}$ & $\begin{array}{l}208 \\
(423)\end{array}$ & $\begin{array}{l}185 \\
(551)\end{array}$ \\
\hline \multicolumn{11}{|c|}{$\begin{array}{l}\text { Numbers in parentheses are baseline conservation in the load forecast } \\
\text { * Numbers are cumulative }\end{array}$} \\
\hline
\end{tabular}


The savings shown in Table $2-2$ for all conservation measures are not the maximum savings that are theoretically !ossible. Instead, they are based on program success estimates. Program accomplishments were assumed based on BPA and area utility experience with conservation programs. Projections of future savings were limited to results that actual programs could be expected to achieve. This means conservation is installed in only a portion of houses or businesses that can actually accommodate this equipment. Savings may be more than assumed here. Costs merely reflect the costs of doing projects earlier than planned, for the accelerated programs.

Peak savings are shown for normal winter days and extreme winter days assuming the medium load forecast. Separate calculations were needed because most programs have results that are weather sensitive. Some programs, such as residential weatherization, provide more peak savings on extremely cold days while others save less at the hour of peak demand during extreme weather.

Table 2-2 shows that accelerating conservation programs provides savings in a normal and extreme peak year. The peak savings are greatest for 2003 (194 MW normal year, $208 \mathrm{MW}$ extreme year), then decrease by 2010, the time most programs would be completed regardless of this Plan. Energy savings follow this pattern; savings increase to 2003 and then decrease by 2010 . All programs provide 104 aMW of energy savings by 2010 . If a forecast other than the medium load forecast is assumed, combined savings would be different. More energy would be saved with a higher load forecast, and less would be saved with a lower load forecast.

Residential Weatherization Program - This is an acceleration of the existing weatherization program. Working through utilities, BPA provides funding to weatherize existing homes and apartments. After an energy audit, homeowners and landlords have conservation measures installed in their homes or rental units. Measures installed include adding insulation to ceilings, floors and walls, and weather-stripping and energy-efficient windows to houses and apartments.

The cost of accelerated weatherization is shown in Table $2-2$ as an annual finance cost based on a $3 \%$ real interest rate. This represents the additional cost of weatherizing homes sooner than originally planned.

Accelerating this program will weatherize all eligible homes or rental units by 2000 . Under the baseline, these units would not have been completed until 2010. Savings shown in Table $2-2$ increase through 2003 and drop back to zero as the baseline catches up. By 2010 savings are zero because, absent accelerating the program, the same number of dwellings would have been weatherized. For temperature sensitive loads such as residential space heat, peak savings are higher during extremely cold weather than during a normal heating season.

Residential weatherization programs have the potential to affect indoor air quality. Air leakage in homes is reduced when houses are weatherized, and indoor air pollutants may increase. Actual rates are based on the combination of ventilation available and sources of pollution.

Industrial Conservation Program - The industrial sector includes manufacturing firms. Among industries, the pulp and paper, lumber and wood products, and chemical industries consume the most electricity. Among applications, lighting and motors for production lines consume the most electricity. Process heating and refrigeration also consume large amounts of electricity. Industrial conservation is achieved by retrofitting existing facilities to use less energy and by building new facilitie's for maximum energy efficiency. This could include incentives to conserve? energy.

This measure accelerates the existing tnergy \$avings Plan program currently offered by BPA. This program promotes electric efficiency in both new and existing industrial plants. Under the existing tnergy Savings Plan, BPA and utility staff work with industrial firms to find ways to save energy. The industries then submit proposals for energy conservation projects directly to BPA for funding. Any measure that saves energy is eligible. This program includes installing efficient lighting, heating, ventilation, and air conditioning (IVAC) systems, process heating systems, pumps, compressed air, and motors. 
Costs, shown in Table 2-2, are annual costs because this program only accelerates expenditures that are already planned. By 2000, this program will complete installation of measures that under present plans would take until 2010. Savings, shown in Table 2-2, first increase and then decline to zero by 2010 because this program only accelerates conservation investments already planned. By 2010 the baseline program would have accornplished everything the accelerated program accomplishes.

There is no significant difference in the savings on a normal winter day and an extreme day because industrial loads are not temperature sensitive. This means the costkW saved is about the same for either day.

Industrial conservation measures have minimal environmental effect. Measures involve minor modifications or additions to existing systems.

Accelerating the Commercial Retrofit Program - Based on energy use, the commercial sector is the fastest growing sector in the Pacific Northwest. This sector is divided into ten building types: offices, retail buildings, restaurants, grocery stores, lodging, colleges, schools (primary and secondary), warehouses, health facilities, and miscellaneous. The most energy-intensive uses in the commercial sector are lighting, refrigeration, space heating, water heating, and air conditioning. Office and retail buildings have the largest percentage of use because they have the largest share of commercial building floor space. Restaurants and grocery buildings have substantially higher ene: iy use per square foot than other building types and have great savings potential.

This measure accelerates the commercial retrofit program being developed by BPA and area utilities. This would speed up the rate conservation is acquired in commercial buildings by retrofitting these buildings with more energy-efficient equipment. BPA and utility staff will work with commercial establishments to encourage installing energy conservation measures when buildings are remodeled.

The costs of this program, shown in Table 2-2, are the full cost of the equipment to be installed. The baseline for the commercial sector does not propose to acquire all commercial conservation by 2010, so it is assumed the projects completed by this accelerated program would not have been done before 2010 without the program acceleration.

The commercial retrofit program is modeled as a $10 \%$ reduction in load for a portion of commercial buildings in the Puget Sound area. A $10 \%$ load reduction is applied to all hours of the day for both the normal winter day and the extreme winter day. Commercial loads are temperature sensitive, resulting in greater peak savings on extremely cold days.

Like residential programs, commercial conservation programs carry the potential to affect indoor air quality and ozone depletion. Another concern is the need for proper disposal of polychlorinated biphenyl (PCB) contained in ballasis in fluorescent light fixtures constructed before 1979. However, an organized program probably increases the chance that these ballasts will be disposed of properly rather than thrown into the solid waste stream one by one as they wear out under normal use.

High-efficiency Shower Head Program - High-efficiency shower heads reduce the amount of hot water required per shower. This means the water heater operates for less time per shower. Because each water heater operates for less time, fewer water heaters throughout the area operate at once. Therefore, total water heater demand is reduced because of greater diversity in operating times.

High-efficiency shower heads are part of a water heater package that includes water heater controls and more efficient tanks. High-efficiency shower heads are in the package to increase consumer acceptance and increase participation because less water will be drawn from the lank and consumers are less likely to experience low water temperatures. High-efficiency shower heads also would be offered free to consumers who do not choose the entire water heater package. This proposed program would install high-efficiency shower heads in $60 \%$ of showers by

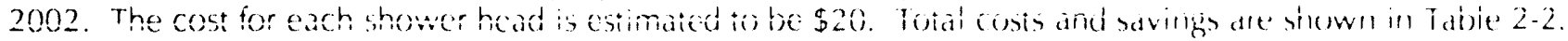




\subsubsection{Voltage Support Option 1}

The power flowing in and out of storage in magnetic and electric fields is called reactive power. All clements of the power system rely on magnetic and electric fields to generate, transmit, and convert electrical power to work. Reacive power must be in balance for stable voltage on the system. Capacitors are devices that store energy in electric fields and are used to raise voltage on the transmission system.

The voltage support measures solve a portion of the voltage stability problem by adding equipment at existing substations in the area. There are two voltage support measures, Option 1 and Option 2. Voltage Support Option 2 is described in Section 2.3.3. Table 2-3 shows costs, capacity, and lead time for both voltage support options. Voltage Support Option 1 is included in this and all other strategies. This option would add shunt capacitors ai Echo Lake Substation after it is completed in 1993. Shunt capacitors are installed in racks and would require an area of less than one acre. A more detailed description of both options is given in Appendix $E$.

Table 2-3. Transmission Measures Costs, Loss Savings, and Lead Time

\begin{tabular}{|c|c|c|c|}
\hline MEASURE & $\begin{array}{c}\text { COST } \\
(1990 \\
\text { \$Millions) }\end{array}$ & $\begin{array}{c}\text { CAPACITY } \\
(\mathrm{MW})\end{array}$ & $\begin{array}{l}\text { LEAD } \\
\text { TIME } \\
\text { (years) }\end{array}$ \\
\hline Transmission line & 250 & 2000 & $5-6$ \\
\hline Voltage Support 1 & 6 & 600 & 2 \\
\hline Voltage Support 2 & 40 & 1000 & 3 \\
\hline \multicolumn{4}{|c|}{ LOSS SAVINGS IN THE PACIFIC NORTHWEST (Peak MW) } \\
\hline MEASURE & 1994 & $1990 \dot{0}$ & 2003 \\
\hline Transmission line & [1] & 80 & 105 \\
\hline Voltage Support 1 & 0 & 0 & 0 \\
\hline Voltage Support 2 & [1] & 9 & 12 \\
\hline
\end{tabular}




\subsubsection{Cross-Cascadc 500-kV AC Double Circuit Transmission Line}

A new transmissiun lir e crossing the Cascadt Mountains from eastern Washington to the Puget Sound area is another possible solution. The transmission line would allow power from existing generation resources east of the Cascades to be transmitted to Puget Sound beginning in 1998. Crossing the Cascade Mountains with a transmission line may require:

- right-of-way

- steel structures

- access roads

- improvements at some existing substations

- upgrading some existing lines

These additions could be both in the Puget Sound area and east of the Cascade Mountains. Location for a new line would most likely be influenced by existing lines and land use constraints. BPA, the U. S. Forest Service (USFS) and U.S. Bureau of Land Management (BLM) have studied potential corridors for transmission lines across the Cascade Mountains. The Draft Northern Cascades Corridor Availability Study (BPA, 1990), evaluates public and private land and provides detailed information on existing and potential corridors for most of Washington. Most likely routes for a line would be locaied between these BPA substations, shown on Map 1:

- Chief Joseph and Echo Lake

- Chief Joseph and Monroe

- Sickler and Echo Lake

There are three possible corridors for a transmission line. They are identified as Alternate Corridors A, B, and $C$. Each crosses the Cascades. On Map 1, the existing corridors are identified in yellow. Existing BPA transmission lines are in red. New corridors are shaded in black. A new line could be a replacement of an existing line on existing right-of-way. A new line could be built parallel to an existing line by expanding the existing right-ofway. Or, a new line could be built either partially or totally in a new corridor.

These corridors are divided into three parts for analysis: an eastern segment, a central segment, and a western segment. Segments are defined by topography and land use. The boundaries are shown on this map by a green dashed line. These coriidors are described in Chapter 3. Within the corridors there are many options for transmission line routes. Potential routes and any impacts associated with individual routes would be discussed in a site-specific environmental impact statement if a transmission line is included in the Plan.

No Cascades crossings are considered north of Stevens Pass, which is about 160 miles south of the Canadian border. Corridor development would be difficult. The terrain is rugged, and large Wilderness areas cover much of the mountain range, blocking potential east-west routes. Crossing the Cascades through North Cascades National Park is difficult because the North Cascades Highway's scenic quality is protected by legislation. The rest of the Park is strictly managed and would be considered only if all other routes were exhausted. Passes to the south exhibit gentler terrain. Corridors A and B contain fewer transmission lines now and because of reliability concerns (having all eggs in one basket) are favored over Corridor $C$, which contains four 500-kV lines.

Table 2-3 shows potential costs, capacity, and lead time for a transmission line. This table also includes potential transmission system loss savings. These lusses are the results of the heat generated in the line conductors when electrical current flows through the transmission line. If a new transmission line is added, the power flowing through the transmission system is redistributed. The current flowing through each transmission line will typically decrease, so less electrical energy is lost. Since this energy is then free for other uses, fewer resources need to be developed. A more detailed description of these and other characteristics can be found in Appendix $E$. 


\subsubsection{Contingency Measures}

In Chapter 1, Section 1.4.6 described events that could change the future and the size of the transmission capacity deficit in the Puget Sound area. If load growth is not as predicted, certain steps can be taken to respond to higher or lower load growth. In this strategy, if load growth is less than the medium forecast, or if additional resources in the Puget Sound area are developed, the transmission line could be delayed. If the deficit is larger, Alternative Strategy 1 provides about 1600 MW surplus in 2003 under medium load growth.

Also, common to all strategies is using load curtailment measures for contingencies. Load curtailment restricts electricity consumed by end-users. It limits the electricity available during short periods of system stress. For example, BPA has certain curtailment rights in existing power sales contracts with customers. These are described under the No Action Alternative in Section 2.6. Area utilities also have curtailment programs operating but they are not necessarily designed to operate during peak conditions.

Other curtailment options could be pursued now to be activated later if needed. Two types are described here: contractual, and curtailment coops. These options are over and above what is already obtained through the power sales contracts mentioned above.

Contractual Load Curtailment - Under a curtailment contract, a utility would negotiate contracts with interested commercial and industrial customers in its service area to provide utilities with the right to request specific curtailment. Contracts would specify advance warning, and limits on the frequency and duration of curtailments. When needed, the customer would curtail electricity use and the utility could, for example, compensate the customer with a rate reduction throughout the year.

The utility or customer could manually interrupt use, or the system could automatically curtail use through control devices. The method used would be established in each contract, providing flexibility for individual industry characteristics. Automatic interruption would provide a more responsive resource, but some industries would be unable to allow such interruptions because of safety or other concerns.

There are examples of this kind of contract in the Pacific Northwest. As described as part of the No Action Alternative, existing BPA contracts with DSI's allow interrupting approximately $600 \mathrm{MW}$ of Puget Sound area peak load for 15 minutes, to ensure the stability of the Federal system.

Curtailment Cooperatives (CO-OPS) - Co-ops are groups of commercial and industrial customers joined to provide specific curtailment amounts. Co-op members could be commercial building owners or industrial facilities owners who band together and contract with the utility for a set amount of curtailment. This curtailment would be negotiated between the co-ops and the utility with the co-op members receiving a special rate for the curtailment. The members agree to limit their collective demand to certain levels on request from the serving utility. For example, utilities could contract with commercial customers to operate the energy management systems in their buildings to curtail loads during extreme peak periods. Other utilities across the country have already established these co-ops. For example, utilities such as Boston Edison and Pepco have contracts with members of co-ops. The advantage to the members is that they can shift participation among members to meet the contract. Payment is based on percentage of participation by a commercial or industrial member. The advantages for the utility are that they receive a firm amount of curtailment, and only have one contract to manage. 
PUGET SOUND AREA ELECTRIC RELIAB

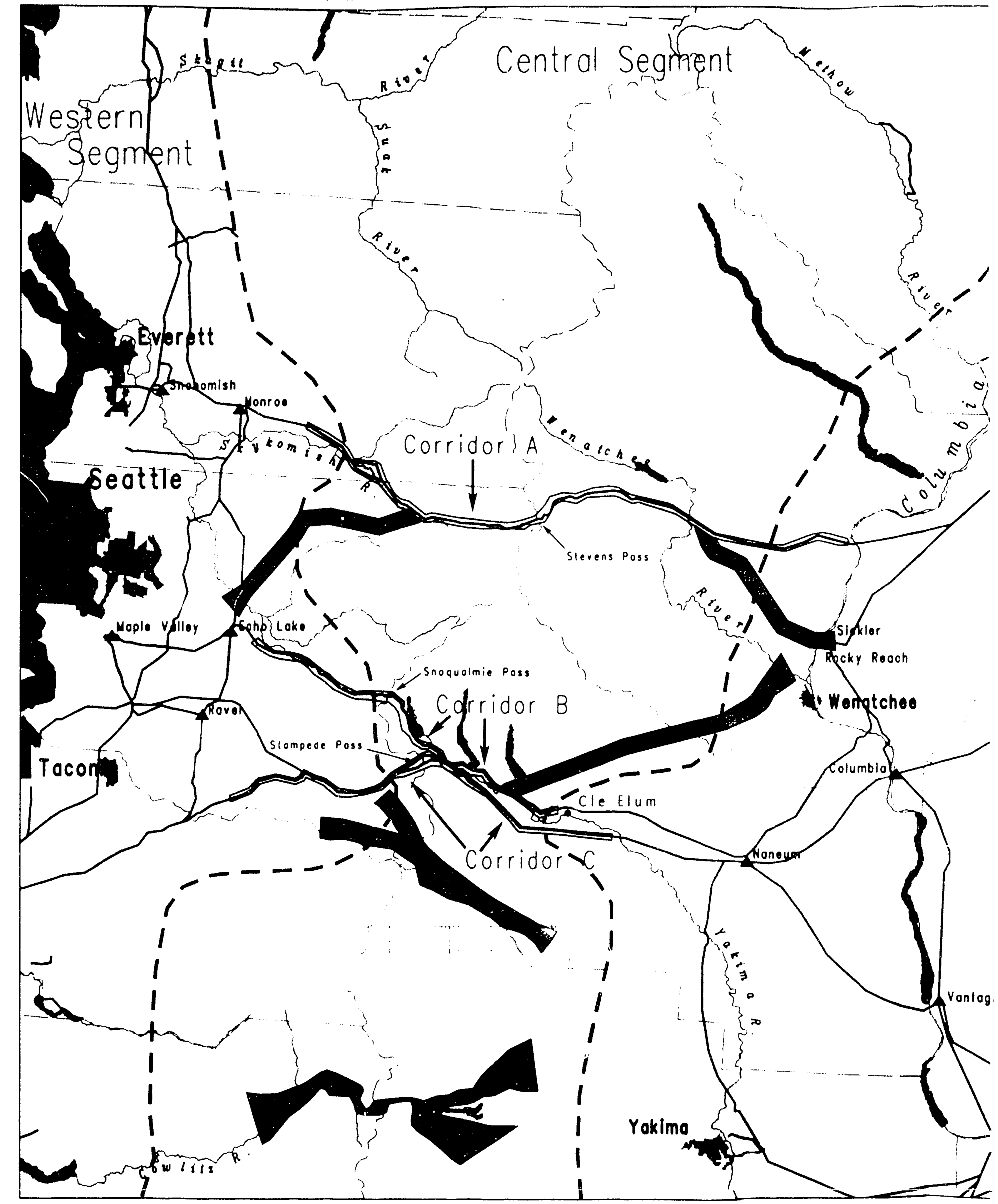




\section{ABILITY PLAN}

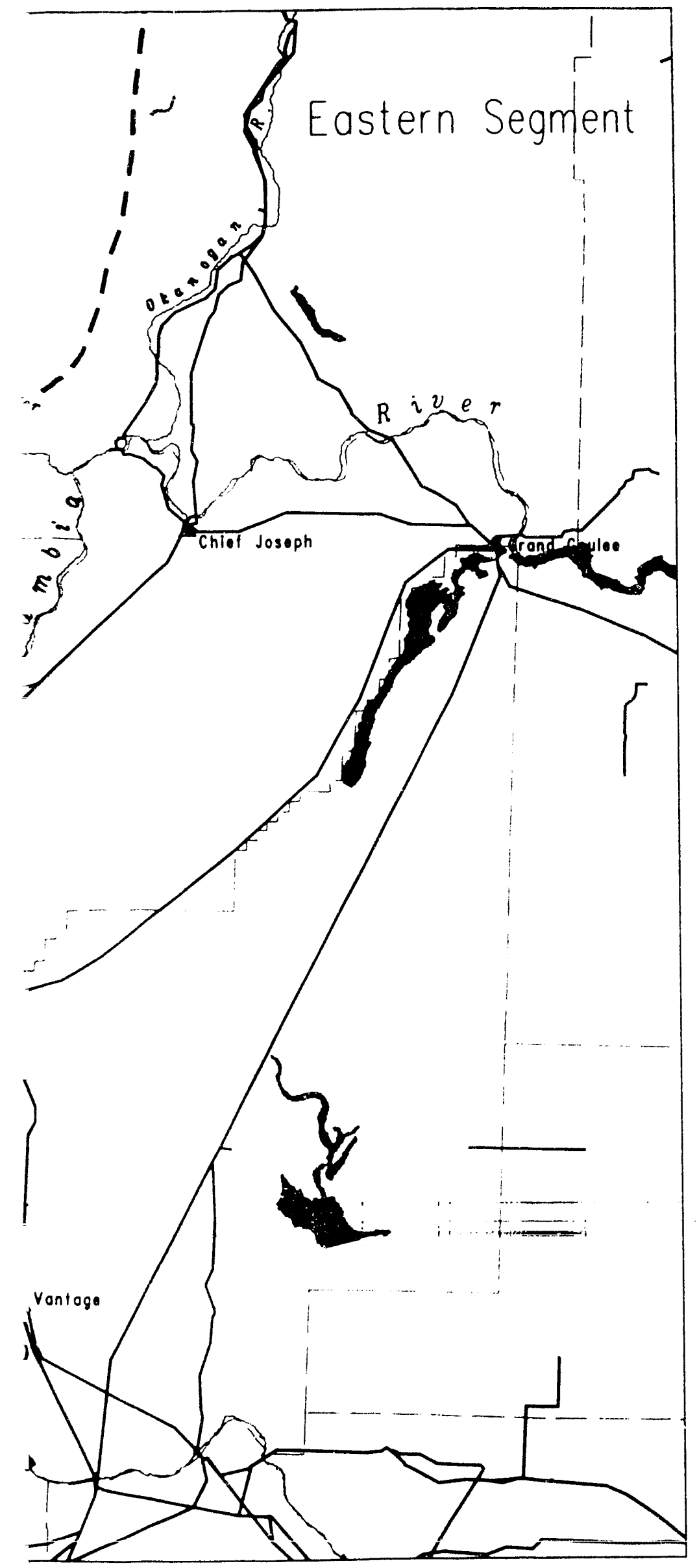

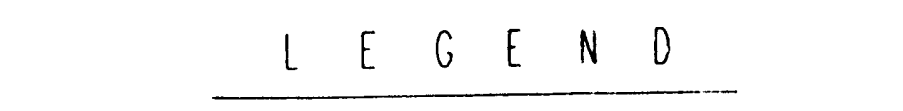
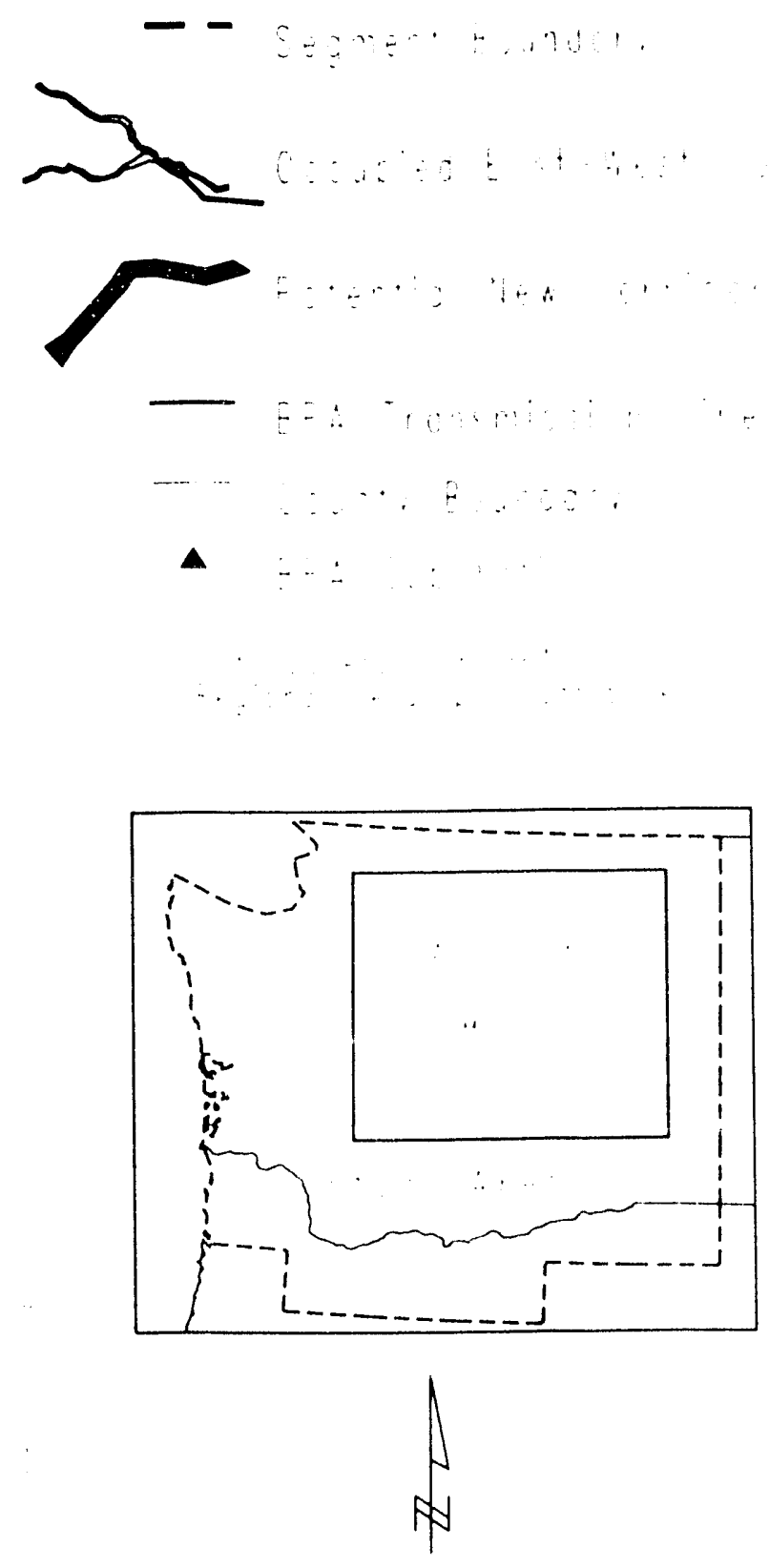

Miles

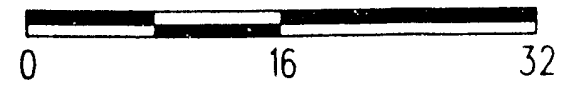


These additional curtailment programs have some advantages over the existing rights that BPA has with their contracts:

- contract curtailment may be more acceptable than involuntary curtailment during emergencies

- larger loads may be curtailed with fewer impacts

- advance notice may be possible before curtailment begins

- some programs allow for cooperative efforts among consumers

- payments will compensate consumers for curtailment

- programs provide increased flexibility to avoid adverse effects on critical loads

It has been estimated that customers, including larger industrial customers in the Puget Sound area, would be willing to curtail about $800 \mathrm{MW}$ at a cost of twenty dollars per $\mathrm{kW}$-year to protect the system in an emergency. This amount is over and above what is available through the DSI contracts. Technical studies of the power system have found that relying on more than $600 \mathrm{MW}$ of curtailment would lead to unacceptable system performance because the base system is so highly stressed.

An industry's willingness to participate in a load curtailment program is affected by the amount of advance warning, the frequency and duration of curtailments, and the price utilities will pay for curtailment. Advance warning is important for shutting down processes safely and economically. If curtailment is used often and for long periods, fewer industries may judge curtailment economically feasible. The more utilities are willing to pay, the greater the participation. Some industries may not participate despite incentives.

Impacts frum curtailment vary by level of compensation for customers and the frequency and duration of the curtailment. Impacts are found in health and safety, and socio-economics. Load Curtailment may have greater impact thian the conservation, load management, and fuel switching measures. It may have less impact than some local generation and transmission measures. The complete discussion of environmental impacts is in Chapter 4 , and Appendix F.

Load management and fuel switching measures can be used as contingencies as they become available in the marketplace. Direct load control is still in a relatively early stage of development in the Northwest, and information on all aspects of load control is limited. BPA and area utilities are studying these types of programs to gain information on cost, benefits, and availability. A description of programs is given in Sections 2.4.3 and 2.4.4.

\subsubsection{Environmental Impacts of Alternative Strategy 1}

Accelerating conservation programs have low health and safety impacts. Conservation could increase indoor air pollution. There are adverse impacts related to providing material for conservation products, but these are insignificant compared to raw material used for other measures. Voltage Support Option 1 has minimal impacts contained within existing substations. Transmission line impacts vary. If the line is in new or expanded right-of-way, impacts could be high. If the line is on existing right-of-way or is a rebuild of an existing line, impacts would be low. Detailed information about impacts is in Chapter 4 and Appendix $F$. 


\subsection{ALTERNATIVE STRATEGY 2 - VOLTAGE SUPPORT}

Alternative Strategy 2 includes Voltage Support Option 1 and the conservation measures described in Alternative Strategy 1 . Also, additional voltage support is added to the system. Figure 2-2 shows how these measures meet the need to serve the forecasted extreme winter peak loads. Voltage Support Option 2 provides additional capacity in late 1994. Table 2-4 provides data on each of the measures included in this strategy. Table 2 4 shows the total capacity of Alternative Strategy 2, the timing and amount of capacity provided by each of the measures included, and the surplus capacity of the strategy. Table 2-3 shows the cost of Voltage Support Option 2. This strategy provides about 600 MW of surplus capacity in 2003.

Figure 2-2. Alternative Strategy 2

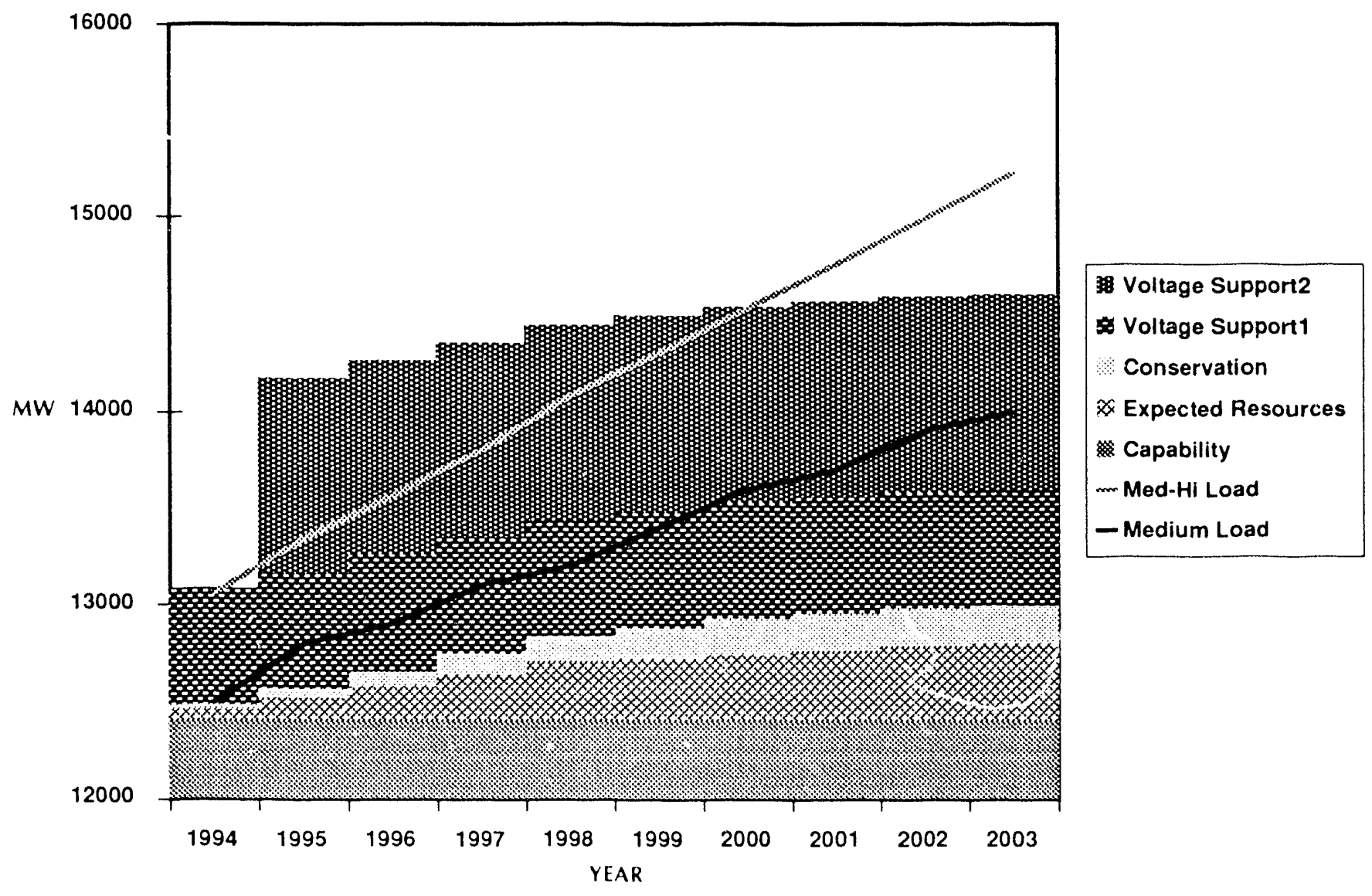


Table 2-4. Alternative Strategy 2 Capacity (MW)

\begin{tabular}{|l|r|r|r|r|r|r|r|r|r|r|}
\hline \multicolumn{7}{|c|}{ ALTERNATIVE STRATEGY 2: VOLTAGE SUPPORT } \\
\hline YEAR & 1994 & 1995 & 1996 & 1997 & 1998 & 1999 & 2000 & 2001 & 2002 & 2003 \\
\hline CAPABILITY & 12400 & 12400 & 12400 & 12400 & 12400 & 12400 & 12400 & 12400 & 12400 & 12400 \\
\hline EXPECTED RESOURCES & 60 & 120 & 180 & 240 & 300 & 320 & 340 & 360 & 380 & 400 \\
\hline CONSERVATION & 21 & 48 & 82 & 116 & 148 & 180 & 211 & 214 & 218 & 208 \\
\hline VOLTAGE SUPPORT 1 & 600 & 600 & 600 & 600 & 600 & 600 & 600 & 600 & 600 & 600 \\
\hline VOLTAGE SUPPORT 2 & 0 & 1000 & 1000 & 1000 & 1000 & 1000 & 1000 & 1000 & 1000 & 1000 \\
\hline $\begin{array}{l}\text { TOTAL PLAN } \\
\text { CAPACITY }\end{array}$ & 13081 & 14168 & 14262 & 14356 & 14448 & 14500 & 14551 & 14574 & 14598 & 14608 \\
\hline $\begin{array}{l}\text { LOAD FORECAST } \\
\text { (EXTREME PEAK) }\end{array}$ & 12500 & 12800 & 12900 & 13100 & 13200 & 13400 & 13600 & 13700 & 13900 & 14000 \\
\hline $\begin{array}{l}\text { SURPLUS CAPACITY } \\
\text { (PUGET SOUND) }\end{array}$ & 581 & 1368 & 1362 & 1256 & 1248 & 1100 & 951 & 874 & 698 & 608 \\
\hline
\end{tabular}

\subsubsection{Conservation Measures}

See description of conservation measures in Section 2.2.1.

\subsubsection{Voltage Support Option 1}

See Section 2.2.2 for a description of Voltage Support Option 1.

\subsubsection{Voltage Support Option 2}

Thic nption adds a new 500-kV substation or the existing transmission line corridor approximately ten miles north of Ellensburg, Washington. The proposed substation would be approximately 1.500$)^{\prime}$ by 1.50()$^{\prime}(52$ acres) and most of the site would be within the existing right-of-way. Naneum Substation is one possible site location (see Map 1). The remaining three sites are located to the west. All four potential sites are on Map 14. A brief description of the sites is in Sections 3.2.4 and 4.3. This substation would connect all lines in the corridor. Series capacitors would be installed for the two lines from Grand Coulee Dam. The series capacitors would increase the loading on these two newer and more efficient lines while reducing loads on others. They would stabilize voltages on the transmission system. Circuit breakers would be installed in a manner that would enable power to be' redirected in any manner desired. Cost, capacity, lead time, and loss savings are shown in Table 2-3. A detailed technical discussion of this option is given in Appendix E. A detailed environmental description of this ontion is given in Appendix G. 
Puget Sound Area Electric Reliability.Plan - Draft Environmental impact Statement

\subsubsection{Contingency Measures}

To respond to a deficit that grows faster than expected, measures can be delayed or added. If load growth is lower than expected, Voltage Support Option 2 can be delayed. If high load growth occurs, combustion turbines and/or a transmission line can be built. As in Alternative Strategy 1, load curtailment could also be used on an interim basis until other measures are available.

\subsubsection{Environmental Impacts of Alternative Strategy 2}

Environmental Impacts of the voltage support additions would be fewer than impacts from a transmission line. Impacts from the conservation programs are equal in all alternative strategies. Impacts are described in Chapter 4 and Appendix F and $\mathrm{G}$.

\subsection{ALTERNATIVE STRATEGY 3 - DEMAND REDUCTION}

This strategy includes the conservation measures and Voltage Support Option 1 common to all strategies, but also includes load management and fuel switching measures instead of a transmission line or Voltage Support Option 2. Figure 2-3 shows how this strategy supplies powei for extreme winter peak loads. The load management and fuel switching measures provide some surplus in each year through 2003.

Figure 2-3. Alternative Strategy 3

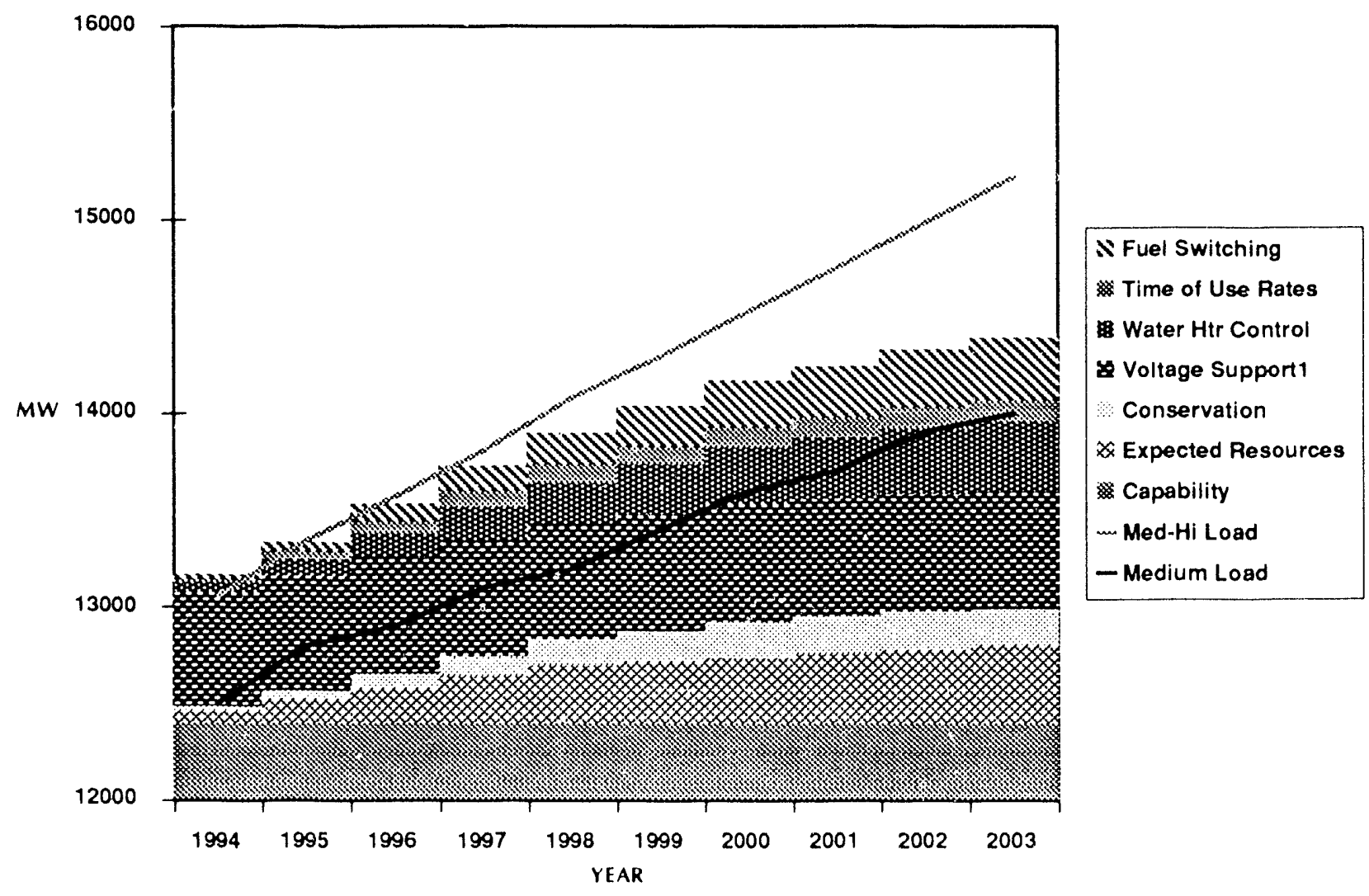


The numeric values and total conservation savings of Alternative Strategy 3 using the medium load forecast are provided in Table $2-5$.

Table 2-5. Alternative Strategy 3 Capacity (MW)

\begin{tabular}{|l|r|r|r|r|r|r|r|r|r|r|}
\hline \multicolumn{7}{|c|}{ ALTERNATIVE STRATEGY 3: DEMAND REDUCTION } \\
\hline YEAR & 1994 & 1995 & 1996 & 1997 & 1998 & 1999 & 2000 & 2001 & 2002 & 2003 \\
\hline CAPABILITY & 12400 & 12400 & 12400 & 12400 & 12400 & 12400 & 12400 & 12400 & 12400 & 12400 \\
\hline EXPECTED RESOURCES & 60 & 120 & 180 & 240 & 300 & 320 & 340 & 360 & 380 & 400 \\
\hline CONSERVATION & 21 & 48 & 82 & 116 & 148 & 180 & 211 & 214 & 218 & 208 \\
\hline VOLTAGE SUPPORT 1 & 600 & 600 & 600 & 600 & 600 & 600 & 600 & 600 & 600 & 600 \\
\hline $\begin{array}{l}\text { WATER HEATER } \\
\text { CONTROL }\end{array}$ & 22 & 58 & 104 & 143 & 182 & 219 & 256 & 292 & 326 & 356 \\
\hline TIME-OF-USE RATES & 20 & 47 & 73 & 99 & 105 & 110 & 116 & 123 & 129 & 129 \\
\hline FUEL SWITCHING & 22 & 43 & 82 & 120 & 159 & 197 & 236 & 262 & 289 & 315 \\
\hline $\begin{array}{l}\text { TOTAL PLAN } \\
\text { CAPACITY }\end{array}$ & 13145 & 13316 & 13521 & 13718 & 13894 & 14026 & 14159 & 14251 & 14342 & 14408 \\
\hline $\begin{array}{l}\text { LOAD FORECAST } \\
\text { (EXTREME PEAK) }\end{array}$ & 12500 & 12800 & 12900 & 13100 & 13200 & 13400 & 13600 & 13700 & 13900 & 14000 \\
\hline $\begin{array}{l}\text { SURPLUS CAPACITY } \\
\text { (PUGET SOUND) }\end{array}$ & 645 & 516 & 621 & 618 & 694 & $\mathbf{6 2 6}$ & 559 & 551 & 442 & $\mathbf{4 0 8}$ \\
\hline
\end{tabular}

\subsubsection{Conservation Measures}

See Section 2.2.1 for a description of conservation measures.

\subsubsection{Voltage Support Option 1}

See Section 2.2.2 for a description of Voltage Support Option 1. 


\subsubsection{Load Management Measures}

Load management programs cause customers to reschedule electricity use through incentives or direct control. These programs are designed specifically to reduce loads at peak times. Programs that reduce peak load growth could help the problem in the Puget Sound area.

As part of the PSAERP, BPA has joined with the utilities to study two load management programs. The load management measures used in this strategy are a water heater control program and time-of-use rates. These programs could provide peak load reduction by encouraging or controlling electricity use during peak periods. These programs could be implemented by 1994, and could provide $607 \mathrm{MW}$ peak load reduction within ten years during normal years. These programs have a minor impact on annual energy consumption (except for savings from the hot water program from larger, better insulated hot water tanks). Costs for these programs are the full costs of completing a program since they are in addition to existing or planned load management prugrams. A detailed description of how the following programs were developed and analyzed is given in Appendix D.

Water Heater Control Program - This program would allow direct control by a utility of electric water heaters in houses and apartments. The utility could cycle or shed water heater loads at its discretion from a central location for a period of time previously agreed upon between the utility and homeowners.

A utility operating this program could contact residences and offer a monthly incentive, $\$ 5$ per month for November, December, January and February in return for an agreement that the utility could be allowed to shut the water heater off for eight to ten hours per day. This allows the utility to shed water heater loads for two four-hour periods. The shut-off periods would be from $7 \mathrm{a} . \mathrm{m}$. to $11 \mathrm{a} . \mathrm{m}$. in the morning and from $5 \mathrm{p.m}$. to 9 p.m. in the evening. Some agreements could allow the utility to keep some heaters off for an additional one or two hours so that all heaters do not come on at the same time and create a later and possibly larger peak in system loads.

Single family residences could be offered a larger energy-efficient hot water tank that would provide energy savings as well as peak savings. For manufactured houses and multifamily dwellings the program only includes the controls because most of these dwellings do not have sufficient room to fit a larger tank.

The costs of the program include $\$ 228$ for the equipment for each home and an additional $\$ 120$ for homes that get larger tanks. In addition, there is a $\$ 28$ annual cost that covers the $\$ 20$ annual incentive per home and $\$ 8$ for administrative costs. These are the full costs of operating this program because the baseline case does not include a water heater control program. Cost per household is converted to cost per kilowatt and displayed in Table 2-6.

The program can recruit participants at the time they are shopping for a new or replacement hot water tank. The program is expected to enroll $60 \%$ of consumers replacing electric water heaters in single family homes. $20 \%$ of multi-family and manufactured homes are expected to enroll. The number of participating homes increases steadily until 2006 as existing water heaters wear out.

Residential Time-of-Use-Rates - This program could offer new retail electric rates to homeowners that volunteer to participate. These participants could pay electric rates that are twice as high from 7 a.m. to 11 a.m. as they are during the rest of the day. Typical loads that might be shifted include hot water heating loads and electric: space heat. Participants who can shift some loads to the off-peak period can expect to reduce their electric bills by $\$ 5$ per month on average. The utility could install a time-of-use meter at each house.

Peak savings for participating households are expected to be about $15 \%$ of the peak prior to program participation. The program is not expected to alter total energy consumption but merely to shift the time when energy is used The maximum projerted enrollment is abuut? ?n\% of both new and existing cingle family residfences in the Puget Sound area. 
Costs per household include $\$ 115$ for the TOU meter and a customer incentive of $\$ 5$ per month during the four winter months. Administrative costs are estimated to be $\$ 2$ per house per year. Costs per household are divided by kilowatts saved per household to obtain the figures shown in Table 2-6.

Peak savings come only from voluntary behavior changes due to price incentives. The actual performance of this program under extreme cold weather is difficult to predict.

The load management programs supply increasing savings through 2010)(731 MW normal year, $576 \mathrm{MW}$ extreme year). Energy savings increase with time also, and load management provides 11 aMW of energy savings by 2010.

Pilot Programs - Load management programs are relatively new to BPA and Puget Sound area utilities. At the present time, BPA has contracted for about $\$ 300,000$ of load management demonstration projects. These are implemented through several Puget Sound area utilities and are described in the following paragraphs. It is these demonstration projects and future programs like these that will provide the niegawatts available in this strategy.

Snohomish County Public Utility District No. 1(PUD) will be installing $4(0)$ dispatchable radio-activated controls on residential hot water systems. Control strategies may vary for family size and water heater tank storage capability. For these households, hot water heating occurs at off-peak times.

Ohop Mutual Light Company will be installing 80 maximum size water heater tanks with electronic timer controls, sensors, and data recorders already attached. These tanks range from 6610150 gallons of storage capability. Control strategies have been developed for each type of tank and each household to maximize peak reduction. Utility programmed time switches are used to control loads. Data from this program can be used to refine radio control, two-way radio control, and other pre-programmed "stand alone" control systems.

The town of Steilacoom has begun a program which schedules municipal water and wastewater system pumping at non-peak periods.

Snohomish County PUD will design and install a voltage/var control system at one of their power supply substations. The system will control shunt capacitors and minimize substation voltage but keep it within limits so that acceptable service is always available to customers. It will also supply maximum vars and reduce load to alleviate voltage collapse conditions.

Seattle City Light has designed a pilot program that would reduce peak power demand during winter months. Seattle City Light will implement weatherization measures, efficient showerheads, and a system that controls space heat and water heaters. The direct load control equipment that residents install will allow substation operators to shift operation of participant water heaters and/or space heaters when peak loads in a specific area reach certain levels. If the budget allows, Seattle (ity Light also would like to test thermal storage and general load control, and expand the program to commercial customers. Seattle City Light is asking BPA to provide about $\$ 200,000)$ to help co-fund this program. Snohomish County PUD also has expressed interest in implementing space-heat control in their service area. 
Table 2-6. Cost and Savings of Load Management Programs

\begin{tabular}{|c|c|c|c|c|c|c|c|c|c|c|}
\hline \multirow[b]{2}{*}{ Load Management } & \multicolumn{5}{|c|}{$\begin{array}{c}\text { PEAK COST }(\$ / K W) \text { Normal } \\
\text { Winter Peak }\end{array}$} & \multicolumn{5}{|c|}{$\begin{array}{c}\text { ENERGY SAVINGS } \\
\text { (Average annual megawatts) * }\end{array}$} \\
\hline & \multicolumn{3}{|c|}{ Initial Cost } & \multicolumn{2}{|c|}{ Annual Cost } & 1994 & 1996 & 1998 & 2003 & 2010 \\
\hline Hot Water Control SF & \multicolumn{3}{|c|}{$\$ 319$} & \multicolumn{2}{|c|}{$\$ 26$} & $\mathbf{0}$ & 2 & 4 & 9 & 11 \\
\hline $\begin{array}{l}\text { Hot Water Control MF \& } \\
\text { MH }\end{array}$ & \multicolumn{3}{|c|}{$\$ 344$} & \multicolumn{2}{|c|}{$\$ 42$} & $\mathbf{0}$ & $\mathbf{0}$ & $\mathbf{0}$ & $\mathbf{0}$ & $\mathbf{0}$ \\
\hline Time-of-Use Rates & \multicolumn{3}{|c|}{$\$ 249$} & \multicolumn{2}{|c|}{$\$ 48$} & $\mathbf{0}$ & 0 & $\mathbf{0}$ & $\mathbf{0}$ & $\mathbf{0}$ \\
\hline \multicolumn{6}{|l|}{ TOTALS* } & $\mathbf{0}$ & 2 & 4 & 9 & 11 \\
\hline & \multicolumn{5}{|c|}{$\begin{array}{l}\text { PEAK SAVINGS NORMAL YEAR } \\
\text { (Units are megawatts) * }\end{array}$} & \multicolumn{5}{|c|}{$\begin{array}{l}\text { PEAK SAVINGS EXTREME YEAR } \\
\text { (Units are megawatts) * }\end{array}$} \\
\hline Load Management & 1994 & 1996 & 1998 & 2003 & 2010 & 1994 & 1996 & 1998 & 2003 & 2010 \\
\hline Hot Water Control SF & 23 & 113 & 201 & 404 & 513 & 17 & 81 & 145 & 291 & 370 \\
\hline $\begin{array}{l}\text { Hot Water Control MF \& } \\
\text { MH }\end{array}$ & 8 & 31 & 51 & 89 & 102 & 6 & 23 & 37 & 64 & 74 \\
\hline Time-of-Use Rates & 19 & 66 & 95 & 114 & 116 & 20 & 73 & 105 & 129 & 132 \\
\hline TOTALS* & 50 & 210 & 347 & 607 & 731 & 43 & 177 & 287 & 484 & 576 \\
\hline \multicolumn{6}{|l|}{$\begin{array}{l}\text { Key to abbreviations: } \\
\text { Numbers are cumulative }\end{array}$} & \multicolumn{5}{|c|}{$\begin{array}{c}M H=\text { Manufactured Housing } \\
M F=\text { Multifamily Housing } \\
\text { (apartments) }\end{array}$} \\
\hline
\end{tabular}




\subsubsection{Fuel Switching}

The fuel switching program encourages homeowners to substitute natural gas for electricity for residential space and water heating. Switching to gas reduces both peak loads and overall energy requirements for electricity. Although many new homeowners are already selecting gas, there is a potential to convert the electric space and water heat in existing homes to gas. There is also the potential to expand the gas distribution system to reach homes that would not have access to gas. This analysis looks at fuel switching potential beyond what is expected to occur anyway through market forces because of the generally lower cost of heating with gas. Since no fuel switching program is yet planned, social costs are the full costs to society of the program.

Table 2-7 shows the costs and savings potential from switching some residential customers to natural gas. The fuel switching program would encourage switching from electricity to natural gas for residential space and water heating in single family homes and manufactured homes. Multifamily homes and the commercial and industrial sectors were not included because of the expense and difficulty of implementing fuel switching in these segments. Fuel switching induced by natural market forces is included in the load forecast. This analysis targets both new and existing homes, and for the purposes of developing estimates of the potential load impacts and costs, makes the following assumptions:

1. Most new homeowners will select gas if it is available (those who do not probably would not participate in a fuel switching program). Therefore, fuel switching in new homes requires expanding the gas distribution system.

2. Only central forced air electric space heating systems are included as candidates for fuel switching; zonal (resistance) electric space heat conversion would be too expensive and difficult to market.

3. Homes with electric water heat but gas space heat were not included because it is assumed that homeowners will convert their water heaters to gas.

4. Costs include the cost of replacing electric equipment before it is worn out, any additional cost of replacing with gas instead of electric equipment, and any flue or venting work necessary for gas but not electric equipment. For homes where gas is not available, an additional cost for expanding the gas distribution system is included. For all homes in this analysis, the cost of hooking up the home to gas is included.

The cost of service drop connection for natural gas is $\$ 550$ and the cost of a typical extension of a gas main for those houses that do not have gas available on the street is an average of $\$ 900$ per house. The social costs shown in Table 2-7 are the difference between the cost of switching to natural gas and the cost of continuing to use electricity.

Both water heaters and central forced air systems would be converted when the existing electric equipment is close to the end of : sseful life. In homes with zonal space heat, water heat conversion only is analyzed. Market penetration rates vary by segment: they are faster and higher for single family than manufactured homes, and for homes where gas is already available at the street. The market segment approach was used because the expected costs and program participation rates are different acruss market segments.

Fuel switching provides increasing normal and extreme peak savings; up t(0 40.3 MW in 2010 of extreme peak savings. Fuel switching could provide 100 aMW of energy savings by 2010.

When conservation, load management, and fuel switching programs are combined, the total savings do not equal the sum of the individual programs. These programs interact and reduce the total. Sere Appendix D for an explanation of these interactions 
Table 2-7. Costs and Savings Potential of Fuel Switching

\begin{tabular}{|c|c|c|c|c|c|c|}
\hline \multirow[b]{2}{*}{ Fuel Switching } & \multirow{2}{*}{$\begin{array}{l}\text { PEAK COST (\$/KW) } \\
\text { Normal Winter Peak } \\
\text { SOCIAL COST }\end{array}$} & \multicolumn{5}{|c|}{$\begin{array}{c}\text { ENERGY SAVINGS } \\
\text { (Units are average aiınual } \\
\text { megawatts) }\end{array}$} \\
\hline & & 1994 & 1996 & 1998 & 2003 & 2010 \\
\hline $\begin{array}{l}\text { Existing SF + CFA + WH, } \\
\text { Gas Yes }\end{array}$ & $\$ 503$ & 3 & 9 & 18 & 31 & 32 \\
\hline $\begin{array}{l}\text { Existing SF + CFA + WH, } \\
\text { Gas No }\end{array}$ & $\$ 589$ & $\mathbf{0}$ & 1 & 4 & 13 & 23 \\
\hline $\begin{array}{l}\text { Existing SF WH Only, } \\
\text { Gas Yes }\end{array}$ & $\$ 890$ & 3 & 9 & 15 & 25 & 25 \\
\hline New SF SH + WH, Gas No & $\$ 1267$ & $\mathbf{0}$ & 1 & 1 & 3 & 8 \\
\hline $\begin{array}{l}\text { Existing } \mathrm{MH}+\mathrm{CFA}+\mathrm{WH} \\
\text { Gas Yes }\end{array}$ & $\$ 756$ & 1 & 2 & 3 & 6 & 6 \\
\hline $\begin{array}{l}\text { Existing } \mathrm{MH}+\mathrm{CFA}+\mathrm{WH} \\
\text { Gas No }\end{array}$ & $\$ 938$ & $\mathbf{0}$ & $\mathbf{0}$ & 1 & 2 & 4 \\
\hline $\begin{array}{l}\text { New MH SH+WH, } \\
\text { Gas No }\end{array}$ & $\$ 867$ & $\mathbf{0}$ & 0 & $\mathbf{0}$ & 1 & 2 \\
\hline \multicolumn{2}{|l|}{ TOTALS* } & 7 & 22 & 42 & 81 & 100 \\
\hline \multirow[t]{3}{*}{ Key to Abbreviations: } & Existing $=$ Existing Units & \multicolumn{5}{|c|}{$\begin{array}{l}\text { Gas Yes = Gas Available With in } 1 / 4 \\
\text { Mile (service drop) }\end{array}$} \\
\hline & $\mathrm{SF}=$ Single Family Residences & \multicolumn{5}{|c|}{$\begin{array}{l}\text { Gas No = Cas Not Available (Main } \\
\text { Extension Required) }\end{array}$} \\
\hline & $\begin{array}{l}\text { CFA }=\text { Central Forced Air Furnaces } \\
\text { (Not Baseboards) }\end{array}$ & \multicolumn{5}{|c|}{ MH $=$ Manufactured Housing } \\
\hline * Numbers are cumulative & SH = Space Heating & \multicolumn{5}{|c|}{$W H=$ Waler Heaters } \\
\hline
\end{tabular}


Table 2-7. continued

\begin{tabular}{|c|c|c|c|c|c|c|c|c|c|c|}
\hline \multirow[b]{2}{*}{ Fuel Switching } & \multicolumn{5}{|c|}{$\begin{array}{c}\text { PEAK SAVINGS NORMAL YEAR } \\
\text { (Units are megawatts) * }\end{array}$} & \multicolumn{5}{|c|}{$\begin{array}{c}\text { PEAK SAVINGS EXTREME YEAR } \\
\text { (Units are megawatts) * }\end{array}$} \\
\hline & 1994 & 1996 & 1998 & 2003 & 2010 & 1994 & 1996 & 1998 & 2003 & 2010 \\
\hline $\begin{array}{l}\text { Existing SF + CFA + WH, } \\
\text { Gas Yes }\end{array}$ & 11 & 40 & 74 & 130 & 135 & 14 & 48 & 89 & 155 & 162 \\
\hline $\begin{array}{l}\text { Existing SF + CFA + WH, } \\
\text { Gas No }\end{array}$ & 0 & 6 & 19 & 56 & 96 & $\mathbf{0}$ & 7 & 22 & 67 & 115 \\
\hline $\begin{array}{l}\text { Existing SF WH Only, } \\
\text { Gas Yes }\end{array}$ & 7 & 20 & 33 & 57 & 57 & 5 & 14 & 24 & 41 & 41 \\
\hline New SF SH + WH, Gas No & 0 & 2 & 3 & 10 & 25 & 0 & 2 & 4 & 12 & 30 \\
\hline $\begin{array}{l}\text { Existing } M H+C F A+W H \\
\text { Gas Yes }\end{array}$ & 2 & 7 & 12 & 21 & 21 & 3 & 9 & 15 & 25 & 26 \\
\hline $\begin{array}{l}\text { Existing } \mathrm{MH}+\mathrm{CFA}+\mathrm{WH} \\
\text { Gas No }\end{array}$ & 0 & 1 & 4 & 9 & 15 & 0 & 1 & 4 & 11 & 19 \\
\hline $\begin{array}{l}\text { New MHSH+WH, } \\
\text { Gas No }\end{array}$ & $\mathbf{0}$ & 1 & 1 & 4 & 8 & 0 & 1 & 2 & 5 & 10 \\
\hline TOTALS* & 20 & 77 & 146 & 287 & 357 & 22 & 82 & 160 & 316 & 403 \\
\hline \multirow[t]{3}{*}{ Key to Abbreviations: } & \multicolumn{5}{|c|}{ Existing $=$ Existing Units } & \multicolumn{5}{|c|}{$\begin{array}{l}\text { Gas Yes = Gas Available Within } 1 / 4 \\
\text { Mile (service drop) }\end{array}$} \\
\hline & \multicolumn{5}{|c|}{$\mathrm{SF}=$ Single Family Residences } & \multicolumn{5}{|c|}{$\begin{array}{l}\text { Gas No = Gas Not Available (Main } \\
\text { Extension Required) }\end{array}$} \\
\hline & \multicolumn{5}{|c|}{$\begin{array}{l}\text { CFA }=\text { Central Forced Air Furnaces } \\
\text { (Not Baseboards) }\end{array}$} & \multicolumn{5}{|c|}{ MH = Manufactured Housing } \\
\hline * Numbers are cumulative & \multicolumn{5}{|c|}{ SH = Space Heating } & \multicolumn{5}{|c|}{$W H=W$ ater Heaters } \\
\hline
\end{tabular}

\subsubsection{Contingency Measures}

If load growth is not as predicted, measures can be delayed or added. The load management and fuel switching programs can be delayed if load growth is lower than expected. If load growth is higher, Voltage Support Option 2 can be added to the system and load curtailment can be used on an interim basis. This strategy provides almost $400 \mathrm{MW}$ of surplus capacity in 2003. 


\subsubsection{Envi:onmental Impacts of Alternative Strategy 3}

Load management and fuel switching programs do not disturb land use. Load management measures could create some discomfort for individuals in homes and buildings as water temperatures go down while controls are functioning to limit use. Customers who agree to curtail use and receive incentives from the utility may have an economic gain. Load management measures may cause life-style changes more significant than other measures. These socio-economic impacts are considered low. Fuel switching may create low impacts to air quality. Impacts to the physical environment, air, water, land use, and wildlife are all less than for other measures. Overall, this strategy has the fewest environmental impacts. More discussion of environmental consequences of the measures is in Chapter 4 and Appendix F.

\subsection{ALTERNATIVE STRATEGY 4 - COMBUSTION TURBINES}

This strategy includes the conservation measures, and Voltage Support Option 1 in all other strategies, but adds combustion turbines for winter peak loads. This strategy is shown in Figure 2-4. Table 2-8 provides numeric values of Alternative Strategy 4.

Figure 2-4. Alternative Strategy 4

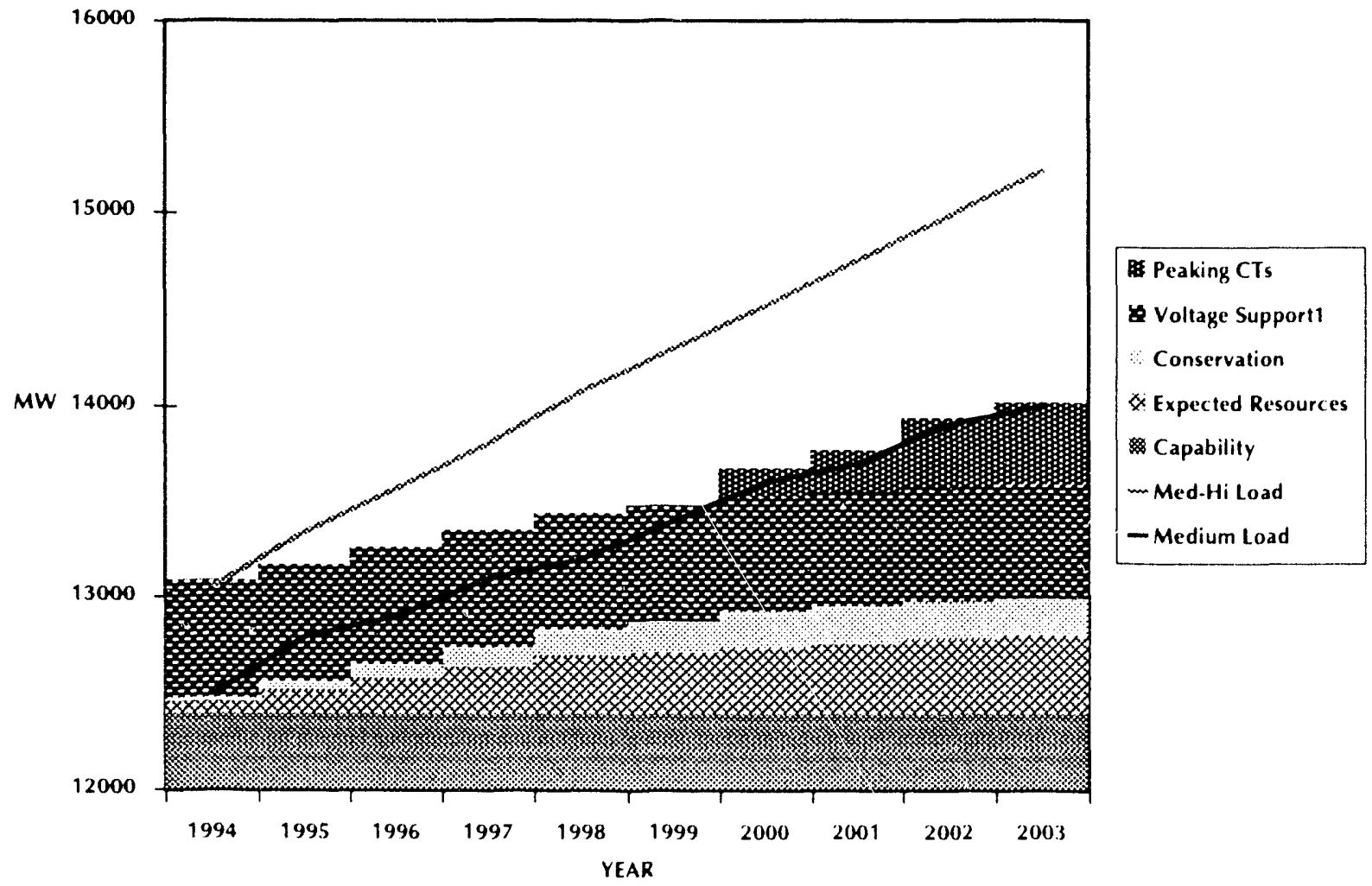


Table 2-8. Alternative Strategy 4 Capacity (MW)

\begin{tabular}{|c|c|c|c|c|c|c|c|c|c|c|}
\hline \multicolumn{11}{|c|}{ ALTERNATIVE STRATEGY 4: COMBUSTION TURBINES } \\
\hline YEAR & 1994 & 1995 & 1996 & 1997 & 1998 & 1999 & 2000 & 2001 & 2002 & 2003 \\
\hline CAPABILITY & 12400 & 12400 & 12400 & 12400 & 12400 & 12400 & 12400 & 12400 & 12400 & 12400 \\
\hline EXPECTED RESOURCES & 60 & 120 & 180 & 240 & 300 & 320 & 340 & 360 & 380 & 400 \\
\hline CONSERVATION & 21 & 48 & 82 & 116 & 148 & 180 & 211 & 214 & 218 & 208 \\
\hline VOLTAGE SUPPORT 1 & 600 & 600 & 600 & 500 & 600 & 600 & 600 & 600 & 600 & 600 \\
\hline PEAKING CTS & 0 & 0 & 0 & 0 & 0 & 0 & 140 & 210 & 350 & 420 \\
\hline $\begin{array}{l}\text { TOTAL PLAN } \\
\text { CAPACITY }\end{array}$ & 13081 & 13168 & 13262 & 13356 & 13448 & 13500 & 13691 & 13784 & 13948 & 14028 \\
\hline $\begin{array}{l}\text { LOAD FORECAST } \\
\text { (EXTREME PEAK) }\end{array}$ & 12500 & 12800 & 12900 & 13100 & 13200 & 13400 & 13600 & 13700 & 13900 & 14000 \\
\hline $\begin{array}{l}\text { SURPLUS CAPACITY } \\
\text { (PUGET SOUND) }\end{array}$ & 581 & 368 & 362 & 256 & 248 & 100 & 91 & 84 & 48 & 28 \\
\hline
\end{tabular}

\subsubsection{Conservation Measures}

See Section 2.2.1 for a description of the conservation measures.

\subsubsection{Voltage Support Option 1}

Section 2.2.2 describes Voltage Support Option 1.

\subsubsection{Peaking Combustion Turbines}

The type of combustion turbine considered for this strategy is built to serve peak loads only. It is a single cycle $70 \mathrm{MW}$ unit that operates infrequently, about $5 \%$ of the year. These turbines have a lower capital cost than combined cycle turbines and are easier and faster to start up. They would be able to use gas or oil for fuel, with oil the assumed fuel used for this analysis. These units are assumed built on industrial or agricultural land. Oil tanks with a two week supply of fuel are assumed at each site. Some transmission line additions may be necessary to reliably connect combustion turbines to the system. 


\subsubsection{Contingency Measures}

If load growth is not as expected, combustion turbines can be delayed or stopped if unnecessary. This strategy provides $28 \mathrm{MW}$ surplus capacity in 2003, however, Voltage Support Option 2 and additional combustion turbines could be added to the system or load curtailment could be used if loads are high.

\subsubsection{Environmental Impacts of Alternative Strategy 4}

Combustion turbines have impacts ranging from low to moderate. This strategy is the only strategy with moderate air quality impacts. Combustion creates air pollutants. The turbines would require about 4 acres. Noise is a concern when combustion turbines operate, though the turbines would operate infrequently. Mitigation measures are available to reduce noise. Transmission lines needed to integrate combustion turbines into the power system may create impacts. Impacts are described in Chapter 4 and Appendix F.

\subsection{NO ACTION ALTERNATIVE}

EIS's traditionally define the No Action Alternative as a no build measure. Because this EIS will focus on a regional planning decision, this approach is inappropriate. Instead, this alternative assumes individual utilities will undertake some actions to meet their needs. These activities may not be coordinated with other utilities or BPA. This alternative will cause decreasing reliability as loads continue to grow even at a moderate rate. By the end of the decision period in 2003, normal winter peak load will so severely stress the system, even minor disturbances could cause instability and blackout in the Puget Sound area. By 2003, the base system, with all facilities intact, will be unable to meet extreme winter peak loads. Actions already planned by or available to BPA and Puget Sound area utilities are described below.

\subsubsection{Undervoltage Load Shedding Scheme}

This measure mınimizes the consequences of a voltage collapse. Utilities, through the Northwest Power Pool, will install equipment to arrest voltage collapse by shedding loads at substations in the Puget Sound area. These devices automatically disconnect a portion of the load if voltages drop precipitously for a specific period of time following the failure of key power system equipment. Shedding loads, if done in time, provides a safety net to prevent a total or partial collapse of the system. However, there is some doubt whether these relays can be set sensitive enough to drop load in time to prevent collapse without being so sensitive that they cause frequent unnecessary load dropping in response to minor disturbances. The load amount dropped depends on the type of emergency. Up to $1800 \mathrm{MW}$ ( $15 \%$ of the Puget Sound load) could be shed.

Until the failed equipment is returned to service, ongoing curtailment of area load would be required The average line outage is four hours but can last for days or weeks if extensive repairs were required. Fewer than one outage in ten lasts more than eight hours. Retail utilities set a goal of full restoration in four hours, but service to fringe areas will certainly take longer after a blackout.

\subsubsection{Voluntary Load Curtailment}

Another measure available and considered part of the No Action Alternative is voluntary load curtailment. voluntary load curtailment includes curtailment achieved in the residential, commercial and industrial sectors requested by utilities and government agencies. This is curtailment over and above curtailment which exists through contiacis with bPa or other utilities. Litities and/or government agencies notify businesses and the public directiy or by radio and television that electricity use needs to be reduced. Lp to a $10 \%$ reduction may be achieved. The call for curtailment would be needed whenever cold weather was expected to push load above the critical level.

$$
2 \cdot 24
$$


Unfortunately, this could cause frequent calls for curtailment that may be unnecessary because no transmission problem occurs. Planning and implementation for this kind of program can be done quickly with minimum preparation and cost. Response to requests for curtailment depends on many factors such as weather, request frequency, and market conditions for commercial and industrial sectors. This measure would not prevent a voltage collapse if customers failed to reduce their loads before losing a transmission line.

\subsubsection{Existing BPA Customer Contracts}

BPA has various rights in power sales contracts to curtail loads and make other system adjustments in an emergency. Rapidly changing conditions require prompt responses, and contract terms allow operators flexibility to react quickly to maintain service and avoid damage to the system. Initially, BPA would ask customers with resources to operate them to help BPA meet total loads. For example, customers with thermal resources may delay a planned plant outage for maintenance. How much relief could be provided depends on liow many utilities in the Puget Sound area would have power plants they were not already operating.

BPA could limit peak deliveries to some utility customers. BPA would notify the affected utilities the day before the limitation. This includes utilities outside the Puget Sound area because the limitation must be applied to these customers proportionately. If utilities could not reduce their load, they would have to find other sources to replace the BPA power.

Each contract also has a mutual obligation provision that provides emergency and breakdown relief if there is a peak demand emergency. The party providing relief has sole discretion to determine if it can do so.

If these arrangements are not enough to decrease or meet peak loads, system operators will resort to "real-time" actions to maintain voltage stability. The Direct Service Industry (DSI) contract provides peak power reserves by permitting BPA to restrict up to $100 \%$ of any DSI's Operating Demand for up to 15 minutes. This restriction can be followed immediately by a restriction of up to $50 \%$ of Operating Demand for up to 30 minutes. BPA may also restrict up to $50 \%$ of DSI load for up to two hours in any 24-hour period, but this two-hour limit includes restriction periods under the 15-minute and 30-minute provisions above. The total Operating Demand of the DSI's in the Puget Sound area is over $600 \mathrm{MW}$. BPA also may restrict up to $25 \%$ (the "top-quartile") of DSI loads at any time and for any reason to meet load obligations. This restriction must be proportionally distributed among all DSI's throughout the region unless they agree to restrict a limited area only (see DSI contract, section $7(j)(3)$ ). If these measures are not enough, BPA may interrupt service or reduce deliveries to any of its customers to protect the power system from unstable conditions jeopardizing service throughout the system.

\subsubsection{Resource Acquisitions}

BPA's plan for meeting its energy needs, the 1990 Resource Program, includes a contingency plan if the region experiences high load growth. To meet high load growth, BPA would begin to site and license two combined-cycle combustion turbines or purchase measures for similar resources up to 800 aMW. The purpose of starting this process is to shorten the lead time reeded for these resources to come on-line if high load growth occurs. The 1990 Resource Program affects actions planned for fiscal years 1992 and 1993, and considers the load growth in the Pacific Northwest region, not just the Puget Sound area. At this time, no steps have been taken to acquire these resources. If these resources are sited east of the Cascades, then they could not provide relief for peak loads in the Puget Sound area. 
BPA is also requesting proposals from resource developers for a total of $300 \mathrm{aMW}$. Most of these resources are expected to be new. This request for proposals (RFP) does not specifically target the Puget Sound area but instead looks at the needs of the region. However, the evaluation process gives advantage to resources in the Puget Sound area. If resources in the Puget Sound area are acquired through this RFP, they may provide some peak load relief.

Puget Sound area utilities have individual plans for meeting their projected and unexpected load growth. Some utility plans are done annually and have a short-term focus; others have a long planning hoiizon. Most resource actions come from utility plans designed to satisfy the demand for energy and not necessarily the peak demand. Examples of resource actions taken by utilities are described on the following page.

In June 1989, Puget Power initiated its first competitive bidding program for the acquisition of conservation and generation resources. As a result of that process, Puget executed eight contracts. After the formal bidding process was completed in February 1990, a number of bidders not selected requested the opportunity to improve their bids and resubmit them to Puget. At this same time, Puget was also receiving unsolicited proposals from new developers wanting to sell power to them. Since Puget had a need for additional power, the new projects and improved proposals were compared and evaluated using very similar criteria to the bidding process. As a result of this followup process, two additional projects were acquired.

Puget Power is currently preparing to begin its second competitive bid. Conservation has been given a greater emphasis in the new bid with specific markets and measures targeted for acquisition. In addition, conservation, along with renewable generating resources, is given a $10 \%$ price advantage compared to other generating resources. The new bid began in mid-August following the Washington utility and transportation commissions's review.

Tacoma Public Utilities resource actions for conservation are tied to BPA plans for conservation programs. Tacoma formulates information programs geared towards educating the public, and industrial and commercial customers about conservation programs available to them.

On February 1, 1991, the Snohomish County PUD launched a pilot project with Washington Natural Gas to determine the impact of a joint utility marketing approach to customers on converting the energy source of their water heaters from electricity to gas. Two main objectives were established for the project: 1) to evaluate the feasibility of a cooperative interutility fuel switching project; and 2) to determine the effect of such cooperation on customer responses. A waiver of $\$ 200$ was offered on the installation charge. Through mailings and telemarketing, 318 home appointments were set. 209 customers, or $66 \%$ of the 318 who made home appointments, converted to gas.

Seattle City Light's long-term resource acquisition plan is included in its Strategic Corporate Plan and is updated every two to three years. Potential resources are evaluated for environmental acceptability as well as economic viability, financial impacts, and operations flexibility. In addition to its Resource Plan, Seattle City Light is evaluating the potential of competitive bidding for future resource acquisitions.

\subsubsection{Increased Probability of Voltage Instability and Blackouts}

With projected peak loads, the individual actions taken by utilities, including acquiring resources, dropping load, and using other curtailment measures might not be enough for system operators to prevent voltage instability or a blackout. Voltage instability and blackouts could cause direct and indirect impacts to BPA, local utilities, and the local economy. The number of people affected and length of outage depends on the load conditions and the nature of system problems. As loads grow, outage severity increases. In this analysis, blackouts are assumed to last an average of four hours. For example, unstable voltages and blackouts have the following consequences:

- Residential customers lose service causing heat loss in homes, loss of cooking and refrigeration, frozen water pipes, electrical appliance damage, and inconvenience. Schedules are disrupted, schools close, recreation activities are canceled. 
- Industrial and commercial customers lose service causing equipment damage, computer dysfunction and records loss, business closures, lost revenue, and lost income for employees. Communications may be interrupted, and banking and other financial services may be unavailable.

- Hospitals lose service, causing them to use emergency generators and limit operations to emergencies.

- Traffic and street lights go out, disrupting transportation, and causing safety and security problems.

- Alarm systems may not function.

\subsubsection{No Action Alternative Environmental Impacts}

The No Action Alternative does not respond to the increasing likelihood of voltage instability in a planned coordinated fashion. It would however, avoid the physical impacts of any of the measures identified for the alternative strategies. Uncoordinated planning might cause more local generation to be developed. If brownouts and blackouts occur, air quality would be degraded if consumers turn to wood for heat. The social and economic impacts listed above and others described in Chapter 4 are significant. This alternative may encourage conservation and life-style changes. Detailed information about environmental consequences of this alternative is in Chapter 4 and Appendix F.

\subsection{MEASURES CONSIDERED BUT NOT INCLUDED IN ALTERNATIVE STRATEGIES}

The screening criteria cut the original list of measures to study. After test cases were developed, and more information was available on individual measures, the list was screened again. The following measures were excluded from further consideration. A complete description of measures and why some were excluded is in Appendix D, Conservation, Load Management, and Fuel Switching Analysis; Appendix B, Local Generation Analysis; and Appendix E, Transmission Reinforcement Analysis.

\subsubsection{Conservation and Load Management Measures}

These measures were excluded from strategies:

- Residential Space Heat Set-Back Controls

- New Commercial Conservation Programs

- Lighting Efficiency Controls

- Solar Augmentation for Water Heaters (supports reduce-use)

- Portable Diesel/Gasoline Generators (supports reduce-use)

- Gas Back-up for Electric Heat

- Street Lighting Efficiency and Controls

- Dual-Fuel Boilers

- Commercial and Industrial Time-of-Use Rates

- Space Heat Controls

- Storage Water Heating

- Whole House Demand Control

- Inermai Heat Storage 


\subsubsection{Local Generation Measures}

The following local generation measures were not included in any alternative strategies. Some of the local generation measures will likely be built within the Puget Sound area for energy reasons. Local generation as an energy resource is implicitly included in all alternatives as an adjustment of the deficit, as described in Section 1.4.4. Detailed descriptions of all the measures listed below are in Appendix B.

- Oil and Gas Combustion - Steam Plants, non-peaking Combustion Turbines

- Nuclear Fission (Completion of WNP-3)

- Hydroelectric - Large Hydro, Small Hydro, Pumped Storage, Water Supply (Pressure Reduction)

- Cogeneration

- Biomass - Fired Plants, - Direct Combustion, Gasification

- Municipal Solid Waste (MSW) - Mass Burn, Refuse Derived Fuel (RDF), Gasification

- Standby Generation

- Coal

- Nuclear Fusion

- Geothermal

- Wind

- Solar Thermal Electric

- Photovoltaics

- Ocean - Energy Conversion

- Hydrogen

- Fuel Cells

- Storage Systems

\subsubsection{Transmission Measures}

The following transmission options were studied and excluded from further consideration mainly due to cost considerations:

- 765-kV Alternating Current transmission Line

- 500-kV Direct Current Transmission Line

- Many new or rebuilt line options between various substations

Appendix E describes in more detail the transmission options considered including those excluded.

\subsubsection{Load Curtailment Measures}

Originally, all load curtailment measures discussed in this EIS were considered for solving the peaking problem in Puget Sound. After analyzing the costs and impacts of curtailment, planners decided that depending on curtailment for long-range planning is inappropriate. Load curtailment is considered a contingency interim solution if load growth is higher than expected. 


\subsection{AFFECTED ENVIRONMENT}

This chapter describes environmental features that could be affected by the alternative strategies. The transparent overlay included with this DEIS can be used with the maps in this chapter. The overlay shows the locations of substations, and transmission line corridors so specific information about these locations can be discovered.

\section{$3.1 \quad$ STUDY AREA CHARACTERISTICS}

\subsubsection{Land Use}

Study area land use is shown on Map 2. In the Puget Sound area, land use is determined by nearness to Puget Sound, slope, and population. Residential, commercial, and industrial uses are clustered and defined by the shore of Puget Sound and major rivers. Agricultural land laps up against the steep slopes of the mountains and is mostly between the populated areas, and land unable to sustain crops because of infertile soil or steep slopes. There is little rangeland in the Puget Sound area. Transportation corridors and utilities serve major population centers. Recreation opportunities exist where population is sparse, near water, in or near wildlife areas, and on forest land. Activities range from sailing and fishing in Puget Sound to hiking and mountain climbing on Mt. Rainier.

Outside the population areas surrounding Puget Sound, and the mountainous areas above tree-line, most of the study area is covered by forest, primarily Douglas Fir. About two-thirds is publicly owned and managed. The rest is privately owned.

In the rest of the study area, geography and land use are determined by ine Columbia/Snake river systems. The Columbia River Basin includes more than 258,000 square miles of drainage, including most of Washington, Oregon, and Idaho; Montana west of the Rocky Mountains; small areas of Wyoming, Utah, and Nevada; and southeastern British Columbia. Part of this basin is in this portion of the study area.

The study area contains parts of many Pacific Northwest's geographic subregions: the Columbia River and Snake River Plateau, and valley/plains regions (including part of the Willamette Valley) separated by the Coast Range, and the Cascade Mountains. Part of the study area is covered by forest, most dense west of the Cascade Range. Rangeland occupies substantial areas. Agricultural lands are primarily on the Columbia River Plateau, along the Snake River, and in the Willamette Valley. A large part of the land is publicly owned and managed. Land managers include the U. S. Forest Service (USFS), Bureau of Land Management (BLM), Department of Energy, Indian Tribes, Department of Defense, and state and local governments. The rest is privately owned.

The Columbia River passes from the province of British Columbia, Canada, into the State of Washington, dropping steadily for 748 miles to the Pacific Ocean. The Snake River, which begins in southeastern Idaho, flows west and north, forming part of the border between Oregon and Idaho and between Idaho and Washington. In southern Washington, the Snake River joins the Columbia, which flows west to the Pacific Ocean, forming the border between Oregon and Washington. The rivers flow through extensive wilderness, scenic, and recreation areas in the north and east. The rivers then pass through irrigated agricultural areas in the plateau lands east of the Cascade Mountains, and down through the Cascade and coast mountain ranges to the Pacific.

The size of the rivers and the drop in elevation once created spectacular falls and annual flooding as glaciers and snow melted in the mountains. Over the last 50 years, both the Snake and Columbia Rivers have been dammed to control flooding, provide irrigation, improve navigation, and produce electricity.

Federal hydro projects on the Snake and Columbia river systems are operated to provide multiple uses, including power production, irrigation, navigation, flood control, recreation, fisheries, and wildlife. Flood control constraints vary by project and are adjusted by the Corps of Engineers based oi projected runoff. Fiond controi and navigation requirements are met except in emergencies. 
Recreation - In the Pacific Northwest, Federal Hydro projects provide many opportunities for recreation at the storage reservoirs and the areas downstream. Boating, swimming, water skiing, and fishing are typical water related recreational activities. Other recreation opportunities include camping, picnicking, sight-seeing, hiking, and hunting. Many recreation activities are influenced by changes in reservoir elevation and downstream flows.

A unique recreation area, the Columbia River Gorge National Scenic Area, is in the study area. The Culumbia Gorge is world-renowned for windsurfing, and the Gorge provides many opportunities for hiking, climbing, wildlife viewing, and plant study. There are many unique plants that grow only in the Gorge. The Gorge has many waterfalls and picnic areas.

As noted above, cross-Cascade corridors are dominated by land set aside for recreation. The Pacific Crest National Scenic Trail runs along the entire length of the Cascades, crossing all east-west corridors. There are also waterways designated as Wild and Scenic Rivers in the study area.

National forests also provide opportunities for hiking, hunting, sight-seeing, skiing, and other outdoor activities.

Irrigation - Hydro projects provide water and power for irrigation. The largest irrigation project in the Basin is the U. S. Bureau of Reclamation's (BOR) Columbia Basin Project, which is authorized to provide irrigation to over 1 million acres. This project is half finished.

Cultural Resources - Cultural resources are defined as "the nonrenewable evidence of human occupation or activity as reflected in any district, site, building, structure, artifact, ruin, object, work of art, architecture, or natural feature that was important in human history at the national, state, or local level." Map 3 shows important cultural resources. Many other resources too small to show on this map are found in the study area.

\subsubsection{Natural Resources}

Surface Hydrology - The study area includes a variety of water resources. Water resources potentially affected include rivers, streams, reservoirs, lakes, ponds, estuaries, marshes, and the Pacific Ocean. Many of these can be seen on the maps included in this chapter.

Wildlife and Vegetation - Climate, soil types, moisture, and elevation determine the species, locations and growing habits of the study area's vegetation. Different combinations of geology and growing conditions create site specific diversity in the plant community. Vegetation in this study area falls into four general community types: forest/woodlands, shrublands, grasslands, and riparian/wetland (see Map 4). Each plant community has characteristic wildlife types.

Forest/Woodland and Wildlife - The forest/woodland plant community provides many layers of habitat for wildlife, from the ground into the upper branches of older trees. Most vulnerable to change are older stands of trees of various ages, which may take a century or more to develop and thus cannot be replaced easily.

Large and small mammals, including deer, members of the weasel and skunk family, and rodents such as squirrels and porcupine, are found in forested areas. These mammals prefer a narrowly defined habitat and can be affected by disturbing or removing habitat. The forest community, with its many varieties of trees, houses a large number and variety of birds, depending on the region and composition of the forest, and some of these birds species are very sensitive to habitat disturbance.

Shrubland and Wildlife - Shrublands are in areas tor harsh for forests and/or areas subject to repeated natural disturbances such as floods or fires. They may be replaced by grasslands if disturbed. The major shrubland communities in the study area contain mule deer, coyote, gray fox, mountain lion, and a variety of birds.

Grasslands and Wild!ife With their tremendous volume of seed bearing but nonwoxdy materials, grasslands typically sustain fewer kinds of wildlife, but large numbers of individuals of some spercies such as rodent (e.g., ground 


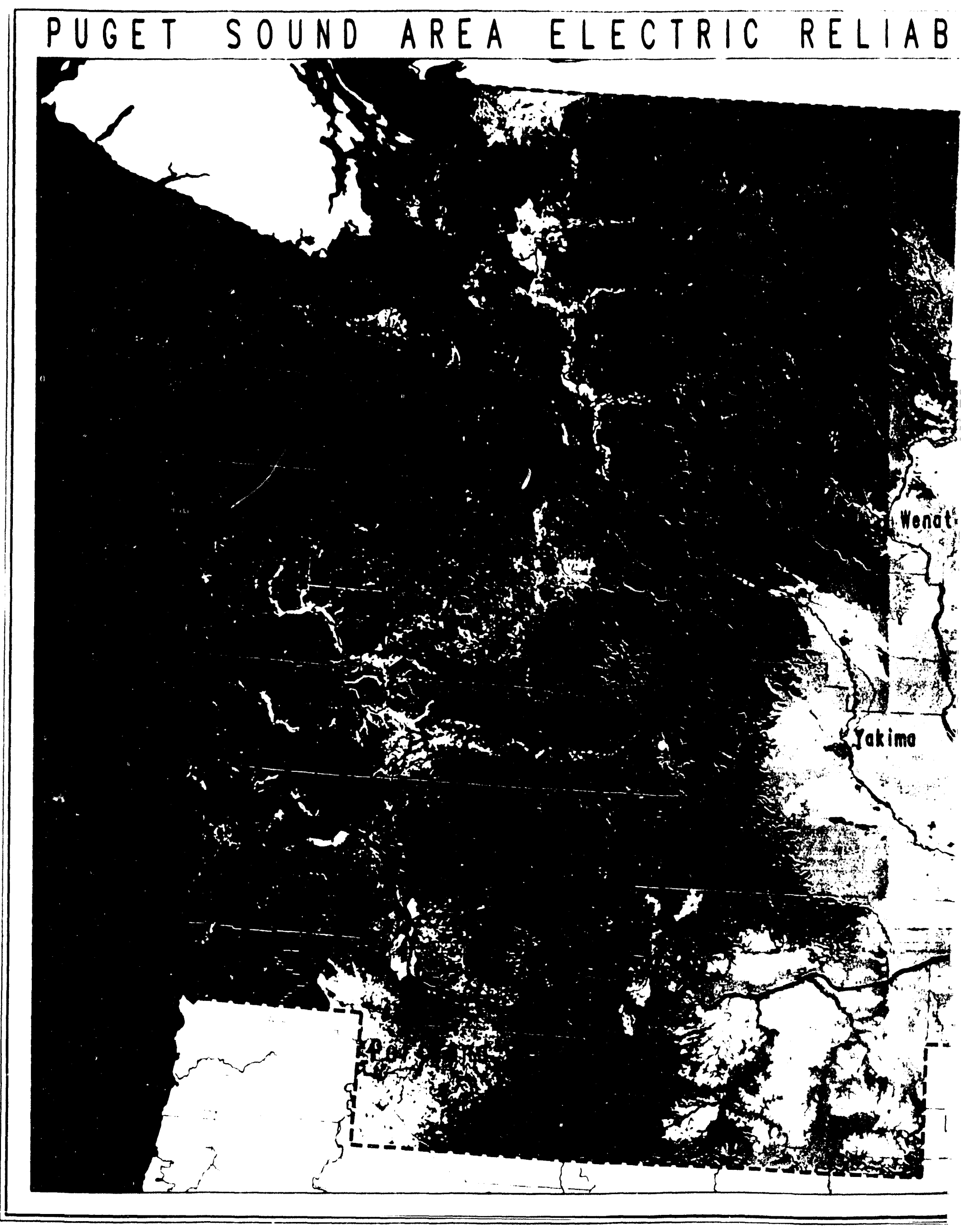


BILITY PLAN

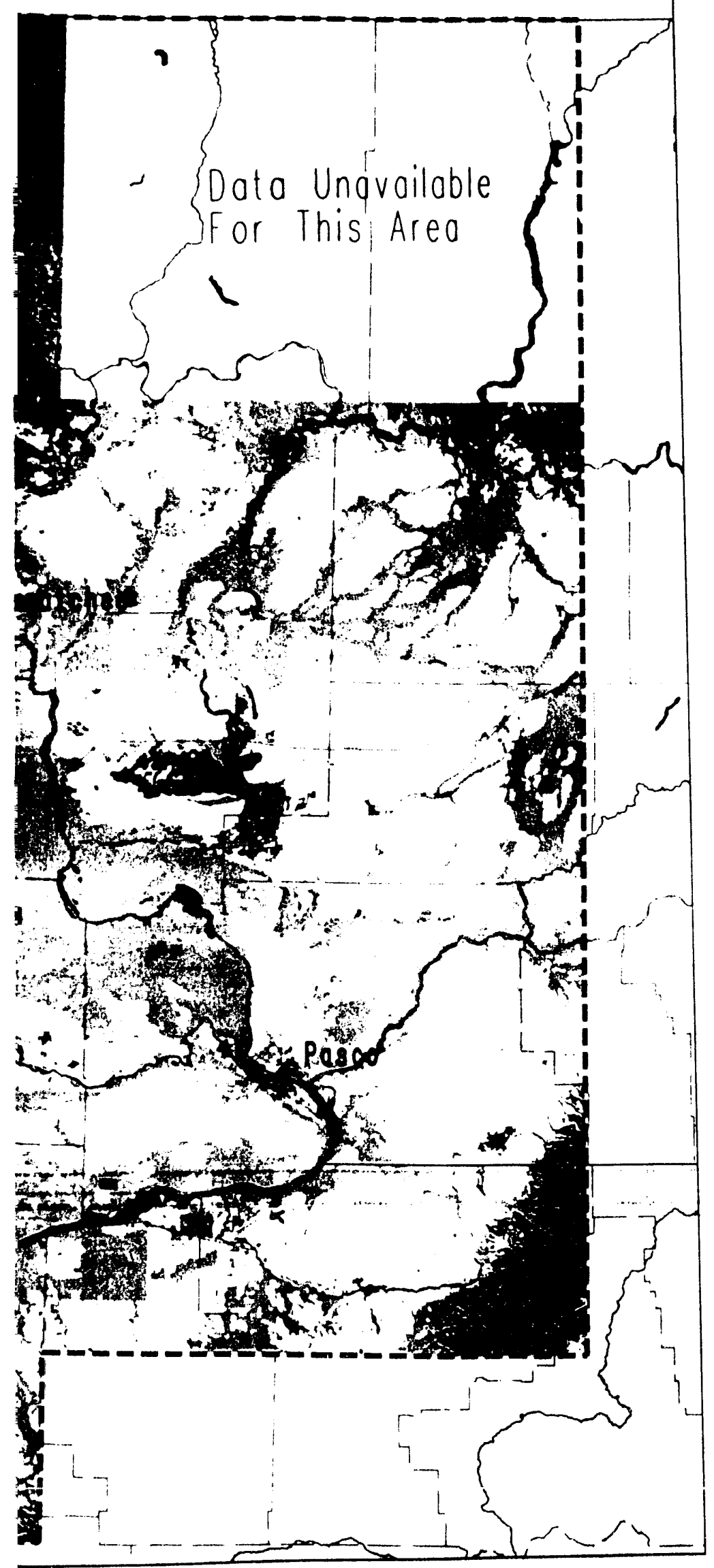

Land Cover/Land Use

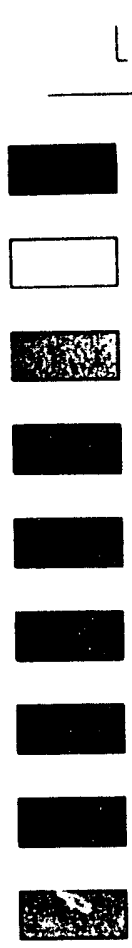

\section{E G $\quad E N \quad N$}

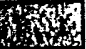

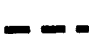



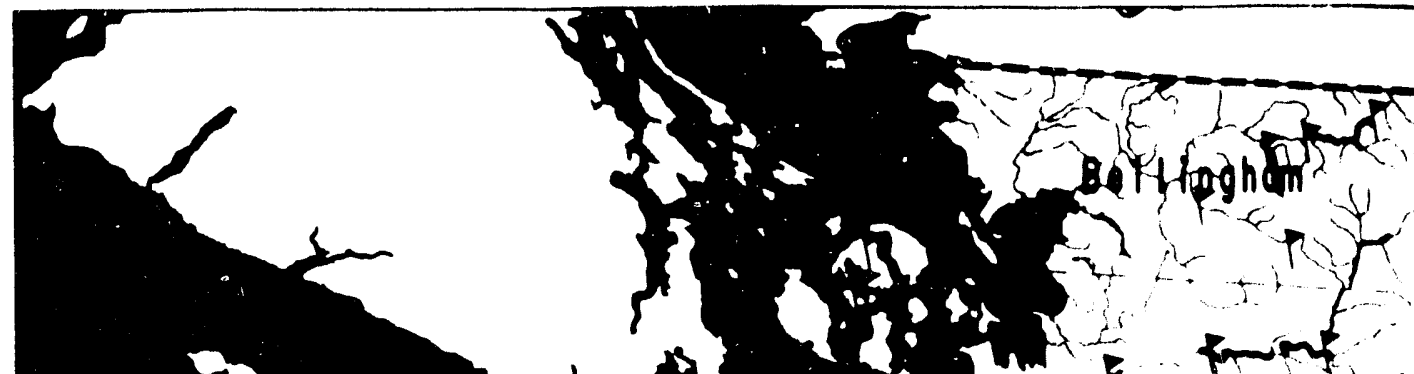

1. $40+4$

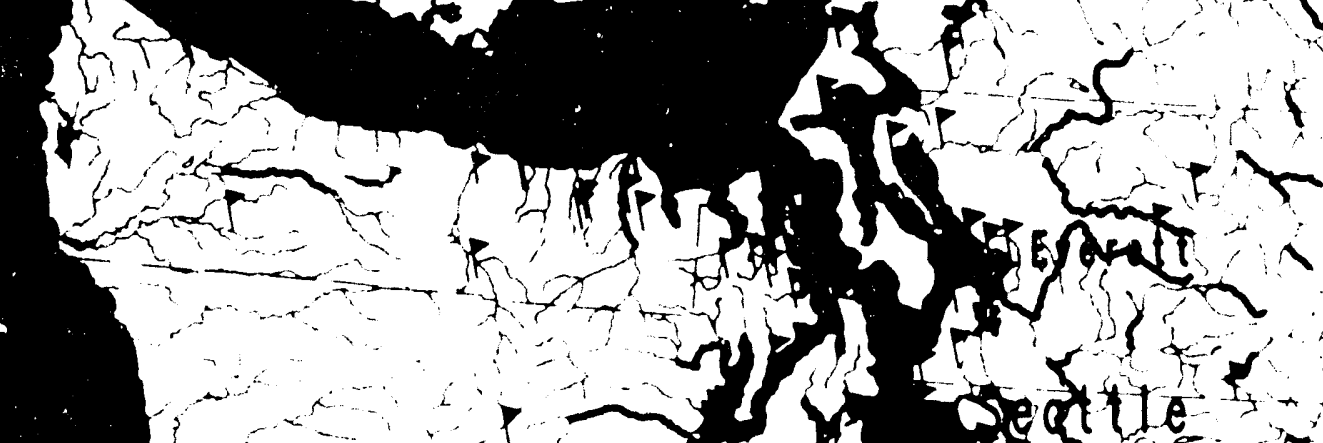

8

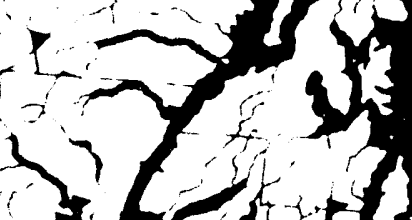

2 2 , 15e * o r monio

,

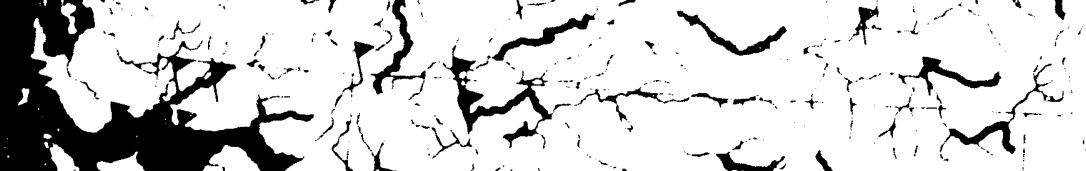
10

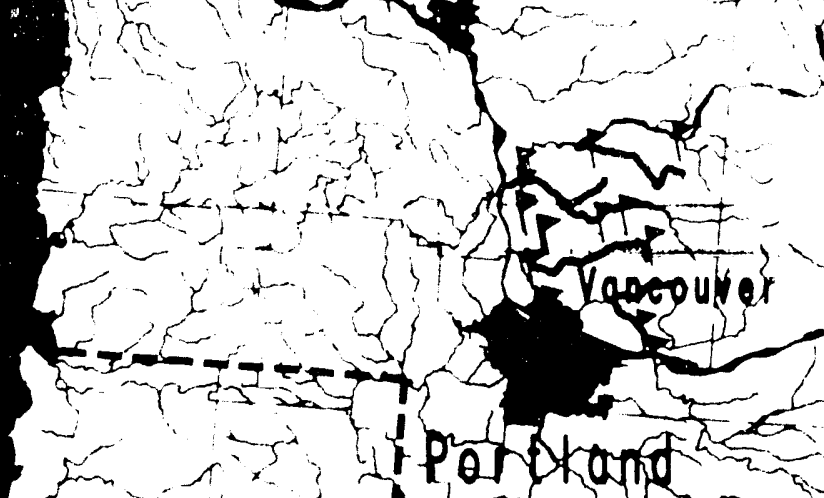

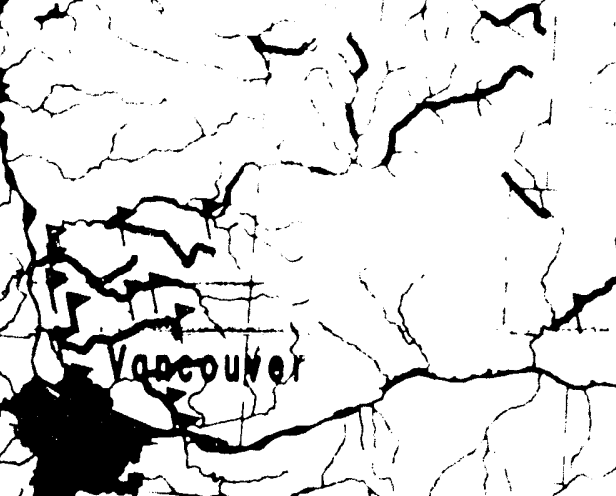

Pencturito 


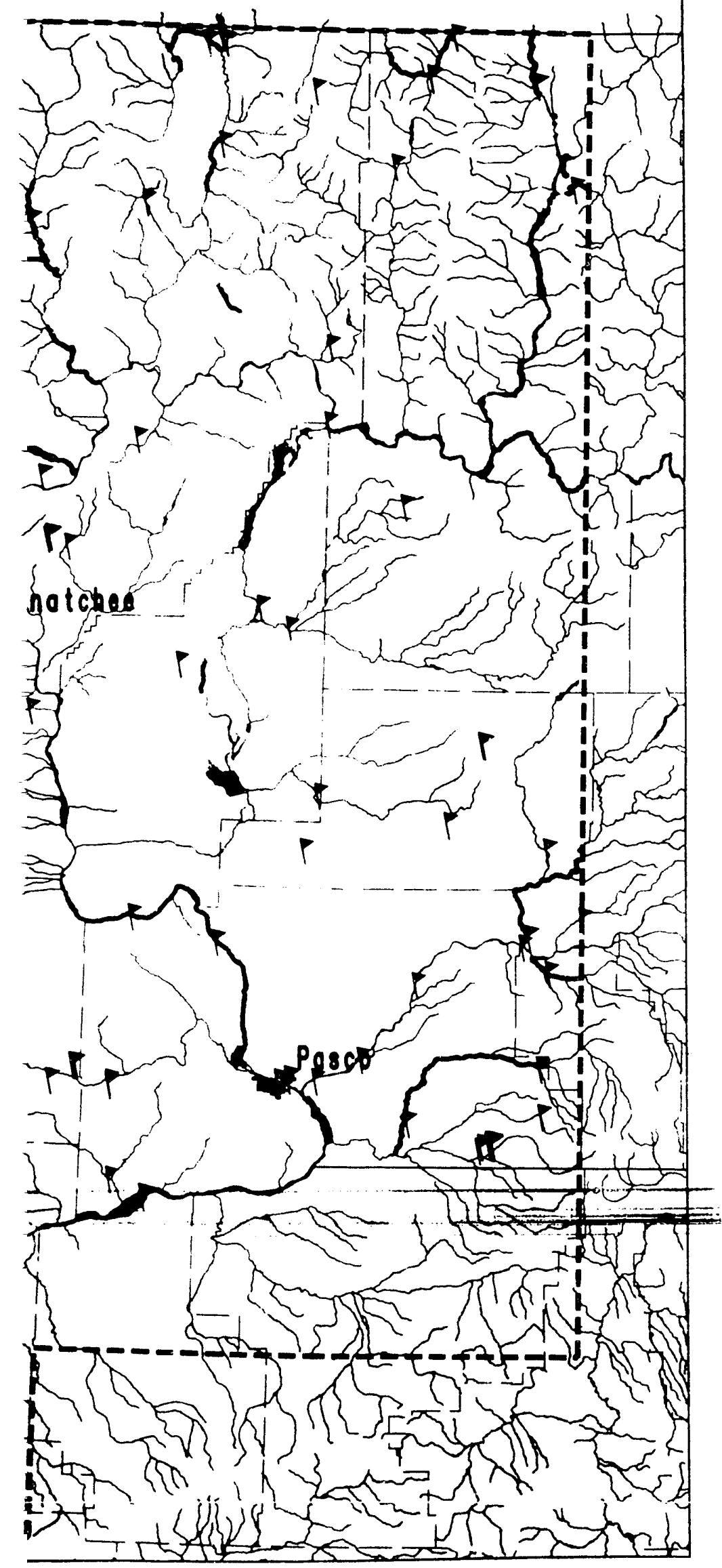

Cultural Resources

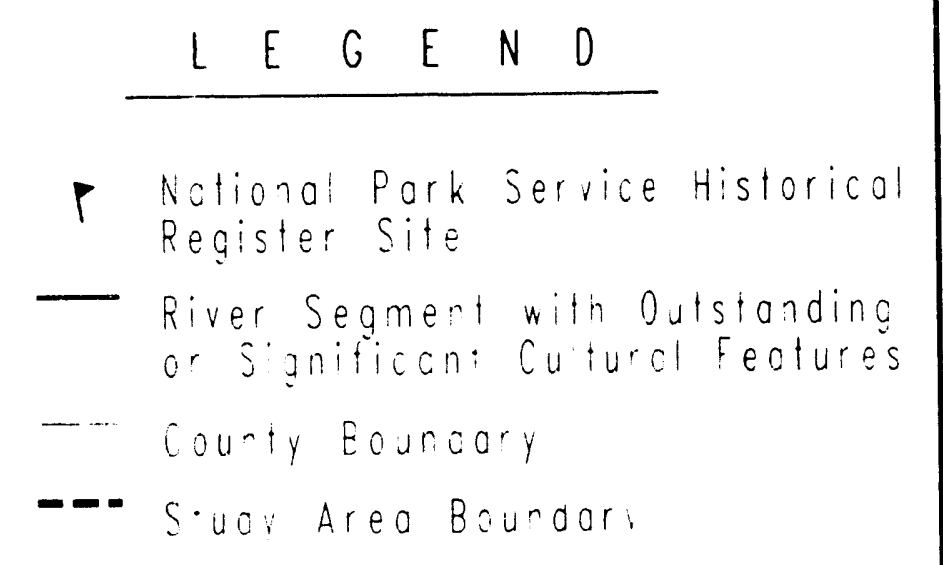




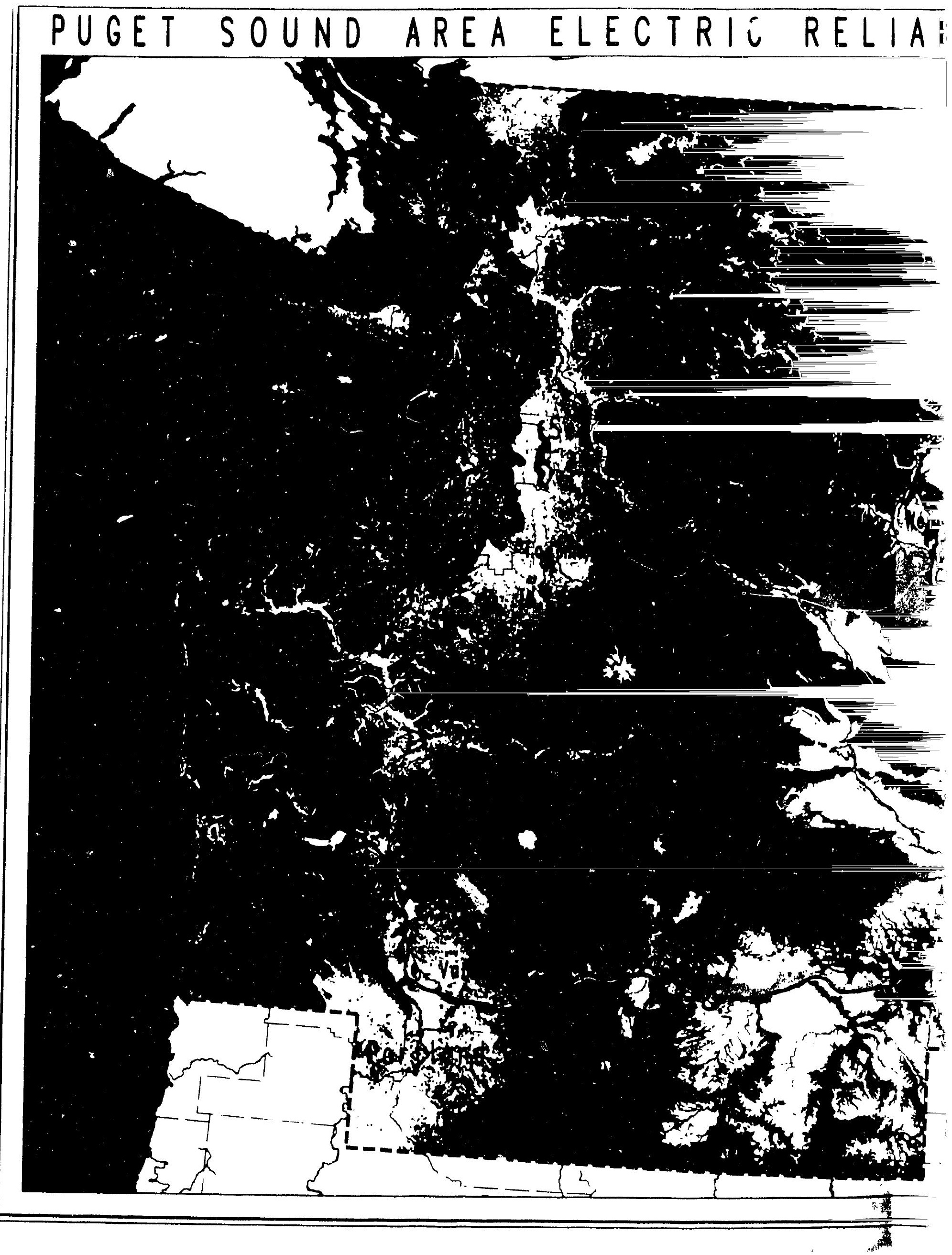




\section{BILITY PLAN}

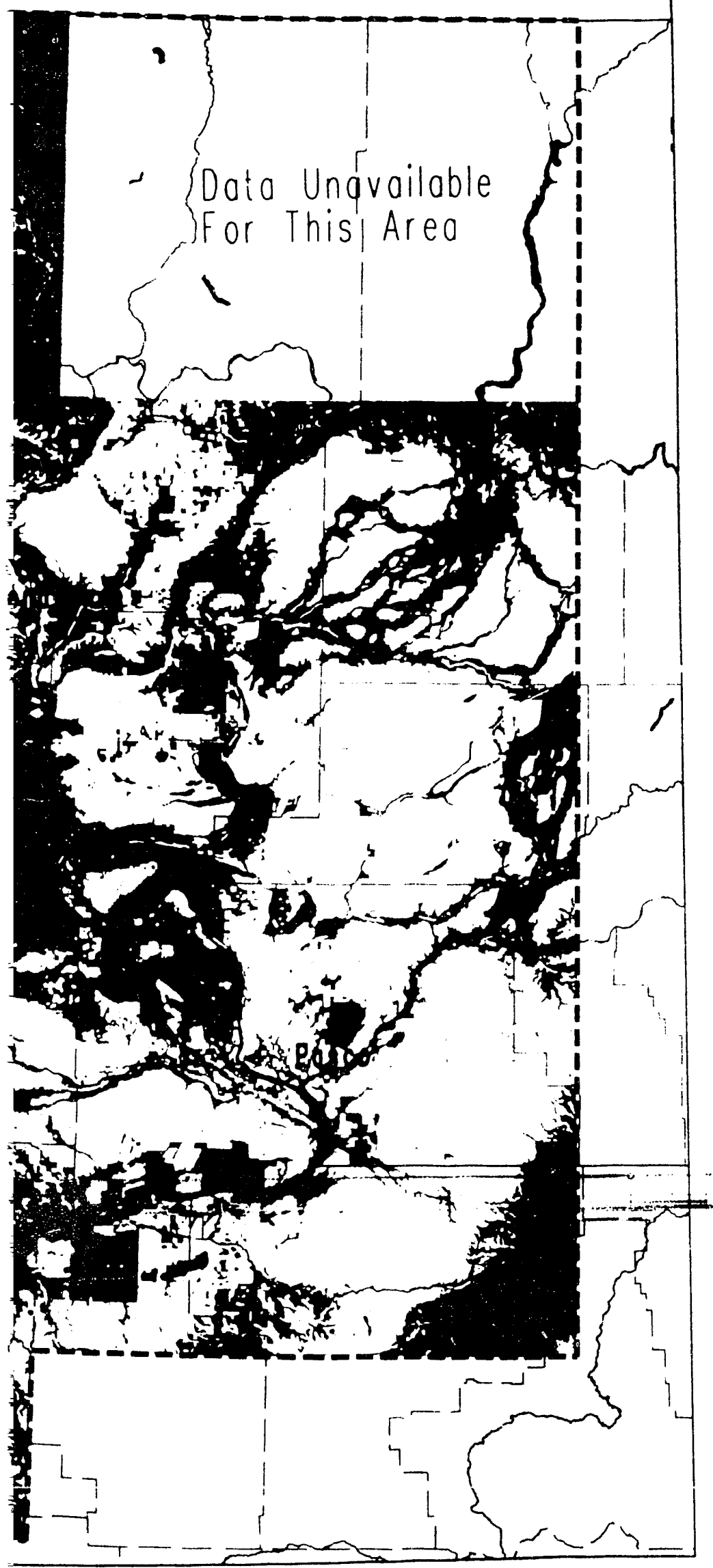

Vegetation Patterns

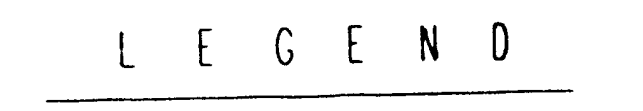

6in

D Sorut ord Brust Pagelono

D M.eg Fongetcrio

+1.
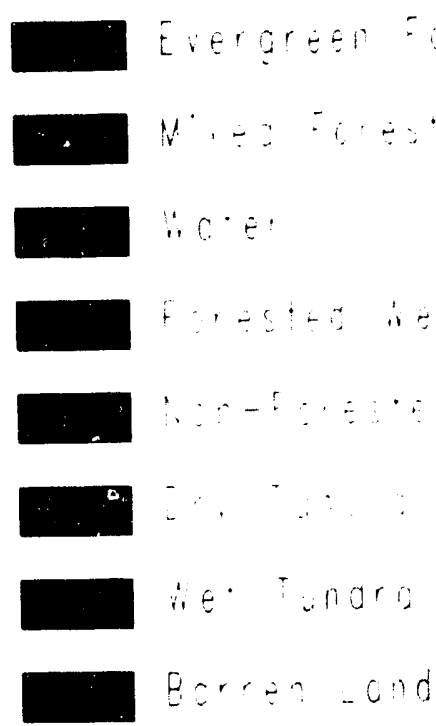

ite iondra
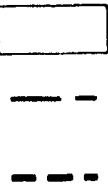
squirrels). These small animals attract predators such as hawks. Mule deer, badger, and coyotes occur here. Grasslands support fewer birds because perching and nesting habitat is sparse.

Riparian/Wetland and Wildlife - Riparian/wetland communities have high vegetation and wildlife value. There is great diversity in this community with habitat types ranging from sand dunes to various types of wetlands. Deer, beaver and other aquatic and terrestrial furbearers, small mammals, waterfowl, upland game birds, reptiles, and amphibians are among the common year-round users of riparian/wetland areas. Wintering elk and moose may use these areas. Riparian and wetland areas are important habitats and nesting areas for numerous bird species. Map 5 shows outstanding and substantial wildlife habitat along rivers designated by the State of Washington.

Threatened and Endangered Species - A number wildlife species which occur in the study area have been identified for protection due to dwindling populations or special habitat needs. Species in danger of extinction are classified as Federal Endangered. Species at risk of becoming endangered are Federal Threatened. Species being considered for listing as Federal endangered or threatened species are listed below as Federal Candidate species. Federal Sensitive is a designation used by the Portland office of the U.S. Fish and Wildlife Service for species at risk of becoming threatened because their numbers are small or they require special habitat. The following species are in each of these categories:

Federal Endangered - Peregrine Falcon, Grey Wolf, and Columbian White-tailed Deer

Federal Threatened - Bald Eagle, Northern Spotted Owl, Spotted Owl, Oregon Silverspot butterfly, and Fritilpry butterfly.

Federal Sensitive - Sandhill Crane, Purple Marten, Common Loon, Lewis Woodpecker, Western Bluebird

Federal Candidate for Listing - Marbled Murrelet, Western Pond Turtle, Bull Trout, Olympic Mud Minnow, Beller's Ground Beetle, Hatch's Click Beetle, and Larch Mountain Salamander.

The State of Washington also maintains lists of wildlife species requiring protection due to reduced populations. The Washington list is considerably longer than the above listing. It contains many of the above species.

The National Marine Fisheries Service has proposed for listing the Snake river sockeye salmon and the Snake river spring, summer, and fall Chinook salmon as endangered or threatened species.

Fish - The study area includes a wide variety of fish species. Maps 6 and 7 show the areas where anadromous and resident fish are present. A typical Cascade Mountain stream supports resident fish and anadromous salmonids (Chinook, coho, and chum salmon; steelhead and cutthroat trout).

Many anadromous fish live in Pacific Northwest rivers. Anadromous fish migrate down the rivers to the ocean, then return upstream to spawn. To complete their journey, they must negotiate up to nine dams on the Columbia River. Fish spawning in the Snake River or the Salmon River must pass over eight dams (four on the Columbia; four on the Snake River). Chief Joseph Dam on the Columbia and Hells Canyon Dam on the Snake are the upstream limits of anadromous fish migration.

The tributaries, lakes, and upper portions of the Columbia River system are the major spawning and nursery grounds for anadromous fish. The principal anadromous fish in the Columbia Basin are steelhead trout; three species of salmon (Chinook, coho, and sockeye); and shad. Other anadromous species include white sturgeor;, striped bass, eulachon, and Pacific lamprey. Anadromous fish and particularly salmonids, require high-quality water. Water temperature, dissolved oxygen, sediment, and nitrogen supersaturation have created the greatest water quality problems for fisheries in the Columbia River Basin.

The Columbia River and its tributaries contain a variety of resident fish. Resident fish spend their entire life in fresh water, although some migrate through the fresh-water system. 
Many resident species are more tolerant of stressful environmental conditions such as high temperature, low concentrations of dissolved oxygen, and small amounts of certain toxic pollutants. Juvenile salmonids are generally more sensitive to many pollutants, temperature, and dissolved oxygen.

Topography and Geology - The landforms of Puget Sound are related to geologic processes. Landforms within the study area are varied. The Northern Cascade Mountains occupy the eastern half of the study area and the Olympic Mountains form the western portion. These mountains were formed by a process called uplift. Rock formations composed of once molten granite and sediments were pushed upward in ancient times to form the basic structure of these mountains. Glacial activity and erosion have modified their form creating what has been termed the most rugged alpine area in America.

Between and along the margins of these two mountainous areas are areas of moderate slope and low elevation. Called the Puget Sound Trough Province, this forms the central portion of the study area. It is within these less mountainous areas that human activity has been extensive. The topography was created by a glacial icecap that pushed into the area from the north. Many lakes and poorly drained depressions are found within the Puget Trough Province. Glacial deposits within Puget Sound consist largely of very porous gravels and sands.

Groundwater - Glacial sedimentary deposits within the Puget Sound Trough provide an important source of groundwater. Terraced lowlands on the western edge of the Olympic Peninsula and the alluvial deposits found along the west trending Chehalis River valley are also important sources of groundwater within the study area. The chemical quality of most groundwater in Washington is satisfactory for municipal, industrial, and agricultural uses, and often is better than necessary to meet limits recommended for drinking water.

Based on dissolved solids, the groundwater of the Puget Sound is classified soft or only moderately hard. The chemical quality of most groundwater is good or excellent. Water from several areas next to Puget Sound contain untreated iron quantities exceeding that recommended for drinking water and some industrial processes.

The groundwater bearing sediments of Puget Sound are replenished by heavy precipitation in the region and by runoff from the less permeable slopes of the adjacent uplands. Shallow well water yield is closely related to precipitation and wells may go dry in the summer during years of inadequate rainfall. Deep wells yield large quantities with little seasonal change in water level.

Air Quality - The Clean Air Act designated air quality classifications to reduce air emissions. Class I areas are the most pristine and little or no degradation of air quality is allowed. These areas are shown on Map 8 . Class III or nonattainment areas are where air quality standards are not now being met for ozone, carbon monoxide, and fine suspended particulates. These are much sm. er than the pristine areas. Measuring concentrations of pollutants determines if an area meets EPA and State air quality standards.

Climate - The climate in the Puget Sound area is strongly influenced by the Pacific Ocean and the Olympic and Cascade Mountains. The result is a temperate, maritime climate characterized by moderately warm summers and wet, inild winters. Average annual rainfall ranges from 133 inches in the (Olympic rainforest to 17 inches in the rain shadow of the Olympics. Seattle's annual rainfall is 35 inches.

As unusually cold winter days pose the greatest threat to electric reliability, winter climatic conditions are of greatest importance. Factors of greatest significance with regard to Puget Sound's winter climate are the position and intensity of semi-permanent high and low pressure centers located over the Pacific Ocean, and the Cascade Mountains.

The Cascades are effective in preventing cold continental air from reaching the Puget Sound lowlands. The typical winter day has high temperatures in the 40's and nighttime temperatures in the 30 's. Freezing days in the Seattle area range from $15 \mathrm{t}$ to 50 days depending on elevation and distance from the bay. 


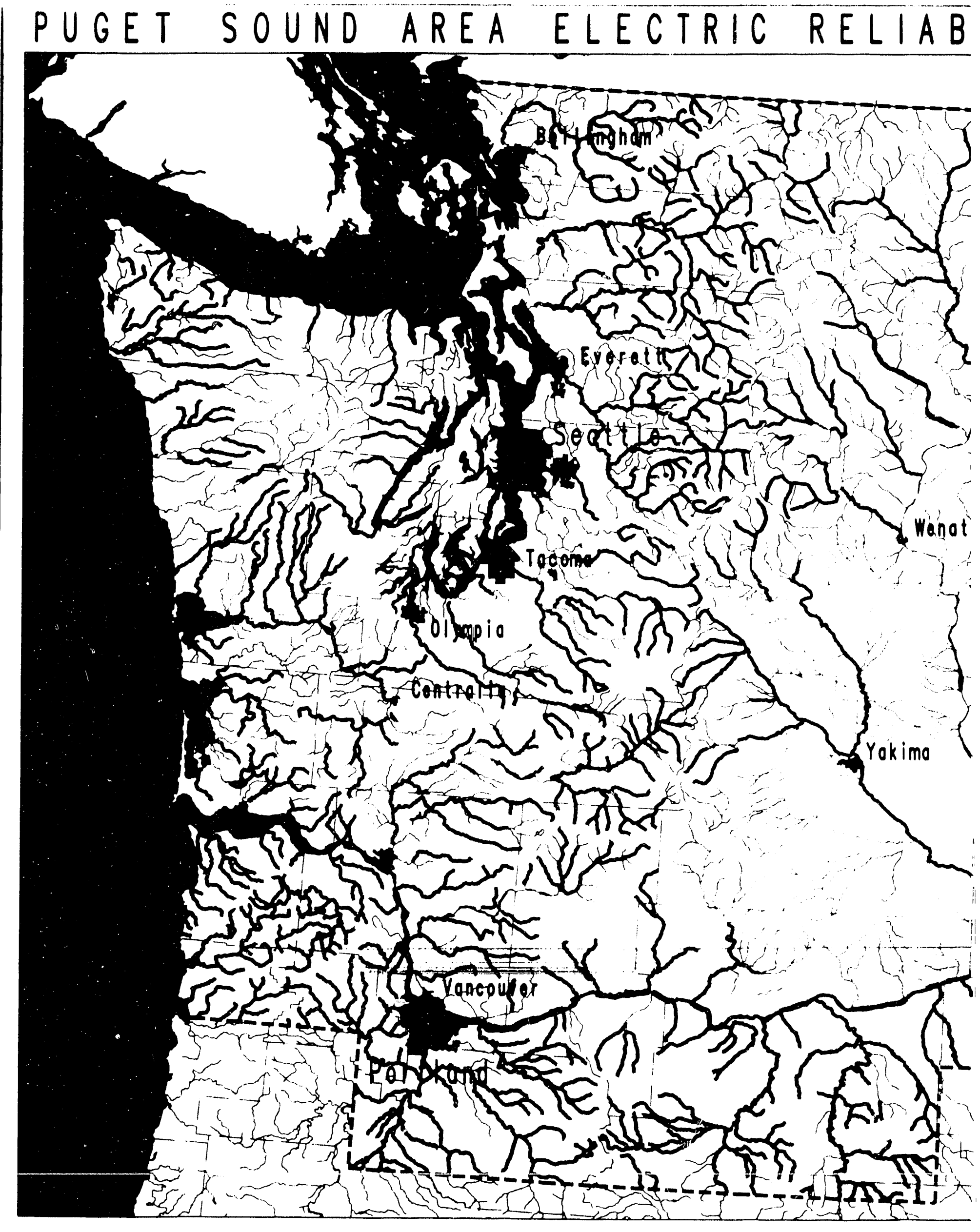




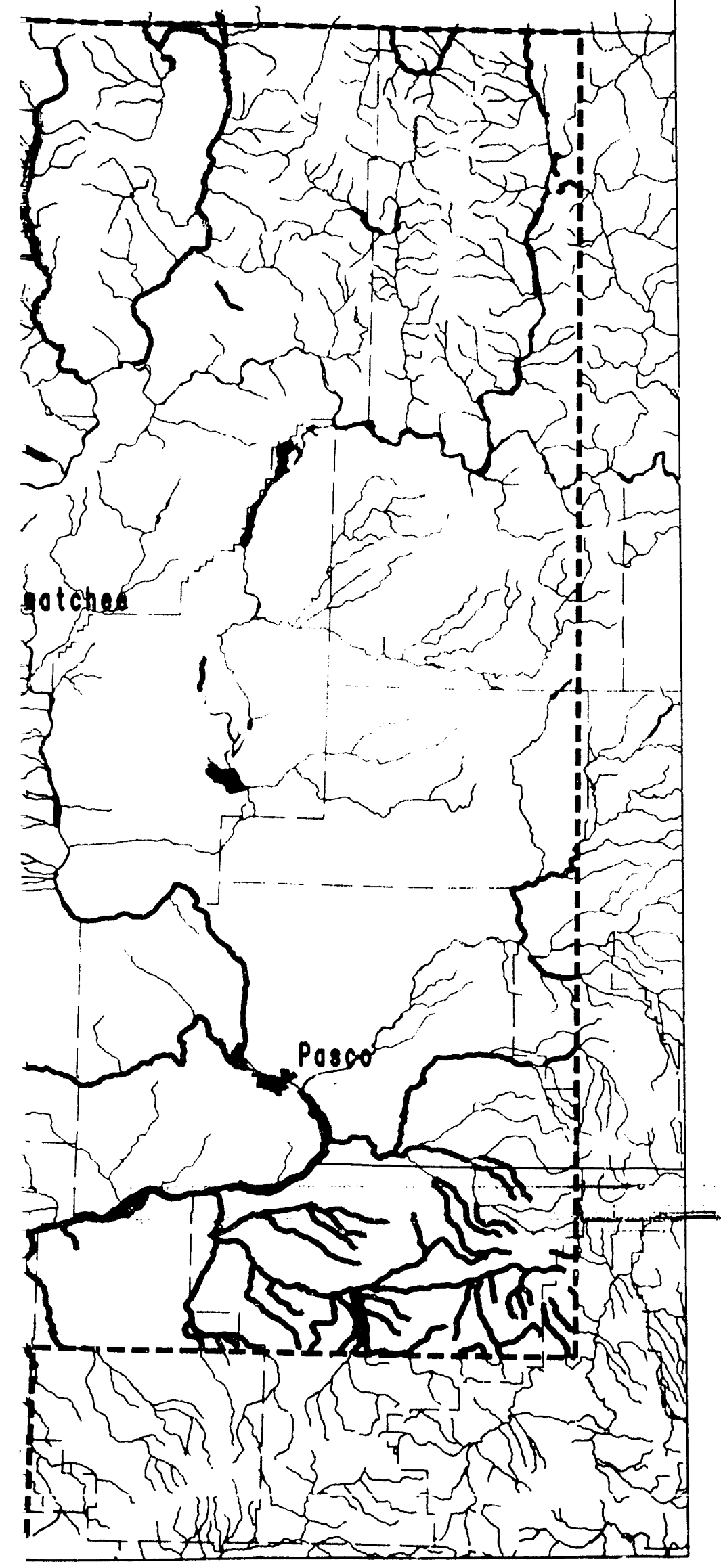

Wildlife Habitat Along Rivers
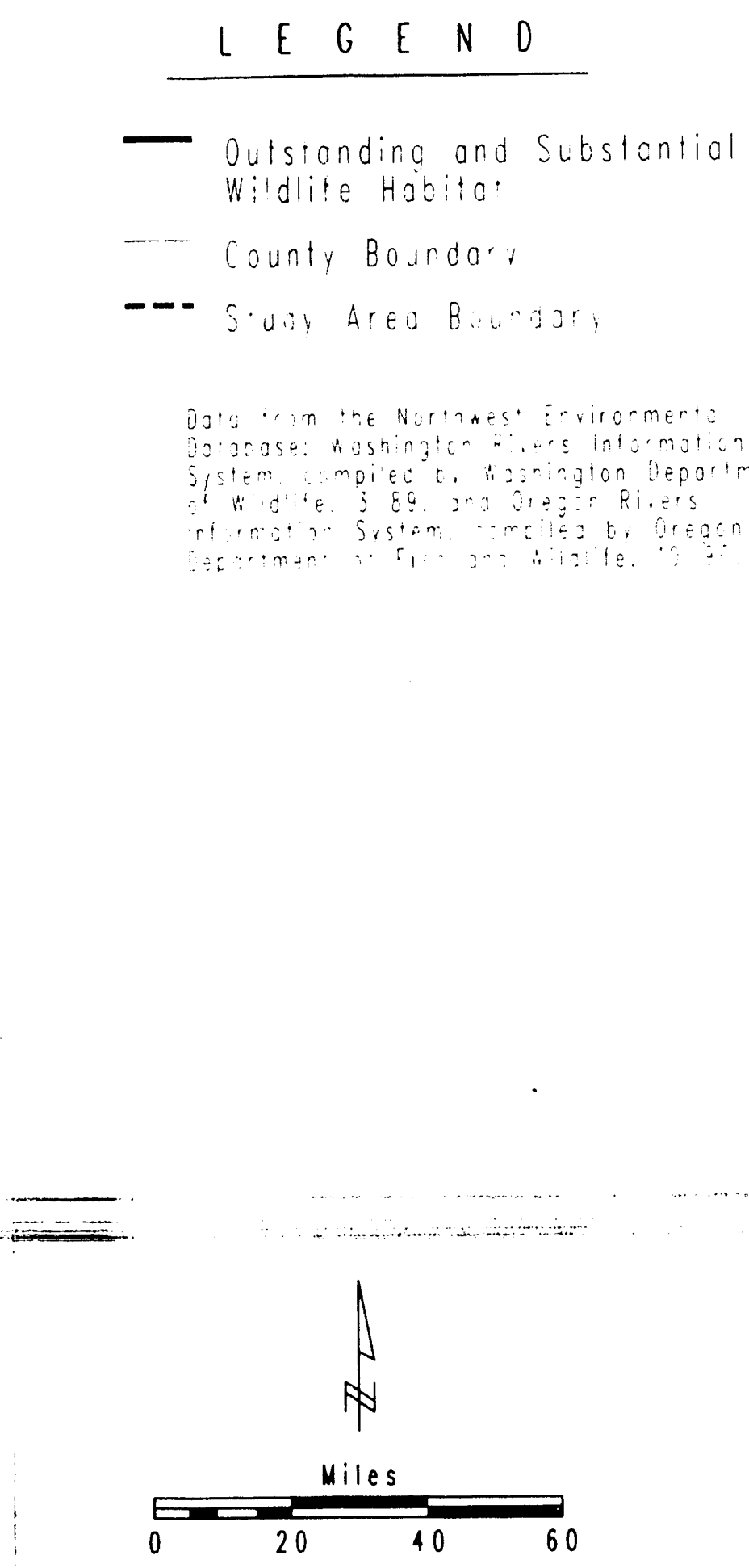


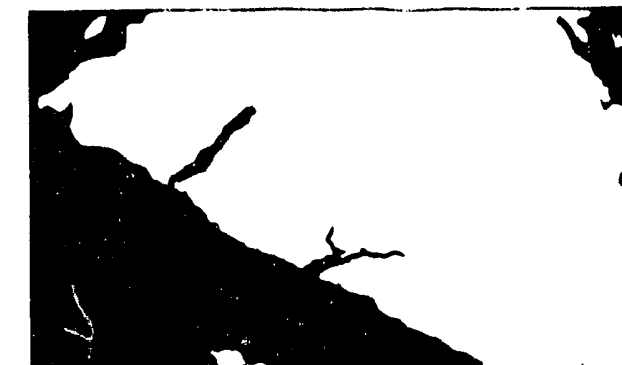

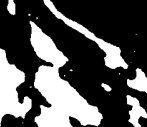

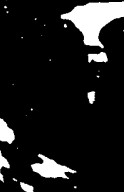

3

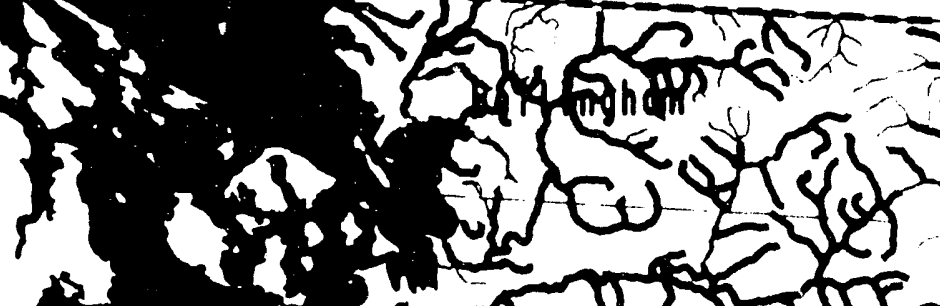

(a) $3+5,45$

(1) 2. $\sin 3 \mathrm{~S}^{2} \mathrm{c}$

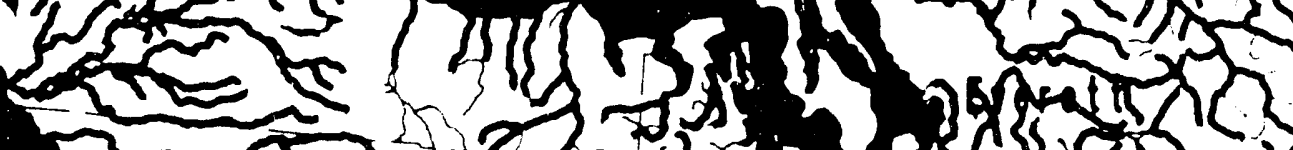

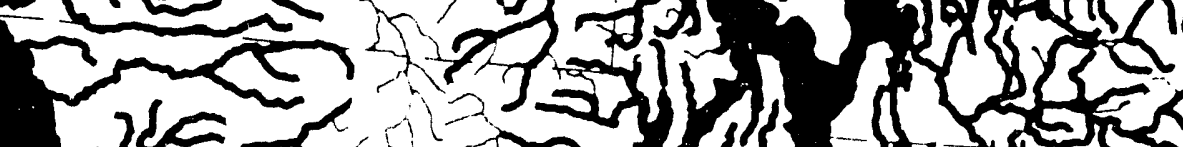

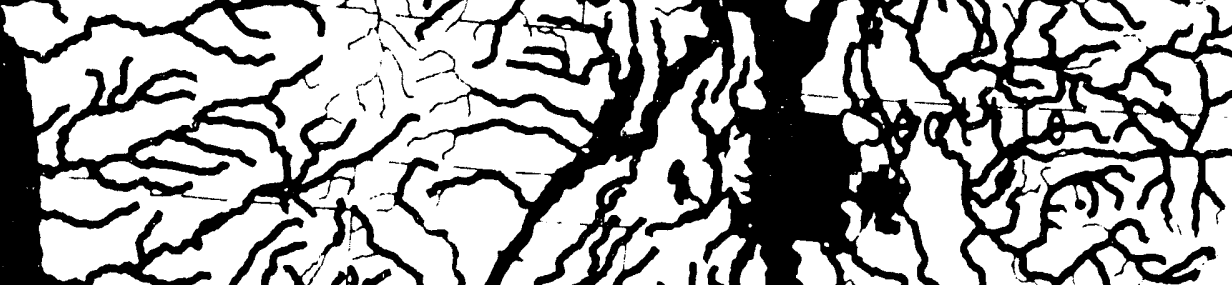
E (i) s. 15. (2) sis

L

n $2 y$ 3 可 ?

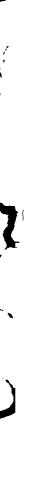

(a) 7

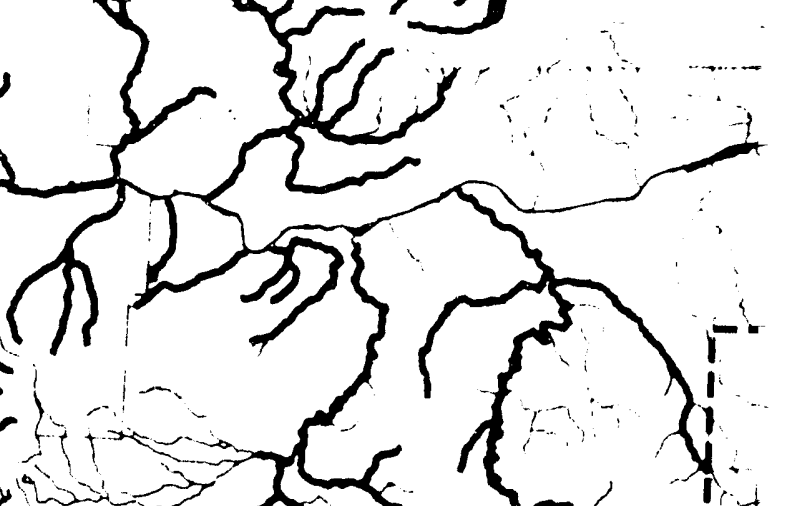
Sm 


\section{BILITY PLAN}

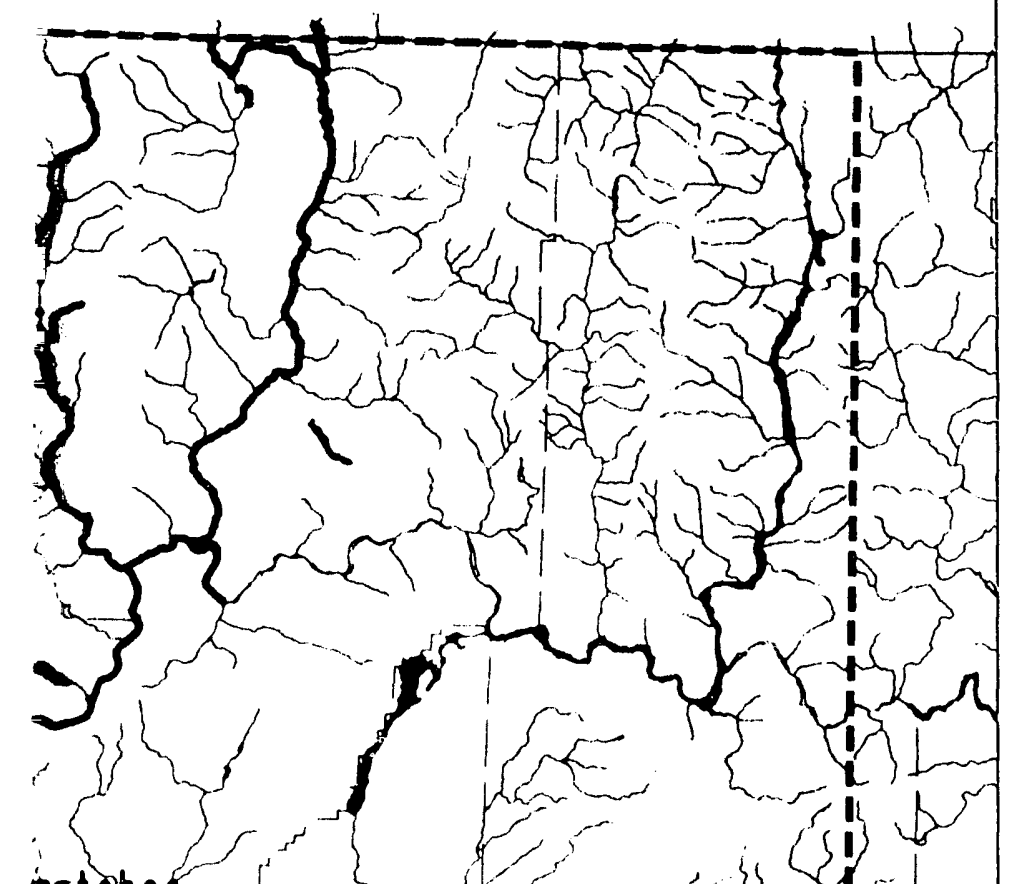

\section{intcher}

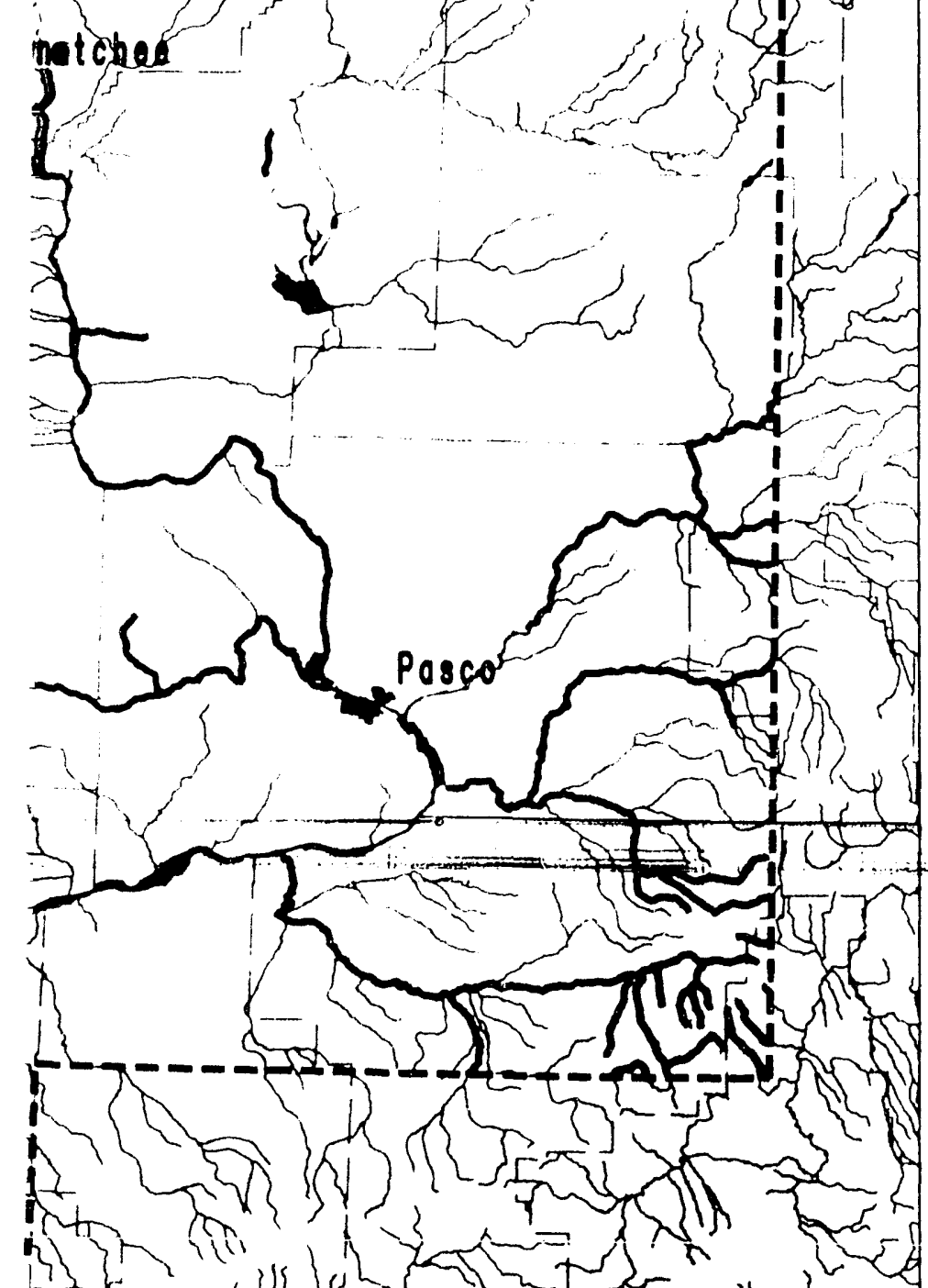

,

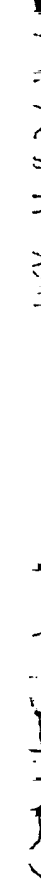
然
Anodromous Fish Presence

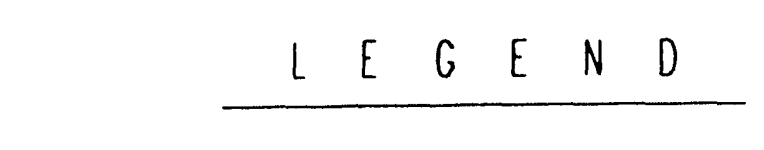
- River Segment with Anodromous is is County Bunady
- - Studr Area Boundar:

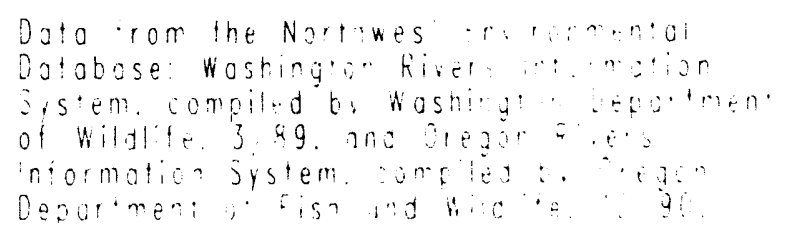

$\therefore=$

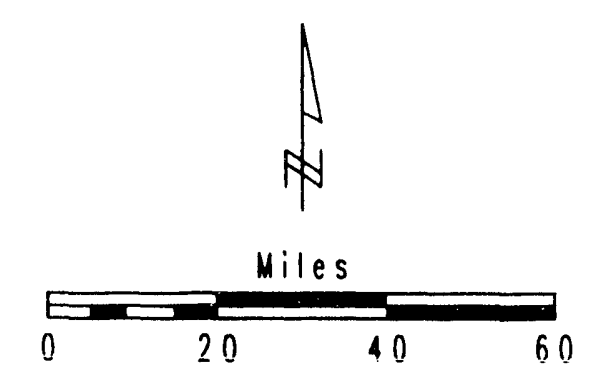

Mop 6 


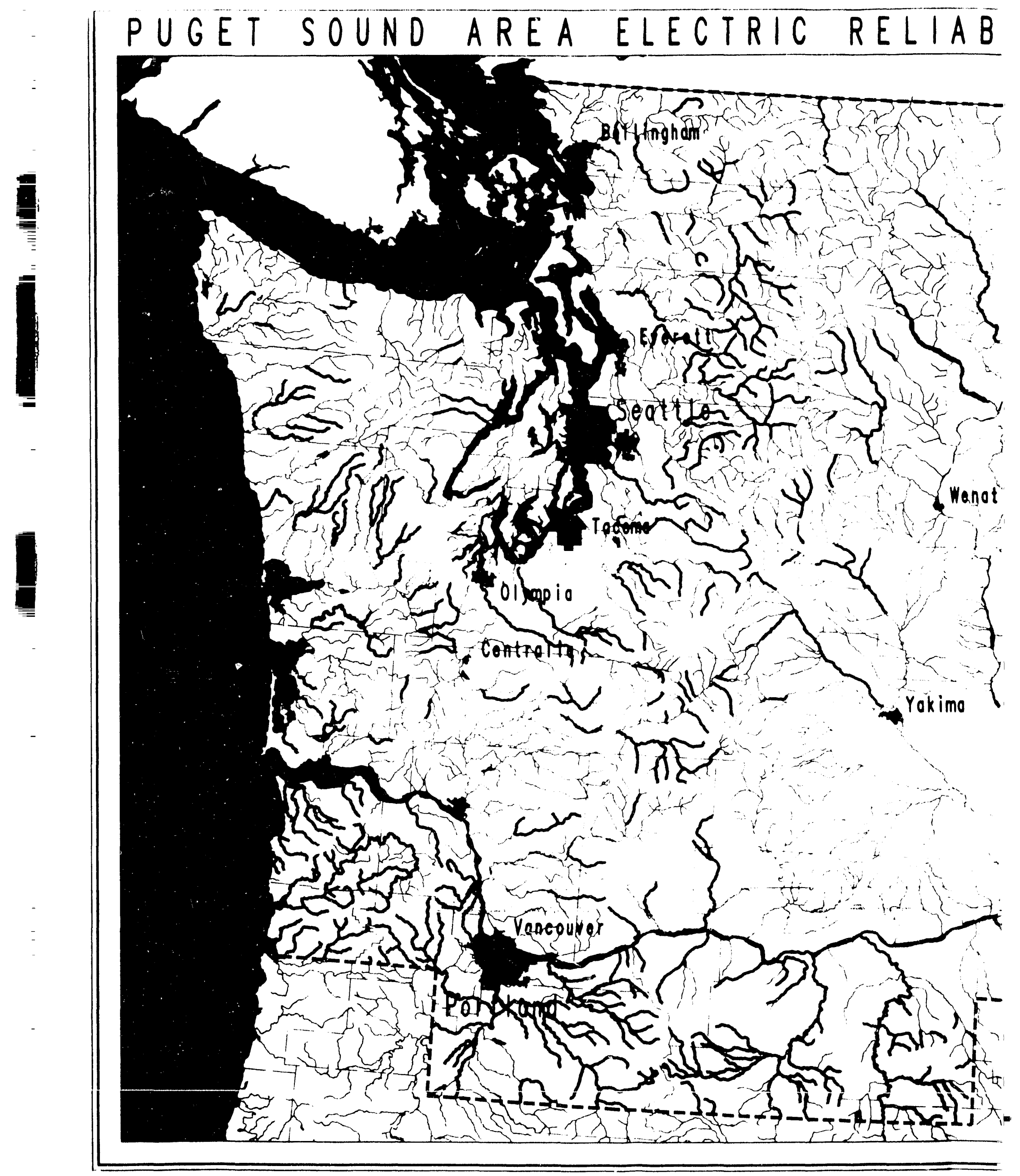




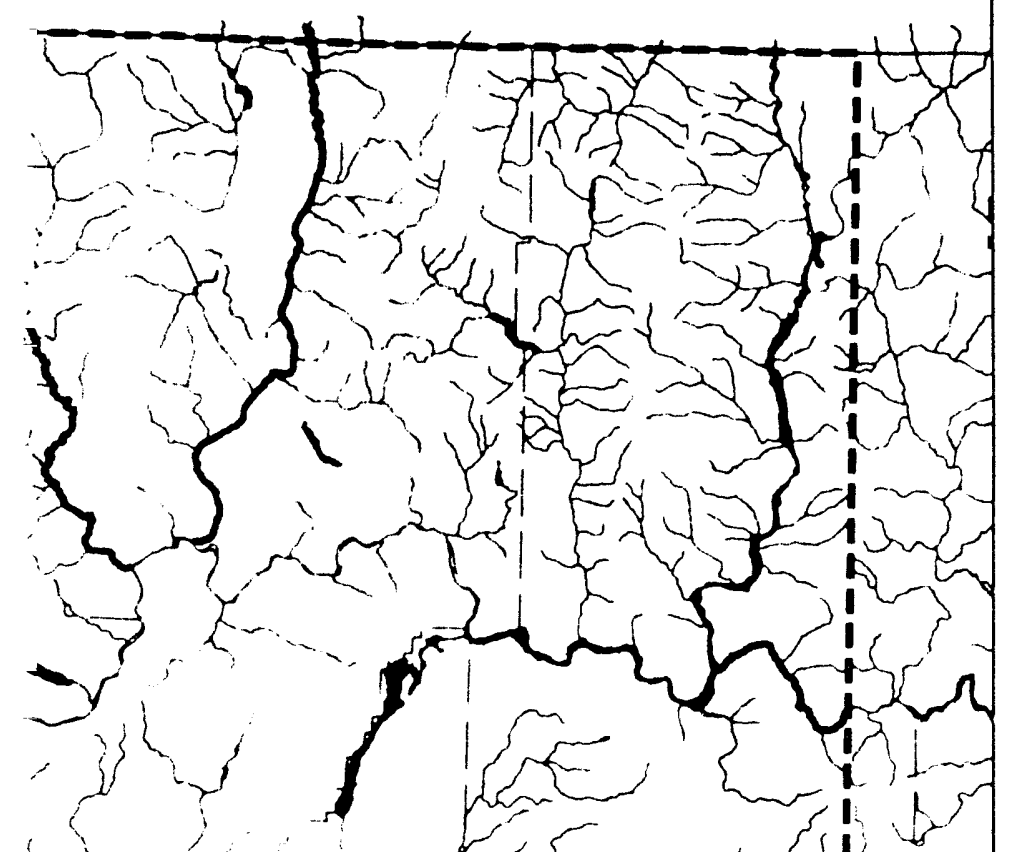

not chese

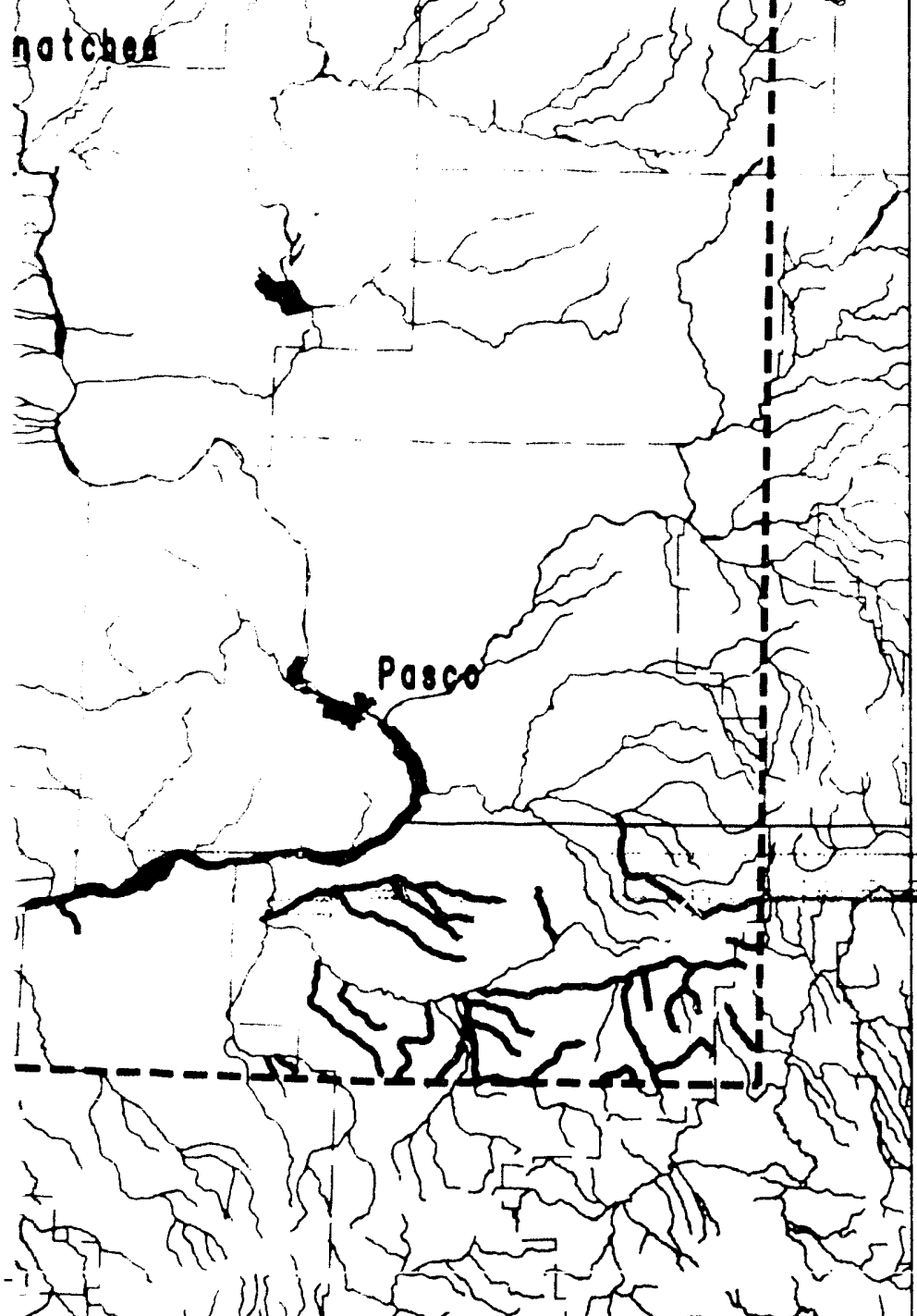

Resident Fish Hobitat
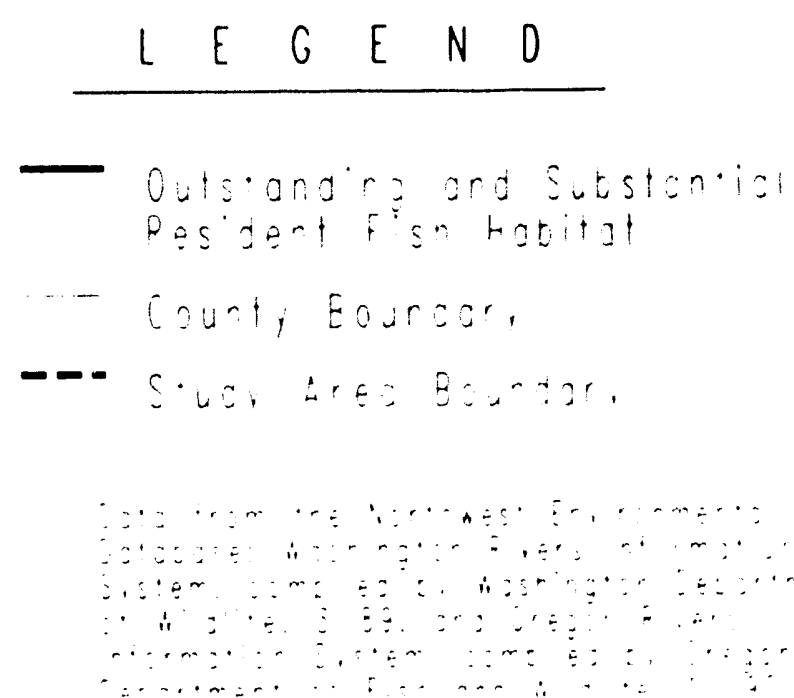


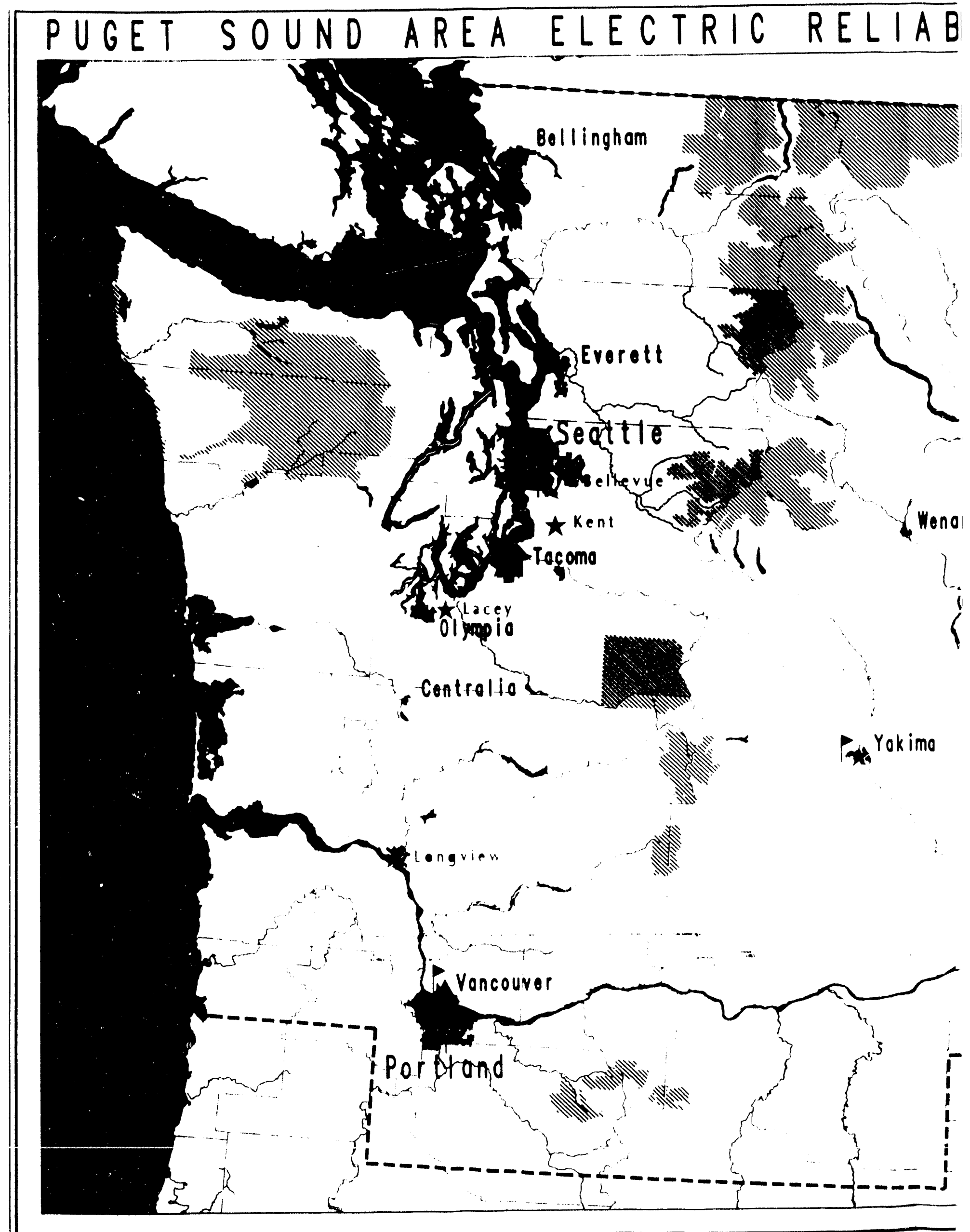




\section{BILITY PLAN}
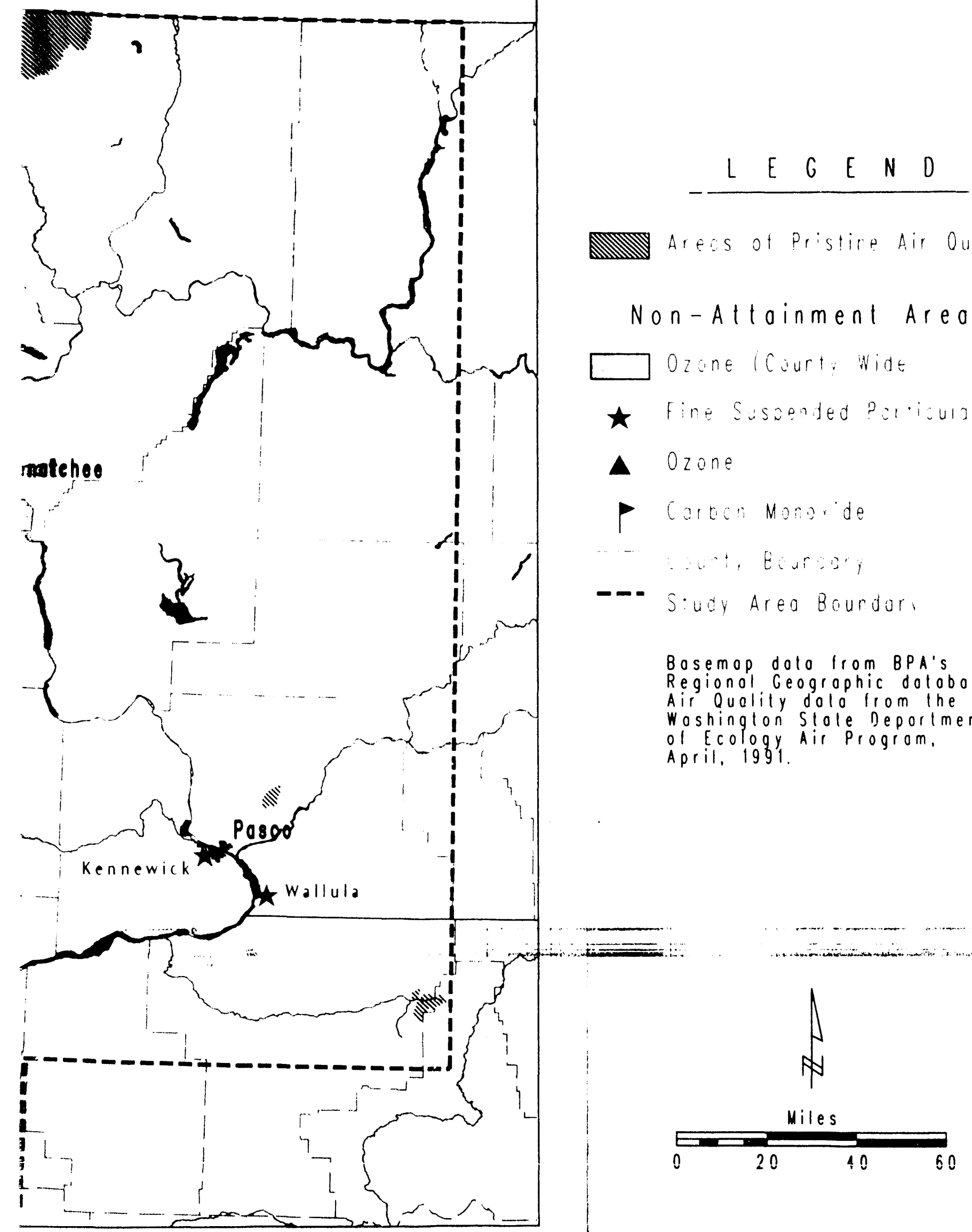

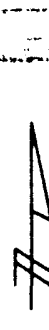

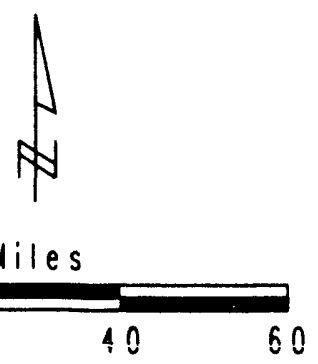

Air Quality

Arecs of pristire Air Oualit.

Non-Attoinment Areos

D Ozane /Court: Wide

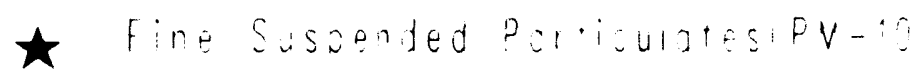

- Ozone

P Cateon Monorde

-- Sildy Area Bourdar.

Bosemop dolo from BPA's

Regionol Geogrophic dolobose.

Air Quality dolo from the

Woshington Slole Deportment

of Ecology Air Progrom.

April, 1991.

Mop 8 
Under normal winter conditions the distribution of high and low pressure centers brings mild and moist air into the area from the southwest. Clouds and persistent rains during this period (October-mid March) are important factors in holding temperatures above the freezing mark. Occasionally, in the winter season, the pressure distribution will result in a southward flow of colder air from Canada. It is under these conditions that the coldest weather usually occurs. The cold temperatures experienced in February, 1989 (termed the Siberian Express) were caused by a southward flow of cold air.

Environmental Hazards - The geological forces that formed the Cascades and the Olympics created an unusual mix of peaks, slopes, valleys, and waters. This study area starts at sea level and climbs steadily to the top of Mt. Rainier. The complex topography has inherent risk. Earthquakes, volcanic eruptions, fiooding, and landslides are possible in the study area. Several environmental hazards are shown on Map 9.

\subsubsection{Economy}

Major Industries - Much of the industrial manufacturing is based on the natural resources of the region. Forests, farmland, the ocean and rivers provide lumber and wood products, paper, and food. The aerospace industry also is very important in the Puget Sound area. Government and service industries such as communications, utilities, trade, and financial services are a large part of the economy.

The economy of the Puget Sound area has recovered from the recession of the early 1980's. Map 10 shows the average annual actual and projected rate of growth in non-farm employment for Washington for 1987-2008. In the Puget Sound area, only Grays Harbor County may experience less than $1.5 \%$ employmerit growth during this period. Some counties in this area may grow up to $2.4 \%$ annually.

The economy of the rest of the study area is, leavily resource-based. The extensive forests provide material for lumber, wood products, and pulp and paper. These industries and others, such as chemical and metal (principally aluminum) production, rely heavily on historically cheap hydroelectric power produced by the water resources of the region. The size and extent of the river systems allow large withdrawals for irrigation, a critical economic factor for agriculture, particularly in central and eastern W'ashington. The Columbia River Basin supports many anadromous fish stocks, a resource important to the Pacific Northwest for the substantial economic value of sport and commercial fisheries. The river systems are also economically important in providing multiple recreational opportunities (including boating, swimming, fishing, and windsurfing) and scenic tourist attractions, including the nationally valued Columbia River Gorge. The river systems provide economic support for trade, as in transporting goods into the interior of the Pacific Northwest.

High technology manufacturing is an important part of the economy, but employment is dominated by service sectors such as communications, utilities, trade, financial services and government. Unemployment rates usually follow the cyclical nature of the region's economy.

Fisheries - The ocean and rivers provide an important resource to the Puget Sound area, namely the large economic value of the sport and commercial fisheries and the high cultural and religious value to Indian Tribes and others.

Demographics - The population in the Puget Sound area is centered in Seattle and Tacoma. The population of Washington has grown from 4.13 million in 1980 to 4.80 million in 1990 , a 16 percent increase. Map 11 shows the annual growth rate for Washington from 1987 10 20(1)8. Population in the rest of the study area is centered in Portland/Vancouver (ORNA), the Tri-Cities (Kichland, Pasco), Kennewick (WA)), and Yakima (WA). Oregon's population has increased $4.2 \%$ in that period (Initial Northwest Power Act Power Sales Contracts DEIS, BPA, 19901. 


\subsubsection{Public Health and Safety}

Power plants and transmission facilities provide electricity for heating, lighting, and other services essential for public health and safety. These same facilities can potentially harm humans. Impacts include injury from contact with transmission lines that can injure birds, people and aircraft, and pollutants produced by power plants and hazardous wastes produced by the normal operation and maintenance of elecrical and generating and distribution transmission facilities and the risk of emergency releases of these substances (spills). Studies are currently being conducted to find whether exposure to electric and magnetic fields can endanger human health. A more complete description of these impacts is in Chapter 4.

\subsubsection{Visual and Aesthetics}

The study area is rich in visual beauty. Large mountains and mountain ranges, forests and the expanse of water in Puget Sound dominate the landscape in the Puget Sound area. Contrasting with the natural beauty are the skyline of Seattle and surrounding urban communities, and cultivated fields and pastureland.

The rest of the study area includes diverse landscape characteristics. Part of the study area borders the crest of the Cascade Mountains, with all the scenic values and variety of an alpine environment. The valleys to the east of the mountains are generally flat and bounded on the east, west, and south by rolling hills. Outside the urban centers, valleys exhibit diverse patterns of color and texure that change with the seasons. Vegetation is mainly open pasture or cultivated fields, broken up by groups of trees, mostly deciduous. Moderate-to-steep slopes are covered with Douglas Fir, oak, and pine.

The Columbia Plateau is generally flat. Large cultivated fields are broken up by rolling hills, gullies and scattered trees. Farmsteads are scattered throughout the fields. The land here has more climatic extremes than west of the Cascades, and these affect the vegetation colors and texture of the landscape.

The Columbia and Snake rivers are the dominant water features within the study area. The Columbia Gorge, with steep basalt cliffs, the wide Columbia River, and large mountains in the background dominate the landscape between Washington and Oregon.

\subsubsection{Noise}

It is difficult to discuss the existing noise environment in this study area because it is site-specific. There are sensitive areas in the study area such as national parks, wildlife areas, and major recreation areas where current low noise levels need to be preserved. Noise from a new power plant or transmission line would need to meet State and Federal standards.

\subsubsection{Protected Resources}

Map 12 shows protected areas such as wild and scenic rivers, nationa! parks, national forests, Indian reservations, wildlife refuges, and other Federal and State management areas.

This map includes rivers designated by the Northwest Power Planning Council as protected. Based on BPA's Pacific Northwest Rivers Study and the Council's Anadromous Fish Study, the Council derignated portions of stream reaches and wildlife habitat in the region that should be protected from new hydroelectric development. 


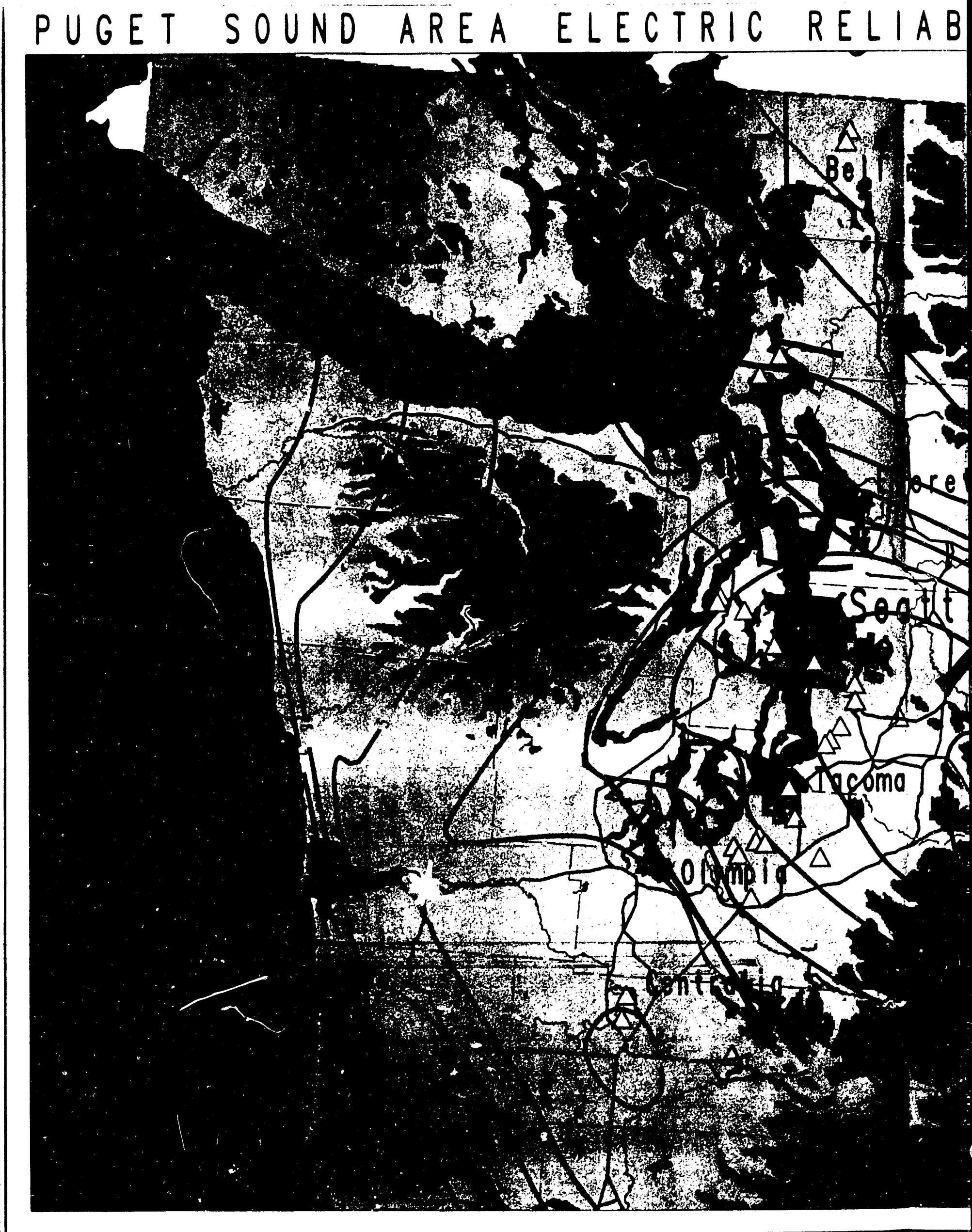




\section{BILITY PLAN}
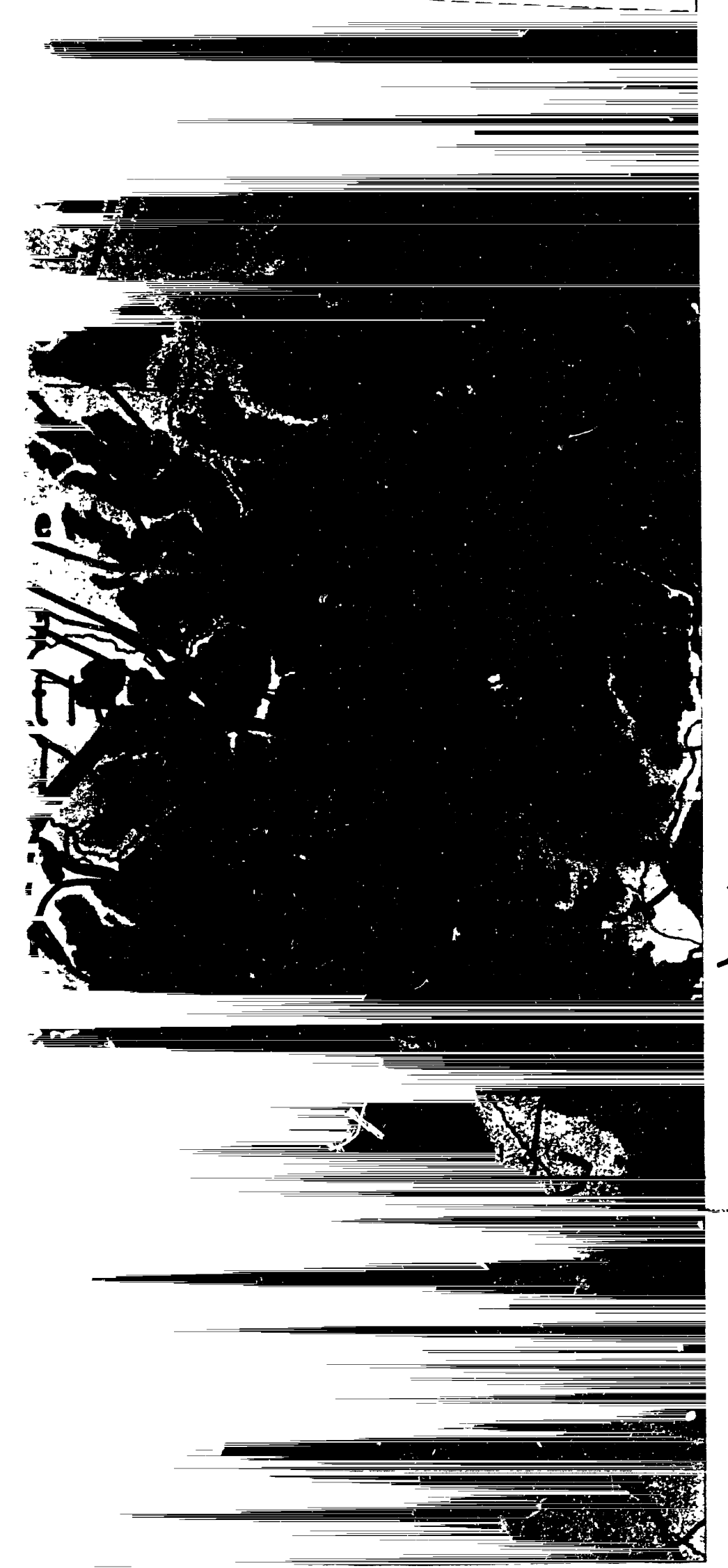

Puget Sound Area Environmental Hazards
50 - 2000 Ft. Elevation

D2000 - 4000 Fi. Elevation

$4000-6000$ Ft. Elevotion

- Above booc $\because$. Eleluction

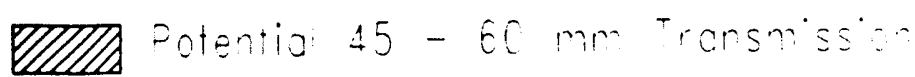
-ine cing

- nferred roul me

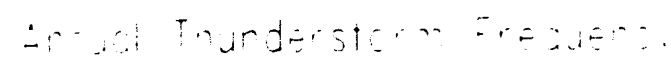

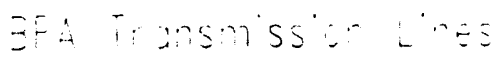

Equ'y Boundary

- - Slldy Area Boundary
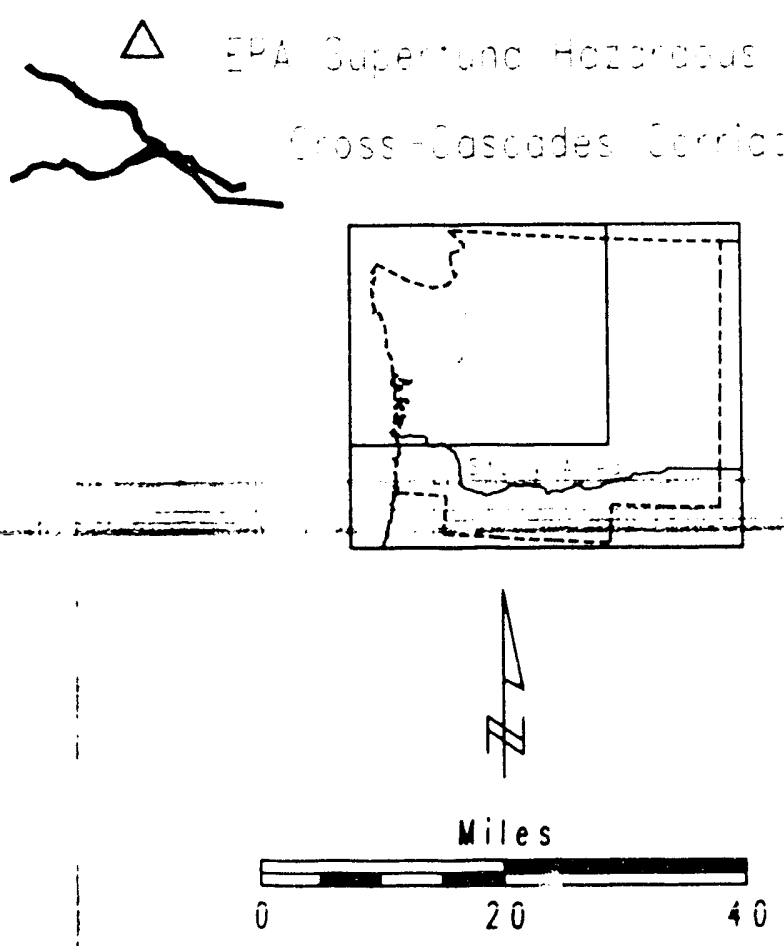


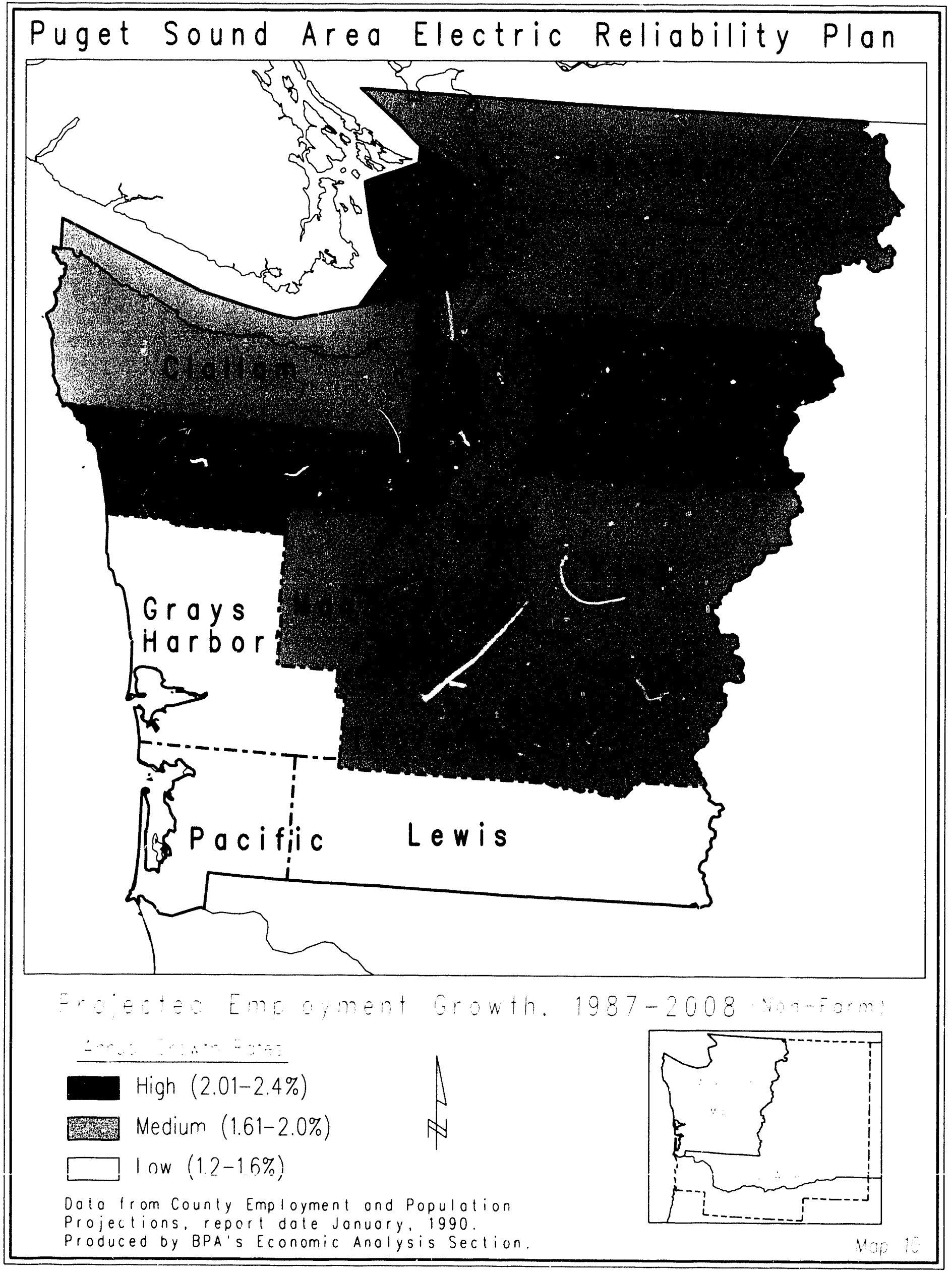




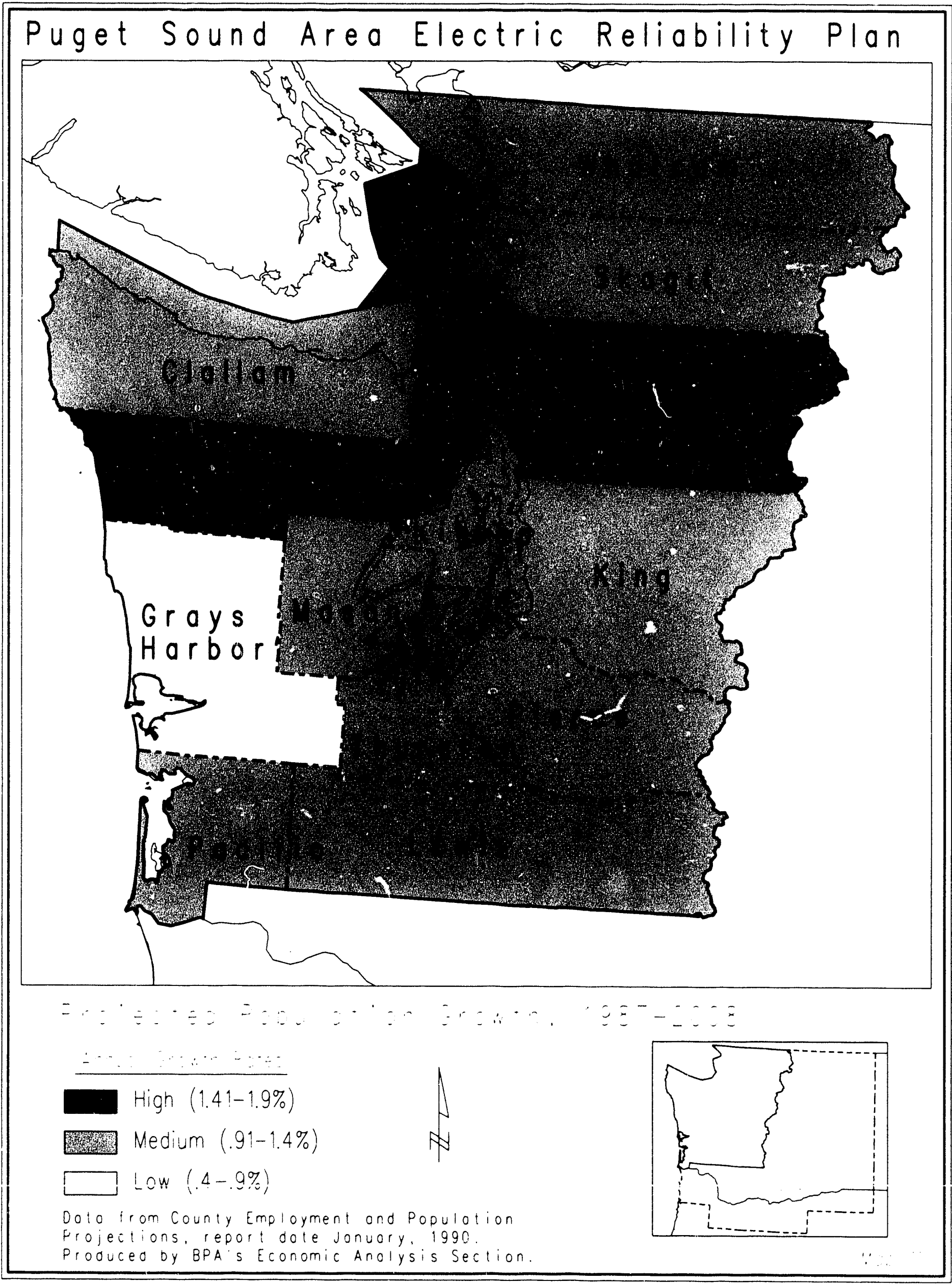




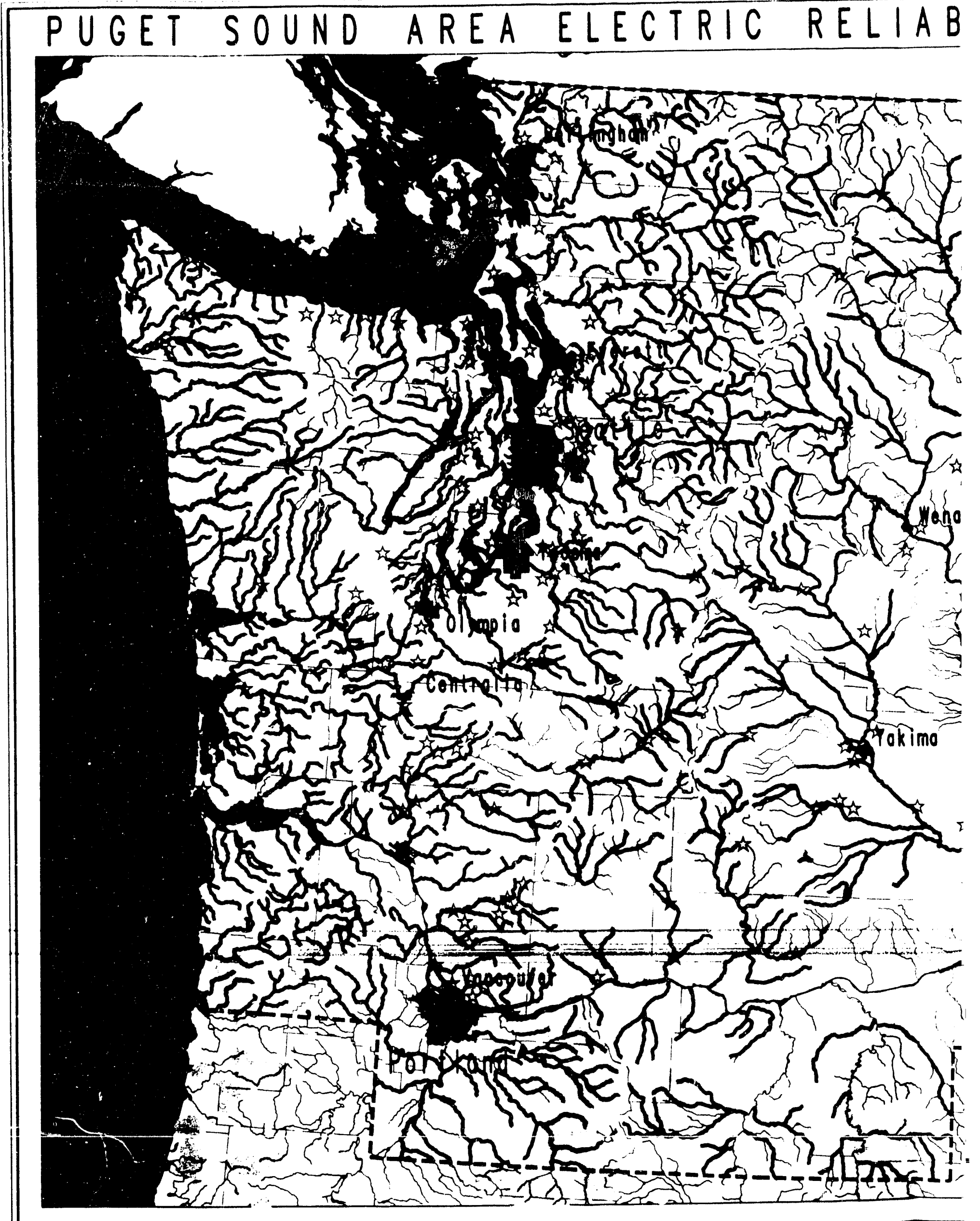




\section{BILITY PLAN}

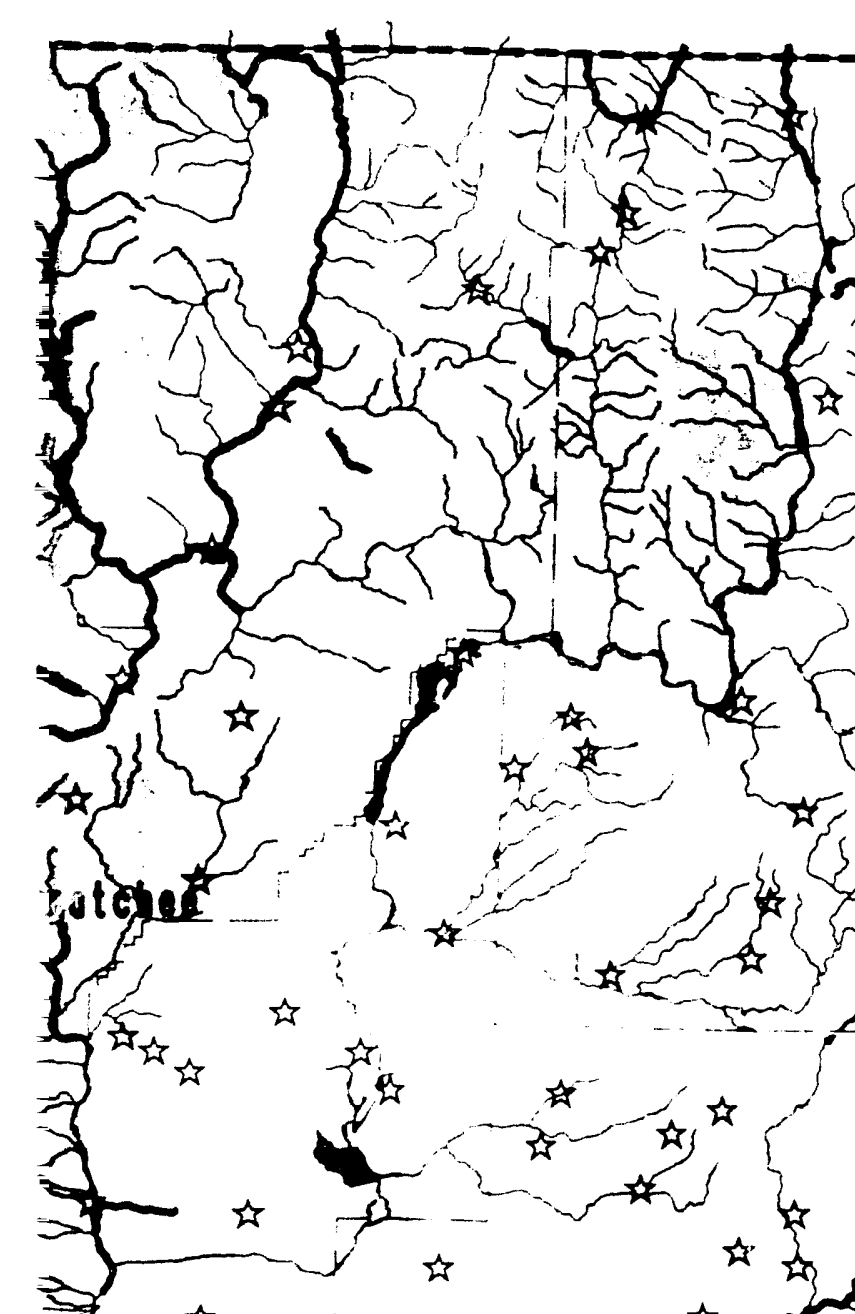

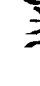

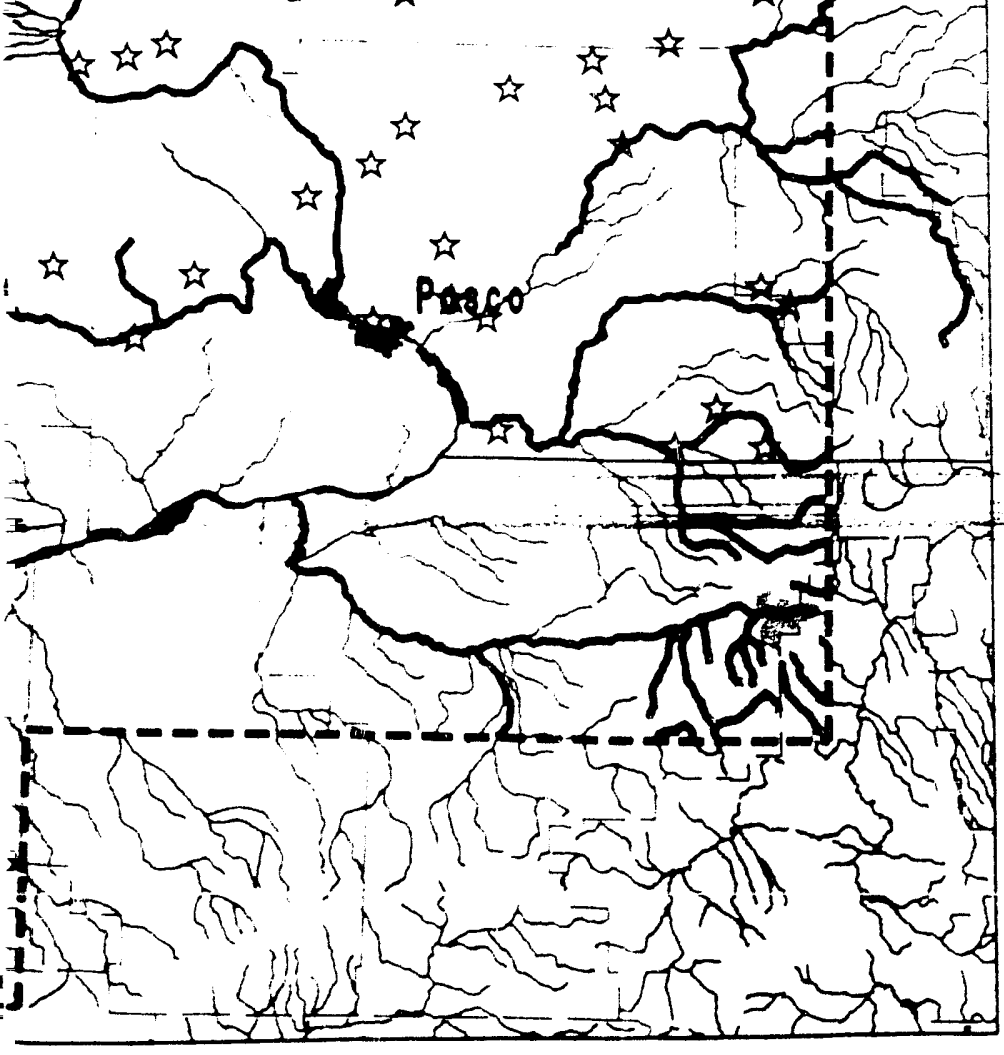

Federal and State Protected Areas

$L E G E N \quad D$ 


\subsection{AREAS POTENTIALLY AFFECTED BY VOLTAGE SUPPORT OPTIONS OR A TRANSMISSION LINE}

A transmission line or Voltage Support Option 2 suggested in some alternative strategies may, if built, require changing land use in specific locations. These locations are unknown, but a general discussion of the environment that could be affected is beneficial. This section describes possible corridors for a transmission line, and locations of substations where voltage support equipment may be installed.

The study area contains an existing transmission grid that brings power from generation resources outside of the Puget Sound area into the area. Potential new or rebuilt transmission lines will most likely be defined by patterns already established by existing transmission lines, and would cross from east of the Cascade Mountains, through a pass to the Puget Sound area. Designated corridors are incorporated into Federal land and resource management plans. BPA, utilities and the USFS and BLM work together to design and plan corridors as part of regular forest and district planning processes.

The Draft Northern Cascades Corridor Availability Study identifies available corridors for utility planning through the Northern Cascades. The study evaluates USFS and BLM land, and private and publir lands for corridors. It provides detailed information on constraints and opportunities for existing and potential corridors. Information on potential cross-Cascade corridors for this EIS were developed from this study.

Poiential connections to bring power from eastern generation resources to the Puget Sound area are shown on Map 1 and described in the following section. For discussion purposes, these corridors are divided into eastern, central, and western segments.

\subsubsection{Alternative Transmission Line Corridor A}

A transmission line in Alternative Corridor $A$ could be a new 500-kV line parallel to an existing line, a rebuild of an existing 345-kV line, or a new line on existing and new corridors. This line would be about 125 miles long. The line could begin at BPA's Chief Joseph Substation on the east, cross the Cascades through Stevens Pass, and end at BPA's Monroe or Echo Lake Substations.

Eastern Segment - The eastern segment is mostly cropland/pastureland and rangeland. There is a small amount of forest land, and orchards, vineyards, and nurseries. Map 13 shows that it is both privately and publicly owned. The State of Washington, the USFS, and the BLM manage the publicly owned land. This section contains existing BPA lines. There are airports and historical sites in or near this segment, and two State Wildlife Recreation Areas. This segment includes key big game habitat and crosses the Entiat River which the Facific Northwest Rivers Study has described as "rivers which should be protected for their resource value." This river has anadromous fish.

Included in the eastern segment of Alternative Corridor A is a potential new corridor from Sickler Substation extending northwest to the existing corridor. This corridor is shown on Map 1. The section from Sickler Substation to the eastern segment boundary includes the following land uses: residential, transportation, other urban or built-up land, cropland/pastureland, orchards, vineyards, nurseries, rangeland, forest land and reservoirs. About twenty percent of this land has been identified as key big game habitat. This corridor also includes Lincoln Rock State Park adjacent to and between Sickler Substation and the Columbia River.

Central Segment -- This corridor contains two BPA transmission lines (double-circuit 345-kV, 500-kV), a Chelan County PUD line $(115-\mathrm{kV})$, and a railroad. The corridor passes through three valleys, which vary from 1/ 4 mile to 1 mile wide. Map 13 shows that most of this segment is National Forest land. Other public or private idnd composes the rest of this segment. Of the Natıonal forest land, about one third is classified as avoidance areas, including some "Spotted Owl Habitat," and scenic and recreation areas. An avoidance area has 
significant resource values which cannot be successfully mitigated and should be avoided for transmission or utility corridors. About one fourth is non-avoidance areas. Non-avoidance areas are suitable for transmission or utility corridors because resources there are of lessor significance than those found in avoidance areas, and impacts can normally be mitigated. Other management areas include potential Wild and Scenic Rivers, waterways identified in the Pacific Northwest Rivers Study as "rivers which should be protected for their resource value," and the Stevens Pass Historic District. The Pacific Crest Trail also crosses this segment. The $\epsilon$ are two airports along this segment, and two State Parks. Some of these sensitive areas could be avoided. There are also engineering constraints for this segment, including proximity to buildings and residences, rugged terrain with steep slopes, wetlands, and heavy icing in one area.

This central segment includes parts of two new corridors. These corridors are shown on Map 1. The first new corridor is the continuation of the new corridor from Sickler Substation discussed in the eastern segment section. Nearly all of this portion of this new corridor is National Forest land. The remaining land is cropland/pastureland and rangeland. This corridor contains key big game habitat. This corridor also includes scenic areas that should be protected.

The second new' corridor begins about 29 miles east of Monroe Substation and heads toward Echo Lake Substation. This, too, is mostly National Forest land. Included in this forest land is wilderness area, scenic areas, Mountain Goat habitat, and mature old growth timber. This new corridor includes some protected rivers where anadromous fish are present, and seven miles of Wild and Scenic river. It also includes outstanding and substantial resident fish habitat. The private or other public land is residential, other urban or built-up land, reservoirs, mines and quarries, or forest land.

Western Segment - The western segment includes using an existing corridor from the central boundary to Monroe Substation, and new corridor from this boundary to Echo Lake Substation. Map 1 shows the boundaries of these corridors in this segment.

Map 13 shows that the existing corridor into Monroe Substation is mostly private land. This private land is residential, cropland/pastureland, forest land, or mines, quarries, and gravel pits. Almost half of the land is owned by the State of Washington, and includes all the same land uses as the private land. National Forest is less than one percent.

The new corridor into Echo Lake Substation from the central boundary is almost entirely private land. Other land is owned by the State. Land use in this corridor is mostly forest land, with other residential, commercial and industrial, other urban or built-up land, cropland/pastureland and quarries as the other land uses. This portion of the corridor also includes a municipal watershed which serves the Seattle area, some protected rivers where anadromous fish are present, and outstanding and substantial resident fish habitat. About four river miles have significant historical features. One airport is in this corridor.

\subsubsection{Alternative Transmission Line Corridor B}

Alternative Corridor B is about 25 miles south of Alternative Corridor A (see Map 1). It also could begin at Chief Joseph Substation, then travel southwesterly and cross the Cascades through Snoqualmie Pass. This alternative offers the option of a new line parallel to existing lines, or a rebuild of the existing $345-\mathrm{kV}$ line to $50(0) \mathrm{kV}$. An eastwest line using Corridor B would be about 130 to 150 miles long, depending on the route.

Eastern Segment - The eastern segment of this line would follow the same route as Alternative Corridor A from Chief joseph Substation io Sickler Substation. These routes are described under Alternative Corridor A. from Sickler Substation the line could go two directions: follow existing lines toward Naneum, or follow a new corridor. Following existing lines would cross cropland and ranged and both puthlirly and privately owned following the new corridor in this segment would cross mostly vational forest land. 


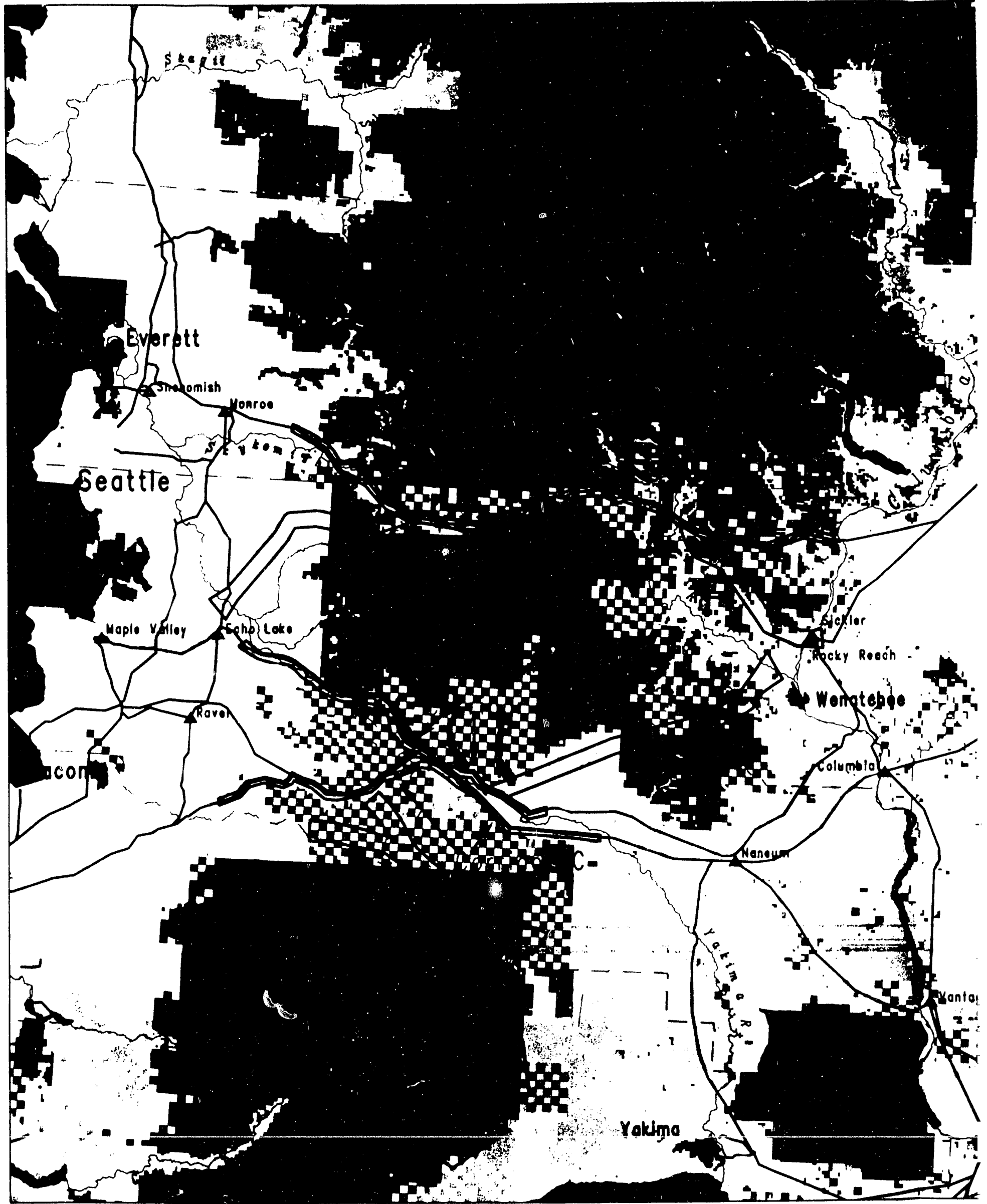




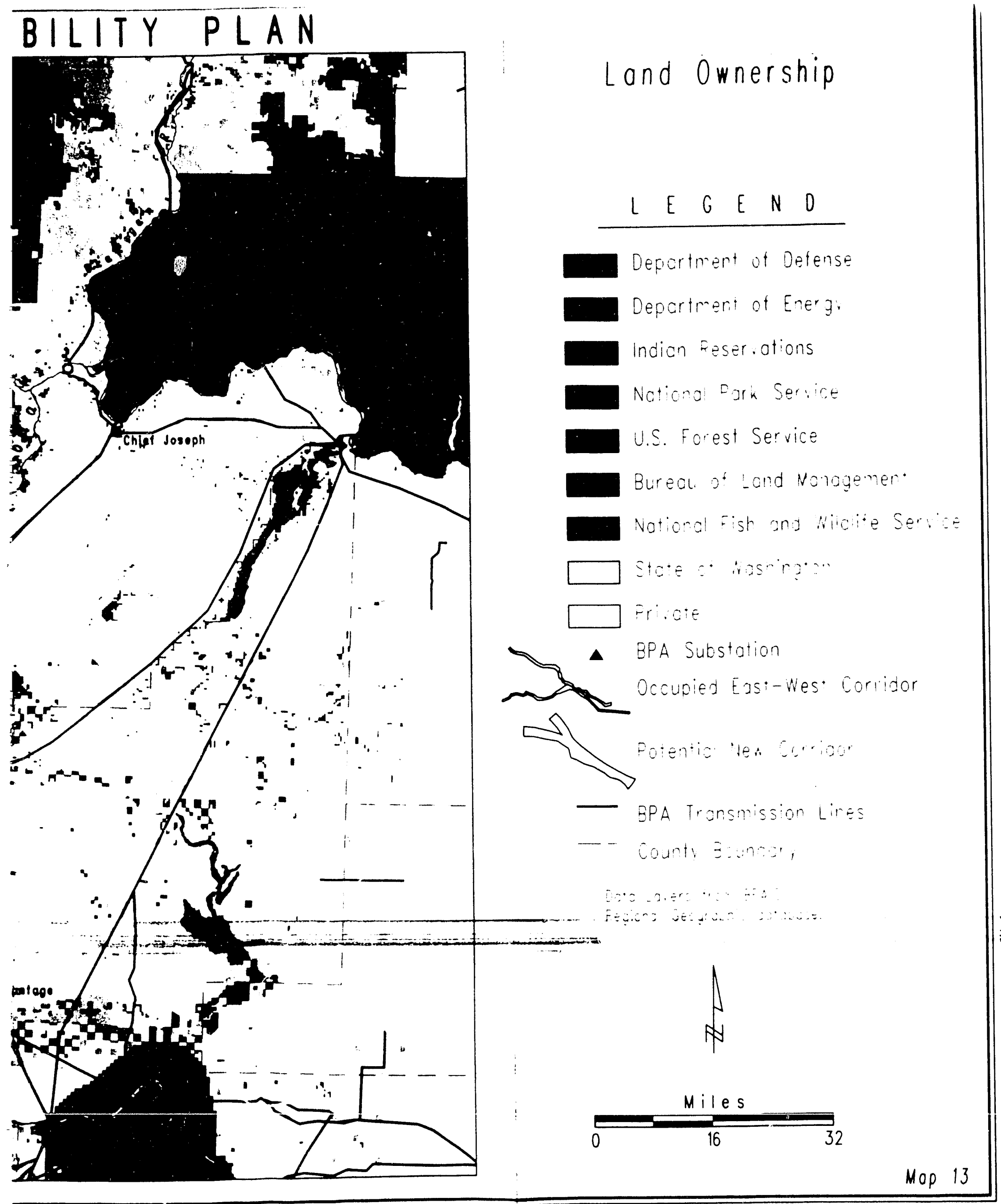


Central Segment - This potential corridor through the Cascades is about 45 miles long. This corridor contains a BPA transmission line $(345-\mathrm{kV})$, and a Puget Sound Power and Light transmission line $(115-\mathrm{kV})$. The corridor goes through valleys varying from $1 / 2$ mile to 2 miles wide, with varying moderate to steep slopes. Map 13 shows that about half of this segment crosses National Forest land. About one third of this land is classified as avoidance areas, and includes "Spotted Owl Habitat," and scenic areas. About one fourth is classed non-avoidance areas.

The other half of this segment is other public or private land. It includes some land classed as avoidance areas. These include the Yakima River, which is a "Potential Wild and Scenic River," waterways identified in the Pacific Northwest Rivers Study as "rivers which should be protected for their resource values, "two State Parks, a National Trail, the Pacific Crest National Scenic Trail, and two airports. Mitigation would need to be considered for these avoidance areas, and some areas must be avoided.

A portion of one of the alternatives for a new corridor is in this segment. It is mostly forest land, privately or publicly owned. Map 1 shows the portion on this corridor in this segment.

This segment also has some engineering constraints, including buildings and residences along the corridor in some areas, snow avalanche paths west of Snoqualmie, and wetland areas.

Western Segment - This segment is owned mostly by the State of Washington or private parties. The land use is mostly forest land, with some urban or built-up land.

\subsubsection{Alternative Transmission Line Corridor C}

Map 1 shows that Alternative Corridor $C$ is located immediately south of Corridor B. From the Puget Sound area, the corridor passes through the Green River and Sunday River valleys, over Stampede Pass, down along the south side of the wide Yakima River Valley, and east past Cle Elum. The corridor carries BPA transmission lines (two single-circuit 500-kV, a 500-kV double circuit, and a $287-k V$ double circuit), one Puget Sound Power and Light transmission line (230-kV single circuit), and a railroad. An east-west transmission line using Corridor $C$ would be about 150 miles long, depending on the route. The terrain along the corridor tends to be flat to rolling, except through Stampede Pass, where the valley is narrow, with steep side slopes.

Eastern Segment - The land use of this segment is similar to the eastern segment of Corridor B. However, this segment has no new corridor. This segment includes one airport.

Central Segment - Most of this segment crosses National Forest land. The forest land is divided into avoidance or nonavoidance areas. This segment contains some "Spotted Owl Habitat," and "Scenic Travel" areas. The Green River Municipal Watershed is in this segment. It also contains deer and elk winter range. This corridor crosses the Yakima River which is classified as a "Potential Wild and Scenic River." Green River and Sunday Creek are waterways identified as "rivers which should be protected" in the Pacific Northwest Rivers Study. Two historical sites are in this segment, and the Pacific Crest Trail crosses the corridor around Stampede Pass. This segment contains two airports. This segment contains an area of concern for reliability. With so many high-voltage transmission lines in one corridor, a major disaster such as an avalanche or earthquake could knock out more than one line at once.

Western Segment - The western segment is a mix of publicly and privately owned forest land.

\subsubsection{Proposed New Substation}

In 1978, BPA prepared an environmental analysis on a 50 J-kV switching station called kittitas Switching Station. At that time, this facility was designed to prevent ovcriloading on the Rocky Reach-Columbia and ColumbiaVantage 230-kV lines. The station was never built. As dec cribed in Section 2.3.3, BPA is again proposing to build a $500-k V$ substation in the same area but as part of Alternative Strategy 2. 
The siting area is shown on Map 14. Four locations have been proposed approximately ten miles north of Ellensburg, in Kittitas County, Washington. The site will be approximately $1500^{\prime}$ by 1.500$)^{\prime}(.52$ acres) and located as much as possible within the transmission corridor right-of-way.

Because of low annual precipitation, the climate is generally considered to be semi-arid. The landscape for the most part is relatively flat with gradual slopes occurring nearer to the creeks. Wilson and Naneum Creeks located closer to the eastern boundary of the siting area run south towards the Yakima River. Both creeks run year around but are quite small. Reecer Creek, located more to the west of the siting area, also runs year around. A canal flows mostly east-west through the siting area and is used for irrigation. Intermittent drainage systems are apparent throughout the siting area.

Land use within the siting area consists mostly of forest land, rangeland and agricultural land. Potential sites are located only on privately-owned rangeland and the transmission right-of-way. Residential land use occurs within the siting area but not within the boundaries of the proposed sites.

Vegetation consists of bunchgrass, sagebrush, rabbitbrush, bitterbrush, and hopsage. Riparian vegetation and any potential for wetlands exists along Wilson or Naneum Creeks to the east, far away from potential sites. The creeks are also home to fish, waterfowl, furbearers, deer and elk. The remaining parts of the siting area are home to upland birds, insects, and snakes.

A more complete description of the affected environment is given in Appendix $G$. 


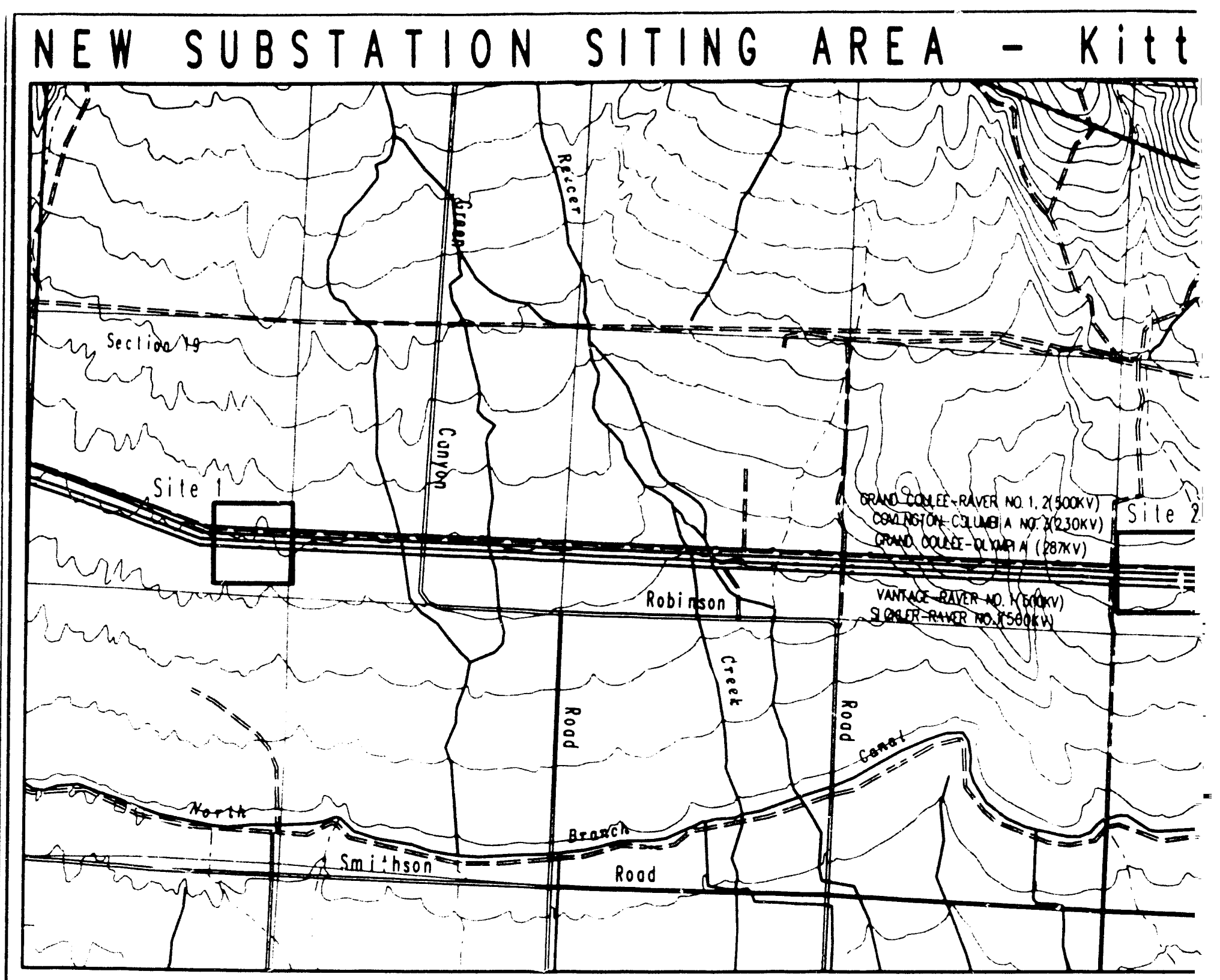

Legend

- Pered Rood

- Dirt Rood

Seciion Boundories

- Surface Hydrology

- 40 Foot Contour Intervals

BPA Transmission Lines

- Potential Substation Site 


\subsection{ENVIRONMENTAL CONSEQUENCES}

This chapter evaluates the environmental, technical and economic qualities of a preferred and alternative strategies to strengthen the reliability of the cross-Cascades transmission system. A No Action Alternative is also evaluated.

To aid in understanding trade -offs among the strategies, consequences are discussed under two headings: Environmental Evaluations; and Economic and Technical Evaluations. Impacts attributed to a strategy can often be mitigated. Mitigation measures are described under the heading, Mitigation Potential. Finally, contingencies are built into the strategies enabling them to expand or contract as conditions demand. The contingencies for each plan vary somewhat depending on what has already been included in the strategy and the lead times required to install a contingency measure. Contingency measures and their likely impacts are discussed under the heading, Contingency Impacts.

The analysis conclusions stated in the following pages were extracted from the Environmental Analysis Appendix F, and the Economic and Technical Evaluation - Appendix C. Reviewers interested in evaluations for measures not included in strategies are directed to these appendices.

The following discussion explains the study approach and the goal of this decision making phase.

Decision Making Strategy - Early in the planning stage (September, 1989), a two-step decision making strategy was established for the Puget Sound Area Electric Reliability Plan. The first step (this EIS) evaluates alternative strategies by which the underlying need could be met. The intent of this step is to evaluate the widest possible range of solutions, and lead to selection of a regional solution plan. The first step considers impacts on what might be termed a generic level because proposals would not in most instances be site-specific. The second step would be to review measures in the selected plan and determine if follow-up site-specific EIS's or other documents should be prepared. To avoid duplication, follow-up site-specific EIS's or Environmental Assessments (EA's) would be prepared to meet both the requirements of Washington's State Environmental Policy Act (SEPA) and the National Environmental Policy Act (NEPA).

As the study progressed, alternative solutions became more clearly known. When the Steering Committee met to select a Preferred Alternative for the Draft EIS in July, 1991, it appeared that the primary component of the preferred alternative (Voltage Support Option 2) would have relatively low environmental impact. For example, new substations typically require Environmental Assessment coverage and yield Findings of No Significant Impact. It was decided to take additional time and provide site specific environmental coverage on Voltage Support Option 2 reducing the lead time by two years while avoiding unnecessary administrative complexity. Implementing Voltage Support Option 2 two years sooner was desirable because Puget Sound area load growth continues to exceed the medium-high forecast. Thus, site specific coverage has been provided for Voltage Support Option 2, both within this EIS and within Appendix G. This measure, if a part of the plan recorded in the Record of Decision, would be implemented without supplemental (second step) environmental review.

Environmental Impact Definitions - Analysts evaluated individual measures and alternative strategies using a scale with four impact levels. The high impact level means taking an action would create a significant adverse change in present environmental conditions. A significant adverse change in present environmental conditions would satisfy one or all of these outcomes:

1. Create an effect that cannot be mitigated.

2. Significantly reduce the quantity or quality of a regionaily or nationally significant resource.

3. Pose a clear risk to human health or safety. 
Puget Sound Area Electric Reliability Plan - Draft Environmental Impact Statement

4. Affect the long-term productivity of the affected environment.

5. Irreversibly or irretrievably damage the environment.

6. Consume significant quantities of non-renewable natural resources.

An action with a moderate impact level would create a significant adverse change in present environmental corditions by one or more of these outcomes:

1. Create an effect that could be mitigated partially.

2. Cause a localized reduction in the quantity or quality of a resource.

3. Create a possible, but unlikely risk to human health or safety.

4. Reduce marginally the productivity of adjacent resources.

5. Removing the facility or stopping the action can partially reverse the impacts.

6. Consume small but not negligible amounts of non-renewable resources.

A low impact action would create a significant adverse change in present environmental conditions by one or more of these results:

1. Create an effect that could be largely mitigated.

2. Reduce the quantity or quality of resources confined to the site of the action.

3. Create insignificant or very unlikely health and safety risks.

4. Cause no effect on productivity of adjacent resources.

5. Removing the facility or ceasing the action will reverse the impacts.

6. Consume negligible amounts of non-renewable resources.

A minimal or no impact action creates no or fewer impacts than the low impact level.

Assumptions Drive Evaluations - Analysts used the key assumptions discussed in Chapter 1 for the environmental analysis and the evaluation $\mu$. xess. The appendices contain additional assumptions used.

\subsection{PREFERRED ALTERNATIVE}

To hasten improved electric reliability, and focus public discussion on the potential solutions, a preferred alternative was identified by the five-utility Plan Steering Committee with advice from the Sounding Board, a citizen review panel.

In choosing a preferred alternative several qualities were looked for by the Steering Committee beyond the normal criteria such as environmental suitability, cost, and technical performance. Adaptability in view of such uncertainties as higher than medium load growth, Canadian entitlement return, local generation development or decommissioning, Endangered Species Act listings, and electromagnetic field health effects was one such desired quality. This flexibility was felt best achieved by identifying contingency measures to be taken if one or more of the above events becomes a certainty.

A second quality that the Steering Committee was sensitive to was the need to regularly review the electric reliability of Puget Sound and update the plan when conditions warrant it.

Finally, it was recognized that utilities are moving in new directions and that demand reduction pilot projects in water heater load control and fuel switching will provide useful information on costs, benefits and the deliverability of these measures. Thus, the Puget Sound Area Electric Reliability Plan may be changed to take advantage of these and other technological developments as a part of the periodic review and updating process. 
Measures Included in the Preferred Alternative - The Preferred Alternative is a hybrid of Alternative Strategy 2. Alternative Strategy 2 ranks first in all evaluation factors except environmental impacts where it ranks a close second. It includes the common elements of all the strategies: accelerated conservation programs in the residential, commercial, and industrial sectors, a high-efficiency shower head program, and Voltage Support Option 1.

The preferred alternative also proposes a second voltage support element, Voltage Support Option 2. Voltage Support Option 2 involves construction of a new substation in the area where four existing 500-kV transmission lines converge near Ellensburg, in Kittitas County, Washington. Refer to discussions within Alternative Strategy 2 for a detailed description of these measures and their impacts. See Chapter 3 for a discussion of possible sites for the new substation.

The Preferred Alternative proposes continued efforts by the region's utilities in demonstration fuel switching and water heater load control programs. These programs and their impacts are described under Alternative Strategy 3.

While Voltage Support Option 2 is expected to create $600 \mathrm{MW}$ of surplus capacity in 2003, the uncertainties listed above have the potential for increasing the transmission capacity deficit by several thousand megawatts. Thus added contingency measures were defined for the Plan. One contingency action proposed is to begin environmental and permitting work for a cross-Cascade transmission line by the fall of 1993. Such work would need to begin at this time due to the long lead time required for a transmission line. A second contingency proposed in the preferred alternative is development of additional combustion turbines. Combustion turbines could be built at existing sites or advanced environmental and permitting work could be undertaken at new sites by the region's utilities. Combustion turbines enable a quick response to a sudden increase in the deficit. A third contingency would be load curtailment contracts. An analysis of environmental, economic and technical attributes of the contingency options is provided within discussions for Alternative Strategies 1-4. it is important to keep in mind that contingency actions are provisional proposals which would not be taken unless conditions required. In the above contingencies, supplemental site specific environmental coverage would most likely be needed.

\subsection{ALTERNATIVE STRATEGY 1 - TRANSMISSION LINE}

This strategy uses measures common to all strategies: accelerated conservation, and Voltage Support Option 1. In addition, a new high-voltage transmission line to transmit power from generation resources east of the Cascade Mountains to the Puget Sound area would be built. Individual measures that are part of this strategy are discussed first. Possible mitigation, and impacts of contingency measures follow. Figure 4-1 shows the impact ratings for this strategy.

\subsubsection{Environmental Evaluation}

\section{Direct Impacts-Conservation Measures}

For this analysis, the conservation considered is from accelerated, voluntary programs. The impacts considered are the additional impacts attributed to these accelerated programs. The residential conservation measures applied are residential weatherization and high-efficiency shower heads. Commercial conservation measures applied are weatherization, and refrigeration and lighting improvements. Industrial conservation measures considered are motor efficiency, lighting, and process efficiency improvements. The impacts of raw material production for, and manufacturing of, conservation products are assurned to be negligible. 
Figure 4-1 shows the environmental evaluation factors and individual rankings for conservation measures. Residential and commercial conservation measures have low impacts to health and safety. Industrial conservation measures create minimal impacts.

Figure 4-1.

Environmental Impact Evaluation Matrix - Strategy 1

\section{Impact Evaluation Matrix}

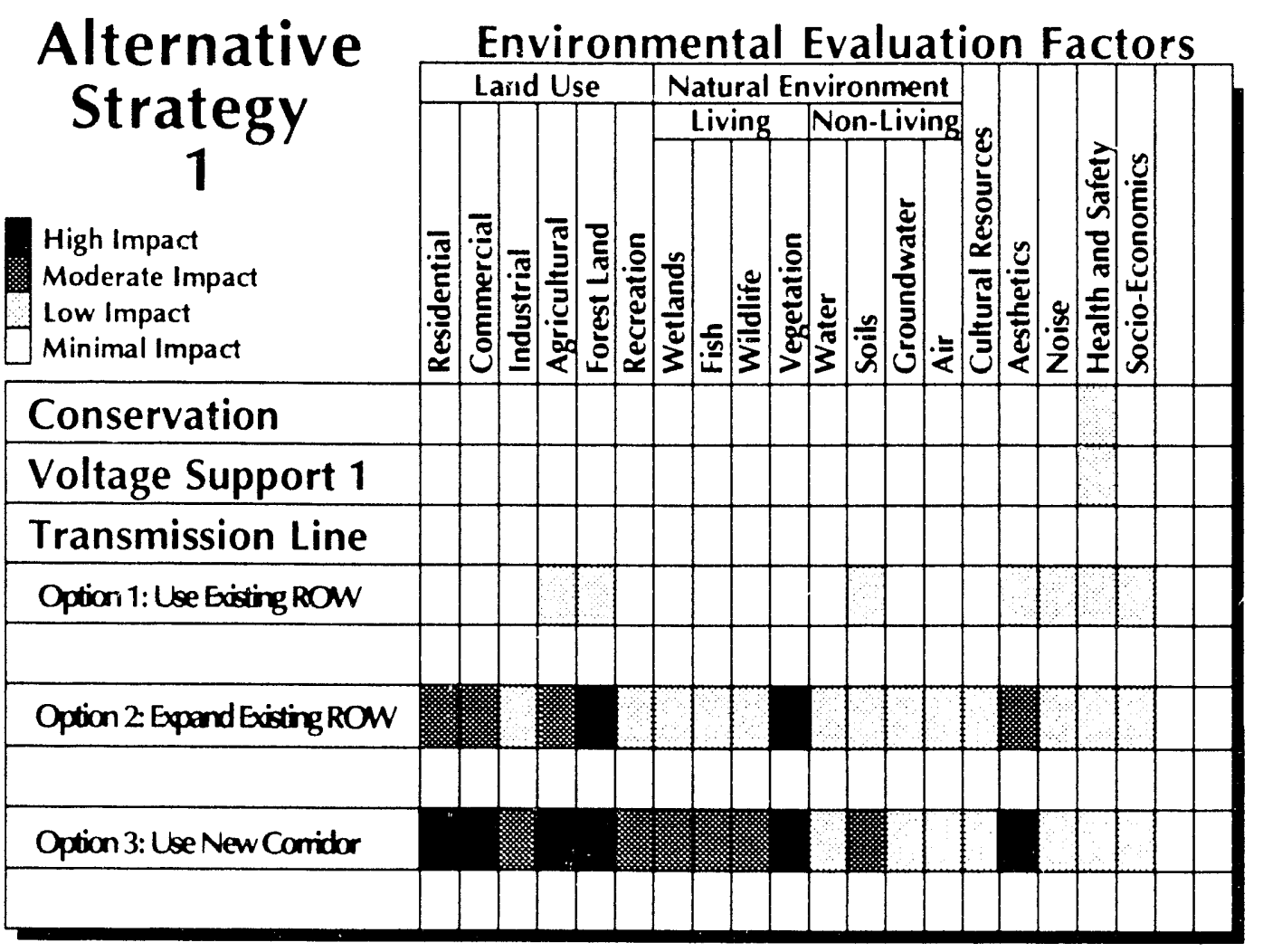

Health and Safety Impacts - Conservation measures can lead to negative impacts on indoor air quality. Conservation measures reduce air leakage and prevent warm air from escaping outdoors. As air leakage decreases, indoor air pollutants may increase. Formaldehyde, radon, and combustion by-products are of most concern. Excessive moisture or humidity can stimulate molds and mildew. Inhalıng higher than normal concentrations of indoor air pollutants can cause minor heaith problems such as headaches and sore throats, and major problems such as an increased chance of lung disease. Pollutants can be reduced by avoiding pollutant sources, controlling an existing source, and removing pollutants with ventilation. Some compounds used in insulation may contribute to depleting the ozone layer shielding the earth. 


\section{Direct impacts - Voltage Support Option 1}

Shunt capacitors will be added at Echo Lake Substation which is now under construction. The impacts of placing a facility at this location were described in a 1974 supplement to BPA's Environmental Statement Fiscal Year 1975 Proposed Program, called "Facility Location Supplement for Maple Valley 500-kV Reinforcement Study Area 75 -14." A recent determination has been made that further environmental analysis is not needed. The Record of Decision is published in Federal Register Vol. 56, No. 92, May 13, 1991.

The substation has adequate space within its fenced yard for the capacitor equipment. No land acquisition or yard expansion will he required. Amounts of materials required for voltage support additions are small. Impacts from producing and manufacturing them are considered negligible.

Health and Safety Impacts - Increasing loads on existing lines may slightly increase magnetic field levels. Electric and magnetic fields are fields of force caused by electric voltage and current respectively. There is controversy about the possible health effects of electric and magnetic fields produced by transmission lines. Other than snocks, no health effects are definitely known to be caused by the fields created by electric power lines, but studies suggest the possibility of adverse effects. BPA is continuing to study these potential health and safety effects.

Groundwater impacts - Shunt capacitors are comparable in size and shape to the rectangular shaped 5-gallon gas cans attached io recreational vehicles. They are filled with a plastic and metallic material that is soaked with insulating oil (less than five gallons). Large numbers of capacitor units are installed on steel racks and electrically connected to the transmission system. In the event of a capacitor failure, a small amount of insulating oil could spill onto the substation yard. The chance of ground or surface water contamination is considered minimal because the volume of oil is small and BPA design standards require installation of liners below the surface of the substation to collect oil should spills occur. Any capacitors used will not contain materials that if spilled would be classified as dangerous waste under the Washington Administrative Code (WAC).

\section{Direct Impacts - Transmission Line}

A double-circuit 500-kV transmission line similar to the Grand Coulee-Raver line is assumed for this analysis. Portions of this line that cross mountain passes are assumed to be either built beside existing lines, which would require expanded right-of-way, or, after an existing line or lines are removed, built on existing right-of-way.

Remaining portions of the line could require builc'ing in new corridors although development of new corridors would be minimized. The eastern and western terminals for a new line would be at existing or planned BPA substations. A list of transmission line and substation components is provided in Table 4-1. These materials are commonly used within the electric power industry and are acquired competitively. The environmental screening factors to avoid protected sites and unique habitats and to meet environmental quality requirements are assumed to be applied to transmission line proposals, which will reduce environmental impacts. 
Puget Sound Area. Electric Reliability Plan - Draft Environmental Impact Statement

Table 4-1.

\begin{tabular}{|l|l|}
\hline \multicolumn{2}{|c|}{ Transmission Line Material Requirements } \\
\hline \multicolumn{1}{|c|}{ Transmission Line } & \multicolumn{1}{c|}{ Substation Terminals } \\
\hline Tower Steel - 24,000 Tons & Substation Dead Ends (steel) \\
\hline Conductor - 1800 miles (steel and aluminum) & Bus Tubing (aluminum) \\
\hline Overhead Ground Wire - 300 miles (steel) & Bus Pedestals (steel) \\
\hline Insulators (glass and porcelain) & Diconnect Swilches \\
\hline Hardware (steel and aluminum) & Power Circuit Breakers \\
\hline Access Road Surfacing (rock) & Electronic Relays \& Controls \\
\hline & Ground Wire (copper) \\
\hline & Footings and Supports (concrete and steel) \\
\hline & Switchyard Surfacing (rock) \\
\hline
\end{tabular}

Land Use Impacts - Land use impacts are directly related to the amount of new and existing rights-of-way affected. Building a transmission line with new corridor segments could have a high impact to residential, commercial, agricultural, and forest land because new line segments would intrude on existing land use. In residential and commercial areas, noise, electrical interference, and visual impacts would be long term. Agricultural land would be removed from production for tower sites and access roads, and structures could interfere with farming operations. Forest land would be removed from production for the right-of-way and for access roads. Impacts to industrial and recreation land would be moderate. Transmission lines may cross trails and intrude on scenic views. A transmission line may be more compatible with industrial land use.

A transmission line using expanded or existing right-of-way segments would create fewer land use impacts, and is ranked accordingly. Impacts are either moderate, low, or minimal for all land use types, except an expanded right-of-way would have a high impact on forest land.

Wetlands Impacts - New corridor segments create moderate impacts to wetlands. Wetlands may be affected during construction of structures and access roads, and vegetation may be removed. Expanding a right-of-way would have less impact as the habitat close to the existing right-of-way has already been disrupted. Using existing right-of-way decreases potential wetlands impacts.

Fish Impacts - During construction, acrelerated runoff can increase sediments in streams and affect fish. These impacts would be temporary. Long-term impacts are minimal to moderate depending on the amount of new right-ofway needed. If a line is replaced, the impacts to fish should not increase. Impacts may increase if the right-of-way is expanded. This depends upon location and placement of towers in proximity to streams. The relative impact of disturbing a pristine environment if a new corridor is built is even higher, depending on the location and placement of towers. Use of pesticides to clear vegetation could also impact fish. 
Wildlife Impacts - Impacts to wildlife from new corridors could be moderate. Birds may collide with the new line. Right-of-way clearing changes the habitat for wildlife and increases access for hunters. Expanding existing right-of-way would create low impacts to wildlife during construction and change some habitat permanently. Using existing right-of-way would impact wildlife during construction only.

Vegetation Impacts - Clearing new and expanding existing rights-of-way can create high impacts to vegetation. Existing vegetation is removed, and vegetation composition may change. Vegetation communities also are affected by maintenance, especially if herbicides are used. Disturbed areas can be reseeded; success rates for reseeding vary. If a line uses existing right-of-way, vegetation is disturbed during construction only.

Water Impacts - Clearing new right-of-iray, expanding existing right-of-way, and constructing access roads can increase sediments in streams. This increase would be short term. Using existing right-of-way may also cause temporary increases in sedimentation during construction. Access roads would already be in place.

Soil Impacts - If new corridor segments, expanded rights-of-way or existing rights-of-way are in areas with steep slopes and moderate soil erosion potential, as the transmission line is constructed, soil may erode. If erosion is severe, vegetation recovery may be slow, and slumping may occur. Because line maintenance requires using access roads, soil impacts may continue over a long period. Constructing a transmission line in a new corridor would have the greatest soil impact potential, and is rated moderate.

Groundwater Impacts - Herbicides used to control vegetation for all three options could affect groundwater. The chance of potential contamination is considered low.

Air Quality Impacts - Construction vehicles create dust and exhaust emissions. Some construction debris is burned. These impacts are temporary. During operation, the line produces minor amounts of oxidants in the air next to the electrical conductors. These impacts are considered low or minimal.

Cultural Resources Impacts - Using an existing line would create minimal cultural resource impacts. Constructing a new corridor, or expanding an existing right-of-way could disturb cultural resources. Construction may disturb subsurface sites, and the line may intrude visually on cultural resources.

Aesthetics Impacts - A new corridor would create a significant visual impact. A new line could cross a scenic highway, and towers may be out-of-scale with the surrounding landscape. Views would be disrupted for the long term. Expanding or using an existing right-of-way would have low to moderate visual impacts. Impacts would occur during construction, and if taller structures are used.

Noise Impacts - Transmission lines produce noise. Construction activities also create noise. These impacts are considered low for all three options.

Health and Safety Impacts - This section discusses the possible effects of the electrical properties of transmission lines on public health and safety. These effects include electric shocks and potential long-term health effects.

Safety - Powerlines, as with electrical wiring, can cause serious electric shocks if certain precautions are not taken. These precautions inciude building the lines to minimize the shock hazard. All BPA lines are designed and constructed in accordance with the National Electrical Safety Code (NESC). NESC specifies the minimum allowable distances between the lines and the ground or other objects. These requirements basically determine the edge of the right-of-way and the height of the line, i.e., the closest point that houses, other buildings, and vehicles are allowed to the line, to limit electric field effects to acceptable levels.

People must also take certain precautions when working or playing near powerlines. It is extremely important that a person not bring anything, such as a TV antenna or irrigation pipe, too close to the lines. BPA provides a free booklet that describes safety precautions for people who live or work near transmission lines. It is entitled, "Living and Working Around High Voltage Power Lines." 
Transmission lines can also induce voltages into objects near the lines. This effect can lead to nuisance shocks if a voltage is induced on something like wire fencing which is on wood posts and, therefore, insulated from ground. Usually, however, this becomes a problem only with lines of voltages above $230-\mathrm{kV}$. Should problems develop with either high-or low-voltage lines, they can be corrected by simple grounding techniques. For $500-\mathrm{kV}$ lines, grounding of certain objects near the lines is a routine part of the construction process.

Electric and Magnetic Fields - Powerlines, like all electrical devices and equipment, produce electric fields and magnetic fields. Current (movement of electrons in a wire) produces the magnetic field. Voltage (the force that drives the current) is the source of the electric field. The strength of these fields also depends on the design of the line and on distance from the line. Field strength decreases rapidly with this distance.

Electric and magnetic fields are found around any electrical wiring, including household wiring and electrical appliances and equipment. Throughout a home, the electric field strength from wiring and appliances is typically less than 0.01 kilovolts per meter $(\mathrm{kV} / \mathrm{m})$. However, fields of $0.1 \mathrm{kV} / \mathrm{m}$ and higher can be found very close to electrical appliances.

Average magnetic field streingth in the home from wiring and electrical appliances is typically less than 1 milligauss ( $\mathrm{mG}$ ). Very close to appliances carrying high current, fields of tens or hundreds of milligauss are present. Unlike electric fields, magnetic fields from outside powerlines are not reduced in strength by trees and building material. So, powerlines can be the major source of magnetic field exposure throughout a home located close to the line. There are no national standards for electric or magnetic fields.

Both electric and magnetic alternating-current (a-c) fields induce currents in conducting objects, including people and animals. These currents, even from the largest powerlines, are too weak to be felt. However, some scientists believe that these currents might be potentially harmful and that long-term exposure should be minimized. Dozens of research projects on electric and magnetic fields have been conducted in the U.S. and other countries. Studies of laboratory animals generally show that these fields have no obvious harmful effects. However, a number of subtle effects of unknown biological significance have been reported in some laboratory studies.

Much attention at present is focused on several recent reports suggesting that workers in certain electrical occupations and children living close to power lines have an increased risk of leukemia and other cancers. The evidence, however, has not established a cause-and-effect relationship between electric or magnetic fields and cancer.

Of the seven studies involving children, four reported that the cancer cases were around 1.5 to 3 times more likely to have lived near high current powerlines compared to the control children (those without cancer). The magnetic fields produced by the lines were suggested as possible factors influencing this finding. However, statistically significant associations with actual measured magnetic fields were generally not found in these studies.

A 1982 study in Washington state first reported that men in various "electrical occupations" had died more frequently from leukemia than men in other occupations. Several other studies reported similar findings suggesting an increased risk of around 20 to 50 percent. More recent studies have also reported increased risks for brain tumors, and breast cancer in electrical workers. So far, the factor(s) responsible for these results have not been established.

The U.S. Environmental Protection Agency has initiated an extensive review of the research on EMF and cancer. A draft report by that agency is currently receiving extensive scientific review. To date, this review has not found evidence to show that EMF causes cancer in humans. It appears ihat several more years of research will be needed before questions raised about the possible health effects of EMF can be answered. 
Because of scientific uncertainty, and increasing public concern, in 1988 BPA adopted "Guidance for Addressing EMF Concerns." For proposed new transmission projects, practical alternatives are evaluated that will avoid increasing EMF exposures of the public. Such alternatives include different transmission line designs, and locations that would avoid nearby residences. This approach will be used on this project.

More detailed information on the studies discussed above can be found in a publication available free from BPA. It is titled, "Electrical and Biological Effects of Transmission Lines: A Review."

Socio-Economic Impacts - Population will increase during construction of a transmission line. New access roads may increase access to private land. Operating the line may cause radio and television interference, and individuals living near a transmission line may experience strong negative feelings and many contend that lines reduce the value of their property. A transmission line may disrupt normal farming practices.

\section{Indirect Impacts}

Many of the adverse social and economic impacts attributed to blackouts under the No Action Alternative would be avoided if Alternative Strategy 1 is implemented.

The accelerated conservation measures included in the strategies also reduce energy needs at off-peak times which lessens the need for conventional generating resources. As traditional energy resources such as hydroelectric dams, coal-fired plants, and combustion turbines have greater environmental impacts, accelerating conservation also accelerates the environmental benefits of energy conservation.

An indirect impact of a new double-circuit line across the Cascades might be a continuation of the current tendency to site energy resources east of the Cascades. Generating technology impacts (adverse and beneficial) might thus occur in eastern Washington or nearby states, if a reliable transmission delivery path is available. This may cause conflict between ratepayers living east of the Cascades where power is sufficient, and ratepayers living west of the Cascade where power is needed.

Building a transmission line could reduce the sense of urgency to conserve.

\subsubsection{Mitigation Potential}

Impacts attributed to energy conservation are caused by trapping undesirable gases in residences. To preserve indoor air quality, mitigation measures such as controlling and avoiding pollution sources or removing pollution with ventilation can be used. Compounds to replace ones that can deplete the ozone layer are available or are being developed.

Historically, the dominant environmental issue for shunt capacitors was the insulating fluids containing PCBs used in them. This will not be an issue because the new capacitors no longer use fluids containing PCBs.

The greatest opportunity for impact reduction is for the transmission line component of the strategy. As shown in the impact evaluation matrix, rebuilding an existing line or expanding an existing line right-of-way offers opportunities to reduce impacts significantly. In addition many design and location measures have been used to reduce the visual, land use, clearing and construction impacts of transmission lines. 
Pưget Sound Area Electric Reliability Plạn - Draft Environmental Impact Statement

\subsubsection{Contingency Impacts}

If load growth is not as predicted, or if any of the actions outlined in Chapter 1 occur to change the load/ resource balance, certain steps can be taken to respond to changing conditions. If less peaking capacity than expected is needed, the transmission line in this alternative strategy can be delayed. This would postpone the impacts of the line. If more power is required, Voltage Support Option 2 could be added. Impacts from this measure are discussed under Alternative Strategy 2. Briefly, Voltage Support Option 2 would impact some land use because a new substation would be required.

Load Curtailment measures are a contingency measure for all strategies. Curtailment measures evaluated were contracts with industrial and commercial customers, or cooperatives. The contracts would use reduced power rates in exchange for curtailing power during peak load. Contract curtailment would begin following an outage on the transmission system during winter peak loads. In some cases, advance notification of curtailment may be possible, but in other cases it may not. This creates more socio-economic impacts than would occur were advance notice possible. Residential, institutional, or health and safety-oriented organizations would not be included in contracts. Load curtailment affects health and safety, and has socio-economic impacts. Impacts are similar to, but less severe than, impacts from the No Action Alternative (see Section 4.6.1).

\subsection{ALTERNATIVE STRATEGY 2 - VOLTAGE SUPPORT}

Alternative Strategy 2 includes accelerated conservation measures and Voltage Support Option 1 described under Alternative Strategy 1 . Instead of a transmission line, additional voltage support (termed Voltage Support Option 2) is provided. Voltage Support Option 2 requires construction of a new substation at the point where the four 500-kv transmission lines of the southern transmission corridor first converge. Geographically, this area is located about 10 miles north of Ellensburg, Washington ( see Map 14 in Chapter 3 ). Environmental impacts predicted to result from the new substation are summarized graphically in Figure 4-2 and described in the following paragraphs. A comprehensive discussion of environmental impacts for the substation is provided in Appendix G.

Figure 4-2.

Environmental Impact Evaluation Matrix - Strategy 2

\section{Alternative Strategy 2}

High Impact Moderate Impact Low Impact Minimal Impact
Environmental Evaluation Factors
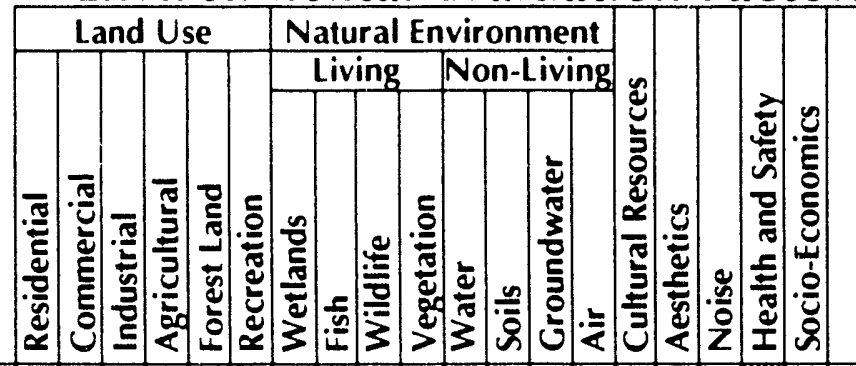

Conservation

Voltage Support 1 Voltage Support 2 


\subsubsection{Environmental Evaluation}

\section{Direct Impacts - Conservation (see 4.2.1)}

\section{Direct Impacts - Voltage Support Option 1 (see 4.2.2)}

\section{Direct Impacts - Voltage Support Option 2}

Description of the New Substation - A 90.100 acre site (about 50 acres fenced) is needed for the new substation. This site would be graded to form a level land surface. Gravel would be applied to the ground surface and a chain link fence would be built around the substation's perimeter to insure safety and security. An existing transmission line access road would be improved from the nearest county road to the site. As heavy equipment is used within substations, access roads are similar to county roads. Four alternate sites are being considered (see map 14 which follows page 3-10.) Site 3 is preferred.

Two small buildings will be constructed at the substation for control and communication equipment and to accommodiate operation and maintenance functions. The added maintenance requirements imposed by the new substation will require additional substation operation and maintenance staff in the Ellensburg area. A maintenance building is planned at the new substation for the new staff.

The electrical equipment planned for the new substation are switches, breakers, series capacitors and a station service transformer. These devices contain oil, but the amount of oil is small and the oil will not contain toxic or hazardous substances. Oil containment will be provided. Appendix $G$ provides additional information on the design and layout of the new substation.

Land Use Impacts - Sites under consideration for the proposed substation are on an existing transmission line corridor. As currently conceived, most of the substation would lie within the existing rights-of-way, thus most of the land impacted by the substation now serves an electric utility function.

The current land use on sites under consideration is rangeland. This rangeland has low productivity. Removing about 50 acres of rangeland from production is considered a low land use impact. Ranch homes and rural residences are sparsely scattered throughout the area. Choosing Site 2 would require acquisition of three subdivided lots. The proposed substation will not directly impact residences, however it will in some instances be partly visible. Impacts to residential properiies are considered low for Sites 1,3, and 4 and moderate for Site 2.

The new substation would have no impact on commercial, industrial, or forest lands. The Soil Conservation Service has confirmed that Prime and Unique Agricultural or Forest land do not exist in the project area.

Wetlands Impacts - None of the sites under consideration for the substation would impact a wetland. The U.S. Army Corps of Engineers requires that a Section 404 permit be secured before placing fill in waters of the United States. The wetlands inventory of the U.S. Fish and Wildlife Service was consulted and although wetlands occur in the study area, all sites under consideration are far from these areas and would not be affected by the placement of fill. Fill activity', therefore would not impact any wetlands.

Fish Impacts - All potential substation sites are located far enough from Naneum, Wilson and Reecer Creeks, that no fish impacts are expected.

Wildlife Impacts - All sites under consideration for the new substation are far from riparian zones, which are the most important wildlife habitat type in the area. Small numbers of upland animals now occupying the substation site would be displaced and adjacent populations temporarily disturbed during construction of the substation. A low level of impact to wildlife is predicted. Consultation with the U.S. Fish and Wildlife Service to determine if rare and or endangered wildlife species are known to occupy the area revealed that wintering bald eagles may occur in the 
vicinity of the project area from October 1 through March 31 as well as the Northern Spotted Owl. No proposed species have been identıfied. A candidate species, the long-billed curlew may also occur in the vicinity of the prciect area. These species most likely inhabit the Wenatchee National Forest to the north. A biological assessment has been initiated by a BPA wildlife biologist to determine the location of these species and if the building of a substation would interfere with their needs. No impact to these species is expected from the proposed substation.

Vegetation Impacts - Expanding or constructing a new substation would remove about 50 acres of rangeland. Vegetation within the substation would be prohibited to minimize fire hazards; this loss would be permanent. As the existing vegetation types are common throughout the area and the amount lost is minor, a low impact to vegetation is predicted in the vicinity of Site 1 and 2. A minimal impact is expected at Site 3 and 4 as both sites contain fewer vegetation types than exist at Site 1 and 2 . Site 4 is already maintained as a substation and water resources that would encourage vegetation growth at site 3 are especially far from the site. A noxious weed survey of the area will be conducted, and appropriate measures to prevent introducing and stimulating the spread of noxious weeds will be done during construction.

Water, Soil and Groundwater Impacts - Low or minimal impacts to water, soil and groundwater are expected. In comparison to Site 3 and 4 , Site 1 and 2 are relatively flat. Surface drainage patterns reveal seasonal flow that occurs over a wide area and is not constrained by uneven land forms. Construction would most likely interrupt this flow but drainage systems can be designed to reroute this flow around the substation into an existing stream or canal. Impacts are expected to be low. In the vicinity of Site 1, groundwater is accessed by ranchers, digging approximately 15 feet below the surface, for purposes of getting drinking water for their cattle. Grading for a substation may interfere with this subsurface flow causing it to change direction.

Sites 3 and 4 do not appear to have the same potential for problems with surface drainage or subsurface flow. Slopes are greater and drainage patterns found at Site 1 and 2 were not apparent indicating that significant overland Jrainage may not occur here. A narrow shallow canal was dug to the east of Site 3 but a culvert will be put in as to not interrupt flow by the access road. There is no evidence that subsurface flow is accessed by ranchers in the vicinity of these sites. It is hard to predict depth to groundwater or whether construction on these sites will interfere with a subsurface flow.

Erosion of soil for Sites 1, 2, and 3 will be low as slopes are not as steep as can be found at Site 4 . Grading will occur at the chosen site so the continuity of the soil layers will be disrupted. This 'will only occur within the boundaries of the substation. Precautions are taken during construction to prevent soils from blowing away.

The oil used in series capacitors and the station service transformer will not be toxic and will be of small volume. However, if oil is accidently spilled it could contaminate the soil, and groundwater. Small spills will be cleaned up in accordance with BPA's Spill Prevention Control and Countermeasures Plan. To protect surface and ground water and adjacent soils from contami. ion, oil collection membranes would be installed beneath equipment containing large volumes of oil. Use of herbicides in substation areas to prevent vegetation growth could affect soil and ground water.

The proposed substation sites are far enough from Naneum, Wilson and Reecer Creeks, and irrigation canals that no impacts to these surface water features are expected.

Cultural Resources Impacts - Consultation with the Washington State Historic Preservation Office has begun to determine if known historic or archeological sites occur in the siting area for the new substation. An environmental review conducted in 1976 revealed no known archaeological or historic sites in the area. Hence, no or minimal impacts to culturai resources are expected. BPA routinely conducts archeological surveys for substaticin sites once their location is known to assure that unknown cultural resources are not inadvertently damaged during construction.

Aesthetics Impacts - Visual impacts created by the substation would be low to moderate. The sites under consideration are about 10 miles from Ellensburg and major transportation routes. A good indicator of potential impact is BPA's existing Gas Insulated Cable site called Naneum, which is Site 4. The Naneum site is not visible 
from Ellensburg or from nearby highways, and it occupies a higher elevation than the other three sites under consideration for the new substation.

If Site 4 were selected, a large earth excavation would be needed due to the steep slopes of this site. The excavation would be very large and contrast with the natural colors and texture of the surroundings. It's aesthetic impact is considered moderate. Several ridges and knolls lie between Ellensburg and the Sites 2, 3 and 4, further restricting views. Views from the few scattered ranches and rural homes in the area will be impacted by the new substation, more so at Site 2 and 4 . In these instances the existing transmission line corridor already impacts visual conditions hence the added impact of the substation is considered low to moderate.

Noise Impacts - Construction creates short-term noise. Noise generated by the station service transformer will comply with Washington noise standards. The transmission lines presently make a low frequency crackling noise, which is most noticeable when it rains. Noise levels at the new substation will not be perceptible from that made by the transmission lines.

Health and Safety Impacts - Health and safety impacts associated with the new substation are predicted to have a low impact magnitude.

One safety issue is that electrocution and serious injury including death can occur if individuals contact energized equipment. Historically, substation electrocution hazards have been minimal.

Adding voltage support at the new substation will change how power flows on transmission lines within the corridor and to a lesser degree on other lines in the transmission grid. Magnetic field levels associated with transmission lines vary proportionately with the level of power flow on the lines. How the power is distributed among the lines that comprise the NW power grid depends on a number of factors. Power demand varies daily and seasonally. Generation patterns change in response to economic considerations, maintenance schedules, hydro system water conditions, and power exchanges with Canada and California. Changes to the transmission network, both temporary and long-term, also change how power flows in the grid. Because of this dynamic nature of the power system it is difficult to characterize specifically how any one change impacts magnetic fields throughout the transrnission grid.

It is important to note that the fields near substations are typically dominated by the lines entering and leaving the substation. Adding voltage support to the electric power system at the proposed substation will significantly change how electrical !oads are distributed between transmission lines in the corridor, particularly those west of the substation. Some lines on the corridor will experience load increases and some will experience load decreases. Quantitative estimates of the change in magnetic field produced by the lines in the vicinity of the new substation are provided in Appendix G. Overall, maximum levels do not change at the edge of the right-of-way. However, the distribution of magnetic fields across the right-of-way will change. Magnetic fields on the southern portion of the right-of-way will decrease. Added loads on the double-circuit $500-\mathrm{kV}$ line, located at the northern edge of the rightof-way, will cause magnetic fields to increase somewhat in the northern portion of the corridor. The substation will not change EMF exposures at any existing residences in the vicinity of the facility.

Generally the new substation will cause a shift of some cross-Cascade power flow from the northern Stevens pass corridor to the southern Stampede Pass corridor. Depending on system conditions, it could also increase power flow on the south to north lines in the Puget Sound Basin. The impact of these load changes are very much sitespecific depending on electrical and geometrical considerations. There will be both increases and decreases in magnetic fields for various lines due to these power shifts. However, magnetic field levels will be within the range normally associated with transmission lines. 
Puget Sound Area Electric Reliability Plan - Draft Environmental Impact Statement

Socio-Economic Impacts - Constructing the new substation would employ at most 30 construction workers from outside the immediate area of the project. The duration of construction is expected to be one year and workers from outside the area are not expected to bring dependents due to the short construction time. Workers from outside the area would likely stay in motels/hotels or rent an apartment for the short time they are in the area. Given the small number of the construction force compared with the population of the area there would be no need for additional housing or community services.

The project would have a low impact on area employment, unemployment and income distribution. A maximum of 20 people would be hired locally to fill short-term jobs. This represents a small number compared to the total local labor force.

\section{Indirect Impacts}

Many of the adverse social and econo nic impacts attributed to blackouts under the No Action Alternative would be avoided if Alternative Strategy 2 is implemented.

The accelerated conservation measures included in the strategies also reduce energy needs at off-peak times which lessens the need for conventional generating resources. As traditional energy resources such as hydroelectric dams, coal fired plants, and combustion turbines have greater environmental impacts, accelerated conservation also speeds the environmental benefits of energy conservation.

To allow the system to operate at the levels needed after the voltage support additions are complete, some localized transmission system upgrades may be necessary. These upgrades would probably be reconductoring of existing lines, or adding new lines in existing corridors.

\subsubsection{Mitigation Potential}

Before the site for the new substation is chosen, surveys will be done to rule out areas with cultural resources, wetlands, or other uses incompatible with a new substation. Local agencies and interest groups will be contacted to encourage suggestions for a site. The substation will be designed to minimize its visual impact. A weed-barrier fabric could be installed underground to reduce the need for herbicides.

Mitigation for the conservation measures is in Section 4.2.2.

\subsubsection{Contingency Impacts}

Load curtailment, a transmission line and combustion turbines are contingency measures for this strategy. Load curtailment measures are described in Section 4.6.1, and transmission line impacts are described in Section 4.2.1. Impacts for combustion turbines are described in Section 4.5.1.

\subsection{ALTERNATIVE STRATEGY 3 - DEMAND REDUCTION}

This strategy includes the conservation measures and Voltage Support Option 1 common to all strategies. Load management and fuel switching measures are added for additional energy needs. Figure 4-3 shows the environmental evaluation factors and predicted impacts for Alternative Strategy 3. 
Figure 4-3. Environmental Impact Evaluation Matrix - Strategy 3

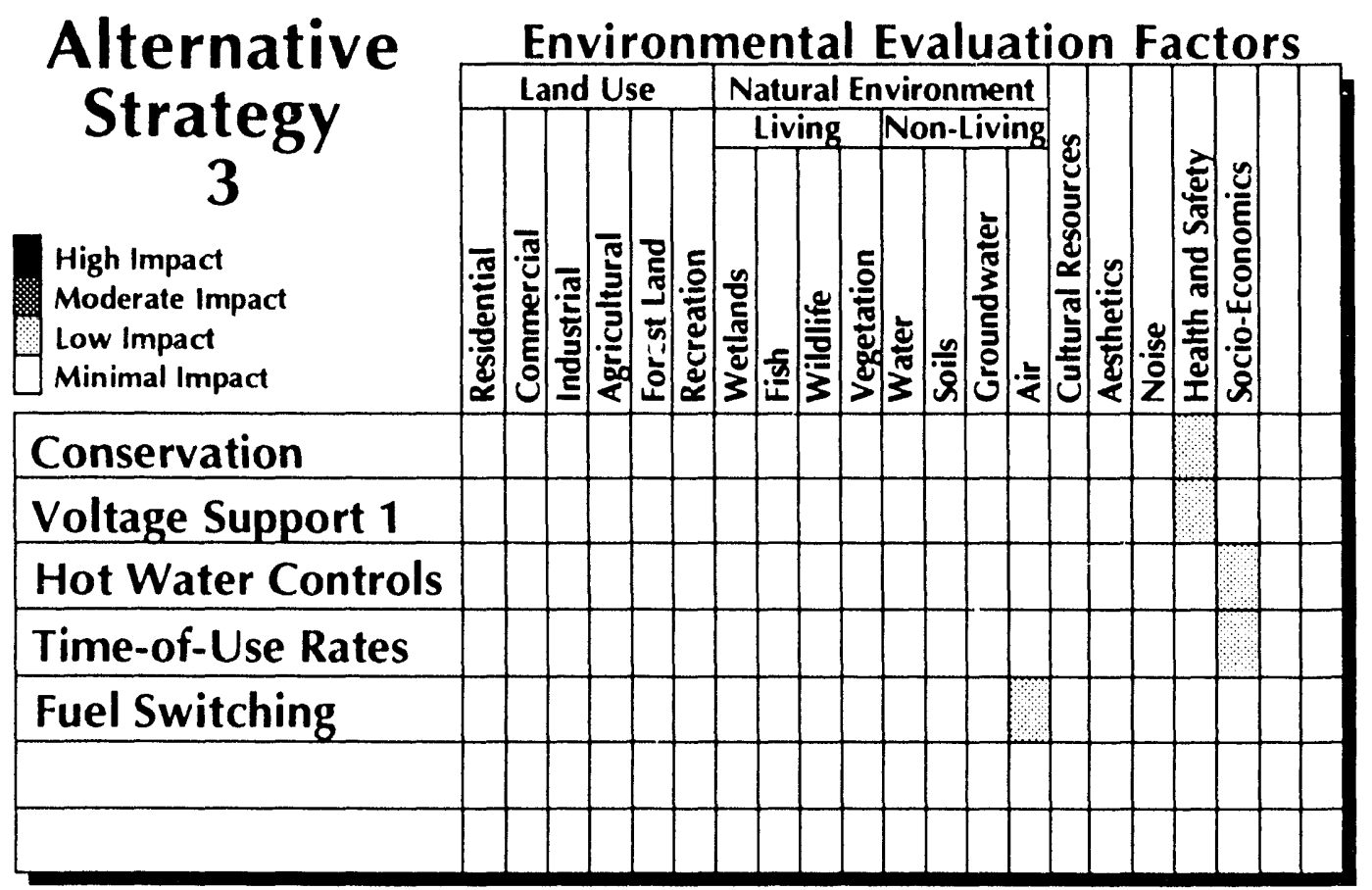

\subsubsection{Environmental Evaluation}

\section{Direct Impacts - Conservation (see 4.2.1)}

\section{Direct Impacts - Voltage Support Option 1 (see 4.2.2)}

\section{Direct Impacts - Load Management Measures}

Load management is achieved using water heater controls and time-of-use price changes. Analysts used reported impacts from utilities using load management programs.

Socio-Economic Impacts - Load management can help utilities reduce costs by reducing or deferring the need for new power plants. Fuel costs, and operating and maintenance costs can be reduced, and existing power plants can be run more effectively. Public attitudes toward utilities may improve with time-of-use pricing if customers feel a greater control of utility bills, but may worsen when service is controlled by utilities. Income benefits would likely go to middle-income groups, not disadvantaged customers.

\section{Direct Impacts - Fuel Switching}

Fuel switching expected to occur because of market forces is already included in the load forecast. Additional residential fuel switching measures are assumed for this analysis. Water heaters and space heating would be changed from electricity to natural gas. Natural gas service is assumed available, or installed. The supply of natural gas is assumed to be adequate for the demand in the Puget Sound area. 
Air Quality Impacts - Air quality impacts are hard to assess as the actual number and location of households switching to natural gas is hard to predict. For the number of households assumed for this study, using more natural gas would not increase $\mathrm{CO}, \mathrm{HC}$, and $\mathrm{NO}_{x}$ in significant amounts.

\section{Indirect Impacts}

Shifting electricity use through the load management prograrns could move the peak to a different time. The load management program could foster a new or expanded control equipment industry. The additional impacts from natural gas extraction and delivery are assumed to be negligible. The utilities supplying natural gas will gain new customers and revenue from the fuel switching program. Electric utilities will lose customers and revenues. Since the input of carbon into the atmosphere will be negligible, the contribution to global warming will also be negligible.

\subsubsection{Mitigation Potential}

Impacts from this strategy are low. Load management programs create impacts that do not require mitigation. Depending on the number and location of households that switch to natural gas, a certain amount of uncontrolled emissions are added to an airshed. Mitigation for conservation measures is in Section 4.2.2.

\subsubsection{Contingency Impacts}

If load growth slows, the load management and fuel switching programs can be delayed. If load growth increases above predictions, Voltage Support Option 2 can be added. Load curtailment measures can also be used. Impacts of Voltage Support Option 2 are in Section 4.3.1. Load curtailment impacts are described in Section 4.6.1.

\subsection{ALTERNATIVE STRATEGY 4 - COMBUSTION TURBINES}

This strategy also contains the conservation measures and Voltage Support Option 1, but adds combustion turbines to provide power for peak loads. Figure 4-4 shows the expected impacts from this strategy.

Figure 4-4. Environmental Impact Evaluation Matrix - Strategy 4

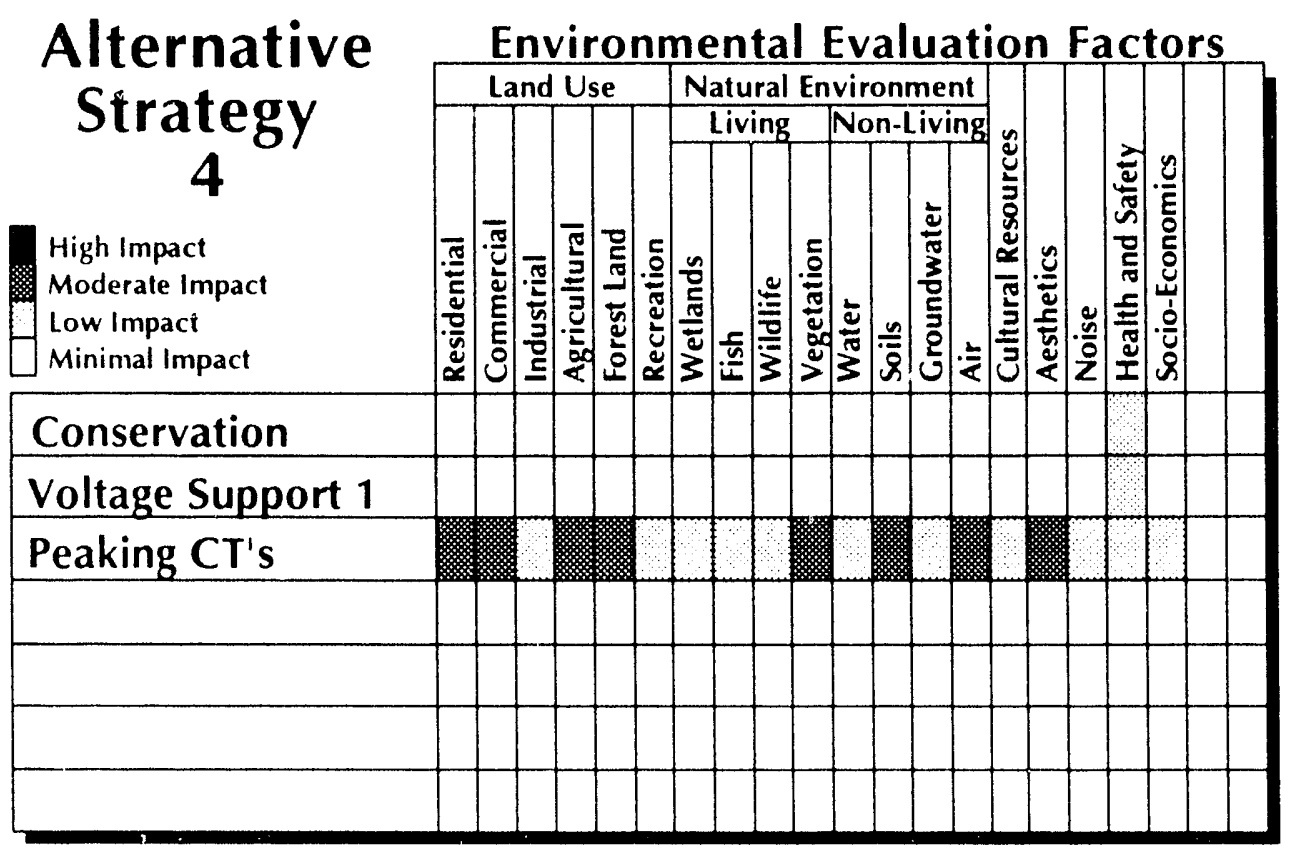




\subsubsection{Environmental Evaluation}

\section{Direct Impacts - Conservation (see 4.2.1)}

\section{Direct Impacts - Voltage Support Option 1 (see 4.2.1)}

\section{Direct Impacts - Combustion Turbines}

The type of combustion turbine considered in this alternative strategy is built to serve power for peak loads only. It is a single cycle $70 \mathrm{MW}$ unit that operates infrequently ( $5 \%$ of the year). Combustion turbines are assumed built on industrial or agricultural land. Other land uses would be affected indirectly only.

The primary fuel for the turbines is intended to be natural gas. Natural gas pipelines would be extended to the combustion turbine sites. During recent cold snaps, natural gas service to existing Puget Sound combustion turbines was curtailed. Thus oil tanks with a two week supply of fuel are planned as a backup fuel source during gas curtailment periods. In recognition of fuel uncertainty, assessments of $\mathrm{CT}$ air quality impacts are based burning oil $\left(\mathrm{SO}_{2}\right.$ in addition to $\left.\mathrm{NO}_{2}\right)$.

Impacts associated with producing and manufacturing material used in combustion turbines, and fuel burned by the turbine, are expected to be minimal. Impacts associated with combustion turbines are ultimately dependent upon where the facility is located. Integration of output from CT's may require transmission system modifications. See Alternative Strategy 1 for a discussion of transmission impacts.

Land Use Impacts - About four acres are required for a combustion turbine site. A combustion turbine may create conflicts with existing land use. Impacts depend on specific location.

Wetlands Impacts - Combustion turbines produce pollutants such as oxides of nitrogen $\left(\mathrm{NO}_{\mathrm{x}}\right)$ and sulfur $\left(\mathrm{SO}_{\mathrm{x}}\right)$. $\mathrm{NO}_{2}$ and $\mathrm{SO}_{2}$ can react with moisture and form acid rain, which may affect wetland vegetation.

Fish Impacts $-\mathrm{NO}_{2}$ and $\mathrm{SO}_{2}$ may form acid rain, enter surface water, and affect fish.

Vegetation Impacts - $\mathrm{NO}_{2}$ can react with moisture to form nitric acid that can harn vegetation. $\mathrm{SO}_{2}$ is also toxic to vegetation.

Water Impacts - Surface water pollution from storm runoff and chemical discharges could occur during construction and operation, but are not expected to be significant. Surface water in the vicinity of the site may be affected by $\mathrm{NO}_{2}$ and $\mathrm{SO}_{2}$ causing acidification. Water is needed for cooling; returned water may raise the temperature of the water source.

Soil Impacts - Erosion is possible during plant construction. Soil may be contaminated by acid rain created by air pollutants.

Groundwater Impacts - Groundwater may be contaminated during construction and operation of the plant if oil is spilled. Area surrounding oil tanks are usually protected by membranes which catch oil if a spill occurs.

Air Quality Impacts - The principal air pollutants from oil burned through the combustion turbine process are oxides of nitrogen, sulfur dioxide, carbon dioxide and waste heat. Burning oil (or gas) contributes to greenhouse gases. Nitrogen dioxide and sulfur dioxide irritate mucous membranes and cause coughs, headaches, and shortness of breath. Nitrogen oxides can become nitrates and form ozone. Ozone can damage plants and cause minor eye irritation. Burning oil produces more pollutants than burning gas. 
Cultural Resources Impacts - Impacts to cultural resources are expected to be low, and would occur during construction.

Aesthetics Impacts - The visuai nature of the landscape is changed during plant construction and operation.

Noise Impacts - Noise is a major concern at operating combustion turbine plants. Noise control measures can reduce noise impacts.

Health and Safety Impacts - Plant operations produce pollutants that may affect the health of the public. Acid rain produced from these pollutants is believed to be a carcinogen. Pollutants produced irritate the mucous membranes and cause coughs and headaches.

Socio-Economic Impacts - $\mathrm{NO}_{2}$ and $\mathrm{SO}_{2}$ reacts with moisture and forms acid rain that damages buildings and bridges. Combustion turbines produce greenhouse gases that may contribute to global warming.

\section{Indirect Impacts}

Additional transmission lines may be needed to reliably connect CT's to the transmission system. Impacts of transmission lines can be found in Section 4.2.1.

\subsubsection{Mitigation Potential}

The most significant impacts attributed to Combustion Turbines are related to air emissions, noise and land use disruption. The provisions of the Clear Air Act and following Best Available Control Technology provisions would help assure that emissions would not significantly affect public health. Noise created during operation of the turbines can be partially reduced through careful design, and the use of noise buffers such as mufflers to shield noise sensitive properties. Careful site selection can eliminate many adverse land use effects. For example, if an industrial site is chosen for the CT's land use impacts would be low.

Impacts to soils, vegetation and aesthetics also can be reduced by careful siting and design.

\subsubsection{Contingency Impacts}

The combustion turbines can be delayed if they are unnecessary. If load grows unexpectedly, Voltage Support Option 2 or more combustion turbines can be added to the system. Load curtailment also can be used. Impacts of Voltage Support Option 2 are in Section 4.3.1. Load curtailment impacts are described in Section 4.6.1 under the No Action Alternative.

\subsection{NO ACTION ALTERNATIVE}

The No Action Alternative is a theoretical alternative defined as individual utilities independently taking actions deemed appropriate considering their customers' needs. It is a "business as usual" alternative where utilities may or may not coordinate planning for projects.

Without a coordinated plan, there is a potential for one or more voltage collapse or partial collapse incidents to occur during the 1994-2003 planning period. The result is a brownout or blackout. Analysts assumed an area-wide blackout will last an average of four hours because restoring service on distribution lines that serve them requires additional time. If transmission lines or generators need major repairs, the blackout will last longer. Fewer than one outage in ten extends more than eight hours. The chance that service will be disrupted increases with time as load grows. Commerce and industry are adversely affected as the quality and reliability of power decreases. 
The No Action Alternative assumes individual utilities will make resource decisions. Without a coordinated plan for resource acquisition, more local generation may occur. However, this possibility is speculative, and estinating the impacts from this speculation is not discussed in this EIS.

Figure 4-5 shows the environmental evaluation factors and the individual ratings for the No Action Alternative Analysts used reported impacts from blackouts that have occurred elsewhere to make their findings. No Action has high health and safety, and socio-economic impacts, and low air quality impacts.

Figure 4-5.

Environmental Impact Evaluation Matrix - No Action Strategy

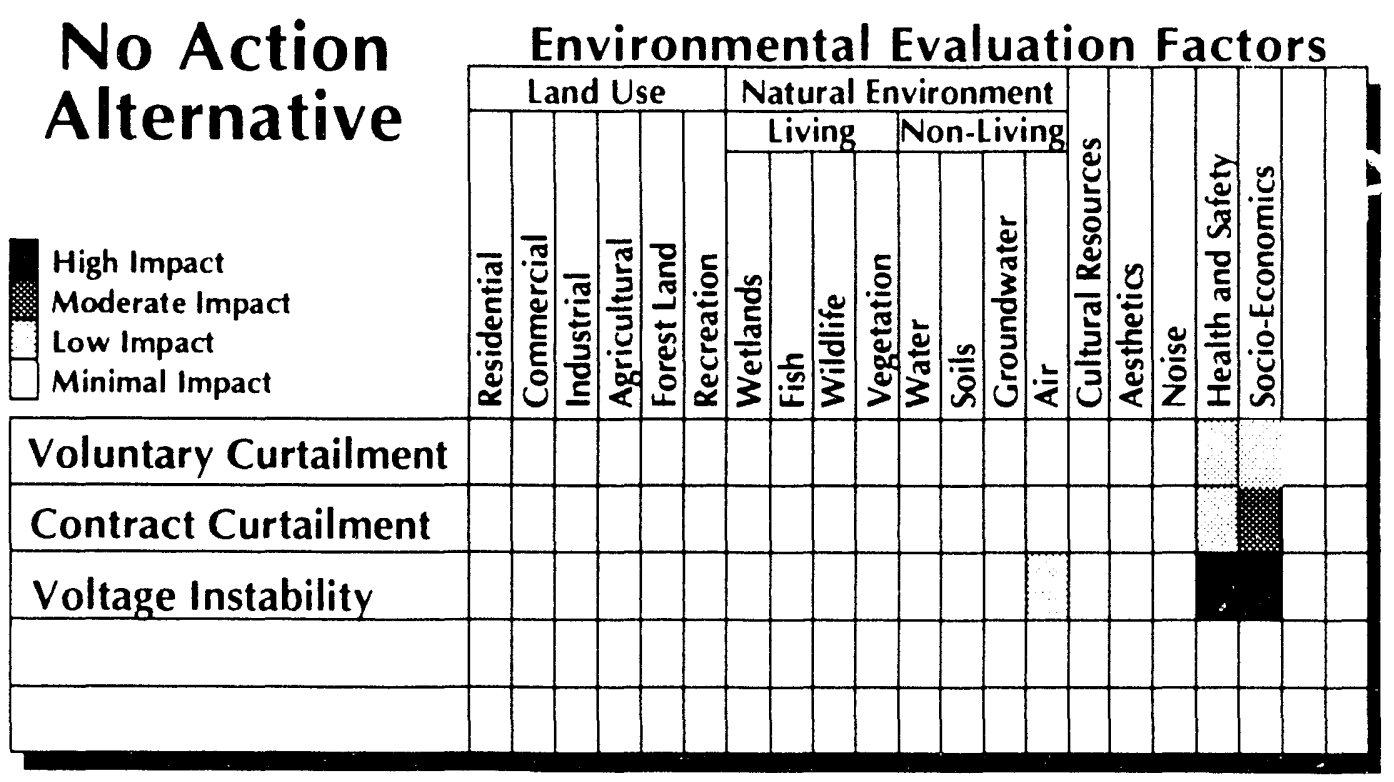

\subsubsection{Environmental Evaluation}

\section{Direct Impacts}

Health and Safety Impacts - When a loss of electricity occurs, all services provided by electrical energy cease. Illumination is lost. Lighting used by residential, commercial, industrial and municipal customers for safe locomotion and security is affected. Residential consumers lose heat. Highways experience gridlock where traffic signals fail to operate. Industrial production is halted. Residential, commercial, and industrial customers experience comfort/safety and temperature impacts, increases in smoke and pollen, and changes in humidity, due to loss of ventilation. Mechanical drives stop, causing impacts as elevators, food preparation machines, and appliances for cleaning, hygiene, and grooming are unavailable to residential customers. Commercial and industrial customers also lose service for elevators, food preparation, cleaning, office equipment, heavy equipment, and fuel pumps.

Transportation impacts include propulsion loss. Sewage transportation and treatment can be disrupted.

Electricity for cooking and refrigeration is lost. Residential, commercial, and industrial customers cannot prepare or preserve food and perishables. A special problem is the loss of industrial continuous process heat. Electricity loss also affects alarm systems, communication systems, cash registers, and equipment for fire and police departments. 
Puget Sound Area Electric Reliability Plan - Draft Environmental Impact Statement

Socio-Economic Impacts - When services provided by electricity described above are lost, there are also socioeconomic impacts. Customers incur costs as they turn to alternative energy sources. Hospitals, nursing homes, federal prisons, airports, farms, and others with standby generators and fuel reserves use them. Other effects include increased theft, loss of retail business, loss of production time, reduced tax revenues, damaged equipment, lost data, spoiled products, and additional maintenance costs.

Government agencies experience additional expenses during a blackout. The major expenses are related to overtime payments to fire, police and other personnel, emergency aid payments, and costs incurred to control looting.

Utilities also incur costs from lost revenue, and costs to restore service. New equipment purchased to pievent future incidents requires capital. Responding to legal suits brought against a utility incurs costs.

Long-term economic effects could occur if industry, in general, concludes that the region's power supply' system is unreliable and below acceptable standards.

Air Quality Impacts - If home owners burn wood during a blackout, air quality could be degraded. Emergency generators usually burn oil and could increase air pollution locally. This may be offset by decreased industrial air pollutant releases, and reduced automobile exhaust emissions if workers remain home. Impacts would be temporary.

\section{Indirect Impacts}

Lacking a coordinated resource acquisition plan, individual utilities may develop more local generation than otherwise developed. More local generation could increase the level of impacts on land use, air quality, fish and wildlife, and/or other resources. More individuals may participate in conservation programs or conserve on their own than in other alternative strategies. Individuals may change their life-styles to adapt to the potential for brownouts and blackouts. If power interruptions become frequent, businesses and industries dependent on a reliable power supply may relocate to regions with a more reliable power supply system. This would lead to loss of jobs and economic stability within the region.

\subsubsection{Mitigation Potential}

Mitigation is not a logical component of the No Action Alternative. Mitigation of adverse impacts is an expected outcome of long-range planning. Uncoordinated planning and hurried problem solving could cause duplication of facilities, and lost impact mitigation opportunities.

\subsubsection{Contingency Impacts}

The No Action Alternative is an unplanned strategy and one which, by nature, has no contingency measures to be undertaken if rapidly changing needs occur. System failure, which has high health and safety and socioeconomic impacts, would be the default contingency under the No Action Alternative.

\subsection{ENVIRONMENTAL COMPARISON OF ALTERNATIVE STRATEGIES AND THE NO ACTION ALTERNATIVE}

This section takes the information from the environmental, and economic: and technical evaluations about each strategy and uses it to compare the strategies. Each strategy is evaluated against the purposes listed in Chapter 1. The environmental impacts are compared first. A comparison of the projected impacts for the alternative strategies is provided in Figure 4-6. Measures common to all strategies are evaluated first followed by the alternative strategies. 
Figure 4-6.

\section{Strategy Impact Comparison Matrix}

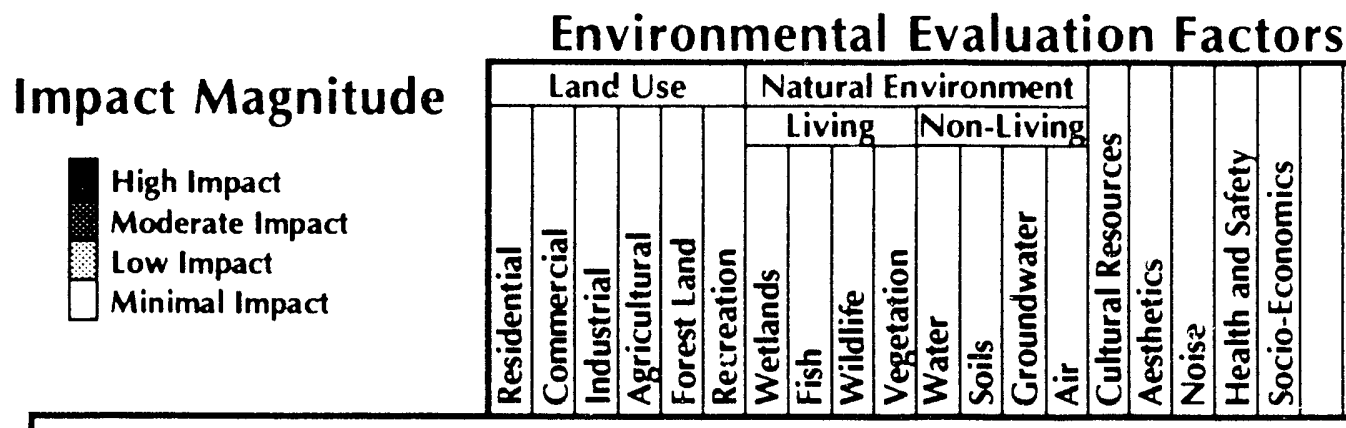

MEASURES IN ALL STRATEGIES

\begin{tabular}{l} 
Conservation \\
Voltage Support 1 \\
\hline
\end{tabular}

ALTERNATIVE STRATEGY 1

Transmission Line

Option 1: Use Existing ROW

Option 2: Expand Existing ROW

Option 3: Use New Corridor

ALTERNATIVE STRATEGY 2

Voltage Support 2

ALTERNATIVE STRATEGY 3

Hot Water Controls

Time of Use Rates

Fuel Switching

ALTERNATIVE STRATEGY 4

Peaking CT's

NO ACTION ALTERNATIVE

Voluntary Curtailment

Contract Curtailment

Voltage Instability 
As explained in Chapter 1, a key purpose for any plan is to meet Federal and State environmental quality requirements. Each strategy will be discussed with this in mind. Individual measures cause impacts to different parts of the environment, both living and non-living. Analysts are reluctant to judge relevance of impacts, e.g., whether an air quality impact is equal to or greater than an impact to fish. The relevance of impacts is not given, just the level of impact.

When composing the strategies, planners eliminated most measures with significant impacts. The remaining measures can, with mitigation, create low and moderate impacts only. The difference among the strategies are minor. Only the transmission line and peaking combustion turbines have the potential to affect many environmental sectors. Other measures only affect a few. The conservation measures and Voltage Support Option 1 are common to all strategies except the No Action Alternative.

Preferred Alternative - The preferred alternative is a hybrid of Alternate Strategy 2. The strategy is second lowest in impact and about equal to Alternate Strategy 3.

Alternative Strategy 1 - The transmission line in this strategy is the only measure that has the potential for high impacts. These impacts could be reduced with careful siting. This strategy has greater impacts than Alternative Strategies 2,3 and 4.

Alternative Strategy 2 - This strategy has fewer impacts than Alternative Strategies 1 and 4 and the No Action Alternative. It is close in impact to Alternative 3.

Alternative Strategy 3 - This strategy has the fewest impacts.

Alternative Strategy 4 - The combustion turbines in this strategy cause more impacts than the measures in Alternative Strategies 2 and 3, but somewhat !ower than Alternative Strategy 1.

No Action Alternative - The No Action Alternative would avoid the physical impacts of the transmissinn line in Alternative Strategy 1 , and the peaking combustion turbines in Alternative Strategy 4. The social and economic impacts of this alternative are greater than any of the strategies.

The procedural provisions for implementing the National Environmental Policy Act asks that comparisons of alternatives discuss: 1) adverse affects that cannot be avoided; 2) the relationship between short-term uses of man's (sic) environment and the maintenance and enhancement of long-term productivity; and 3) any irreversible and irretrievable commitments of resources that would be involved in the proposal should it be implemented.

Discussions on these topics are provided below:

Adverse Effects that Cannot be Avoided - In Alternative Strategy 1, the transmission line rights-of-way will unavoidably restrict certain activities. Trees that would interfere with the line, and buildings and similar structures would be prohibited on the right-of-way. Ample site alternatives are normally available for such uses adjacent to rights-of-way.

Short-Term Use of The Environment and Maintenance and Enhancement of Long-Term Productivity - The alternatives under consideration do not pose impacts that would alter the long-term productivity of the affected environment. Were the measures proposed in the alternative strategies removed and the affected areas restored, little change in long-term environmental productivity would have been caused.

Irreversible and Irretrievable Commitment of Resources - Resources committed to the alternative strategies are the materials used in the various measures (transmission line, substation equipment, combustion turbine, gas furnaces installed through fuel switching) and the fuels consumed either during construction or operation of the measures. Alternative Strategies 3 (fuel switching) and (combustion turbines) both use natural gas, a non-renewable resource. There could be loss of habitat with Alternative Strategy 1. 


\subsection{ECONOMIC AND TECHNICAL EVALUATION}

This section explains six economic and technical evaluations that were conducted. Coupled with the preceding environmental analysis, one can judge the relative merits of alternative strategies.

The No Action Alternative by definition is undefined both from the standpoint of what actions would be taken, by whom and when. Conventional economic and technical evaluations for the No Action Alternative thus were not possible. Yet, the cost of No Action can be predicted in less precise terms. For example, the economic consequences of blackouts nistorically have been high. If No Action leads to a blackout in Puget Sound, economic effects would be high, as would public health and safety impacts. The No Action Alternative is expected to have the greatest long-term economic impact.

As defined, the technical performance of a No Action Alternative (blackouts are likely), provides a level of electrical service that would not comply with utility transmission system reliability criteria. The No Action Alternative ranks lowest from a technical perspective.

More information on the economic and technical evaluation is provided in Appendix $\mathrm{C}$.

\subsubsection{Description of Economic and Technical Study Framework}

This study assumes that the Puget Sound area is served by a single utility. Therefore, no distinction is made between private and public utilities or load served by BPA and load served by utility-owned generation. Where appropriate, costs incurred by consumers are included as well as utility costs.

This study has two relevant time periods. First is the decision period, which extends from 1994 through 2003. In these ten years, actions are proposed to meet forecast peak loads. The analysis continues beyond 2003 through 2010 in order to capture adequately the costs and benefits of artions taken through 2003.

Six evaluation factors are used in this study. They provide a measure of how well each of four alternative strategies solve the peak load problem of Puget Sound. Five of these factors are routinely used by utilities in the region for energy planning and have received public review. The last factor "Power System Reliability" is new for this project. Each factor is explained below.

No economic benefit is assigned to solving the reliability problem. While consumers will have fewer outages, no dollar values were included in this analysis. Therefore, the net cost of fixing the problem may be negative.

\subsubsection{Minimize Present Value of System Costs}

This factor examines the costs and benefits of the measures in each alternative. Results are presented as a net present value (NPV), where costs and benefits occurring in different years are summarized as a single number which recognizes the time value of money. For this study, costs and benefits are analyzed over the study period, 1994 to 2010. This calculation takes a societal perspective including costs and benefits to utilities and consumers.

The capital costs required to build, operate and maintain the measures are estimated and their sum represents the cost of a strategy. The monetary value of power produced or saved is calculated and subtracted to determine the net benefits of a strategy. The balance of the costs and benefits are adjusted by applying a $5 \%$ inflation rate and a $3 \%$ discount rate to deterinine the net present value of the strategy. The net present value of the alternatives is provided in Table 4-2. Alternative Strategies 1,2 and 4 have positive net present values. This indicates that benefits exceed costs. Alternative Strategy 3 has greater costs than benefits. Alterinative Strategy 2 provides the greatest net present value. 
Puget Sound Ag̣ea Electric Reliabịlity Plan - Draft Environmental Impact Statement

Table 4-2. Present Value of System Costs

\begin{tabular}{|c|r|}
\hline Strategies & $\mathbf{1 9 9 0 \$}$ \\
\hline Alternative Strategy 1 & $\$ 67,000,000$ \\
\hline Alternative Strategy $2^{*}$ & $\mathbf{\$ 1 0 5 , 0 0 0 , 0 0 0}$ \\
\hline Alternative Strategy 3 & $-\$ 128,000,000$ \\
\hline Alternative Strategy 4 & $\$ 40,000,000$ \\
\hline
\end{tabular}

(* Preferred Alternative)

\subsubsection{Minimize Sensitivity to Load Growth}

The alternative strategies were designed to meet medium load growth. The Minimize Sensitivity to Load Growth factor evaluates the economic impacts of each strategy under different load growth rates. If load growth is slower than predicted, delaying high-cosi measures would yield monetary savings. If investments in a measure are made and low growth conditions occur, revenues and costs will be greater than benefits. Conversely, if loads increase rapidly, strategies with surplus capacity may incur no additional costs. Table 4-3 shows how the four alternative strategies perform under different load growth rates.

Table 4-3. Sensitivity to Load Growth

\begin{tabular}{|c|c|c|c|c|}
\hline & \multicolumn{4}{|c|}{ Present Value $1990 \$$} \\
\hline Strategies & $\begin{array}{l}\text { Low } \\
\text { Growth }\end{array}$ & $\begin{array}{l}\text { Medium } \\
\text { Growth }\end{array}$ & $\begin{array}{l}\text { High } \\
\text { Growth }\end{array}$ & Range \\
\hline Alternative Strategy 1 & $-\$ 88,000,000$ & $\$ 67,000,000$ & $\$ 109,000,000)$ & $\$ 196,000,000$ \\
\hline Alternative Strategy $2^{*}$ & $-\$ 21,000,000$ & $\$ 105,000,(000$ & $\$ 97,000,000$ & $\$ 126,000,000$ \\
\hline Alternative Strategy 3 & $-\$ 212,000,000$ & $-\$ 128,0(0), 000$ & $-\$ 131,000,000$ & $\$ 84,000,000$ \\
\hline Alternative Strategy 4 & $-\$ 35,000,000$ & $\$ 40,000,000$ & $-\$ 63,0(0), 0(0)$ & $\$ 102,0(0),(0) 0$ \\
\hline
\end{tabular}


The analysis assumes that a change in growth begins in 1994 and utilities begin to take actions in 1998. This acknowledges that it takes time to both discover a problem and to take corresponding actions. For low load growth, conservation, load management and fuei switching programs are stopped in 1999. Within the four alternatives, peaking combustion turbines are the only other measures that can be delayed or stopped after 1998, so Alternative Strategy 4 has fewer combustion turbines with low load growth.

For high load growth, contract curtailment is acquired to cover deficits before new measures can be brought on-line. Measures are added to cover the additional peak deficits from high load growth. Alternative Strategy 1 has enough excess capacity to cover the high peaks. Alternative Strategy 2 adds a transmission line in 2002. Alternative Strategies 3 and 4 both add Voltage Support Option 2 in 2001. In addition, Alternative Strategy 4 also adds more combustion turbines from 2001-2003. Alternative Strategy 3, although the highest cost under all three load growth scenarios, has the smallest range, or least sensitivity to load growth.

\subsubsection{Minimize Near-Term Revenue Requirements}

This factor looks at the annual amount utilities, and indirectly ratepayers, would need to pay to acquire the measures in each alternative strategy. Costs in this analysis factor are termed revenue requirements, as the money required would be gathered through customer paid rates. In contrast to the NPV calculations, this analysis only looks at the dollars utilities would need to pay for the alternatives. It does not include the effects of lost revenues or changes that would occur in system operations. Results reported are average gross impacts on revenue requirements for the years 1996-1998. For a full discussion of assumptions see Appendix C.

Table 4.4 displays the near-term revenue requirements. Notice that revenue requirements are not included for fuel switching in Alternative Strategy 3 ; it is unclear what electric utilities would pay for this measure (see Appendix D on reduce-use options for discussion on possible costs). Results are expressed in terms of the average yearly revenue requirement between 1996-1998. Alternative Strategies 2 and 4 have the lowest near-term revenue requirements.

Table 4-4. Near-Term Revenue Requirements

\begin{tabular}{|c|c|}
\hline Strategies & $\mathbf{1 9 9 0 \$}$ \\
\hline Alternative Strategy 1 & $\$ 50,000,000$ \\
\hline Alternative Strategy $2^{*}$ & $\mathbf{\$ 2 5 , 0 0 0 , 0 0 0}$ \\
\hline Alternative Strategy $3^{* *}$ & $\$ 50,000,000$ \\
\hline Alternative Strategy 4 & $\mathbf{\$ 2 0 , 0 0 0 , 0 0 0}$ \\
\hline
\end{tabular}

* Preferred Alternative $\quad$ ** Does Not Include the Cost of Fuel Switching 


\subsubsection{Minimize Long-Term Revenue Requirements}

This evaluation factor is the same as minimizing near-term revenue requirements except it looks at the years 2006-2008. Long-term impacts are also important to consider. These are shown in Table 4-5. Alternative Strategy 2 has the lowest long-term revenue requirement.

\section{Table 4-5. Long-Term Revenue Requirements}

\begin{tabular}{|c|c|}
\hline Strategies & $\mathbf{1 9 9 0 \$}$ \\
\hline Alternative Strategy 1 & $\$ 75,000,000$ \\
\hline Alternative Strategy $2^{*}$ & $\mathbf{\$ 4 0 , 0 0 0 , 0 0 0}$ \\
\hline Alternative Strategy $3^{* *}$ & $\$ 110,000,000$ \\
\hline Alternative Strategy 4 & $\$ 105,000,000$ \\
\hline
\end{tabular}

* Preferred Alternative $\quad$ ** Does Not Include the Cost of Fuel Switching

\subsubsection{Maximize Deliverability in View of Social and Political Factors}

In every decision process, factors other than economic or financial impacts affect the final decision. "iese influences are largely political and/or social and can strongly affect whether an alternative strategy is practical and achievable, regardless of its economic attractiveness. Certain technologies or actions may be well known and proven, but public acceptance may keep them from occurring. This evaluation factor attempts to assess the impact of factors such as regulatory influences, institutional complexity, and public acceptability on the ability to implement each alternative strategy.

It is likely there will be sume overlap with the environmental impacts and other evaluation factors. However, this factor assesses how the perception of environmental impacts affects the feasibility, or deliverability, of a particular alternative. It does not necessarily follow that the alternative' with the fewest or mos' benign environmental impacts will be the most deliverable. Finally, in contrast to other evaluation factors, this factor is largely the result of judgment.

Members of the Sounding Board were asked to rank each measure on a scale ranging from deliverable (1) to undeliverable (4). Rankings of the 19 members present were averaged and are shown in Table 4-6. Only the measures that differ among the alternatives are presented in the table below. We found little difference in deliverability among alternative strategies. Conservation measures, included in all four alternatives, are ranked as deliverable to somewhat deliverable (1.4 to 1.9). For contrast, a nuclear plant was rated as undeliverable (3.7). The No Action alternative was not ranked. 
Table 4-6. Deliverability

\begin{tabular}{|c|c|}
\hline \multicolumn{1}{|c|}{ Strategies } & Deliverability \\
\hline Alternative Strategy $\mathbf{1}$ & $\mathbf{1 . 6}$ \\
\hline Transmission Line & 1.6 \\
\hline Alternative Strategy $\mathbf{2}^{*}$ & $\mathbf{1 . 5}$ \\
\hline Voltage Support 2 & 1.5 \\
\hline Alternative Strategy $\mathbf{3}$ & $\mathbf{2}$ \\
\hline Water Heater Control & 2 \\
\hline Time-of-Use Rates & not ranked \\
\hline Fuel Switching & 1.8 \\
\hline Alternative Strategy $\mathbf{4}$ & $\mathbf{1 . 7}$ \\
\hline Combustion Turbines & 1.7 \\
\hline
\end{tabular}

$1=$ Deliverable $2=$ Somewhat Deliverable $3=$ Somewhat Undeliverable $4=$ Undeliverable *Preferred Alternative

\subsubsection{Maximize Power System Reliability}

Reliability is a measure of the capability of the power system to meet consumer demanas over a period of time. It is typically measured in terms of unreliability, such as how often outages occur, how long they last, and how much load is affected. The goal is to maximize reliability to the extent economically justifiable.

Planners use a set of rules, such as the BPA Reliability Criteria, to establish reliability requirements for the power system. All proposed alternatives must meet the tests specified in the Criteria. However, even after meeting the tests, each alternative may provide a different level of reliability. For example, two transmission circuits on the same tower pose a greater risk than two transmission circuits on separate rights-of-way.

Existing transmission reliability models are not capable of examining the Puget Sound area peak load problem because of the complexity of the system and the difficulty of detecting voltage collapse. Therefore, a simplified analysis was performed that qualitatively ranks the alternatives according to their respective reliability. The results of the analysis are illustrated in Table 4-7. 
Table 4-7. Reliability

\begin{tabular}{|l|c|}
\hline \multicolumn{1}{|c|}{ Strategies } & Reliability \\
\hline Alternative Strategy 1 & $\mathbf{2}$ \\
\hline Transmission Line & 2 \\
\hline Alternative Strategy 2* & $\mathbf{2}$ \\
\hline Voltage Support 2 & 2 \\
\hline Alternative Strategy 3 & $\mathbf{2}$ \\
\hline Water Heater Control & 2 \\
\hline Time-of-Use Rates & 2 \\
\hline Fuel Switching & 1 \\
\hline Alternative Strategy 4 & $\mathbf{2}$ \\
\hline Combust* on Turbines & 2 \\
\hline 1= Highly Re iable 2=Reliable 3=Somewhat Reliable & $4=$ Not Very Reliable \\
\hline
\end{tabular}

The following factors were considered:

- Number of units (100,000 water heaters vs. two transmission circuits)

- Failure rate (based on experience, how often it is unavailable)

- Common mode outages (loss of one tower with two transmission circuits)

All of the measures were ranked on a scale of highly reliable (1) to not very reliable (4). Of the measures that are different among the alternatives, only fuel switching stands out as highly reliable (1). This is because an appliance, such as an electric water heater, is removed, and cannot add to the peak load problem. At the other extreme, a nuclear plant, with a lot of eggs in one large basket, was ranked as not very reliable (4). We cannot differentiate among the alternatives based on measure reliability.

\subsubsection{Surplus Capacity}

One factor which is not captured by the evaluation is the potential benefits of surplus capacity provided by each alternative. Some alternatives, such as the transmission line, provide more capacity than needed during the decision period. Table 4-8 gives the surplus capacity that exists for each strategy in 2003. 
Table 4-8. Surplus Capacity of the Strategies

\begin{tabular}{|c|c|}
\hline Strategies & $\begin{array}{c}\text { Excess Capacity } \\
\text { (MW) }\end{array}$ \\
\hline Alternative Strategy 1 & 1,608 \\
\hline Alternative Strategy 2* & 608 \\
\hline Alternative Strategy 3 & 408 \\
\hline Alternative Strategy 4 & 28 \\
\hline
\end{tabular}

* Preferred Alternative

These margins provide for additional reliability throughout the decision period should the deficit increase due to higher load growth or a delay in expected generation or conservation. In addition, the margin can serve load growth beyond the decision period without requiring further investment.

\subsubsection{Summary}

Findings $f$ or the six economic and technical evaluation factors are tabulated below. The alternative which ranks highest, or gioup of high ranking alternatives, are shown in bold.

Table 4-9. Economic and Technical Evaluation Summary

\begin{tabular}{|c|c|c|c|c|}
\hline \multirow[b]{2}{*}{ EVALUATION FACTORS } & \multicolumn{4}{|c|}{ ALTERNATIVE STRATEGIES } \\
\hline & Strategy 1 & Strategy $2^{*}$ & Strategy 3 & Strategy 4 \\
\hline Net Present Value & $\$ 67,000,000$ & $\$ 105,000,000$ & $-\$ 128,000,000$ & $\$ 39,000,000$ \\
\hline Sensitivity to Load Growth & $\$ 196,000,000$ & $\$ 126,000,000$ & $\$ 84,000,000$ & $\$ 102,000,000$ \\
\hline Near Term Revenue Requirements & $\$ 50,000,000$ & $\$ 25,000,000$ & $\$ 50,000,000$ & $\$ 20,000,000$ \\
\hline Long Term Revenue Requirements & $\$ 75,000,000$ & $\$ 40,000,000$ & $\$ 110,000,000$ & $\$ 105,000,000$ \\
\hline Deliverability $(1=\mathrm{Hi}, 4=\mathrm{Low})$ & 1.6 & 1.5 & 2.0 & 1.7 \\
\hline$(1=H i, 4=L o w)$ & 2.0 & 2.0 & 2.0 & 2.0 \\
\hline
\end{tabular}




\subsection{ENVIRONMENTAL CONSULTATION, REVIEW, AND PERMIT REQUIREMENTS}

Several Federal laws and administrative procedures must be met depending on the actions contained in the selected Plan. This section lists and briefly describes requirements that may need to be met by a specific project. Some of the requirements listed relate to site-specific impacts beyond the scope of this DEIS. These will be addressed through any site-specific EIS's. Since all measures are not part of the alternative strategies, some of the requirements listed will not apply. This is noted. Table 5-1 shows which measure must meet which requirement. For example, if a new transmission line is in the Plan, a checkmark shows which requirement must be met. If BPA proposes an action, all requirements of NEPA will be met. All requirements of the Washingtun State Environmental Policy Act (SEPA) will be met by participating utilities proposing an action.

\subsection{NATIONAL ENVIRONMENTAL POLICY ACT}

This DEIS is prepared according to NEPA (42 USC 4321 et seq.). BPA will take into account potential environmental consequences and will take action to protect, restore, and enhance the environment.

\subsection{ENDANGERED AND THREATENED SPECIES}

The Endangered Species Act (16 USC 1536) provides for conserving endangered and threatened species of fish, wildlife and plants. Federal agencies must ensure proposed actions do not jeopardize the continued existence of any endangered or threatened species, or cause the destruction or adverse modification of their habitat. When conducting any environmental impact analysis for specific projects, agencies must identify practicable alternatives to conserve or enhance such species.

A consultation letter was sent to the Department of Fish and Wildlife requesting a list of endangered and threatened species in the siting area. Listed species include wintering bald eagles that may occur in the vicinity of the project area from October 1 through March 31 as well as the northern spotted owl. No proposed species have been identified. A candidate species, the long-billed curlew may also occur in the vicinity of the project area. A biological assessment has been initiated by a BPA wildlife biologist to determine if the building of a substation would interfere with species needs. No interference is expected.

\subsection{FISH AND WILDLIFE CONSERVATION}

The Fish and Wildlife Conservation Act of 1980 (16 USC 2901 et seq.) encourages Federal agencies to conserve and promote conservation of non-game fish and wildlife species and their habitats. The Northwest Power Planning Council's Protected Areas, intended to protect, mitigate, and enhance fish and wildlife of the Columbia River and its tributaries, are part of the screening criteria used to eliminate alternatives from this Plan. Other identified critical areas are precluded from development because it would cause significant adverse effects to fish and wildlife. The Fish and Wildlife Coordination Act (16 USC 661 et seq.) requires Federal agencies undertaking projects affecting water resources to consult with the U. S. Fish and Wildlife Service to conserve or improve wildlife resources. As projects are proposed, BPA will consult with the U.S. Fish and Wildlife Service to conserve and improve wildlife resources.

Water resources that promcte fish and wildilife habitat $r$ ave been identified in the siting area. All four proposed locations are far enough away from water resources thai the do not interfere with surface flow or riparian vegetation. The Washington Department of Wildlife will be contacted to deiormine if the proposed site locations interfere with any upland wildlife habitat migration patterns. No interference is anticipated. 
Puget Sound Area Electric Retiability Plan -Draft Environnenfial Impact Statement

\subsection{HERITAGE CONSERVATION}

Congress has passed many Federal laws to protect the nation's historical, cultural, and prehistoric resources. These include the National Historic Preservation Act, the Archeological Resources Protection Act, the American Indian Religious Freedom Act, the National Landmarks Program, and the World Heritage List. Preserving cultural resources allows Americans to have an understanding and af preciation of their origins and history. A cultural resource is an object, structure, building, site or district that provides irreplaceable evidence of natural or human history of national, state or local significance. Cultural resources include National Landmarks, Natural Landmarks, archeological sites, and properties listed (or eligible for listing) on the National Register of Historic Places.

Table 5-1.

\section{Environmental Consultation $\frac{\text { Review, and Permit }}{\text { Requirements Matrix }}$}

$\checkmark$ Possible Consultation, Review and Permit Requirement

\section{Requirements List}

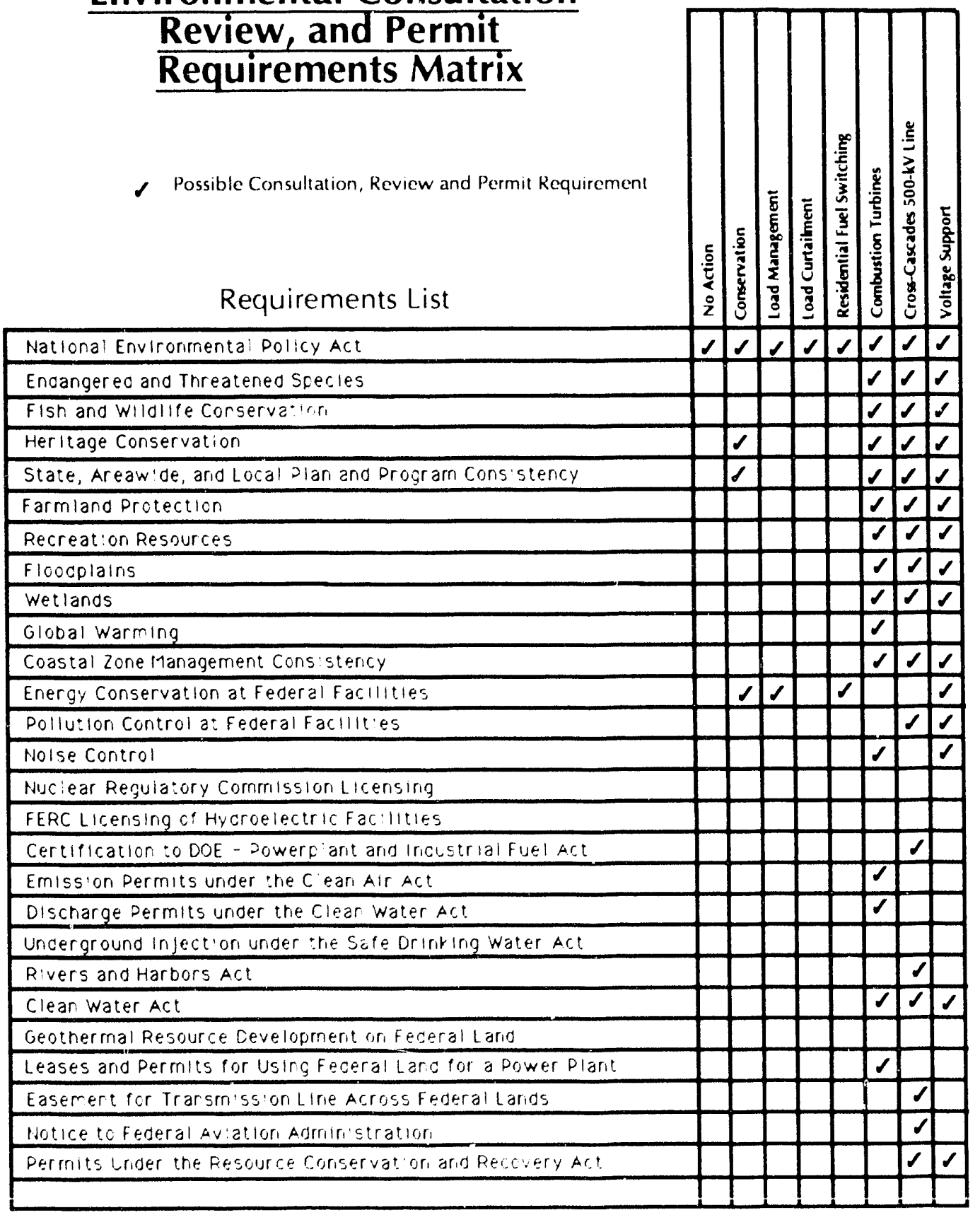

Measures 
Any energy conservation and load management measures that would be undertaken as part of the Plan would follow the procedures in the 1983 Programmatic Memorandum of Agreement for BPA's energy conservation programs, prepared in accordance with Section 106 of the National Historic Preservation Act and implementing regulations at 36 CFR Part 800 . Heritage conservation consultation requirements are therefore fully satisfied for energy conservation and load management measures.

Construction and operation of transmission measures may affect historic properties and other cultural resources. A consultation letter was sent to the Washington State Historic Preservation Office requesting a list of resources that are located in the siting area. They responded that "No National Register or eligible properties are known to exist within the area of the undertaking's potential environmental impact, but it is highly possible that the area contains undiscovered historic sites of potential significance. Therefore, a cultural resources field survey is required". BPA will conduct a cultural resources survey and the findings will be reported in the FEIS. It is BPA policy to comply with requirements should previously unidentified cultural resources be revealed during construction.

Load Curtailment undertakings would not alter existing properties and therefore historic or cultural resources would be unaffected.

\subsection{STATE, AREAWIDE, AND LOCAL PLAN AND PROGRAM CONSISTENCY}

BPA and the Puget Sound area utilities will coordinate distribution of this plan with clearinghouses for State and local agency review and consultation as required by Executive Order 12372. BPA will follow each State's permit process and will be consistent with land use plans. Individual projects would be coordinated with state and local government agencies to ensure all requirements are met.

The Kittitas Planning Department was contacted regarding land use consistency for the proposed new substation. Siting of transmission facilities on Forest/Rangeland will require a plan amendment and application for a conditional-use permit.

\subsection{FARMLAND PROTECTION}

The Farmland Protection Policy Act (7 USC 4201 et seq.) directs Federal agencies to identify and quantify adverse impacts of Federal programs on farmlands. The Act's purpose is to minimize the amount Federal programs contribute to unnecessary and irreversible conversion of agricultural land to non-agricultural uses. As individual projects or actions are proposed, local Soil Conservation Service maps will be used to decide whether any prime or unique farmland or additional land of local importance is affected.

A letter was sent to the Soil Conservation Service requesting identification of any proposed sites as prime agricultural or forest land. None were identified in the siting area.

\subsection{RECREATION RESOURCES}

Recreation resources are areas designated by the Wild and Scenic Rivers Act, the National Trails System Act, the Wilderness Act, or parklands, and other ecologically sensitive areas. These areas are excluded from development in this Plan as part of the screening factors for alternatives, and would therefore not be affected by any of the alternatives.

The Washington Department of Natural Resources was contacted regarding recreational use within the siting area. Hunting is very popular in the canyon areas surrounding Wilson and Naneum Creeks to the north of the siting area. The creek areas are a popular weekend destination for the people of Ellensburg. As potential sites are located away from creek habitats, no interference with recreational uses is anticipated. 


\subsection{FLOODPLAINS}

Floodplains are the lowlands adjoining inland and coastal waters, and flat areas and flood-prone areas of offshore islands. Under Executive Order 11988, floodplain development is discouraged whenever there is a practicable alternative. If specific projects are proposed that might cause development in a floodplain, alternatives to developing in the floodplain will be considered.

Inspection of floodplain maps reveal proposed locations for the new substation are far from both Wilson and Naneum Creeks, both of which flow through the siting area.

\subsection{WETLANDS}

Areas inundated by surface or groundwater sufficient to support vegetative or aquatic life requiring saturated or seasonally saturated soil conditions for growth and reproduction are known as "wetlands." Examples include swamps, marshes, bogs, and similar areas such as sloughs, potholes, wet ineadows, river overflow areas, and mudflats. Under Executive Order 11990, construction in wetlands is discouraged whenever there is a practicable alternative. For specific projects other regulations also may apply:

- Section 404 of the Clean Water Act

- Section 10 of the Rivers and Harbors Act of 1899

- National Environmental Policy Act

- Fish and Wildlife Coordination Act

- Emergency Wetlands Act of 1985

- state statutes

If a permit is needed for a specific project, permitting agencies must find that the project's public valuns exceed the resource's public values, and that there are no other practicable alternatives.

U.S. Fish and Wildlife maps were inspected for evidence of wetlands in the siting area. All wetlands are confined to areas bordering the creeks. As proposed sites are far from riparian habitats, no interference with wetlands will occur.

\subsection{GLOBAL WARMING}

As a federal agency, BPA has a responsibility and commitment to provide a reliable, cost-effective, environmentally sound electric power system. Global warming impacts are addressed in this environmental analysis, and will be considered for specific projects proposed where applicable.

\subsection{COASTAL ZONE MANAGEMENT CONSISTENCY}

The Coastal Zone Management Act of 1972 requires federal actions be consistent, to the maximum extent practicable, with approved state Coastal Zone Management Programs. If proposed projects could affect the coastal zone, BPA will consult with the state and ensure consistency with state programs.

Proposed site locations for the new substation are away from creeks located in the siting area and will not come under the jurisdiction of the Coastal Zone Management Act. 


\subsection{ENERGY CONSERVATION AT FEDERAL FACILITIES}

This will be addressed if any project involves constructing new or retrofitting existing federal facilities. Construction of the control house for the new substation project will comply with energy conservation standards for federal facilities. Any other proposals involving federal facilities will also need to follow these standards.

\subsection{POLLUTION CONTROL AT FEDERAL FACILITIES}

Several pollution control acts apply to federal facilities. If this Plan leads to new federal facilities (the new substation included), BPA will comply with the following statutes:

- Clean Air Act

- Resource Conservation and Recovery Act

- Toxic Substances Control Act

- Federal Insecticide, Fungicide and Rodenticide Act

- Noise Control Act

\subsection{NOISE CONTROL}

In Washington state, the Noise Control Act of 1974, amended by the 1987 legislature, gives authority to enforce noise codes to local governments. Operation of the new substation will comply with local noise standards. For other specific projects, BPA will consult with local government and comply with local noise standards.

\subsection{FEDERAL LICENSING AND PERMIT REQUIREMENTS FOR NEW POWER RESOURCES}

This section describes licensing and permit requirements for new power resources. Information on mitigating environmental impacts in the legislation requiring licenses or permits, or references to appropriate regulations covering mitigation, are included in the discussion. The focus here is licensing and permit requirements needed at the generation site. The required permits for fuel procurement, e.g., coal mining, and transportation to the generation site, are also important topics, but are outside the scope of this document. Peaking combustion turbines are the only new power resources considered in any of the alternative strategies. Therefore, the following two federal licensing requirements do not apply:

- Nuclear Regulatory Commission (NRC) Licensing

- Federal Energy Regulatory Commission Licensing of Hydroelectric Facilities

\subsubsection{Certification to DOE under the Powerplant and Industrial Fuel Use Act}

The Powerplant and Industrial Fuel Use Act of 1978, amended in 1981 and 1987, requires that baseload power plants with natural gas or petroleum as the primary energy source must have the capability to use coal or another alternative fuel as its primary energy source in lieu of natural gas or petroleum. Certification is submitted to DOE prior to constructing a new powerplant or converting an existing power plant to baseload operation.

\subsubsection{Emission Permits under the Clean Air Act}

The basic statute for regulating air quality in the U.S. is the Clean Air Act. Four Clean Air Act-related permits described here could apply to a new or modified power resource.

State Emission Permit - State emission permit programs ensure new or modified sources will not violate federal or state ambient air standards. 
Puget Sound Area Electric Reliability Plan -Draft Envirommental Impact Statement

Nonattainment Permit - Nonattainment permits are required for new or modified major stationary emission sources in nonattainment areas. Nonattainment areas are areas where ambient air quality standards are not being met. A major stationary source has the potential to emit 100 tons per year (tpy) or more of any pollutant subject to regulation under the Clean Air Act. The new source must meet the offset requirements of Section 173 of the Clean Air Act, which effectively require that the source provides a net improvement in air quality results.

Prevention of Significant Deterioration (PSD) - The PSD permit program applies to specific pollutants in geographic areas designated as meeting ambient air standards, i.e., attainment areas, and in unclassified areas. It is designed to prevent deterioration of air quality in these areas. Under the PSD program, new major stationary emission sources or major modifications to such sources must obtain a PSD permit setting emission limitations. The term "major emitting facilities" is defined to include certain specifically designated stationary sources with the potential to emit 100 tons per year (tpy) of any air pollutant and all other sources with the potential to emit 250 tpy of any pollutant.

Construction Approval - Construction approval is required for those new power resources subject to EPA's National Emission Standards for Hazardous Air Pollutants (NESHAP). Standards have been issued for certain types of facilities and specified pollutants including asbestos, arsenic, benzene, beryllium, mercury, radionuclides, and vinyl chloride.

\subsection{DISCHARGE PERMITS UNDER THE CLEAN WATER ACT}

The Clean Water Act (CWA) is the principal federal law governing water pollution control. The Act was passed in 1972 and amended in 1977 and 1987. It authorizes federal and state control of discharges into waters of the United States and municipal sewer systems. A person responsible for discharging pollutants into any waters of the United States frc,n a point source must obtain and comply with a permit issued under the National Pollution Discharge Elimination System (NPDES) established under Section 402 of the Act. Permits are issued by EPA or by a state with an EPA-approved permit system. Montana, Oregon, and Washington have authority delegated by EPA to issue NPDES permits. Yermits in Idaho are issued by the EPA Region 10 office in Seattle.

\subsection{UNDERGROUND INJECTION PERMITS UNDER THE SAFE DRINKING WATER ACT}

The principal federal program applicable to intentional discharges to groundwater is the Underground Injection Control (UIC) Program established by Section 1421 of the Safe Drinking Water Act. The UIC program is administered directly by states whose program has been approved by EPA. In the Northwest, UIC permits are issued by state agencies in Idaho, Oregon, and Washington. In Montana, UIC permits are issued by the EPA Region 8 office. Injections except as authorized by permit or rule issued under the UIC program are prohibited.

\subsection{PERMITS FROM THE ARMY CORPS OF ENGINEERS}

The U.S. Army Corps of Engineers administers several permit programs that may apply to certain new power resource projects.

\subsubsection{Rivers and Harbors Act}

A permit from the Corps is needed under Section 9 of the Rivers and Harbors Act of 1899 for constructing a dam or dike in navigable waters. The term "navigable waters" generally covers waters subject to the ebb and flow of the tide and/or waters usable for commerce transportation.

For hydroelectric projects licensed by FERC, the Corps normally recommends appropriate provisions to include in the FERC license rather than issuing a separate permit under Section 9. A permit from the Corps will be needed for hydroelectric projects on navigable waters exempt from the FERC licensing process. 
A permit from the Corps is also required under Section 10 of the Rivers and Harbors Act for constructing structures or work in or affecting navigable waters. Constructing a cooling water intake structure in navigable waters, for example, would require a permit under these regulations. Building electric power transinission lines across navigable waters would require a permit unless the lines are part of a water power project subject to FERC regulation.

\subsubsection{Clean Water Act}

Discharging dredged or fill materials into waters of the United States requires a permit from the Corps issued under the authority of Section 404 of the Clean Water Act. The term "waters of the United States" is defined very broadly and includes almost every surface body of water in the United States including wetlands. Permits are issued only after the state where the dredge or fill activity is to be located certifies under Section 401 of the CWA that existing water quality standards will not be violated if the permit is issued. Permits also must be consistent with the environmental guidelines established by EPA under Section 404(b) of the CWA. The EPA can veto permits authorized by the Corps if EPA finds that the discharge will have an unacceptable adverse effect on the environment.

A consultation letter was sent to the Corps of Engineers requesting that they review this project for permit requirements. They confirmed that a permit would be needed if dredge or fill activities occur in waters of the United States located in the siting area. As all proposed sites are far from these surface flows, a Section 404 permit will not be required.

\subsection{GEOTHERMAL RESOURCE DEVELOPMENT ON FEDERAL LANDS}

Several permits and approvals are needed to develop geothermal resources on federal lands. Under the Geothermal Steam Act of 1970, as amended, the Department of the Interior (DOI) is given authority to execute leases for developing geothermal resources on lands it administers, lands administered by the U.S. Department of Agriculture with that Department's consent, and on lands for which the United States has mineral rights. Competitive leasing is required for land located within any known geothermal resources area. A permit is required for exploration activities prior to executing a lease. Since developing geothermal resources failed the initial screening criteria, this requirement does not apply.

\subsection{LEASES AND PERMITS FOR USING FEDERAL LANDS FOR A POWER PLANT}

Constructing a power resource facility on federal lands requires approval of the agency administering the lands. The approval may be a special use permit or authorization, a lease, or an exchange of lands with the developer.

\subsection{EASEMENT FOR TRANSMISSION LINES ACROSS FEDERAL LANDS}

Building an electric power transmission line across federally owned lands requires the approval of the federal agency administering the lands. The approval may be an easement, a right-of-way authorization, a lease, a special use authorization, or a permit.

\subsection{NOTICE TO THE FEDERAL AVIATION ADMINISTRATION}

Building certain tall facilities such as a cooling tower at a power generation site may require notice to the Federal Aviation Administration (FAA). Specifically, building any facility $200 \mathrm{ft}$. or more above ground level requires notice to the FAA. 
Puget Sound Area Electric Reliability. Plan -Draft Environmentạl Impsict Statement

\subsection{PERMITS UNDER THE RESOURCE CONSERVATION AND RECOVERY ACT}

The Resource Conservation and Recovery ACt (RCRA), as amended, is designed to provide a program for managing and controlling hazardous waste by imposing requirements on generators and transporters of this waste, and on owners and operators of treatment, storage, and disposal (TSD) facilities. Each TSD facility owner or operator is required to have a permit issued by EPA or the state. Construction and maintenance activities in BPA's experience have generated small amounts of hazardous waste. These typically include: solvents, pesticides, paint products, motor and lubricating oils, and cleaners. Under EPA and V Vashington Department of Ecology regulations, the amounts of these wastes would fall within the definition for a "small quantity generator". BPA has a hazardous waste management program in place to assure compliance with Federal and State hazardous waste requirements. 


\subsection{LIST OF PREPARERS}

DENNIS AMIONSEN, P.E., Clectrical Engineer. Responsible for: Develop and review load curtailment measures. Education: B.S. Electrical Engineering. Experience: area engineering, system protection maintenance, power management; with BPA since 1972.

BOB ANDERSON, Public Utilities Specialist. Responsible for: Sector and end-use forecast. Education: M.S. Economics; B s. Economics. Experience: Puget Sound Area economist; with BPA since 1985.

KEN BARNHART, Project Environmental Coordinator. Responsible for: Coordination and completion of environmental requirements. Education: B.S. Landscape Architecture. Experience: Environmental analysis, energy facility planning and location, landscape architecture, appearance planning for substations and transmission lines; with BPA since 1971.

MIKE BERGER, P.E., Electrical Engineer. Responsible for: Generating resource supply forecast. Education: M.B.A.; B.S. Electrical Engineering. Experience: generating resources, project evaluation, quality control; with BPA since 1973.

MARK BOND, P.E., Chief, Project Studies Section. Responsible for: Project studies, transmission planning. Education: B.S. electrical engineering. Experience: system planning, area engineering, construction and maintenance; with BPA since 1974.

STUART CLARKE, External Affairs Manager. Responsible for: Public Involvement. Education: B.S. Economics. Experience: load forecasting, rates, contract negotiation and administration, power management; with BPA since 1981.

GORDON COMEGYS, P.E., Senior Electrical Engineer. Kesponsible for: Transmission system planning. Education: B.S. Electrical Engineering. Experience: insulation coordination, switching studies, system testing, field relay and system protection management; with BPA since 1976.

MAUREEN CONNER, P.E., Electrical Engineer. Responsible for: Writing and editing load management material. Education: B.S. Electrical Engineering. With BPA as a consultant from1989-1990.

KATHLEEN CONCANNON, Writer. Responsible for: Writing and editing the EIS. Education: B.S. Geology. Experience: environmental analysis, NEPA process, resource planning; with BPA since 1980 (as a consultant since June 1990).

ALAN L. COURTS, P.E., Project Manager. Responsible for: Overall project management, management of Puge. Sound utility study team. Education: Graduate study electrical engineering; B.S. Electrical Engineering. Experience: high voltage tr.unsmission engineering, research and development; transmission planning; engineering management; with BPA since 1973.

ANNE DRAPER, Public Affairs Specialist. Responsible for: Public involvement. Education: Master of Management; B.A. Sociology; B.S. Modern Languages. Experience: external affairs, load forecasting, energy conservation; financial management, management analysis; with BPA since 1982.

ELIZABETH EVANS, Public Utility Specialist. Responsible for: Economic evaluation of proposed test cases. Education: PhD. Population Biology; M.S. Urban Planning; B.S. Biology. Experience: Resource Planning and policy analysis; with BPA since 1986. 
Puget Sound Area Electric Reliability Plan -Draft Environmental Impact Statement

CHUCK FORMAN, Chief, Residential and Commercial Forecasting Section. Responsible for: Identifying load characteristics and producing load forecasts. Education: M.S. Public Administration; B.S. Economics. Experience: 9 years load forecasting; with BPA since 1981.

RICH GILLMAN, Section Chief. Responsible for: Supervising various primary demand-side data collection efforts including surveys and direct metering, research and analysis of data collected, computerization of data. Education: M.S. Economics; B.S. Economics. Experience: supervision, project management, peak and load shape analysis, forecasting, rate development; with BPA since 1981.

ION HIRSCH, Industry Economist. Responsible for: Developing load factors for extreme and normal peaks. Education: M.B.A.; B.A. Economics. Experience: power forecasting; with BPA since 1983.

DIANE HOLLISTER, Industry Economist. Responsible for: Conservation and load management analysis. Education: M.A. Economics, B.A. Business Administration. Experience: rate design, NEPA analysis for rate cases, economic analysis of conservation options; with BPA since 1985.

MARVIN LANDAUER, P.E., Senior Electrical Engineer. Responsible for: Transmission system planning studies. Education: B.S. electrical engineering. Experience: transmission planning and high voltage equipment, with BPA since 1976.

ERIC B. LOWRANCE, Geographic Information Specialist (CIS). Responsible for: GIS database design, analysis, and cartographic output. Education: Graduate study in geography, B.S. Geology. Experience: GIS database design, analysis and cartographic output; with BPA as a consultant since 1987.

DENNIS PORTER, P.E., Assistant Director, Division of System Planning. Responsible for: development and review of measures within the transmission category. Education: B.S. electrical engineering. Experience: transmission system planning, reliability criteria, policy development, system protection maintenance; with BPA since 1968.

GEORGE REICH, Area Power Manager. Responsible for: Development and review of load curtailment measures. Education: M.S. Electrical Engineering; B.S. Electrical Engineering. Experience: system engineering, customer service, contracts; with BPA since 1972.

HAIG REVITCH, Public Utilities Specialist. Responsible for: Cost allocation and rate design. Education: M.B.A. Finance and Investment; B.S. Business Administration. Experience: cost allocation and rate design; with BPA since 1981.

LEROY P. SANCHEZ, Visual Information Specialist. Responsible for: Graphics support relating to transmission facilities, environmental impact and assessment analysis. Education: Graphic Design. Experience: GIS mapping, including federal transmission EIS; with BPA since 1978.

RONALD SANDS,Economist. Responsible for: Hourly modeling of conservation, load management, and fuel switching programs. Education: Ph.D. Economics; B.S. Electrical Engineering. Experience: simulation models, load shape analysis; with BPA as a consultant since 1986.

STEPHEN D. SHERER, Geographer, Geographic Information Systems Manager. Responsible for: GIS management. Education: B.S. Geography. Experience: 15 years GIS/image processing related to transmission facilities; environmental impact analysis; with BPA since 1975.

BRIAN SIL VERSTEIN, P.E., Chief, Advanced Planning Staff. Responsible for: Economic evaluation of test cases and proposed alternative strategies. Education: M. Eng. electrical engineering; B. Eng. electrical engineering. Experience: transmission reliability analysis, rate design, policy development; with BPA since 1979. 
PHILIP SMIIH GIS Specialist. Responsible for: GIS daiabase design and geographic analysis. Education: M.S. soil science; B.S. Agronomy. Experience: GIS/image processing experience; soils, agriculture and water analysis; with BPA as a consultant since 1981.

ARNOLD VINNARD Industry Economist. Responsible for: Conservation and load management analysis. Education: M.A. Eronomics, B.A. Philosophy. Experience: economic and financial analysis, policy making; with BPA since 1983.

WENDY WHEELER, Economist. Responsible for: Load forecasting, analyzing historical load forecasts, review forecast projections. Education: B.A. Economics. Experience: same as above; with BPA since 1990.

ROBERT G. WHITE GIS Specialist. Responsible for: GIS database design and analysis. Education: M.S. natural resource management; B.A. psychology. Experience: 9 years GIS/image processing experience related to natural resources; with BPA as a consultant since 1986.

THOMAS I. WHITE, Writer/Editor. Responsible for: Writing and editing. Education: M.S. mechanical engineering; B.S. mechanical engineering; B.A. biological sciences. Experience: technical writer, documentation of software applications, development of training materials, load analysis, conservation and generation program development; project mechanical engineer for BPA since 1981; with BPA as a consultant since 1989.

SCOT WILSON, Industry Engineer. Responsible for: Economic evaluation of test cases and proposed alternative strategies. Education: B.A. Economics. Experience: resource planning, and policy analysis; with BPA since 1989.

NANCY A. WITTPENN Environmental Planner. Responsible for: Environmental data collection and analysis, coordination for the EIS. Education: M.S. marine geophysics; B.S. geology. Experience: resource management, environmental analysis; with BPA as a consuitant since 1989.

DON WOLFE, Public Utilities Specialist. Responsible for: Evaluating existing curtailment impacts and rights. Education: J.D.; B.A. Psychology. Experience: environmental analysis, resource planning, power marketing, contract negotiations; with BPA 1976-1982; 1988 to present.

LOHN M. ZIMMERLY, Geographer. Responsible for: GIS database automation, geographic analysis and cartographic output. Education: Graduate study in GIS; B.S. Biology. Experience: GIS database automation, geographic analysis and cartographic output; with BPA as a consultant since 1988. 
Puget Sound Area Electric Reliability Plan -Draft Environmental Impact Statement

\section{PROJECT MANAGEMENT TEAM}

A project management team has been appointed to ovcrsee project activities, provide project review and serve in a decision making capacity. The following lists utility representatives.

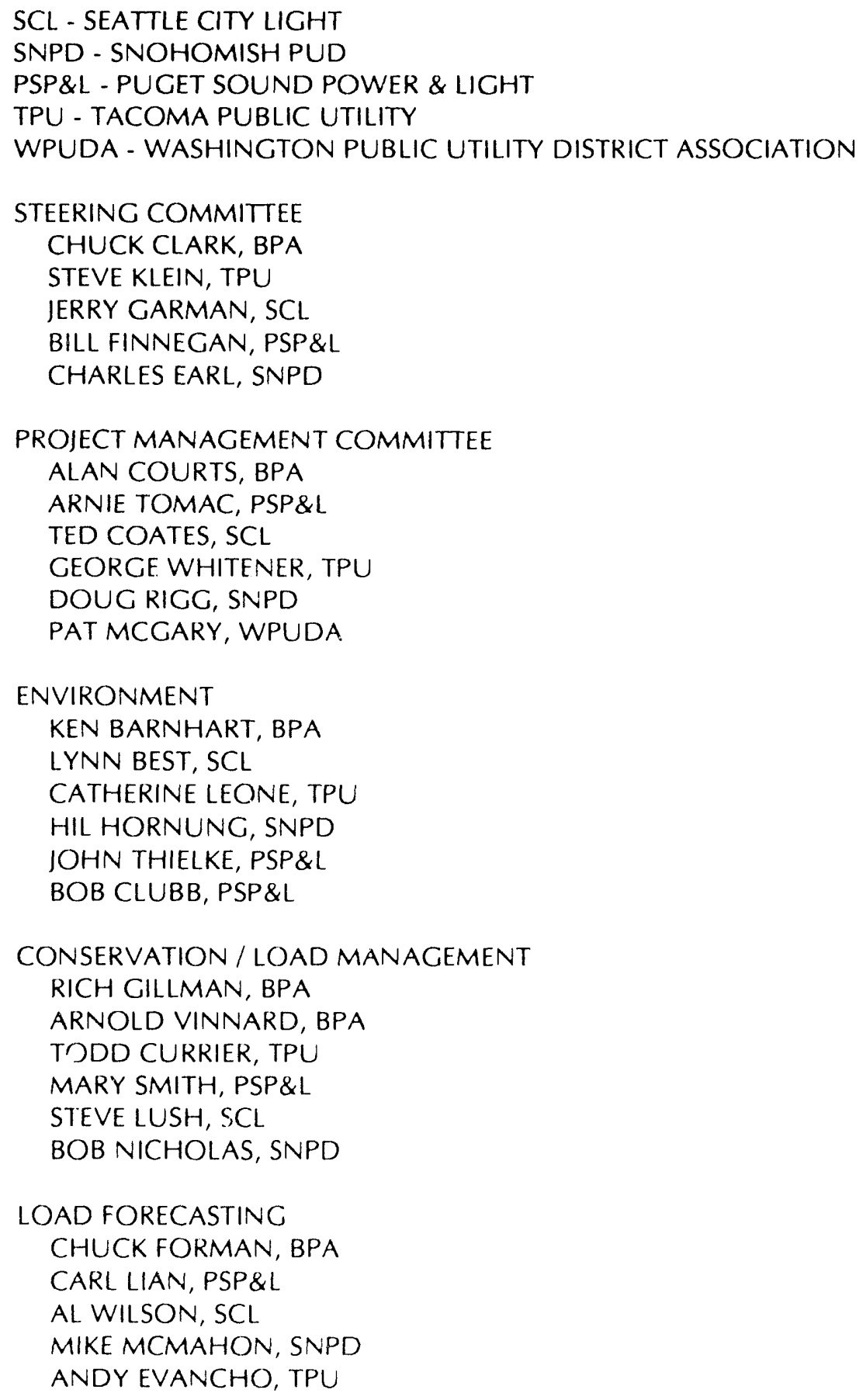




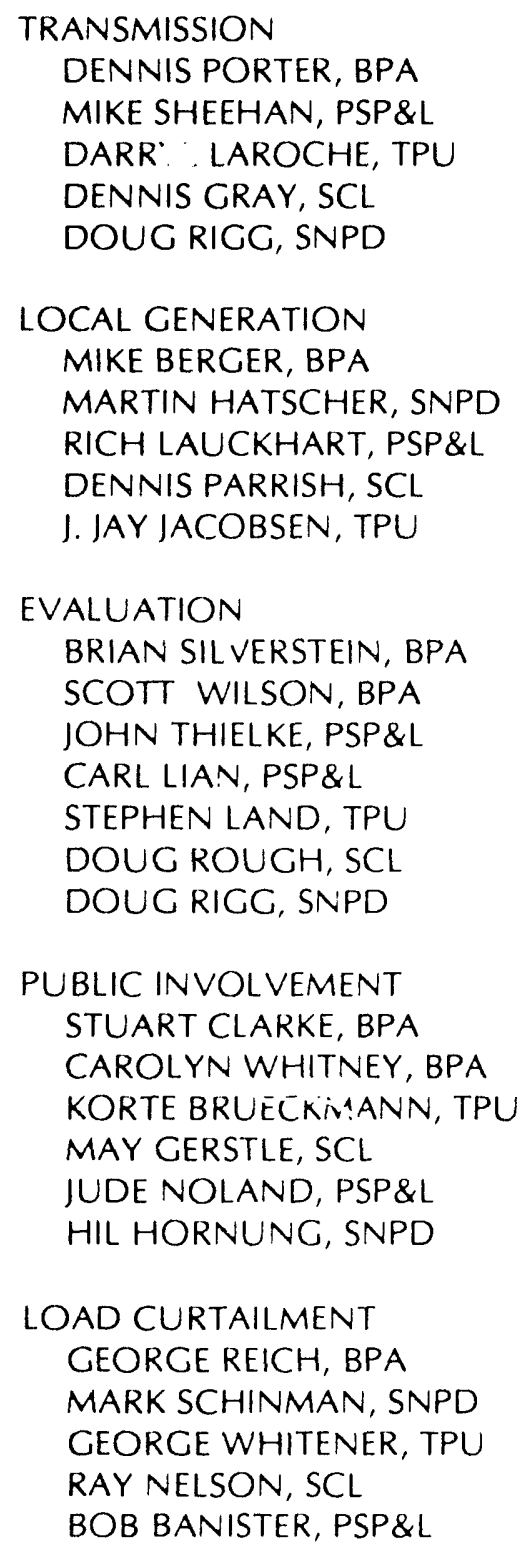

A special thanks is extended to all those who participated as members of the Technical Review Group and the Sounding Board. Your input on process and decision making was invaluable and greatly appreciated. 


\title{
7.0 LIST OF AGENCIES, ORGANIZATIONS, AND PERSONS TO WHOM COPIES OF THE EIS ARE SENT
}

\section{FEDERAL AGENCIES}

\author{
US Environmental Protection Agency, Region X, Seattle, WA \\ US Army Corps of Engineers, Seattle, WA \\ USDOE Federal Energy Regulatory Commission, Portland, OR \\ US Army Corps of Engineers, Seattle, WA \\ USDA Forest Service, Seattle, WA \\ USDA Soil Conservation Service, Portland, OR \\ USDOC National Oceanic and Atmospheric Administration, Seattle, WA \\ USDOE, Richland, WA \\ USDOI Bureau of Indian Affairs, Portland, OR \\ USDOI Bureau of Land Management, Portland, OR \\ USDOI Bureau of Reclamation, Yakima, WA \\ USDOI Fish and Wildlife Service, Olympia, WA \\ USDOI National Park Service, Seattle, WA \\ USDOT Federal Aviation Administration, Seattle, WA \\ US Housing and Urban Development, Seattle, WA
}

\section{TRIBAL ORGANIZATIONS}

\section{OREGON}

Affiliated Tribes of Northwest Indians, Portland

Columbia River Intertribal Fish Commission, Portland

\section{WASHINGTON}

Northwest Indian Fisheries Commission, Olympia, WA Confederated Tribes of Colville Reservation, Nespelem Muckleshoot Tribe, Auburn

Pcrt Gamble Klallam Tribe, Kingston

Swinomish Tribal Community, La Conner

Yakima Indian Nation Tribal Council, Toppenish

Nooksack Tribe, Deming

Tulalip Tribe, Marysville

Small Tribes of Western Washington, Taholah

\section{WASHINGTON STATE AGENCIES}

Department of Community Development, Olympia

Denartment of Fisheries, Olympia

Utilities and Transportation Commission, Olympia 
Department of Natural Resources, Olympia

Office of Archeology and Historic Preservation, Olympia

Office of Energy, Olympia

Department of Ecology, Olympia

Department of Wildlife

Energy Facility Site Evaluation Council

\title{
WASHINGTON LOCAL/COUNTY AGENCIES
}

\author{
City of Olympia \\ City of Seattle \\ City of Tacoma \\ City of Wenatchee \\ City of Port Angeles \\ City of Richland \\ City of Bellevue \\ City of Everett \\ County of Benton and Franklin Governmental Conference, Richland \\ County of Whatcom, Council of Governments, Bellingham \\ County of Chelan, Governmental Conference, Wenatchee \\ County of Lewis, Board of Commissioners, Chehalis \\ County of Clallam \\ County of Douglas \\ County of Grant \\ County of Grays Harbor \\ County of Island \\ County of Jefferson \\ County of King \\ County of Kitsap \\ County of Kittitas \\ County of Mason \\ County of Okanogan \\ County of Pierce \\ County of San Juan \\ County of Skagit \\ County of Snohomish \\ County of Thurston \\ County of Yakima \\ Cowlitz Wahkiakum Governmental Conference, Kelso \\ Douglas Regional Planning Commission, East Wenatchee \\ Grays Harbor Regional Planning Commission, Aberdeen \\ Jefferson Port Townsend Regional Council, Port Townsend \\ Puget Sound Council of Governments, Seattle \\ Skagit Council of Governments, Sedro Woolley \\ Thurston Regional Planning Council, Olympia
}




\section{INTEREST GROUPS}

Clearing Up, Seattle, WA

Northwest Steelheaders, Milwaukie, OR

Columbia Basin Fish \& Wildlife Authority, Portland, OR

Common Cause, Olympia, WA

Fair Electric Rates Now, Olympia, WA

Friends of the Earth, Seattle, WA

Nature Conservancy, Seattle, WA

Northwest Conservation Act Coalition, Seattle, WA

Audubon Society, Seattle, WA

Sierra Club, Seattle, WA

Washington Wilderness Coalition, Seattle, WA

Elder Citizens Coalition of Washington, Seattle, WA

Fair Use of Snohomish Energy, Snohomish, WA

Fuse Ratepayer, Everett, WA

Northwest Steelheaders, Vancouver, WA

Washington Environmental Council, Seattle, WA

\section{WASHINGTON CLEARINGHOUSES}

Chelair County Governmental Conference, Wenatchee

County of Clallam Intergovernmental Clearinghouse, Port Angeles

County of Clark District Clearinghouse, Vancouver

County of Lewis District Clearinghouse, Chehalis

County of Whatcom District Clearinghouse, Bellingham

Department of Ecology, Olympia

Douglas Regional Planning Commission District Clearinghouse, East Wenatchee

Grays Harbor Regional Planning Commission District Clearinghouse, Aberdeen

Jefferson Port Townsend Regional Council District Clearinghouse, Port Townsend

Thurston Regional Planning Council District Clearinghouse, Olympia

Trico Economic Development District Clearinghouse, Colville

Washington Association of Counties, Olympia

\section{WASHINGTON CONGRESSIONAL REPRESENTATIVES}

Brock Adams, Senator, Seattie

Slade Gorton, Senator, Seattle

John Miller, Representative, Edmonds

Al Swift, Representative, Bellingham and Everett

Jolene Unsoeld, Representative, Olympia and Vancouver

Sid Morrison, Representative, Yakima and the Tri Cities

Norman D. Dicks, Representative, Tacoma and Bremerton

Jim McDermott, Representative, Seattle

Rod Chandler, Representative, Bellevue 


\section{STATE GOVERNOR}

Governor of Washington, Olympia

\section{WASHINGTON STATE LEGISLATORS}

Dean Sutherland, Senator, Vancouver

Leo Thorseness, Senator, Renton

Bill Grant, Representative, Walla Walla

Fred May, Representative, Mercer Island

\section{DEPOSITORY LIBRARIES}

\section{OREGON}

Bonneville Power Administration Library, Portland

Oregon State Library, Salem

\section{WASHINGTON}

Western Washington University, Bellingham

Central Washington University Library, Ellensburg

Everett Public Library, Everett

Evergreen State College, Olympia

Washington State Library, Olympia

North Olympic Library System, Port Angeles

Seattle Public Library, Seattle

University of Washington Libraries, Seattle

University of Washington Marion Gould Gallagher Law Library, Seattle

U.S. Court of Appeals. Seattle

Tacoma Public Library, Tacoma

University of Puget Sound Collins Memorial Library, Tacoma

University of Puget Sound School of Law Library, Tacoma

Fort Vancouver Regional Library, Vancouver

\section{UTILITY \& UTILITY ASSOCIATIONS}

City of Port Angeles, Department of Light, Port Angeles WA

City of Tacoma, Department of Public Utilities Power Management, Tacoma WA

Chelan County PUD NO 1, Wenatchee WA

Clallam County PUD NO 1, Port Angeles WA

Clark County PUD NO 1, Vancouver WA

Cowlitz County PUD NO 1, Longview, WA

Douglas County PUD, Wenatchee, WA

Douglas County PUD NO 1, East Wenatchee WA

Grays Harbor County PUD, Aberdeen WA

Industrial Customers of Northwest Utilities, Portland OR

Lewis County PUD, Chehalis WA

Mason County PUD NO 3, Shelton WA

Northwest Natural Gas Company, Portland OR 
Northwest Power Pool, Portland OR Northwest Utilities, Tacoma WA OHOP Mutual Light Company, Eatonville WA Pacific Northwest Utilities Conference Committee, Portland OR Puget Sound Power \& Light Company, Seattle WA Seattle City Light, Seattle WA Snohomish County PUD NO 1, Everett WA Tacoma Public Utilities, Tacoma WA Wahkiakum County PUD NO 1, Cathlamet WA Washington Public Power Supply System, Richland WA Washington PUD Association, Seattle WA Western Washington PUD Corp., Mill Creek WA Whatcom County PUD, Ferndale WA

\title{
BUSINESSES
}

\author{
Pacificorp Electric Operations Group, Portland OR \\ Multipoint Control Systems Inr., Everett WA \\ Boeing Company, Seattle WA \\ $\mathrm{CH}$ Bowers Engineering, Seattle WA \\ Heatways, Federal Way WA \\ Boeing Commercial Appliances, Kent WA \\ Kaiser Aluminum \& Chemical Corporation, Portland OR \\ EBASCO, Bellevue WA \\ Energy Saving Services, Bellevue WA \\ Branch Richards Anderson \& Company, Seattle WA \\ Earle M. Jorgensen Company, Seattle WA \\ Economic \& Engineering Services Inc., Bellevue WA \\ United Industries, Bellevue WA \\ Intalco Aluminum Corporation, Ferndale WA \\ Insul Tray Inc., Redmond WA
}

\section{CANADA}

BC Utilities Commission, Vancouver, BC

BC Hydro \& Power Authority, Vancouver, BC

Canadian Consulate General, Seattle, WA

Department of Fisheries and Oceans, Vancouver BC

Ministry of Energy, Policy Development Branch, Victoria BC

\section{OTHERS}

Northwest Power Planning Council

\section{INDIVIDUALS}

Project mailing lists were started at the beginning of the scoping process. It is the intent of the environmental group to send the summary of the Final EIS to each individual on the mailing lists with information on how to obtain the entire Final EIS. 


\subsection{REFERENCES}

Alessio Frank J., Lewin, Peter, and Parsons, Steve G. The Layman's Guide to the Value of Electric Power Reliability. Palo Alto, California. 1986.

American Gas Association. Planning and Analysis Issues, Issue Brief 1990-5, p. 10. April 1990.

Baechler, M. E., Fickeisen, D. H., and Hendrickson, P. L. Environmental Effects and Mitigation for Energy Resources. Richland, Washington. 1990.

BYTE. Curing the Brownout Blues. Vol. 14, No. 4, p. 162, April 1989.

California Energy Commission. Energy Technology Status Report. Sacramento, California. 1988.

Ciliano, R. Environmental and Socioeconomic Consequences of a Shortage in Installed Generating Capacity. Palo Alto, California. 1986.

City of Seattle, City Light Department. Strategic Corporate Plan 1990-1991. Seattle, Washington. March 1990.

City of Tacoma, Department of Public Utilities, Light Division. Least Cost Resource Development Process. Tacoma, Washington. June 1990.

Cruver, Philip C. America is Running out of Power. USA Today. Vol. 118 pp. 62-63. July 1989.

Devine, Warren D., and Skott, Len Jr. The Cost of Electric Power Interruption to Manufacturers in the Tennessee Valley. Palo Alto, California. 1986.

Eaton, Thomas. Personal Communication to Nancy Wittpenn. Solid and Hazardous Waste Program, Washington State Department of Ecology. May 18, 1990.

Electric Power Research Institute. Customer Demand for Service Reliability, A Synthesis of the Outage Costs Literature. Research Project 2801-1. Palo Alto, California. 1989.

Electric Power Research Institute. Environmental and Socioeconomic Consequences of a Shortage in Installed Generating Capacity. Final Report. Palo Alto, California. 1982.

Electric Power Research Institute. Power Shortage Costs and Efforts to Minimize: An Example. Interim Report Project 1104-1. Palo Alto, California. 1979.

Electric Power Research Institute. The Value of Service Reliability To Consumers. Proceedings. EPRI Project 1104-6. Palo Alto, California. 1986.

Electric Power Research Institute. Workshop Proceedings: Environmental and Social Impacts of an Electricity Shortage. Special Report. Palo Alto, California. 1978.

IEEE Committee Report. Voltage Stability of Power Systems: Concepts, Analytical Tools, and Industry Experience, IEEE 90 TH 0358-2 PWR. 
Miles, William T., Corwin, Jane, and Blair, Peter D. Cost of Power Outages - The 1977 New York City Blackout. 1979 Reliability Conference for the Electric Power Industry. April 1979. pp. 193-197.

Myers, David R., Fullen, Robert E., Suta, Benjamin E., and Miller, Troy P. Impacts from a Decrease in Electric Power Service Reliability. Menlo Park, California. 1976.

Northwest Industrial Gas Users Newsletter. Vol. 90-3(2). August 1990.

Northwest Power Planning Council. Future Natural Gas Cost and Availability in the Pacific Northwest, Issue Paper 90-4, p. 20. Portland, Oregon. February, 1990.

Northwest Power Planning Council. Northwest Conservation and Electric Plan. Portland, Oregon. 1986.

Olsen, Marvin E. Social Effects of Electricity Restriction. Palo Alto, California. 1978.

Porter, Dennis, and Silverstein, Brian. Transmission Planning Criteria Reexamined. 16th Inter-RAM Conference for the Electric Power Industry, pp. 37-42. June 1990.

Puget Sound Power and Light Company. Securing Future Opportunities 1990-1991. Bellevue, Washirigton. December 1989.

Romanish, Orest. An Environmental Analysis of Demand-side Management at Ontario Hydro. 1990.

Sanghvi, Arun P. Economic Costs of Electricity Supply Interruptions: U. S. and Foreign Experience. Palo Alto, California. 1986.

Schmidt, Owen L. The Statement of Underlying Need Determines the Range of Alternatives in an Environmental Document. Portland, Oregon. 1989.

Sheets, Kenneth R. The Coming Power Crunch: With Demand Surging and Few New Plants, Many Electric Utilities Hope Conservation Can Help Stave Off Brownouts. U. S. News and World Reports. Vol. 106, p. 49 . June 1989.

Silverstein, Brian, and Porter, Dennis. Contingency Ranking for Bulk Sy'stem Reliability Criteria. IEEE/PES 1991 Summer Meeting, 91 SM 442-4 PWRS.

Sugarman, Robert. New York City's Blackout: a $\$ 350$ Million Drain. IEEE Spectrum. Vol. 15 (11). November 1978.

U. S. Department of Energy, Bonneville Power Administration. Draft 1990 Conservation Resources Supply Document. Portland, Oregon. 1990.

U. S. Department of Energy, Bonneville Power Administration. Draft 1990 Generation Resources Supply Document. Portland, Oregon. 1990.

U. S. Department of Energy, Bonneville Power Administration. Eugene-Springfield Area Planning Project Draft Environmental Impact Statement. Portland, Oregon. 1989.

U. S. Department of Energy, Bonneville Power Administration. Initial Northwest Power Act Power Sales Contracts Draft Environmental Impact Statement. Portland, Oregon. 1990. 
U. S. Department of Energy, Bonneville Power Administration. Intertie Development and Use Final Environmental Impact Statement. Portland, Oregon. 1988.

U. S. Department of Energy, Bonneville Power Administration. Draft Northern Cascades Availability Study. Portland, Oregon. 1990

U. S. Department of Energy, Bonneville Power Administration. 1990 Resource Program. Portland, Oregon. 1990.

U. S. Department of Energy, Bonneville Power Administration, Pacific Power and Light, and Portland General Electric. Third AC Intertie Northwest System Reinforcement Project. Environmental Report for the California-Oregon Transmission Project and the Los Banos-Gates Transmission Project Draft Environmental Impact Statement. Portland, Oregon. 1986.

U.S. Department of Energy, Bonneville Power Administration, Electrical and Biological Effects of Transmission Lines - A Review. Portland, Oregon. June 1989.

U.S. Department of Energy, Bonneville Power Administration, The BPA Identified Waste Stream Handbook. Portland, Oregon. August, 1991. 


\subsection{GLOSSARY/ACRONYMS}

AC - (see alternating current)

Alternating Current (AC) - An electric current or voltage that reverses its direction of flow at regular intervals and has alternately positive and negative values. In the United States 60 cycles are completed each second.

aMW - (see average megawatt)

Anadromous - Fish species that spawn and initially rear in fresh water, migrate and mature in the ocean and return to fresh water as adults.

Aquifer - Any geological formation containing water, especially one that supplies water to wells, springs, etc.

Average annual megawatt - A unit of energy output over a year equivalent to the energy produced by the continuous operation of one megawatt of capacity over a period of one year (equivalent to 8,760,000 kilowatthours).

Average megawatts (aMW) - The average amount of energy (number of megawatts) supplied or demanded over a specified period of time

Avoidance areas - an area that has significant resource values for which impacts cannot be successfully mitigated; it should be avoided in locating transmission or utility corridors. Can be management or resource areas identified by the U.S. Forest Service or Bureau of Land Management, or specially designated areas or other private and public land.

Baseload - In a demand sense, a load that varies only slightly in level over a specified time. In a supply sense, a plant that operates most efficiently at a relatively constant level of generation.

Biomass - Industrial organic waste products such as agricultural field crops, and noncommercial and urban wood residues used as fuel.

Blackout - The disconnection of the source of electricity from all the electrical loads in a certain geographical area brought about by an emergency or forced outage or other fault in the generation/transmission/distribution system servicing the area. A blackout could also be caused by intentional rotational load drops if adequate generation is not available to meet load.

BLM - U. S. Bureau of Land Management

BOR - U. S. Bureau of Reclamation

BPA - Bonneville Power Administration

Brownout - A partial reduction of electrical voltages that results in lights dimming and motor driven devices losing efficiency.

Capacitor - A device to store an electrical charge. It is usually made of two or more conductors separated by an insulator such as plastic film and oil. Series capacitors are used to compensate for voltage drop along a transmission line. Shunt capacitors are generally located in substations and used to increase the voltage at the end of a line.

Capacity - The maximum amount of power that can be produced by a generator or carried by a transmission facility at any instant. Equivalent terms: peak canacity, peak generation, carrying capacity. 
Capital costs - The costs to construct a facility, including the costs of materials, permits, and interest on borrowing.

Cogeneration. The generation of power with (usually) an industrial process, using waste heat from one process to fuel the other.

Combustion turbine - A generator that burns a mixture of a gaseous or liquid fuel and outside air. As the gas burns it expands ar.d drives the turbine.

Conductor - The wire cable strung between transmission towers through which the electric current flows.

Conservation - Making the most efficient use of energy over the long term.

Corridor - A linear passageway over or through an area of land, water, or air, which has been identified by law, Secretarial Order, land use planning, or other management decision process as being suitable to accommodate one or more facilities requiring a right-of-way. Corridors are categorized as occupied, unoccupied, or designated.

CT - (see combustion turbine)

Cubic feet per second (cfs) - a unit of measure pertaining to the flow of water. One cfs is equal to 449 gallons per minute.

Cultural resources - The nonrenewable evidence of human occupation or activity as seen in any district, site, building, structure, artifact, ruin, object, work of art, architecture, or natural feature that was important in human history at the national, state, or local level.

Current - The flow of electrical charge through a conductor, measured in amps.

Curtailment - A reduction in the use of electricity during emergency conditions.

CWA - Clean Water Act

DEIS - Draft Environmental Impact Statement

Deliverability - Measure of how acceptable a resource is to the public and hence the probability it can be built.

Demand - The amount of electricity that will be purchased at a particular point in time.

Demand-side - Refers to customer's use of energy use (i.e., on the customer's side of the meter).

Direct service industry (DSIs) - Industrial customers (primarily aluminum companies) that purchase energy directly from BPA.

Direct current (DC) - An electric current or voltage that does not reverse direction at regular intervals.

DOI - U. S. Department of Interior

Double-circuit - The piacing of two separate electrical circuits on the same row of towers. For alternating current, each circuit consists of three separate conductors or bundles of conductors.

Drawdown - The distance that the water surface of a reservnir is lowered from? given elevation as water is released from the reservoir (drafted). 
Effluents - A discharge or emission of a liquid or gas, usually waste material.

EIS - Environmental Impact Statement - A document prepared by a Federal agency on the environmental impact of its proposals for legislation and/or other major actions significantly affecting the quality of the human environment. Environmental impact statements are used as tools for decision making and are required by the National Environmental Policy Act of 1969.

Electric field - The invisible lines of electrical force caused by voltage on a conductor.

Electric and magnetic fieids (E/MF) - The two kinds of fields produced around the electric wire or conductor, when an electric transmission line or any electrical wiring is in operation.

Endangered species - A plant or animal species that is in danger of extinction through all or a significant portion of its range because its habitat is threatened with destruction, drastic mudification, or severe curtailment, or because of exploitation, disease, predation, or other factors; federally endangered species are officially designated by the U. S. Fish and Wildlife Service and published in the Federal Register.

Energy - The capability of doing work over a period of time. In electrical systems energy is expressed in kilowatthours. See POWER.

Energy deficit - A condition in which a utility system cannot supply energy demanded.

Energy surplus - A condition in which a utility system can supply more energy than is demanded; the energy may be non-firm, due to water conditions, or firm, due to excess generating capability.

EPA - Environmental Protection Agency

Exclusion areas - Where facilities cannot be built (legislatively excluded).

FERC - Federal Energy Regulatory Commission (FERC) - A federal agency that reviews hydroelectric projects and submitted applications for operating licenses.

Firm Energy - Guaranteed energy.

Firm power - Power that is guaranteed or assured.

Fossil fuel - A combustible, carbonaceous material formed from the remains of ancient plants and animals. Common fossil fuels include coal, natural gas, and derivatives of petroleum such as fuel oil and gasoline.

FSP - Fine suspended particulates.

Fuel switching - Customers using one fuel switch to another fuel. For example, electricity to natural gas.

Gasification - In a fuel plant, mixing fuel, air, oxygen and moisture to produce a gas to burn in a boiler and produce electricity.

Geothermal energy - The heat energy available in the rocks, hot water, and steam in the earth's subsurface.

Groundwater - The supply of fresh water under the earth's surface in an aquifer or soil.

High efficiency shower heads - A device installed at the shower head to reduce the amount of hot water required per shower so the hot water heater operates for less time for each shower. 
Puget Sound Area Electric Reliability Plan -Draft Environmental Impact Statement

High-voltage - Used to describe transmission lines which transport bulk power over longer distances from large generation centers.

HVAC - Heating, ventilation and air conditioning.

Hydraulic head - The vertical distance between the surface of the reservoir and the surface immediately downstream of the turbine and dam.

Hydrocarbons - Chemical compounds containing hydrogen and carbon. Some hydrocarbons may become air pollutants. Some hydrocarbon air pollutants are carcinogenic, and some react with other air pollutants to form photochemical smog.

Hydroelectric - With reference to a power system, the production of electric power through use of the gravitational force of falling water.

Impoundment - The accumulation of water in a reservoir.

INPAPSC - Initial Northwest Power Act Power Sales Contract

Kilovolt - 1000 volts

Kilowatt (kW) - The common unit of electric power equal to 1000 watts.

Kilowatt-hour (kWh) - The common unit of electric energy equal to 1 kilowatt of power supplied to or taken from an electric circuit for 1 hour. A kilowatt equals 1,000 watts.

kV - (see Kilovolt)

kW - (see Kilowatt)

Least Cost Plan - A plan which develops a strategy for supplying future loads using resources that will have the least cost impact on customers.

Levelized - The method of calculating equal, periodic payments or receipts from unequal cost data for the same time period, considering the time value of money.

Load - The amount of electric power or energy delivered or required at any specified point or points on a system. Load originates primarily at the energy-consuming equipment of the customers.

Load growth - Increase in demand for electricity.

Load/resource balance - The point at which the demand for electricity matches or balances the amount and type of resources available to serve that demand.

Load management - Influencing the level and shape of the demand for electrical energy so that it matches resources available and long-run objectives and constraints.

Load shedding - A method whereby loads in isolated areas are dropped by automatic relays to provide protection for the bulk power system.

Magnetic field - Invisible lines of magnetic force produced by current flows in transmission lines and common household appliances. 
Megawatt (MW) - A megawatt is one million watts, or one thousand kilowatts; an electrical unit of power.

MSW - (see Municipal Solid Waste)

MW - (see megawatt)

NEPA - National Environmental Policy Act

NESHAPS - National Emission Standards for Hazardous Air Pollutants

Net present value - The economic value, in today's dollars. Present and future costs and benefits are adjusted for the time value of money.

Nitrogen Oxides $\left(\mathrm{NO}_{\mathbf{x}}\right)$ - Compounds produced by combustion, particularly when there is an excess of air or when combustion temperatures are very high. $\mathrm{NO}_{\mathbf{x}}$ are primary air pollutants.

Non-avoidance area - An area considered suitable for transmission or utility corridor location. Resource impacts can normally be mitigated.

Non-firm energy - Energy available due to better than planned for water conditions. This energy is sold on an interruptible (nonguaranteed) basis.

Nonattainment areas - Those areas which continue to fail to meet primary national Ambient Air Quality Standards. Evaluation and designation is carried out by the EPA.

NO - (see Nitrogen oxides)

NPDES - National Pollution Discharge Elimination System

NRC - Nuclear Regulatory Commission

NWPPC - Northwest Power Planning Council

Off-peak - Period of relatively low system demand for electrical energy, as specified by the supplier (such as the middle of the night).

Outage - In a power system, the state of a component (such as a transmission line) when it is not available to perform its function due to some event such as an aválanche.

Ozone $\left(\mathrm{O}_{3}\right)$ - A pungent, colorless, toxic gas. Ozone is associated with the corona discharge of high-voltage transmission lines, and with incomplete combustion.

Pacific Northwest (PNW) - For this EIS, the States of Washington, Oregon, and Idaho; the portion of Montana west of the Continental Divide; and areas in Montana, Nevada, and Wyoming surrounding coal plants that serve the PNW.

Particulates - Finely divided solid or liquid particles in the air or in an emission. Particulates include dust, smoke, fumes, mist, spray, and fog.

PCBs - (see Polychlorinated biphenyls)

Peak - (see peak load) 
Puget Sound Area Electric Reliability Plan -Draft Environmental Impact Statement

Peak load - The maximum electrical demand in a stated period of time. It may be the maximum instantaneous load or the maximum average load within a designated interval such as 15 minutes.

PNW - Pacific Northwest

Polychlorinated biphenyls (PCB's) - A group of noncombustible synthetic insulating/dielectric fluids used in certain electrical equipment found to be very persistent in the environment and strongly suspected of having carcinogenic effects.

Power - The time rate of transferring or transforming energy. Electrically power is expressed in watts, which are the product of applied voltage and current.

Power Sales Contracts (PSC) - Contracts that establish the terms and conditions of BPA's power sales.

Power system - A group of one or more generating sources and connecting transmission lines operated under common management or supervision to supply load.

ppm - parts per million

PSC - (see Power Sales Contract)

PSD - Prevention of significant deterioration increment - Any one of several incremental changes in ambient total suspended particulate or sulfur dioxide concentrations established by the Environmental Protection Agency to protect existing air quality from being degraded significantly through new developments, such as construction and operation of a new air pollution source.

Public Utilities Regulatory Policy Act (PURPA) - Enacted in 1978, it is the Federal legislation that requires utilities to purchase electricity from qualified independent power producers at a price that reflects what the utilities would otherwise have to pay for the construction of new generating resources. This legislation does not apply to BPA.

Pumped storage - An arrangement whereby electric power may be generated during peak load periods by hydroelectric plants using water previously pumped into a storage reservoir during off-peak periods.

PURPA - (see Public Utilities Regulatory Policy Act)

Raptors - Birds of prey.

RCRA - Resource Conservation and Recovery Act

RDF - (Refused derived fuel) - Fuel consisting of waste that is cleaned of non-combustibles and hazardous wastes, and is then used as a supplemental fuel.

Record of Decision (ROD) - The document notifying the public of a decision taken on a Federal action, together with the reasons for the choices entering into that decision. The Record of Decision is published in the Federa! Register.

Reliability - For a power system, a measure of the ability of the power system to meet customer demands over a specified period of time.

Reliability Criteria - Rules for designing and operating power systems to insure reliable electrical service. 
Renewable resource - A resource for energy that is continually replenished. Water, for instance, is a renewable resource, while coal which is converted into carbon dioxide, water, and ash when burned, is not.

Resident fish - Fish species that reside in fresh water during their entire life cycle.

Retrofit - To weatherize an existing structure.

Revenue requirement - The amount of money a utility needs to recover from rates paid by customers to pay the costs of resource and transmission actions.

Right-of-way - An casement for a certain purpose over the land of another, such as the strip of land used for a road, electric transmission line, ditch, pipeline, etc.

Rolling blackout - Controlled intentional disconnection of the source of electricity from electrical loads in an area brought about by an emergency forced outage. Outages are rotated from one area to another.

Salmonids - Fish belonging to the family of salmonidae, including salmon, trout, whitefish, and allied freshwater and anadromous fish.

Scoping - The definition of the range of issues requiring examination in studying the environmental effects of a proposed action. Scoping generally takes place through public consultation with interested individuals and groups, as well as with agencies with jurisdictions over parts of the project area or resources in that area. Scoping is mandated by the Council of Environmental Quality regulations.

SEPA - State Environmental Policy Act

Series Capacitors - An electrical device used to compensate for voltage drop along a transmission line. See CAPACITOR.

Shunt Capacitors - An electrical device used to increase the voltage at the end of a line. See CAPACITOR.

Small hydro - Generating resources that use running water to generate electric energy, but which are small in generating capacity. BPA generally considers small hydro projects to be those capable of producing 25 average MW or less.

SO $_{x}$ - (see Sulfur Oxides)

Storage reservoirs - Reservoirs maintained behind dams for the purpose of retaining excess water readily available during springtime flows as snow melts. Retained water is then released, as necessary, during periods of lower flow in order to maintain necessary levels of power production. (Water may also be released for other purposes, such as navigation, irrigation, and maintenance of life support for fish.)

Sulfur Oxides - Sulfur containing compounds produced by combustion and pulp and paper processes. Considered hazardous to human health, plants, and buildings.

Surplus energy - Generally energy generated that is beyond the immediate needs of the producing system. Specifically for BPA, firm or non-firm electric energy generated at Federal hydroelectric projects that would otherwise be wasted if there was not a market for the energy.

Surplus capacity - The difference between assured system capacity and the system peak load for a specified period. 
Puget Sound Area Electric Reliability Plan -Draft Environmental Impact Statement

Thermal resources - Generating plants that convert heat energy into electric energy. Coal, oil, and gas-fired power plants and nuclear power plants are common thermal resources.

Threatened species - Those species, as determined by the U. S. Fish and Wildlife Service, that are likely to become endangered within the foreseeable future throughout all or a significant portion of their range.

Top-quartile - The top twenty-five percent of DSI load which can be interrupted at any time for any reason to meet BPA's load obligations.

TPY - Tons per year.

Transmission grid - An interconnected system of electrical transmission lines and associated equipment for the transfer of electric energy in bulk between points of supply and points of demand.

TRG - Technical Review Group

TSD - Treatment, Storage, and Disposal

UIC - Underground Injection Control

Undervoltage - A condition in which the voltage of the system is unacceptably low, usually 90 percent of nominal.

Volt - The unit of voltage or potential difference.

Voltage Instability - A condition under which transmission lines serving areas become too heavily loaded and voltage begins to drop or fluctuate uncontrollably.

Voltage support - Applying electrical devices to a transmission system in order to boost the voltage.

Voltage collapse - A condition which occurs when voltages at substations fall below a certain point, causing affected power lines to shut down; this in turn causes other lines to overload and disconnect in domino fashion. Electrical service can be interrupted by either the low voltages or the disconnection of power lines.

Watt - The electrical unit of power or rate of doing work. One horsepower is equivalent to approximately 746 watts.

Weatherize - The act of installing conservation measures to the shell of a building; weatherization measures include storm doors, storm windows, weather-stripping, caulking, and wall insulation.

WNP-3 - Washington Nuclear Plant \#3 at Satsop, Washington. 


\subsection{INDEX}

A

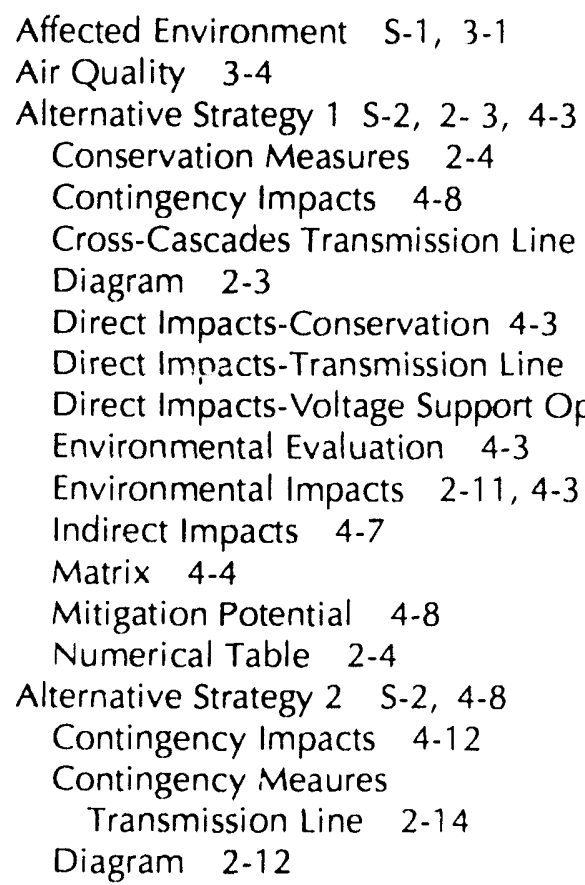

Affected Environment S-1, 3-1

Air Quality 3-4

Alternative Strategy 1 S-2, 2-3, 4-3

Conservation Measures $2-4$

Contingency Impacts 4-8

Diagram 2-3

Direct Impacts-Conservation 4-3

Environmental Evaluation 4-3

Environmental Impacts 2-11, 4-3

Indirect Impacts 4-7

Matrix 4-4

Mitigation Potential $\quad 4-8$

Numerical Table 2-4

Alternative Strategy 2 S-2, 4-8

Contingency Impacts 4-12

Contingency Meaures

Transmission Line 2-14

Diagram 2-12

Cross-Cascades Transmission Line 2-9

Direct Imnacts-Transmission Line 4-5

Direct Impacts-Voltage Support Option 1 4-5

Direct Impacts-Conservation 4-9

Direct Impacts-Voltage Support 1 4-9

Direct Impacts-Voltage Support Option 2 4-9

Environmental Evaluation 4-9

Environmental Impacts 2-14, 4-10

Indirect Impacts 4-11

Matrix 4-9

Mitigation Potential $\quad 4-12$

Numeric Table 2-13

Voltage Support Option $2 \quad 2-12$

Alternative Strategy 3 S-2, 4-12

Contingency Impacts 4-13

Contingency Measures 2-21

Diagram 2-14

Direct Impacts-Conservation 4-13

Direct Impacts-Fuel Switching 4-13

Direct Impacts-Load Management 4-13

Direct Impacts-Voltage Support Option 1 4-13

Environmental Evaluation 4-13

Environmental Impacts 2-22, 4-14

Fuel Switching 2-19

Indirect Impacts 4-13

Load Management Measures 2-16

Matrix 4-12

Mitigation Potential 4-13

Numeric Table 2-15

\author{
Alternative Strategy $4 \quad$ S-2, 4-14 \\ Contingency Impacts 4-16 \\ Contingency Measures 2-24 \\ Diagram 2-22 \\ Direct Impacts-Conibustion Turbines 4-14 \\ Direct Impacts-Conservation 4-14 \\ Direct Impacts-Voltage Support Option 1 4-14 \\ Environmental Evaluation 4-14 \\ Environmental Impacts 2-24, 4-16 \\ Indirect Impacts 4-16 \\ Matrix 4-14 \\ Mitigation Potential 4-16 \\ Numeric Table 2.23 \\ Peaking Combustion Turbines $\quad \therefore-23$ \\ Analysis \\ Alternative Strategy $1 \quad$ S-2 \\ Alternative Strategy $2 \quad \mathrm{~S}-2$ \\ Alternative Strategy $3 \quad \mathrm{~S}-2$ \\ Alternative Strategy $4 \quad \mathrm{~S}-2$ \\ Economic S-2 \\ No Action Alternative $\mathrm{S}-2$ \\ Preferred Alternative S-2 \\ Technical S-2 \\ Analysis for Draft EIS 1-14 \\ Assumptions Drive Evaluations 4-2
}

\section{B}

Blackout 1-2, 1-3

Brownout 1-2

C

Characterizing Measures $\quad 1.12$

Clean Water Act $\quad 5-6$

Climate 3-4

Coastal Zone Management 5-4

Conservation Measures 2-4

Commercial Retrofit Program 2-7

Costs and Savings 2-4

High Efficiency Shower Head Programhead 2-7

residential Weatherization 2-6

Conservation Measures

Industrial Conservation 2-6

Contingency Measures 2-1

Contractural Load Curtailment 2-10

Curtailment Cooperatives 2-10

Contingency Measures S-2

Costs and Benefits 4-21 
Table $4-21$

Cross-Cascade 500-kV AC Double Circuit Transmissio 2-9

Cultural Resources 3-2

D

Decision Making Strategy 4-1

Deliverability 4-23

Table 4-24

Demographics 3-5

Draft Northern Cascades Corridor Availability Study 2-9

$\mathbf{E}$

Easement for Transmission Lines 5-7

Economic and Technical Evaluation 4-21

Costs and Benefits 4-21

Deliverability $4-23$

Long-Term Revenue Requirements 4-23

Near-Term Revenue Requirements 4-22

Reliability $4-25$

Sensitivity to Load Growth 4-22

Study Framework 4-21

Surplus Capacity $\quad 4-26$

Economic and Technical Evalution

Summary 4-27

Economy

Demographics $3-5$

Fisheries 3-5

Major Industries 3-5

Endangered and Threatened Species 5-1

Energy Conservation 5-5

Energy resources

Conservation Programs $1-7$

Local Generation Plants 1-7

Environmental Comparison of Alternative Strategies 4-18

Matrix 4-20

Environmental Consulation, Review, Permit Requirements 5-1

Plan and Program Consistency 5-3

Farmland Protection 5-3

Endangered and Threatened Species 5-1

Fish and Wildlife Conservation 5-1

Heritage Conservation 5-1

Matrix 5-1

National Environmental Policy Act 5-1

Clean Water Act 5-6

Coastal Zone Management 5-4

Easement for Transmission Lines 5-7

Energy Conservation 5-5

Federal Aviation Administration 5-7

Federal Lands for a Power Plant 5-7
Floodplains 5-4

Geothermal Resource Development 5-7

Global Warming 5-4

New Power Resources 5-5

Noise Control 5-5

Pollution Control 5-5

Recreation Resources 5-3

Resource Conservation and Recovery Act 5-8

Rivers and Harbors Act 5-6

Safe Drinking Water Act 5-6

Wetlands 5-4

Environmental Comparrison Table 4-21

Environmental Hazards 3-5

Environmental Impacts

Alternative Strategy $1 \quad 4-3$

Alternative Strategy 2 4-11

Alternative Strategy $3 \quad 4-14$

Alternative Strategy $4 \quad 4-16$

No Action Alternative 4-19

Preferred Alternative $4-2$

Environmental Impact Definitions 4-1

Evaluation $1-13$

evaluation factors 1-13

Expected Resource 1-6

$\mathbf{F}$

Farmland Protection 5-3

February 1989 Cold Snap 1-2

Federal Aviation Administration 5-7

Federal Lands for a Power Plant 5-7

Final EIS $1-14$

Fish 3-3

Fish and Wild life Conservation 5-1

Fisheries 3-5

Floodplains 5-4

Forest/Woodland and Wildlife 3-2

Fuel Switching 2-19

Costs and Savings Table $\quad 2-20$

G

Geothermal Resource Development 5-7

Global Warming 5-4

Grasslands and Wildlife 3-3

Groundwater 3-4

$\mathrm{H}$

Heritage Conservation 5-1

I

Irrigation 3-2 


\section{J}

no entries

K

no entries

$\mathbf{L}$

Land Use $3-1$

Cultural Resources 3-2

Irrigation 3-2

Recreation 3-2

Load Growth 1-3-1-5

Load Management Measures

Pilot Programs 2-16

Residential Time of Use Rates 2-16

Water Heater Control Program 2-16

Load Management Programs

Costs and Savings Table 2-18

Local Generation and Conservation Resources $1-7$

Long Distance Transmission 1-5

Long-Term Revenue Requirements $\quad 4-23$

Table 4-23

\section{M}

Major Industries 3-5

Measures

Screening 1-11

Measures Common to all plans 2-2

Accelerated Conservation Programs 2-2

Voltage Support $1 \quad 2-2$

Measures Considered but Not Selected 2-27

Methodology 1-13

N

National Environmental Policy Act 5-1

Natural Resources 3-2

Air Quality 3-4

Climate $3-4$

Environmental Hazards 3-4

Fish 3-2

Forest/Woodland and Wildlife $3-2$

Grasslands and Wildlife 3-2

Groundwater 3-4

Riparian/Wetland and Wildlife 3-2

Shrubland and Wildlife 3-2

Surface Hydrology 3-2

Threatened and Endangered Species $\quad 3-2$

Topography and Geology 3-4

Wild life and Vegetation 3-2

ivear-Term Revenue Requirements $4-22$
Table 4-23

Need S-1, 1-1

New Directions 2-1

New Energy Resources 1-7

New Power Resources 5-5

New Substation 3-9

No Action Alternative S-2, 2-24, 4-16

Contingency Impacts 4-18

Direct Impacts 4-17

Environmental Evaluation 4-17

Environmental Impacts 2-27, 4-19

Existing BPA Customer Contracts 2-24

Increased Probability of Voltage Instability and

Blackout 2-26

Indirect Impacts 4-18

Matrix 4-17

Mitigation Potential $\quad 4-18$

Resource Acquisitions 2-24

Undervoltage Load Shedding Scheme 2-24

Voluntary Load Curtailment 2-24

Noise 3-6

Noise Control 5-5

Northwest Power Planning Council S-1, 1-1, 3-6

O

no entries

$\mathbf{P}$

Peak Load 1-2

Peak Load Forecast $1-4$

Peaking Combustion Turbines $\quad 2-23$

Pilot Programs 2-17

Planning Assumptions 1-3

Load Forecast 1-3

Load Growth 1-3

Planning Timeframe 1-3

Pollution Control 5-5

Power Exchange with Canada 1-1

Preferred Alternative S-3, 2-1, 2-1-2-2, 4-2

Common Measures 2-1

Contingency Measures 2-2

Environmental Impacts 2-2, 4-2

Problem 1-2

Protected Resources 3-6

Public Health and Safety 3-6

Public Involvement S-2

scoping meetings $\mathrm{S}-2$

Sounding Board S-2

Technical Review Group S-2

Puget Sound Area 1-1

Puget Sound Area Electric Reliability Plan 1-15 
Puget Sound Area Peak Loads 1-6

Puget Sound Area Resources 1-9

Purpose S-1, 1-1

\section{Q}

no entries

$\mathbf{R}$

Record of Decision 1-15

Recreation 3.2

Recreation Resources 5-3

Reliability $4-25$

Table 4-25

Reliability Criteria 1-6

Residential Time-of-Use-Rates 2-16

Resource Conservation and Recovery Act 5-8

Riparian/Wetland and Wildlife 3-3

Rivers and Harbors Act $\quad 5-6$

$\mathrm{S}$

Safe Drinking Water Act $\quad 5-6$

Scope 1-1

Scoping 1-10

Scoping Meetings S-2

Sensitivity to Load Growth

table 4-22

Shrubland and Wildlife $3-2$

Size of the Deficit 1-7

Sounding Board S-2, 1-14, 2-1

Sources of Power 1-5

Sources of Power for the Puget Sound 1-5

State and Program Consistency 5-3

Steering Committee 2-1

Strategies 1-14

Costs and Benefits 4-21

Deliverability 4-23

Long-Term Revenue Requirements 4-23

Near-Term Revenue Requirements 4-22

Reliability $4-25$

Sensitivity to Load Growth 4-22

Surplus Capacity 4-27

Study area 3-1

Study Process

Define Strategies 1-10

Draft EIS \& Public Comment 1-10

Final EIS $1-10$

Record of Decision 1-10

Surplus Capacity 4-26

Table 4-27

System Capacity 1-6

System Emergencies 1-7
$T$

Technical Review Group (TRG 1-11

Technical Review Group (TRG) S-2

The Problem 1-2-1-3

Threatened and Endangered Species 3-3

Topography and Geology 3-4

Transmission Grid 1-5

Transmission Line Corridor A 3-7

Transmission Line Corridor B 3-8

Transmission Line Corridor $C \quad 3-9$

transmission system 1-5

Transmission System Capabilities 1-9

Transmission System Capabilities (1994 and 2003) 1 1-9

$\mathrm{U}$

Uncertainties $\quad 1-10$

Utility Involvement S-2

V

Visual and Aesthetics 3-6

Voltage collapse 1.3

Voltage Support Option $1 \quad 2-8$

Voltage Support Option 2

500-kV Substation 2.2

New 500-KV Substation 2-13

Voltage Support Option $2 \quad 2-2$

\section{W}

Water Heater Control Program 2-16

Wetlands 5-4

Wildlife and Vegetation 3-2

Winier Operating Plan S-1, 1-2

Winter Peak Load Forecast (1994 and 2003) $1-8$

$\mathrm{X}$

no entries

Y

no entries

Z

no entries 


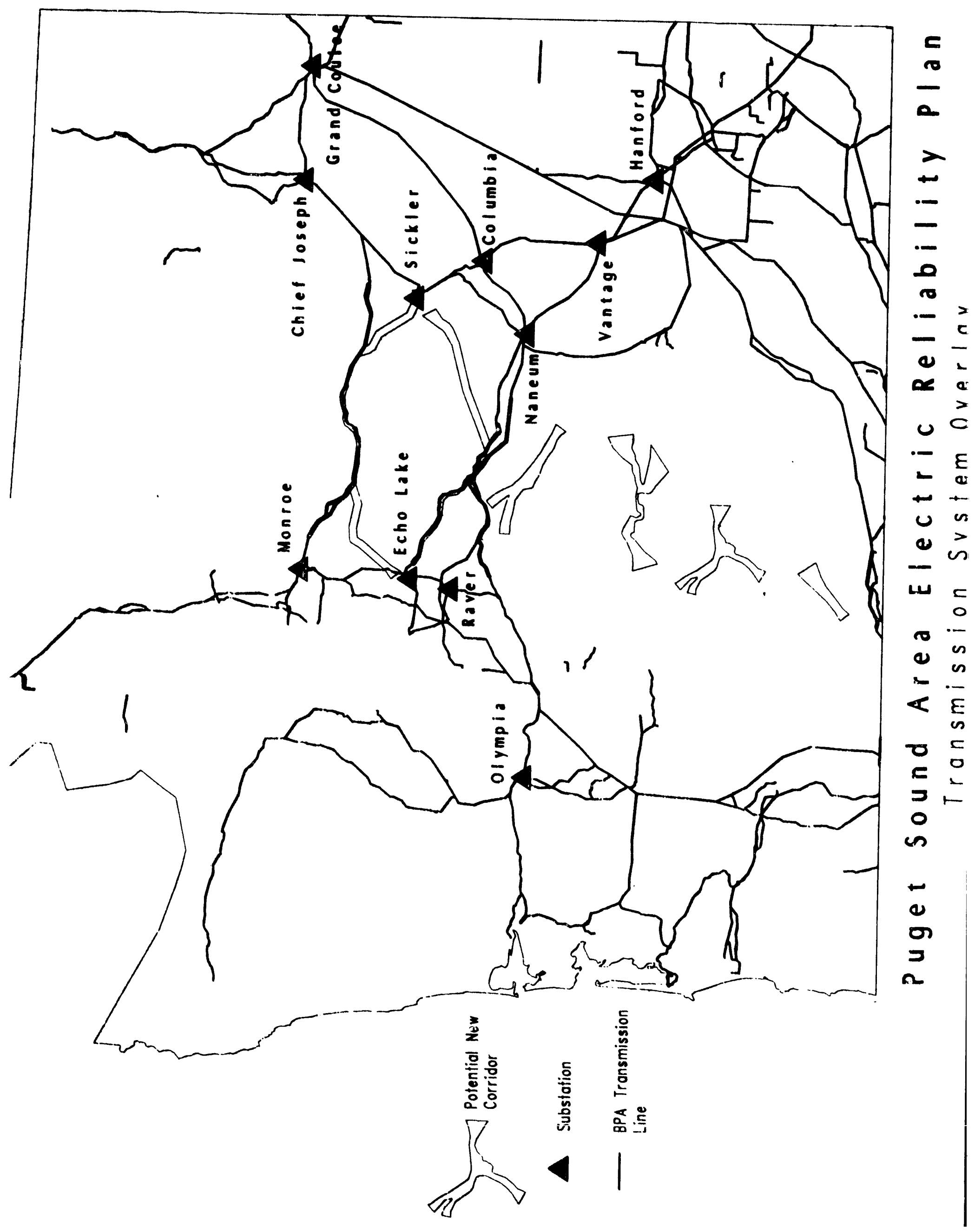



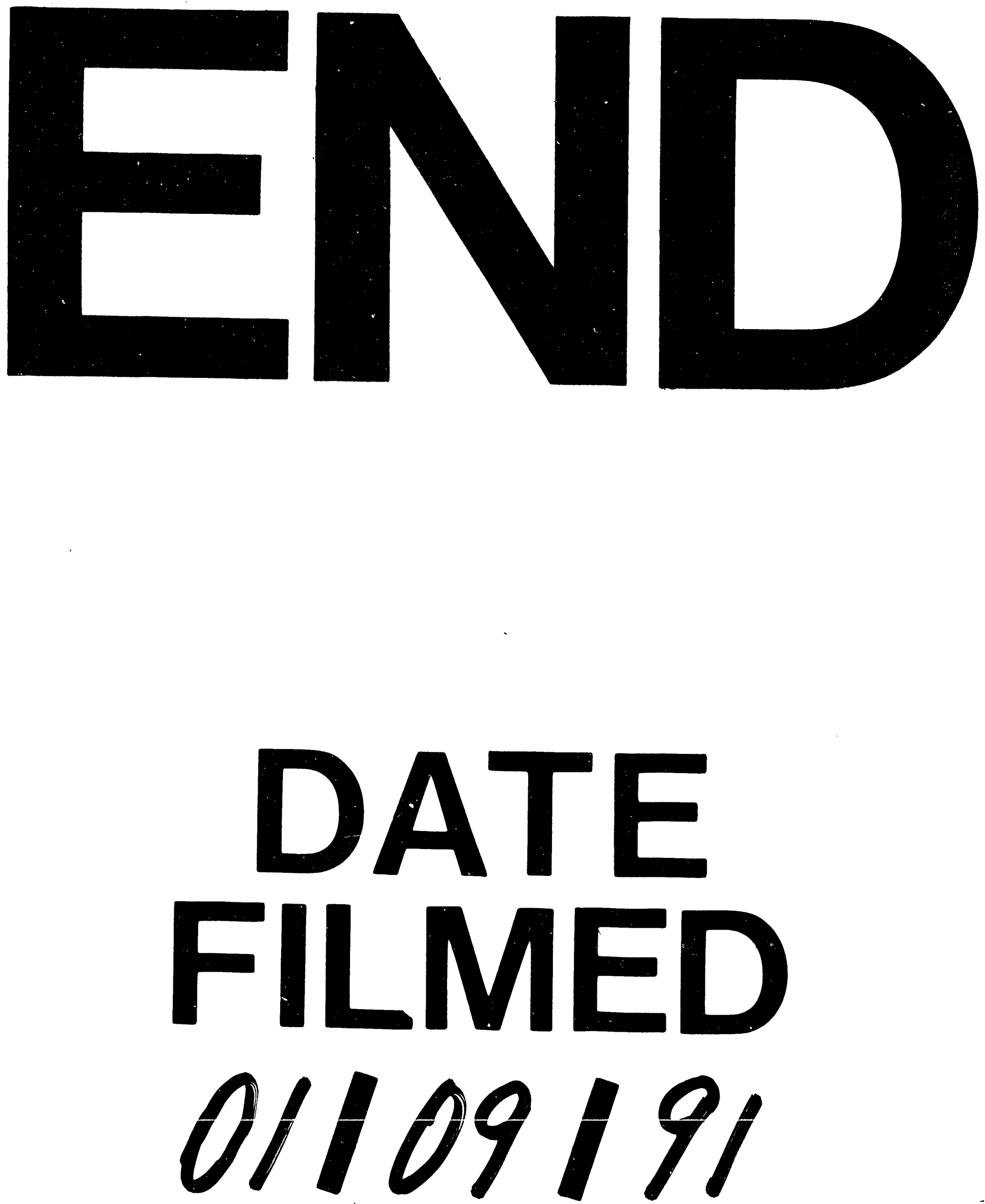
